\title{
Globalisation vs Europeanisation
}

\author{
A Human-centric Interaction
}

\section{Léonce BEKEMANS}
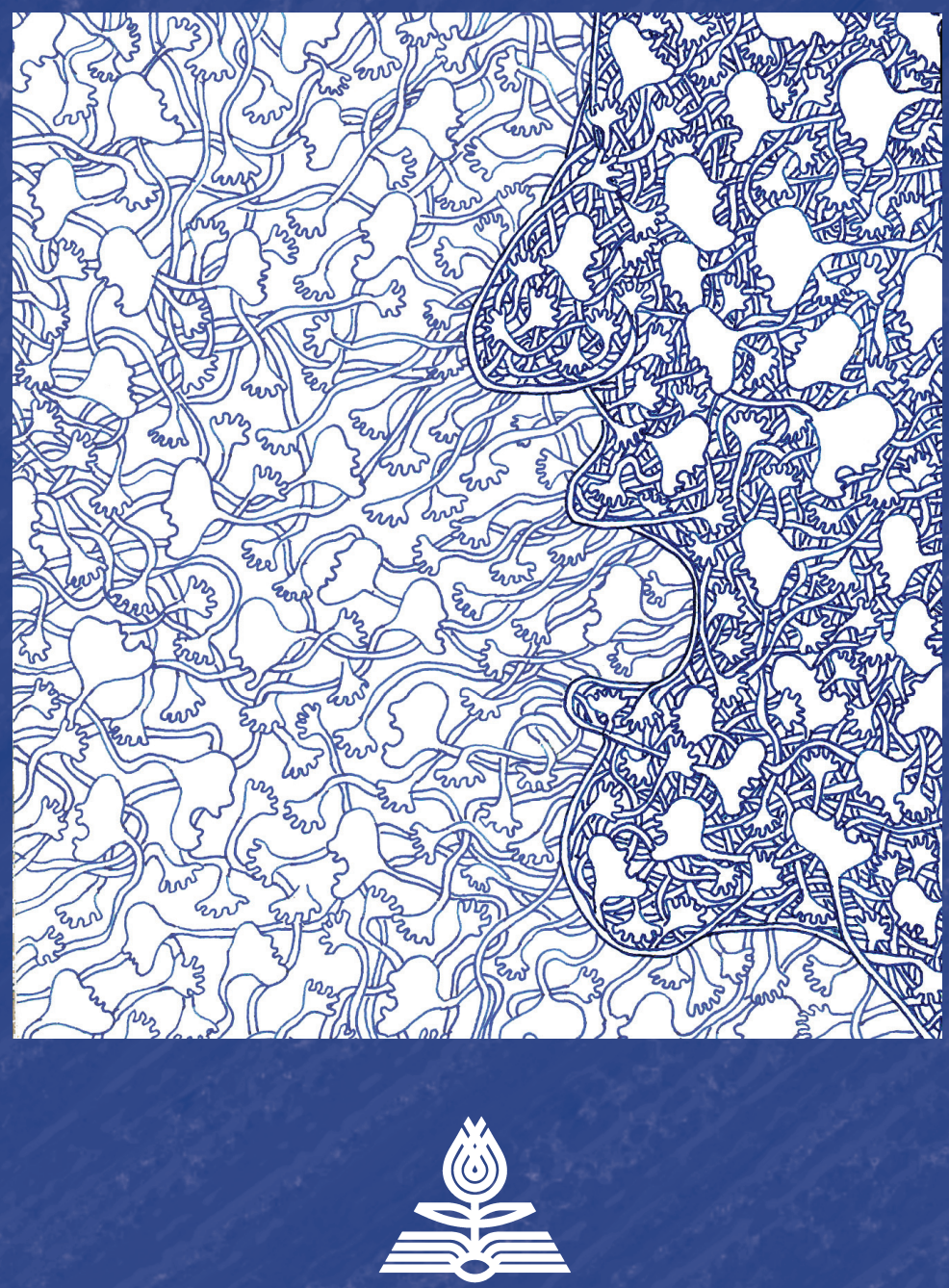

P.I.E. Peter Lang 
Courage and inspiration are needed to renew the European dream and rediscover the purpose of a European civilisation project which responds to the cultural and moral traditions rooted in the vision of its founding fathers. A mobilising and forward-looking interaction between globalisation and Europeanisation can provide some answers in the emerging global transnational era.

This book offers an interdisciplinary in-depth analysis of the relation between globalisation and Europeanisation from a value driven and human-centric perspective. It proposes a broad, diversified and innovative framework and analysis of concepts based on a human rights, cosmopolitan and public goods perspective of sustainable statehood. This approach is applied to interconnected policy areas and issues that are crucial to Europe's future, such as external relations, culture, intercultural dialogue, citizenship, education and territorial cooperation. The book's multidisciplinary readings and critical reflections address the complex issues at play in today's European societies, which require sustainable, cohesive and responsible answers at conceptual and policy level.

Léonce BEKEMANS, MA in Economics, BA in Philosophy, MA in International Studies and PhD in International Relations, holds the Jean Monnet Chair ad personam for Globalisation, Europeanisation and Human Development at the University of Padua, Italy. He is the academic coordinator of its Jean Monnet Centre of Excellence for Intercultural Dialogue, Human Rights and Multilevel Governance and collaborates with the University's Human Rights Centre. He is also the president of Ryckevelde, a non-profit organisation for European citizenship in Damme, Belgium and Secretary General of ECSA World.

Series

Multiple Europes

№. 52 




\section{Globalisation vs Europeanisation}

\section{A Human-centric Interaction}

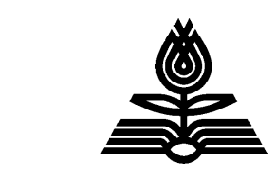

\section{P.I.E. Peter Lang}

Bruxelles $\cdot$ Bern $\cdot$ Berlin $\cdot$ Frankfurt am Main $\cdot$ New York $\cdot$ Oxford $\cdot$ Wien 

Léonce BEKEMANS

\title{
Globalisation vs Europeanisation
}

\author{
A Human-centric Interaction
}

Multiple Europes

No. 52 
Bibliographic Information published by the Deutsche Nationalbibliothek

The Deutsche Nationalbibliothek lists this publication in the Deutsche

Nationalbibliografie; detailed bibliographic data is available in the internet at http://dnb.d-nb.de.

Library of Congress Cataloging-in-Publication Data

Bekemans, Léonce.

Globalisation vs Europeanisation : a Human-centric Interaction / Léonce Bekemans.

pages cm. - (Multiple Europes, ISSN 1376-0904 ; No. 52)

Includes bibliographical references and index.

ISBN 978-2-87574-080-9 (alk. paper)

1. Europe-Economic integration. 2. National characteristics, European. 3. GlobalizationEurope.

I. Title.

D1055.B45 2013 940.55-dc23 2013031109

An electronic version of this book is freely available, thanks to the support of libraries working with Knowledge Unlatched. KU is a collaborative initiative designed to make high quality books Open Access for the public good.

More information about the initiative and links to the Open Access version can be found at www.knowledgeunlatched.org

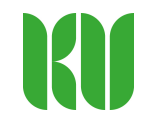

This monograph was published within the project of Pázmány Péter Catholic University TÁMOP 4.2.1. B-11/2/KMR-2011-0002. It was written in the framework of the activities of the Jean Monnet Centre of Excellence of the University of Padua.

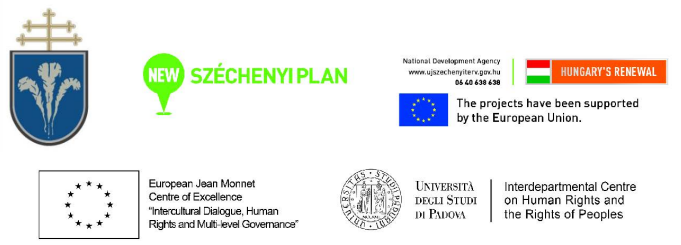

Cover picture : European conversation, 2013, @ Laurens Bekemans

$\mathrm{D} / 2013 / 5678 / 22$

ISSN 0944-2294 • ISBN 978-2-87574-080-9 (Print)

E-ISBN 978-3-0352-6331-2 (E-PDF) • DOI 10.3726/978-3-0352-6331-2
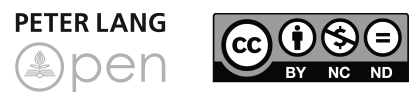

Open Access: This work is licensed under a Creative Commons Attribution NonCommercial NoDerivatives 4.0 unported license. To view a copy of this license, visit https://creativecommons.org/licenses/by-nc-nd/4.0/

This publication has been peer reviewed.

(c) Léonce Bekemans, 2013

Peter Lang S.A.

International Academic Publishers

Brussels

www.peterlang.com 
To Patrizia 

Human development, as an approach, is concerned with what I take to be the basic development idea: namely, advancing the richness of human life, rather than the richness of the economy in which human beings live, which is only a part of it.

Amartya Sen, Professor of Economics and Philosophy, Harvard University, Nobel Prize in Economics (1998)

Without commonly shared and widely entrenched moral values and obligations, neither the law, nor democratic government, nor even the market economy will function properly.

Václav Havel, last president of Czechoslovakia (1989-1992) and the first president of the Czech Republic (1993-2003)

Humanistic Culture is vital to democracy because it educates informed, empathetic, and critical world citizens: the sort of people necessary to sustain democratic societies.

Martha Nussbaum, Ernst Freund Distinguished Service Professor of Law and Ethics, University of Chicago 



\section{Table of Contents}

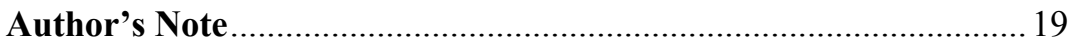

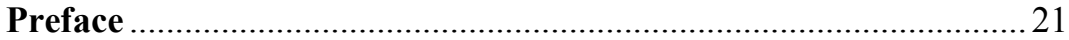

Antonio Papisca

Preface.

Luc Van den Brande

Introduction

Chapter 1.

Points of Departure

I. European Integration Process: Origin and Development ................... 34

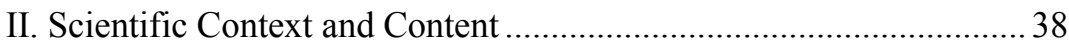

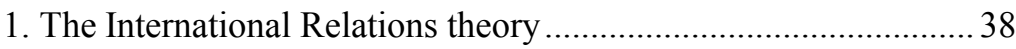

2. Emerging scientific context and content ................................... 45

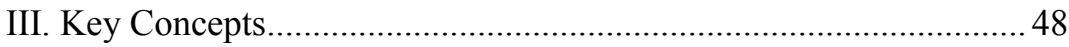

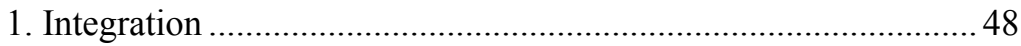

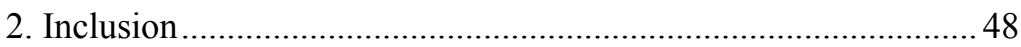

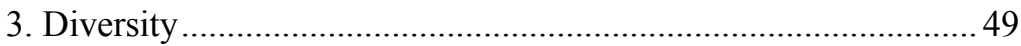

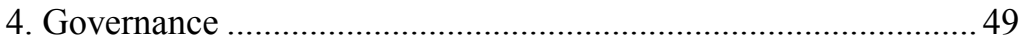

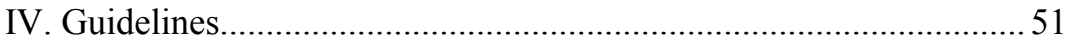

PART I

CONTEXTUAL EUROPE

\section{Chapter 2.}

The Idea of Europe: an Historical Perspective …………………...... 55

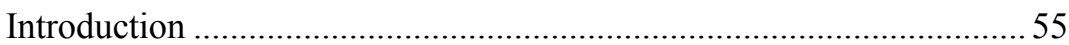

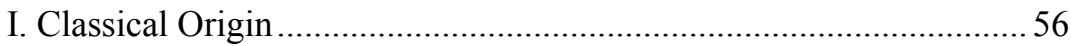

II. A Res Publica Christiana in the Middle Ages....................................57

III. A Process of Secularisation towards a European Civilisation ..........59

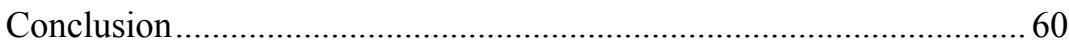

Chapter 3.

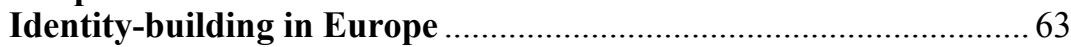

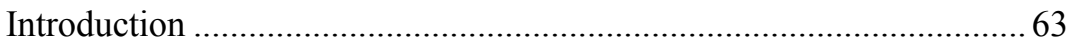

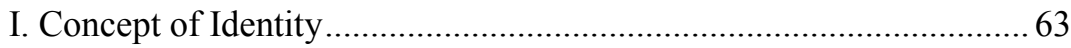

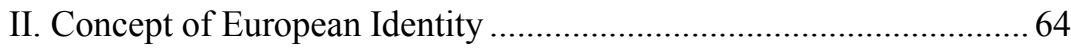




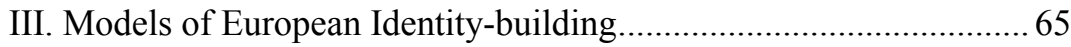

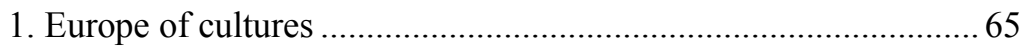

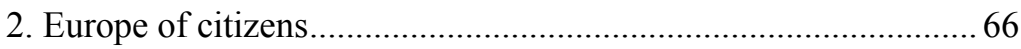

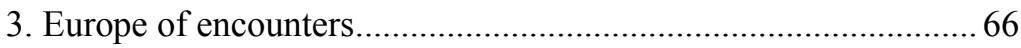

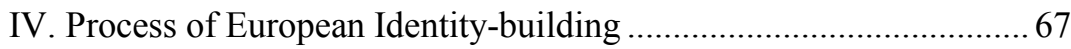

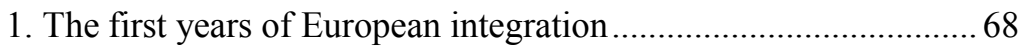

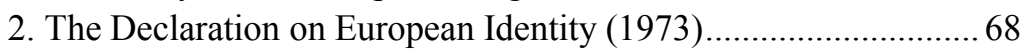

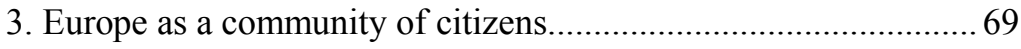

4. The role of cultures and EU founding values............................. 71

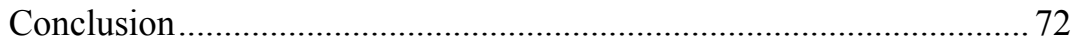

Chapter 4.

Europe's Challenges and Responsibilities

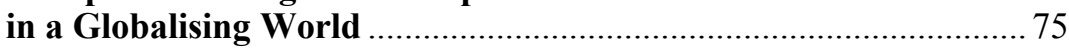

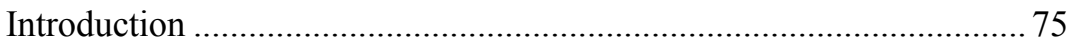

I. Historical Context: Europe at the Crossroads

between Past, Present and Future ......................................................... 76

II. Challenges to the European Model

of Socio-economic Cohesion and Regional Diversity ............................ 77

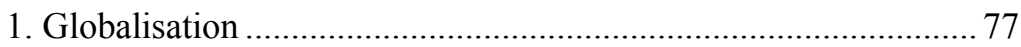

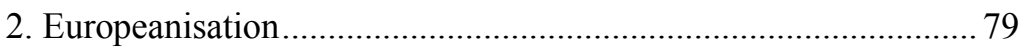

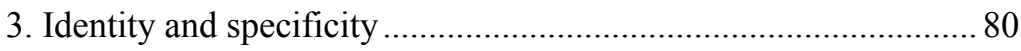

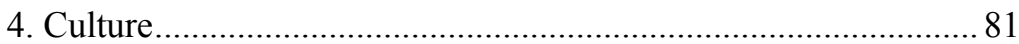

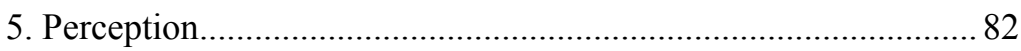

III. Europe's Task and Responsibility in the Globalising World........... 83

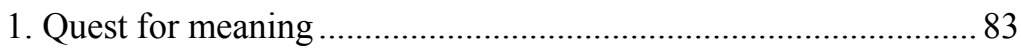

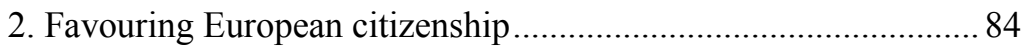

3. Europe's responsibility at global level ....................................... 85

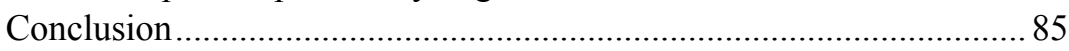

\section{PART II}

RENEWING THE CONCEPTUAL FRAMEWORK FOR EUROPE'S FUTURE

\section{Chapter 5.}

Sustainable Statehood: a Human-centric and Multi-level Governance of Europe's Transformation.............. 89

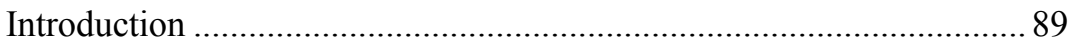

I. The Changing International Context:

EU as a Regional and Global Power. 
1. Changing setting: multilateralism and multipolar world order: characteristics and trends.......................................... 90

2. A weakened position of the EU as a global actor........................ 93

3. The EU as an international reference

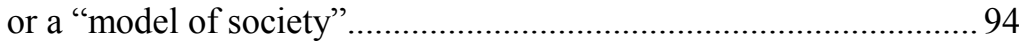

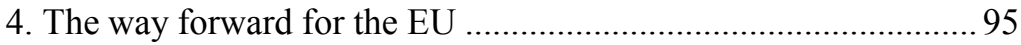

II. Conceptual Content: Sustainable Statehood of Human-centric EU Governance ......................................................... 97

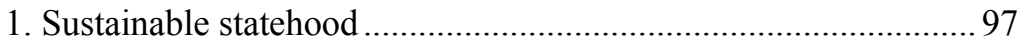

2. A Human-centric approach to sustainable statehood .................. 100

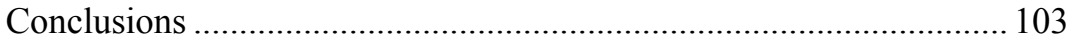

1. State-centric vs human-centric development.............................. 103

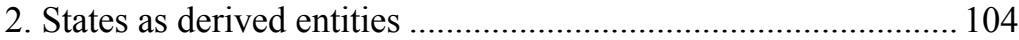

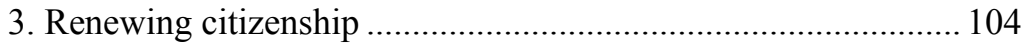

Chapter 6.

A Cosmopolitan Perspective

of Multi-level Governance in Europe............................................ 109

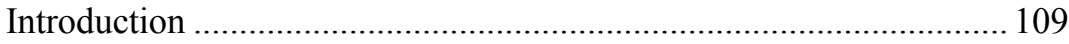

I. Cosmopolitanism and Post-modernity

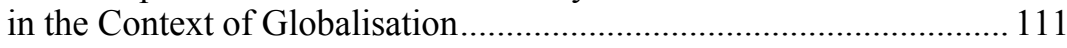

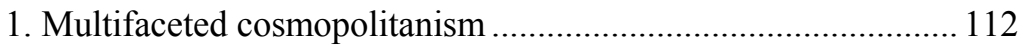

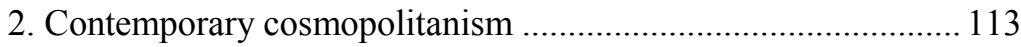

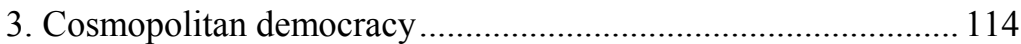

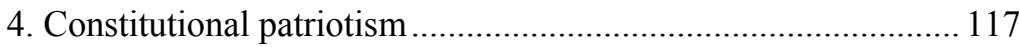

II. A Cosmopolitan Perspective of Europeanisation............................. 119

1. Beck's political and sociological cosmopolitanism ................... 119

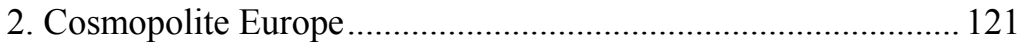

3. Cosmopolitan perspective of the European integration

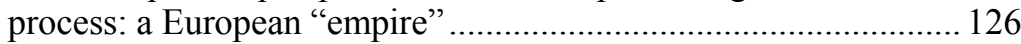

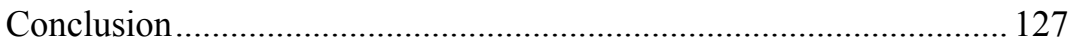

Chapter 7.

Global Public Goods and Human Development ........................... 131

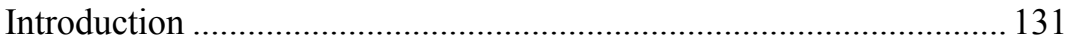

I. Conceptual Context: Rethinking the Definition of Public Goods .... 133

1. A widened concept of public good............................................. 133

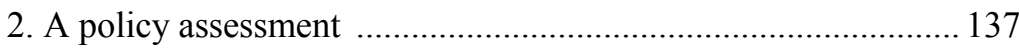

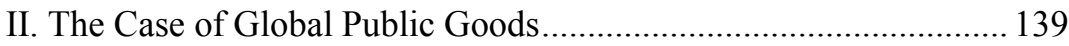


1. Understanding global public goods:

definitions and typologies

2. Provision of global public goods: politics and provision

3. A policy assessment

III. Policy Options and Strategies

1. Global public goods and development:

current trends and patterns

2. Global public goods and policy-making: policy options

3. Global public goods

and the Millennium Development Goals (MDGs)

Conclusion

Chapter 8.

The Changing Content of European Studies:

an Interdisciplinary Perspective and Practice

Introduction

I. Contextual Points of Departure

II. Conceptual Guidelines for Strengthening,

Deepening and Widening European Studies

III. Curriculum Impact in Teaching and Research: Good Practice...... 161

1. The Jean Monnet Programme of the EU

2. The Interdepartmental Centre on Human Rights

and the Rights of People of the University of Padua....................... 162

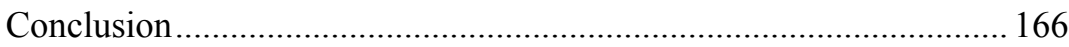

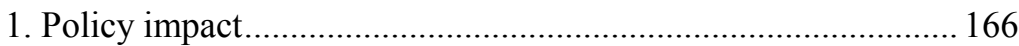

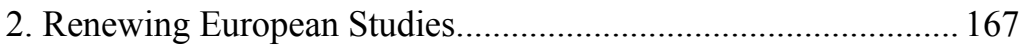

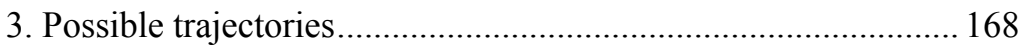

\section{PART III \\ Policy Areas of European HuMAN-CENTRIC DeVElopment}

\section{Chapter 9.}

European Security and Foreign Relations..................................... 173

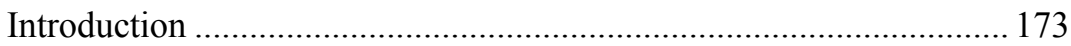

I. Context: EU Foreign Policy: a European

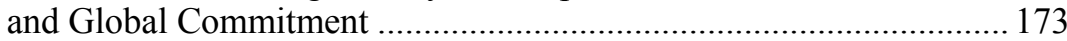

1. Key characteristics of EU external relations ............................. 173

2. Common Foreign and Security Policy (CFSP) ......................... 176

II. The Lisbon Treaty and the EU Foreign Policy:

Changes and Perspectives. 


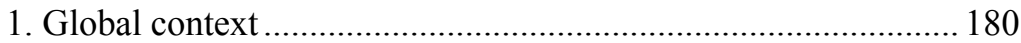

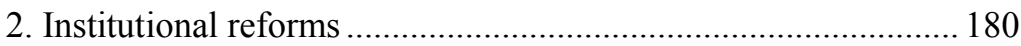

3. The Common Security and Defence Policy ............................. 186

4. The EU External Trade Policy ............................................... 188

5. Development cooperation .......................................................... 189

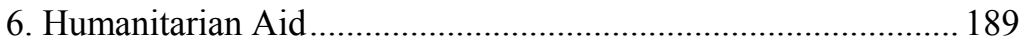

III. A Human-centric Assessment....................................................... 190

1. Human rights and citizenship .................................................. 190

2. Cosmopolitan perspective of EU foreign relations .................... 193

3. Global/European public goods and social democracy................. 194

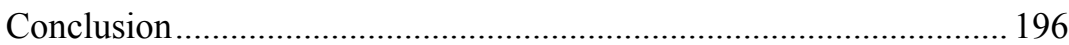

Chapter 10.

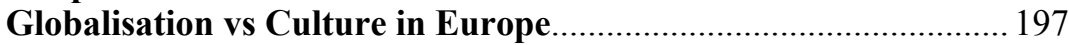

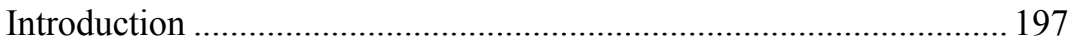

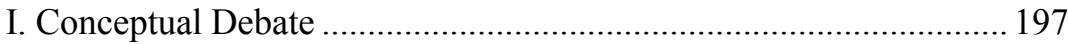

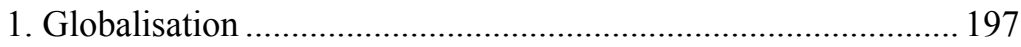

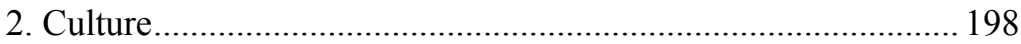

3. Policy implication of the globalisation vs culture debate........... 202

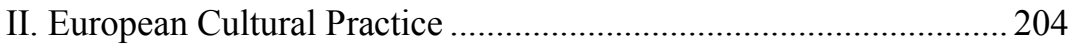

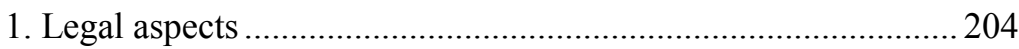

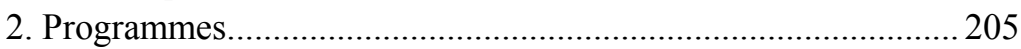

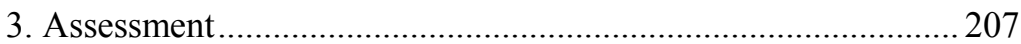

Chapter 11.

Intercultural Dialogue for Cultural Diversity ............................... 209

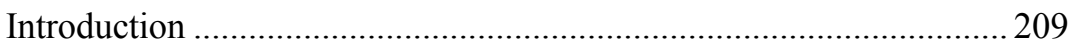

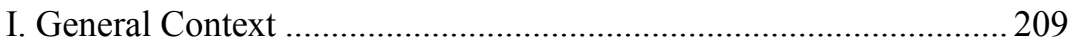

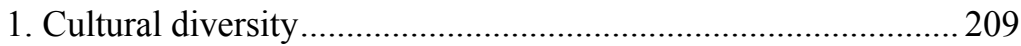

2. Intercultural dialogue: an inventory of usages and practices .....211

3. Intercultural dialogue: content ............................................... 213

4. National approaches to intercultural dialogue........................... 215

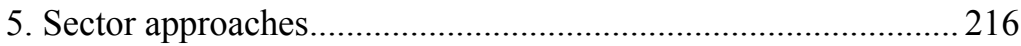

II. Institutional Practices of Intercultural Dialogue ............................. 218

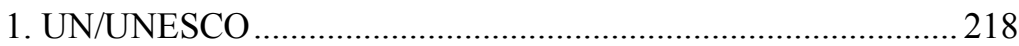

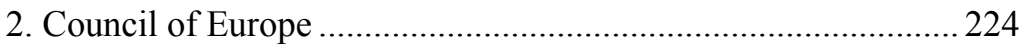

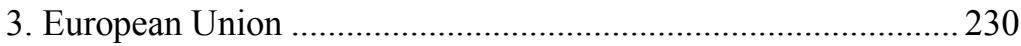

4. Intercultural cities: a good practice

towards a model for intercultural integration ................................ 235 


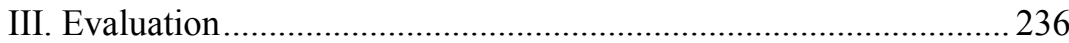

1. Culture as a driving force for genuine intercultural dialogue..... 237

2. Europe's responsibility to favour a dialogue between diverse cultural discourses ............................................ 238

3. Human rights paradigm: the basic point of departure

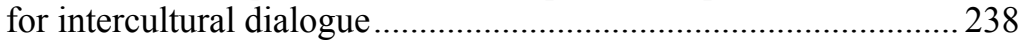

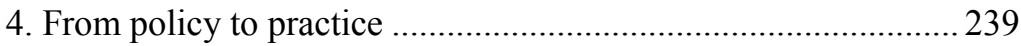

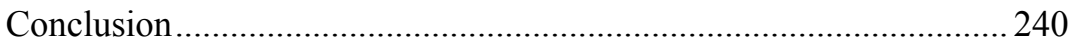

1. Intercultural dialogue and identity .......................................... 240

2. Intercultural dialogue and citizenship: universal basis,

European dimension and plural character ..................................... 241

3. Intercultural dialogue and democracy: major challenges and participatory characteristics................................................ 241

4. The structural/institutional setting for intercultural dialogue: the European Dialogues' framework.............................................. 242

\section{Chapter 12.}

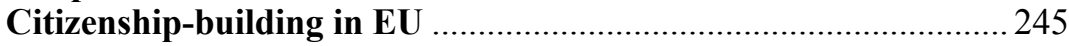

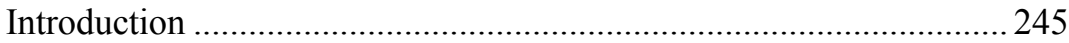

I. Process of European Citizenship-building ….................................. 245

1. The classical concept of citizenship .......................................... 245

2. Challenges to the nation-state and the citizenship equivalent to nationality ..................................246

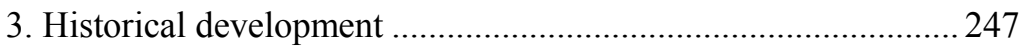

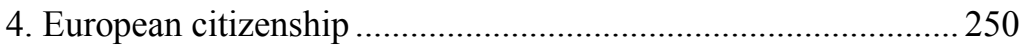

II. Connection between Identity, Nationality and Citizenship............. 255

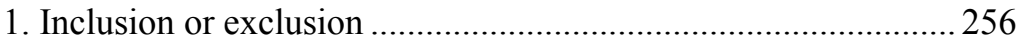

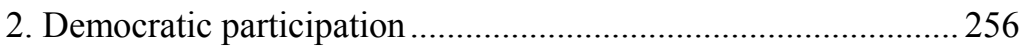

3. Emergence of a European identity ............................................ 257

4. European citizenship in cosmopolitan perspective....................257

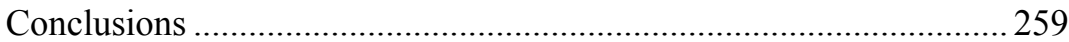

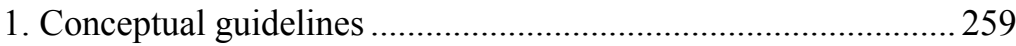

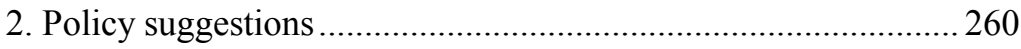

Chapter 13.

Education for European Citizenship-building .............................. 263

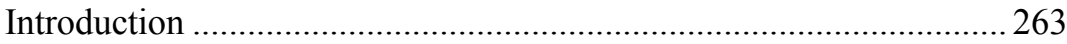

I. The Crucial Role of Education in EU Citizenship-building ............ 263

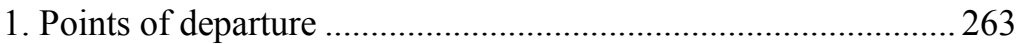

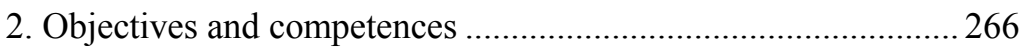


3. Citizenship education: education to active

and responsible citizenship in a plural Europe ..............................2. 268

II. Education Policies for Citizenship-building in Europe....................2275

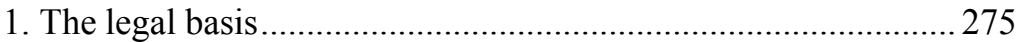

2. Overview of the European lifelong learning agenda

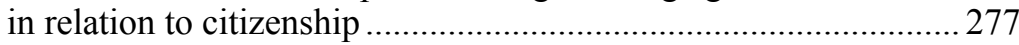

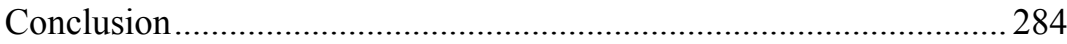

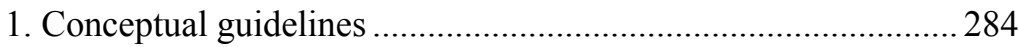

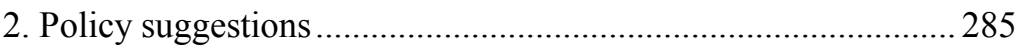

\section{Chapter 14.}

Territorial Cooperation and Multi-level Governance.

The Stimulating Role of the Committee of the Regions .................. 289

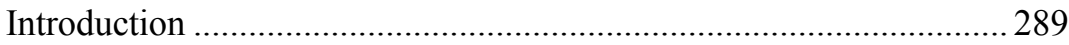

I. Multi-level Governance in European Perspective............................ 289

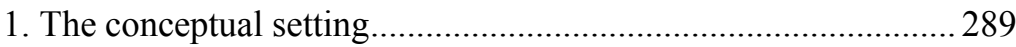

2. Multi-level governance in the context of globalisation .............. 291

3. Multi-level governance and the European integration process .. 293

4. European governance in global perspective ................................ 293

5. Multi-level/multi-actor governance and urban realities:

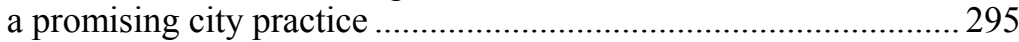

II. The Committee of the Regions: Principles and Practices in European Multi-level/Multi-actor Governance ............................... 297

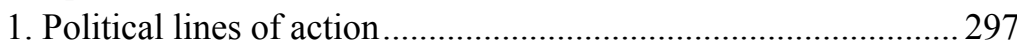

2. European Grouping of Territorial Cooperation (EGTC)............ 299

3. The Ateliers of the CoR:

strengthening the multi-level governance approach........................ 301

4. Scoreboard for monitoring multi-level governance

at the European Union level ..............................................................302

5. Towards an EU multi-level governance charter:

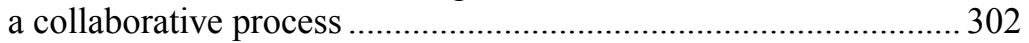

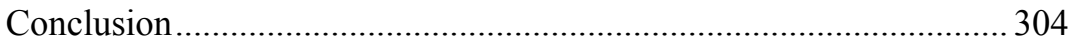

Chapter 15.

Building "Urban civitas"

in Intercultural Dialogue Practices ................................................... 305

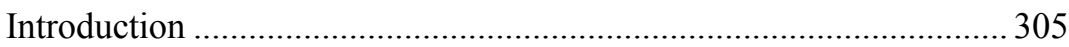

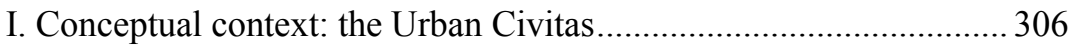

1. Moving from multiculturalism to interculturalism..................... 360

2. Recognising multiple faced identities

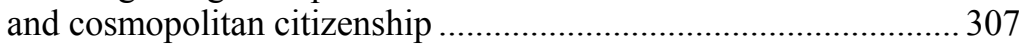




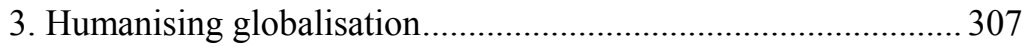

4. Revalorising the role of cultures in Europe............................... 308

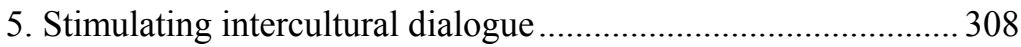

II. Creative Urban Realities in Europe ............................................... 309

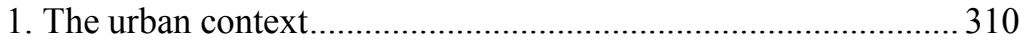

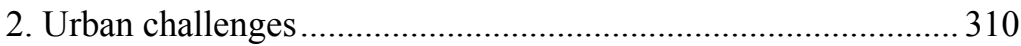

3. Urban opportunities.............................................................. 312

III. Intercultural Dialogue Practices:

Intercultural Routes and Spiritual Spaces........................................... 314

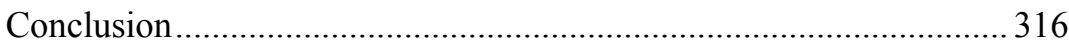

Chapter 16.

Learning Experiences of Participative

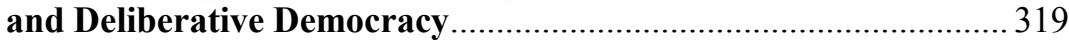

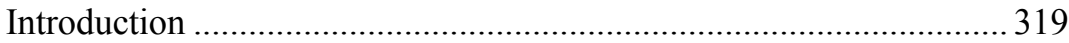

I. Development of a European Public Sphere in Participatory,

Deliberative and Inclusive Democracy.

II. Formal and Informal Learning Experiences

of Participative Democracy

1. The European Movement: a bottom-up approach shaped by inspiration and commitment.

2. The College of Europe: a unique higher learning institute on European affairs

3. Ryckevelde: a locally based and citizens' oriented European and international formation and information centre....................... 326

III. Participative Democracy: an Assessment...................................... 328

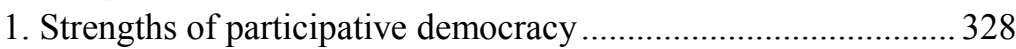

2. Weaknesses of participative democracy .................................... 329

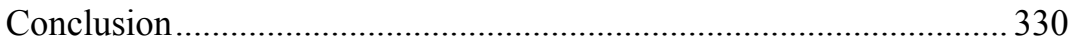

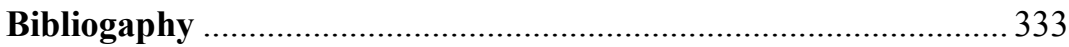




\section{Author's Note}

What is Europe's relevance today? What is its cultural heritage, its values and norms, its societal mode and economic structure? The answers to these fundamental questions will shape both Europe's future and the building of future European societies. Is Europe still an inspiring idea(l) of a value-driven society, worthwhile of pursuit? Will Europe survive the global competition? Themes such as the frontiers of Europe, European citizenship, cultural diversity and the role and purpose of Europe in a global perspective all require a human-centred vision of what Europe is and should be.

In today's multi-faceted and multi-layered globalisation era, the EU is in need of a revisited political project and a common long-term (inspiring) vision, to counterbalance the increasing influence of national interests on European policy-making, at the expense of the "European commons". There is a danger today that the Union, faced with the growing frustration, criticism and indifference of its citizens, could become a mere union of economic interests, detached from its very nature and identity, i.e. a community of opportunities and shared values. The undermining of these fundamentals could negatively influence Europe's economic, social and ecological welfare and finally lead to its marginalisation in the era of globalisation.

A Europe of authentic and open dialogue, both internally and externally defined, in which cultures are perceived as constructive binding forces within and beyond societies, can provide a solution for Europe's future in the emerging global landscape. It is only through strengthening the bonds of participation and cooperation in exploring innovative solutions to its many challenges, and humanising the relationships between living, working and learning together, that Europe will succeed.

Still we believe that Europe's flexible, communitarian model of society, business and citizenship is best suited to the challenges of the 21 st century. Europe is ideally positioned between the pronounced individualism of America and the strong collectivism of Asia to lead the world into the new age. Europe can be a living laboratory for examining the positive and negative consequences of globalisation, in a genuine dialogue of mutual respect, i.e. by adopting a human-centric point of departure, as embodied in the idea of "homo Europaeus". Europe can create a global public square, characterised by unity in diversity, where 
peoples can live together with a common vision of inclusion, sustainable development, universal human rights and genuine peacebuilding. It is the only way to survive as an economic, social and political macro region while keeping and strengthening its own identity and value system. Courage, inspiration and involvement are needed to make this renewed European dream true and to revitalise the sense of the European construction, which is based on a cultural, inspirational and moral heritage.

I wish to thank the students who have followed my courses throughout the years at various European universities, especially those who took my courses in the framework of my Jean Monnet Chair at the University of Padua. They were a continuous source of motivation and feedback. Also my own trajectory, much characterised by the ongoing exchange and interaction of teaching and research, conversations and meetings throughout Europe and beyond, bridging concepts with differentiated realities and transmitting commitment and ideas for Europe's future within a globalising context, has resulted in a fruitful process of lifelong mutual learning. It gave ample satisfaction and content strength for practising change and building responsible citizenship in a value driven and trustworthy path towards Europe's future destiny.

I do hope the content of the book serves its purpose, i.e. as a contribution to the learning of a comprehensive understanding from a human-centric perspective of the issues involved in the complex and intricate relations between globalisation and its consequences for the citizens of Europe. 


\title{
Preface
}

\author{
Antonio PAPISCA
}

\begin{abstract}
Professor Emeritus of the University of Padua, Jean Monnet Professor ad honorem, Chairholder Unesco Chair human rights, democracy and peace
\end{abstract}

The European Union's governance capabilities are being increasingly challenged by the tentacular dynamics of the process of globalisation. Its first response lies in recovering the collective awareness that the EU is an original model of governance, able to set an example to the entire world, as a system specialised in pursuing objectives of both social peace within its borders and international peace, using the resources which nourish the soft power of a macro civil actor.

Among the several resources available to the EU, it is worth underlining the vision of economy as a social market economy oriented to full occupation, the practice of the internal and external "dialogues" of the Union (social dialogue, civil dialogue, intercultural dialogue, political dialogues with third countries), the valorisation of the role of local governments as well as of the "platforms" of civil society organisations, with particular attention to be paid to the architecture of subsidiarity. Moreover, the fact that the EU has broadened the practice of democracy within its borders, both representative and participatory, and the fact that it has introduced the "human rights clause" into all its agreements signed with third countries is certainly indicative, inter alia, of its ability to "lead by example".

With the Lisbon Treaty, which assigns fully binding legal character to the Charter of Fundamental Rights proclaimed in Nice in 2000, the whole system of the Union is marked with the seal of "constitutionality", summarised in the triad "rule of law, human rights, and democratic principles". The Charter of Fundamental Rights itself presents elements of originality within the typology of international human rights legal instruments: it includes both civil and political rights and economic, social and cultural rights, with a logical reference to the principle of their interdependence and indivisibility. Therefore, the Charter also provides an explicit legal basis for a social market 
economy; in other words, it compels the Union to authentically be a "Social Europe".

Léonce Bekemans plans his explorative journey through the thematic galaxy of globalisation and the interactions existing between the processual and institutional reality of Europeanisation, proving himself capable of building a systematic analytical scheme allowing him to avail himself of conceptual categories located in the most advanced frontier of international and European studies: multi-level governance, plural citizenship, multiple identities, sustainable statehood, humancentrism.

Throughout this stimulating analytical journey, he accompanies his scientific exploration with a compass that allows him to evaluate processes and institutions against the yardstick of universal ethics. This is the compass of human rights, recognised at both the global and European levels. This is empirical evidence that neither political science nor international relations scholars can ignore. One only has to recall that reference to a paradigm based on values is indispensable for an action - and policy - oriented type of analysis, such as the one carried out by Bekemans. Far from invalidating the scientific accuracy of this analysis, a wise usage of this compass, beyond conferring an added quality value, allows the author to give the reader a glimpse of the new challenges and opportunities available for the same work of theorisation: hence, the also heuristic utility of this book.

Léonce Bekemans's preoccupation with good governance and with the example that the European Union is urged to set in this field, brings him to make strongly relevant the quality of political culture and, therefore, the strategic role of human rights-based education, with a view to training new generations of citizens and leaders so that they are disposed to pursue common good objectives, such as intercultural dialogue in respect of diversity, and the affirmation of equal citizenship rights in inclusive cities and in an inclusive Europe. The message for the European Union is that it needs to make its educational policy more systematic and turn it into a quality education more marked by human rights than by market demands.

Léonce Bekemans, both in his vocation and as a result of his life experience in a space that is authentically glocal and multi-dimensional, is an educator capable of translating his vast scientific knowledge through publications that are, at the same time, useful to both decisionmakers and students. This current volume, which is structured as a compendium of systematically undertaken reflections and as a strategic agenda for European Union policies, will be particularly appreciated by those who want to see what opportunities might emerge around the corner for human development and human security in Europe and, beyond Europe, in the world. 


\title{
Preface
}

\author{
LUc VAN DEN BRANDE
}

\begin{abstract}
Former Minister-president of Flanders, Belgium, Former President of the Committee of the Regions, European Union
\end{abstract}

The European movement, which was formed after the Second World War, was built upon the conviction that sustainable peace on our continent was only possible if cooperation replaced the confrontations between nation-states that has led to so much human devaluation and destruction in previous centuries.

The founders of the current political European Union recognised that Europe's future was to be rooted in partnership; however, they could not avoid the fact that the scars of the geographical and subsequently democratic re-allocation of the past, would lead to a Cold War which, until the fall of the Berlin Wall, would result in a worldwide bipolarity.

Simultaneously a second movement took shape and what neither religion nor the Enlightenment had been able to achieve, happened: the recognition of human rights as an individual and inalienable right. Despite how imperfect democracies may be, these fundamental rights have been enforced by the European Convention, and now have full European support.

Our world has since been profoundly changed. Multilevelness has replaced centralism. States and institutions have steadily lost their importance. Secularisation has progressed. Glocalism has replaced epicentrism. Citizens have become much more emancipated. New interconnections have emerged, stimulated by the powerful force of the media. Networking is dominating. Sustainability has become an integral part of economic activities and policies. The paradigm that only centrally governed processes and institutions can obtain results has been rendered outdated. Multilateralism, Multi-level Governance and MultiActorship have forcefully entered the academic and policy debate.

Not only has the global and European setting been drastically changed, but the interconnection of mutually influencing views and transformations is urging Europe to reflect on its future, its vision and its mission. Europe is at a crossroads, during a time when economic crisis 
is raging and young people have fewer perspectives. This particular crisis, along with other equally important others, are the consequence of the insecurities felt at numerous levels and illustrate a multiple lack of confidence. This increasing lack of confidence is being felt among people and in the face of structures and mechanisms that have long been inviolable, but are now slowly crumbling away.

All this has been understood by Prof. Dr. Léonce Bekemans. In this comprehensive work the genesis and subsequent slow construction of Europe has been sharply analysed and evaluated. His reflections depart from, rather uniquely, an interdisciplinary context, and go beyond the too often cherished and rigid partitions. Starting from integration, inclusion, diversity and governance he scientifically distances himself from the traditional conceptual framework and introduces new insights and actors to the enlarged and deepened playing field of global and European relations. He further applies this renewed conceptual framework to a number of crosscutting policy areas such as foreign relations, culture, and education with some interesting policy practices. The attention he devotes to the true significance of citizenship is striking, based on the importance of education and shaped by the changed context of multiculturalism towards interculturality. He adopts a cosmopolitan approach and focuses on the regional and territorial identity of the European integration process within the growing globalisation. This brings him to a renewed and applied conceptual framework for the future, a rich idea of a humanising and active "nova civitas".

Not least is to his great merit that he does not limit himself to an indepth analysis and committed reflection, but he further suggests new paths and directions which may once more make Europe more attractive - not only for Europeans themselves but also for the world. Furthermore, his work is also a clear and innovative appeal and plea: a new future for Europe is only possible if it becomes "human-centric". When all attention seems to go to organisational, rule-setting and institutional issues - regardless of their importance and necessity - it seems paradoxical to put the main emphasis on a human-centric perspective. But the real capital for cohesive and sustainable society building, not only for Europe, is the "human capital".

This magnum opus is undoubtedly an important guideline to identifying and straightening out the existing deficits of Europe's future, which the rest of the world is also confronted with. I call these the "Triple D-deficit" (delivery, democracy, and destiny).

A "human-centric" approach to the interaction between globalisation and Europeanisation can offer new content support to a participative, deliberative and inclusive democracy, at the global and European level, 
through a collaborative process driven by committed people and communities.

I am convinced that the "explorations" and proposals of Prof. Dr. Léonce Bekemans will find their way to many - academics and students, and people responsible for politics as well as a host of interested actors; in short, to all who believe in Europe as a project for the future. 



\section{Introduction}

\section{Rationale}

The ongoing and radical process of the transformation of European societies needs a proper contextualisation within a globalising, europeanising, regionalising and localising context. Questions about identity, citizenship, governance, borders, dialogue and human security are in need of proper answers. The EU's role in the world is rooted in its very existence, as an emerging form of multi-lateral governance of national and local diversities towards increasing regional convergence at the European level. What matters is the consolidation of a complex set of common institutions and a mixed intergovernmental/supranational regime among its Member States, sharing several common interests, objectives, values and policies. The European integration process is to date the world's most advanced post-national constellation of states. As such, it has become a laboratory for scholars and philosophers of political theory and international relations and those interested in studying and developing workable models of supranational and/or global and multi-level governance.

Europe is at the crossroads of its historical destiny, rooted in its past, present and future developments and is at a turning point with regards to its integration process. Its historical development shows a dynamic and evolving entity with many faces, multiple identities and diversified cooperation forms. The challenges are manifold both inside and outside of Europe. We are confronted with a number of (internal and external) challenges to the European model of socio-economic cohesion and cultural and regional diversity.

Still, Europe has a mission and a responsibility to the globalising world. It requires an inspiring narrative that responds to institutional governance structures, financing internal and external European solidarity and a vision that motivates the participation of its citizens. Today Europe has an appointment with its destiny. Its model of society, based on a fundamental set of human rights, culture as a vehicle of emancipation, on sustainable development and socio-economic cohesion, and on a multilateral vision of the world order, has been put under stress and pressure. In other words, we are experiencing a confrontation between Europe's actual confusing (political, economic, cultural and institutional) reality and its global responsibility, in the context of an ever-increasing globalisation. 
Foundation: In the fast changing global landscape, Europe is confronted with the preoccupation, but also with the moral responsibility, to maintain its own model of integration and diversity within a resolutely changing world system. This consists of the values, methods and capacity to deal with change processes, global commons and the integration of people in respect of their diversity. It implies that Europe should defend its values and principles of solidarity, tolerance and democracy in the limited but open dialogue between cultures and peoples within and outside Europe. It certainly requires in today's world a change in mentality, a broad imagination and proactive thought and action from the outset. Finally, Europe's future is to be founded on (political, economic, business and spiritual) leadership rooted in an education that focuses on learning responsibility at different levels of space and time.

Questions have to be asked about whether Europe, within a further unifying European economic space, can guarantee an acceptable common institutional basis in which states, regions and communities can live in their diversity (guarantee of internal solidarity) and whether Europe can offer an open societal model within the process of further globalisation (guarantee of external solidarity).

Challenge: The challenge for further European integration (and Europe's survival) is the search for a new equilibrium between diversity and unity in a globalising world (universalism vs particularism). The European model should take into account the economic, historic, social and political changes that are taking place at the international level, but it must remain faithful to its principles of internal and external solidarity. "Repenser l'Europe" implies the recognition of a radical increase in the level of complexity within our societies, the further development of a multiple citizenship within multiple identities and the elaboration of multi-level governance.

Vision: We once more need an inspiring and mobilising vision, which can raise a renewed spirit and enthusiasm within the citizen. Furthermore, we must dare to recall the enthusiasm and faith in the European project that was embodied by the Founding Fathers of Europe. They wanted to guarantee a sustainable peace within the European borders and had a long-term vision as well as the pragmatic conviction to write a new chapter in the relations between European peoples and countries. Economic arguments supported the political goodwill. Therefore, Europe needs bridge-builders who can concretely complete the rhetoric of the European story, promote the European ideals of peace, unity in diversity, freedom and solidarity and mobilise young people towards the European model of society. The role of education is herein fundamental. In this model, new forms and places of dialogue, 
active citizenship and of cooperation, emerge outside of the existing institutionalised structures of representative representation. The European civil society becomes emancipated and develops opportunities in the globalising society through which persons, peoples and cultures within and outside Europe can meet peacefully and respectfully.

Historical lessons: The history of the European integration process shows that in the course of three generations, the EU developed, with both successes and failures, to a community of now 28 countries, all former enemies, with different histories and diverse expectations. Now a unique union of more than 500 million citizens exists, stretching out from the Irish Sea to the gates of Russia; this geographical area constitutes the first transnational political space, based on a community of shared values, which are both multiculturally and multilinguistically defined. It was a success story, but it is now confronted with internal and external tensions and is experiencing a deep sense of crisis.

Different from the traditional forms of politics, mainly geared to market and power the extension and appropriation of human, natural and territorial resources, the EU was conceived and developed out of the realisation of a consensus around collective interests, the extension of reciprocity to all its citizens and the realisation of a durable peace founded on mutual respect between peoples. Despite all the current and dramatic changes, Europe remains a civilisation project, characterised by a rich intellectual (material and immaterial) cultural heritage and common values. Up to now, this has guaranteed a good quality of life, sustainable development, a respect for human rights and internal and external solidarity; in short it has provided economic welfare and built bridges of peace and understanding.

Future fundamentals: Dreams express expectations of people, not their conditions. Still the rhetoric needs to be translated into a workable forward-looking reality, amidst a radically changing world. In spite of its failures and imperfections in the integration process, project "Europe" has been a permanent workplace for "active dreamers" to define the European common good and to develop a unique institutional and operational framework. I distinguish four fundamental tasks:

Firstly, Europe has the moral responsibility to establish best practices of cooperation, both internally and externally. The individual and collective well-being depends more and more on the comprehension of man's capacity to recognise important emerging global trends and act accordingly in the pursuit of economic and social welfare for its citizens. We are in need of a radical change in our vision and methods in order to survive as a European civilisation.

Secondly, Europeans also have the moral responsibility to show that people can live together in the world, despite any differences in 
language, culture, religion, origin, etc. Europe's motto is "unity in diversity", but in practice, Europeans still need to show that they can form an international public space where a cultural diaspora can exist in mutual respect, tolerance and dialogue. European citizens need to be inspired by clear messages, examples and testimonies.

Thirdly, all European countries and regions have to work continuously to make their social and economic systems individually more efficient, so that the weaknesses of one can be compensated by the strength of others. This implies the importance of encouraging individual initiative, of aiming for a broad and just distribution of the benefits of economic welfare and of revalorising senses of responsibility as part of a value driven education with a European dimension.

Finally, Europeans should play a more courageous and dynamic role on the international political scene, by defending Europe's model of peace and transnational cooperation and strengthening its method of collaboration with other macro regions. Europe should work for a transition from the traditional management of geopolitical and global economic conflicts to a new transversal policy of the global political and economic landscape.

Objective of the Book: Globalisation is one of the most important phenomena and processes confronting the world today. Globalisation affects every aspect of society, including economics, politics and culture as well as personal developments. This book offers a general introduction and critical overview (i.e. concepts, definitions, approaches, historical developments and assessment) of the future of the EU in a globalising context. It looks at the phenomena from a multitude of perspectives - as it is studied in different disciplines and perceived by different regions across the world. Globalisation is viewed in all of its dimensions, including economic globalisation, political globalisation, and the globalisation of civil society, global knowledge and global environment.

A mobilising, forward-looking and human-centric European perspective could favour the transition to a global transnational era. Courage and inspiration are needed to make a renewed European dream worthy of envisaging, rediscover the purpose of the European construction and to give life to a voice of the European civilisation project that responds to the cultural and moral traditions rooted in the ambitions of its fathers. A value-driven and human-centric based approach to Europe's future may provide a possible, soft and "slow", but qualitatively strong solution. 


\section{Structure}

The content of the book is structured along three major parts divided into sixteen chapters. In a first introductory chapter we present our points of departure. This deals with the origin and development of the European integration process, the scientific context and content, the key concepts of the proposed analysis and a few guidelines for its elaboration. Part I (Chapters 2, 3 and 4) concerns a contextualised analysis of the idea and practice of Europe in an historical and forwardlooking perspective. The theoretical Part II (Chapters 5 to 8 ) deals with the need for a renewal of the conceptual framework of understanding Europe's future. It introduces some new concepts, tools and perspectives of addressing the major challenges in today's European transformation process. This also has an impact on the context and content of European Studies. The policy-oriented Part III (Chapters 9 to 16) illustrates and applies the contextual and conceptual framework to various crosscutting policy fields and issues such as international relations, globalisation, culture and (inter)cultural dialogue, education, European identity building and citizenship and (participatory) democratic practices.

While the focus is on the societal changes that have taken place in Europe, it also offers interested readers of European affairs, in particular students from different disciplines, an opportunity to reflect and debate on the emerging themes, challenges and inclusive policies in the future of European societies within a globalising context, in particular the social and cultural dimensions of globalisation. The opportunities, challenges and threats that the process of globalisation presents need to be considered, analysed, assessed and managed accordingly, in view of the future perspectives of mankind and Europe's role and responsibility in a multi-level governance structure. This has become even more urgent in the midst of the current global economic crisis and Europe's lack of vision.

The book wraps up my applied thinking and reflections on the role of Europe in the globalising world. It proposes a new conceptual framework - a human-centric cosmopolitan and public goods perspective of sustainable statehood - and applies it to a number of specific policy areas for human-centric development in Europe (such as external relations, culture, intercultural dialogue, citizenship building, education and territorial cooperation). It is both informative and formative and the various chapters can be read separately within the suggested conceptual frame. 



\section{CHAPTER 1 \\ Points of Departure}

The process of European integration, now in the midst of a radically changing economic, social and political landscape, still needs to be understood in its conceptual, theoretical and historical context. Only in such a way can the actual role of Europe be assessed from a global perspective. Points of departure of such a broad understanding refer to: Europe as a visual expression of diversity in unity in a variety of areas and dimensions; Europe as a civilisation and model of society; Europe as a (changing) historical and (loose) geographical entity; and Europe as a community of values and principles. Its raison d'être is linked to the principles of peace, safety \& security, unity and equality, fundamental freedoms, economic and social solidarity, respect of cultural diversity/identities as well as European cultural heritage, inclusiveness, etc.

Europe is a two thousand year old civilisation. Throughout the centuries of its existence it has exhibited different expressions and experienced various historical stages. It is rooted in a religious, mythical and artistic background and first developed into a geo-political entity under Alexander the Great. This was inspired by the Aristotelian paradigm of linking the individual and the community through the "ethos". Under the reign of the Roman Empire, Europe shifted its power centre to the West and slowly developed into a Christian era in the Middle Ages, where the Christian sense of community became the binding and exclusive element of the European people.

With the arrival of the Renaissance and the rebirth of Greek classics through Arab influence, commercial routes and artistic exchanges made city states flourish because of flexible linkages and cooperation. Since the Treaties of Westphalia (1648) and Vienna (1815) the role of nation states in international relations has been legally defined and the boundaries of states have been fixed. In the 19th century Napoleon tried in vain to integrate Europe, using military force.

The dramatic consequences of the two World Wars finally led to an American financed voluntary-based economic integration of former European enemies. During 60 years of phased development, the economic community of the founding member states has evolved into a European Union of now 28 member countries and more than 500 million citizens. However, Europe as a civilisation and the European 
Union as a unique process of integration are now at a crossroads, shaped by challenges of content, structure and destiny.

Since the fall of the Roman Empire, Europe has not been united for a sustained period of time, despite the many military, economic, political and cultural attempts that have been made at integration. Europe exists and is developed as a vague geographical and historical framework of a community of shared values. A cultural integration, which would lead to an American type of "melting pot", is certainly not desirable. What's needed is a community of countries, regions, cities and persons that is built on a clear multi-level institutional structure that binds citizens in a sustainable and cohesive way and introduces rules that respond to its democratic founding principles. The European institutional architecture is in need of strength and transparency, a sense of belongingness that brings people, especially younger generations, closer to the real issues at stake. This must be supported by a learning environment that favours true European citizenship and that structures the wealth of differences within a shared, sustainable but adaptable process to the changing new economic structures of the global landscape, in respect of universal rights.

Europe, in the light of its colonial past, cannot present itself as the only entity that disseminates principles of freedom and democracy without any territorial anchorage. Europe's main task and moral responsibility to the world is a synthesis of the demand for freedom and the pursuit of equality both within and outside of Europe. Freedom must be prevented from becoming a privilege in a world of conflicts and inequality. It cannot be an empty ideological slogan. Each country and each region has its own history and need to communicate and engage in dialogue with the history of each other's. Each citizenship and each citizen presents its own story and characteristics and needs to be guaranteed and maintained at various levels to become a multiple, inclusive identity. The European Union should include any form of regional, local and citizen participation because the European common good serves the national, regional and individual interest.

\section{European Integration Process: Origin and Development}

The originality of the European Union is derived from the special way in which its various constituent parts have evolved. The European Union came into being with the adoption of the Treaty of Maastricht in 1992, when it brought together three organisations established in the 1950 s to integrate activity in specific sectors (the European Communities), and two areas of intergovernmental cooperation (common foreign and security policy and justice and home affairs). 
Since then, the resulting structure has been described as one built on three pillars, the first of which is supranational, comprising of the three European Communities, each of which has its own legal personality. The European Union does not have legal personality, however, even though it encompasses the community pillar and the two intergovernmental pillars within a common institutional structure.

The European Union is the first "general-purpose" international organisation to derive, not from a coordination of its members' national policies, but from the pooling of some of those policies under the umbrella of the European Communities. The result of this pooling of policies was an innovative type of body, i.e. a supranational organisation, formed by the voluntary transfer of certain sovereign powers by its member states. Member states did not surrender their powers, but decided to exercise them jointly at a higher level that had common institutions. Thus, 1951 saw the creation of the European Coal and Steel Community (ECSC) and in 1957 the European Economic Community (EEC) and the European Atomic Energy Community (EAEC or EURATOM).

As specialist organisations, each of the three Communities holds only those powers attributed to them by Member States. The principle of attribution requires that each Community "shall act within the limits of the powers conferred upon it $[. .$.$] and of the objectives assigned to it"$ by the treaties which established them (i.e. the Treaty of Paris establishing the ECSC and the Rome Treaties establishing the EEC and EURATOM). Likewise the Community institutions, i.e. Parliament, Council, Commission, Court of Justice, Court of Auditors, assisted by an Economic and Social Committee and a Committee of the Regions, must each "act within the limits of the powers conferred upon it" by the Treaties.

With the aim of creating an ever closer union among the peoples of Europe, integration has proceeded step by step, firstly by the pooling of policy on certain sectors of member states' national economies, then by the creation of a common market, followed in turn by the gradual introduction of economic and monetary union. Notwithstanding its economic foundations, the objective of European Union was a priori political. The functional approach taken by the "founding fathers" of the Communities, Jean Monnet and Robert Schuman, held that it was necessary to move from the economic to the political sphere. In effect, specific actions in a given sector of the economy were bound to have an impact on the way in which other sectors operated. The questions raised needed answers, which required political choices.

Thus, the completion of a common market in which there was free movement of goods raised the question of the movement of people, 
services and capital, requiring the introduction of a raft of flanking policies in the areas of competition, industry, agriculture, transport, research, etc. Ultimately - little by little - complementary policies addressing the problems of highly sensitive national prerogatives were adopted. This was the case with social and fiscal policy. In addition, the organisation's internal policies had ramifications outside of it, which the organisation, as an entity under international law, had to manage in its dealings with non-member states and other international organisations. As a result it forged external relations in the areas of world trade, development aid, immigration, defence, etc.

Whilst the organisation is a constantly evolving one, the degree of integration achieved at each stage is the result of compromise, which is not always easy to secure. Member states, each with their own economic and social baggage and national susceptibilities, struggle between the benefits of solidarity and the drawbacks of having their political and budgetary autonomy curtailed, something often perceived as a surrender of national sovereignty. Meanwhile the organisation, in a way the victim of its own success, has to manage two inseparable processes at the same time: widening itself through enlargement, with the admission of new member states upon application, and deepening itself by extending its powers and institutional procedures. The imperative is to meet the legitimate expectations of applicant countries without undermining the operational efficiency of the common institutions. Consequently, the collective agreement put in place by the founding treaties evolves pragmatically over time, to reflect the structure of the organisation, the priorities of the various players in the process of building Europe, and changes in the geopolitical environment.

Major reforms to the founding treaties were made with the adoption of the Single European Act in 1986, the Treaty of Maastricht in 1992, the Treaty of Amsterdam in 1997 and the Treaty of Nice in 2001. Of these, the Maastricht Treaty was the one that most radically altered the structure of the organisation. It established the European Union, with its pillar-based structure, and placed the EEC, now the European Community (EC), at the heart of its edifice. In 2002 the ECSC Treaty expired, after 50 years of existence. 2004 saw the signing in Rome of the treaty establishing a constitution for Europe, which must be ratified by all member states of the Union before it can come into effect. This "Constitutional Treaty" would repeal all the earlier treaties apart from the EURATOM Treaty and would at last give the Union legal personality. The European Union established by this new treaty would thus be the successor to the European Union established by the Maastricht Treaty and to the European Community. 
The changes in the nature and operation of the organisation, brought about by successive revisions of the original treaties, reflect the degree to which compromise is possible at any given moment in history. In an increasingly enlarged and diverse Union, in light of opposition from certain member states and their obsession with sovereignty, it can sometimes seem that integration is not the way, or not yet the way, to address the new challenges which the world throws up. In such cases the search for viable solutions acceptable to the greatest number leads to the adoption of new forms of intergovernmental cooperation (cf. Maastricht Treaty) or to enhanced cooperation by a smaller number of member states which are keen to go further (cf. Amsterdam Treaty). That is not to say that an area initially dealt with by intergovernmental cooperation (visas, asylum, immigration) cannot subsequently be moved up to Community level, or that a Member State cannot subsequently join a process of enhanced cooperation which it was not part of to begin with.

Given the major enlargement of the European Union in 2004, fresh compromises appear essential in order to ensure that institutions with 25 and more member states can function. In response to the unsatisfactory outcome of the reform brought about by the Nice Treaty of 2001, changes were made to the procedure for amending the original treaties by means of intergovernmental conferences (IGCs), in an attempt to make this procedure more flexible and more effective. Following the model of the convention which drafted the Charter of Fundamental Rights of the Union in 2000, the European Convention met in Brussels from 2002 to 2003 with the aim of preparing a draft treaty which would form the basis for the work of the next IGC.

The European Convention was made up of representatives of the Heads of State or Government, the national parliaments, the European Parliament and the European Commission, and it introduced a new method of reforming the Union, offering greater transparency and more participation by the players concerned. Member states will still be "masters of the treaties", but this new procedure, which is designed to be more democratic and more consensual, goes beyond the classic method of multilateral diplomatic negotiation and further down the road of gradually constitutionalising the founding treaties. The negative outcomes of the French and Dutch referenda on the "Treaty establishing a Constitution for Europe" in 2004 and the negative result of the Irish referendum on the "Reform Treaty" in 2007, have put the further process of integration at risks. The global finance crisis has aggravated the present economic and political situation but has, simultaneously opened up new possibilities for a stronger political and economic European integration within the global landscape. 


\section{Scientific Context and Content}

\section{The International Relations theory}

The study of international relations takes a wide range of theoretical approaches. ${ }^{1}$ In spite of this diversity, several major schools of thought are discernable, differentiated principally by the variables they emphasise - e.g. military power, material interests, or ideological beliefs. In general, the theory attempts to provide conceptual models upon which international relations can be analysed. Each theory is reductive and essentialist to different degrees, relying on different sets of assumptions respectively. The number and character of the assumptions made by each international relations theory also determine its usefulness. In general, international relations theories can be divided into positivist/rationalist theories, which focus on a principally statelevel analysis, and post-positivist/reflective ones, which incorporate expanded meanings of security, ranging from class, identity to gender and post-colonial security.

Classical realism is a state level theory that argues that all states seek power. This parsimonious and very essentialist theory considers that the international system is anarchic, that states are self-interested, rational actors seeking to survive while increasing their material conditions, and that uncertainty pervades relations between countries. Neo-realism is a system level theory that sees the cause of power struggles and rivalries not as a function of the nature of states, but as a function of the nature of the international system. The realist theories are useful in accounting for historical actions based on the balance of power systems and international power politics but limited in both explaining systemic change and predicting future events. ${ }^{2}$

Institutionalists share many of Realism's assumptions about the international system but rely on microeconomic theory and game theory to reach a radically different conclusion, i.e. that cooperation between nations is possible. The central insight of institutionalism is that

\footnotetext{
Viotti, P.R. and Mark V. Kauppi, International relations theory, realism, pluralism, globalism, and beyond, 5th edition, Pearson, 2012; a short review of the main theories is given by Anne-Marie Slaughter, International Relations, Principal Theories, in Wolfrum, R. (ed.), Max Planck Encyclopedia of Public International Law, Oxford: Oxford University Press, 2011.

2 Waltz, K.N., Theory of International Politics, Reading: Addison-Wesley, 1979. JJ Mearsheimer, The False Promise of International Institutions, in 19(3) International Security, 1994, p. 5-49.
} 
cooperation may be a rational, self-interested strategy for countries to pursue under certain conditions. ${ }^{3}$

Liberal theory considers individuals and private groups, not states, as the fundamental actors in world politics. It is a state level theory, which argues that in many instances cooperation is a better strategy that conflict. States don't just compete or worry about power. States try to build a more just world order. One of its most prominent developments has been the phenomenon known as democratic peace, first imagined by Immanuel Kant. Liberalism examines a wide number of conditions, is less useful in making predictions, but can be insightful when analysing past events. ${ }^{4}$

Constructivism is a theory that examines state behaviour in the context of state characteristics. All states are unique and have a set of defining political, cultural, economic, social, or religious characteristics. It challenges the rationalist framework that underpins many theories of international relations and creates constructivist alternatives in each of these families of theories. In the constructivist account the variables of the international system are important because of their social meaning. ${ }^{5}$ Moreover, a focus on the social context in which international relations occur leads constructivists to emphasise issues of identity and belief. It is also attentive to the role of social norms in international politics ${ }^{6}$ and emphasises the role of non-state actors more than other approaches. ${ }^{7}$

The Theory of International Relations has long studied European relations and has always perceived Europe, in particular the European Union, as an international entity with specific and unique characteristics. Within international relations literature various theories have been applied to the study of European relations since the First World War. These have been applied over time to the specific process of European integration. In the following, we briefly synthesise the major theoretical approaches with the various entities and actors involved in the integration processes. Briefly summarised they can be listed as follows:

Keohane, R.O., After Hegemony: Cooperation and Discord in the World Political Economy, Princeton: Princeton University Press, 1984.

4 Moravcsik, A., Taking Preferences Seriously: A Liberal Theory of International Politics, in International Organisation 51, 1997, p. 513-53.

5 Wendt, A., Social Theory of International Politics, Cambridge: CUP, 2000.

6 March, J.G. and J.P. Olsen, Rediscovering Institutions: The Organizational Basis of Politics, New York: The Free Press, 1989.

7 Keck, M.E. and K. Sikkink, Activists Beyond Borders: Advocacy Networks in International Politics, Ithaca: Cornell University Press, 1998. 
Federalism $^{8}$ is a political theory in which a group of (subnational) states are bound together with a governing representative head. It describes a system of government in which sovereignty is constitutionally divided between a central governing authority and its constituent political units, such as states, regions or provinces. Therefore, federalism is the system in which the power to govern is shared between the national and state governments, creating what is often called a federation. There is a constitutional division of power between one general government (that has authority over the entire national territory) and a series of subnational governments (that individually have their own independent authority over their own territories, whose sum total represents almost the whole national territory).

A Federation consists of a central federal government with specific and well-defined legal/policy competences and self-governmental units, based on a constitution. Examples of federal states in Europe are Belgium, Germany, Austria and Switzerland. A confederation or association of (regional) states (e.g. Switzerland) is a group of empowered states or communities, usually created by treaty but often later adopting a common constitution. Confederations tend to be established for dealing with critical issues, such as defence, foreign affairs, foreign trade, and a common currency, with the central government being required to provide support for all members. A confederation, in modern political terms, is usually limited to a permanent union of sovereign states for common action in relation to other states. The nature of the relationship between the entities constituting a confederation varies considerably. Likewise, the relationship between the member states and the central government, and the distribution of powers among them, is highly variable. Some looser confederations are similar to international organisations, while tighter confederations may resemble federations.

Functionalism $^{9}$ is a theory of international relations that arose during the inter-war period, principally from the strong concern about the obsolescence of the state as a major form of social organisation. Rather than the self-interest of nation-states as a motivating factor of international relations, functionalists focus on common interests and needs shared by states, but also by non-state actors in a process of global integration triggered by the erosion of state sovereignty and the increasing weight of knowledge in the process of policy-making.

\footnotetext{
8 Dosenrode, S., Federalism Theory and Neo-Functionalism: Elements for an analytical framework, in Perspectives on Federalism, Vol. 2, issue 3, 2010, 28 p.

$9 \quad$ Ibid.
} 
Functionalism can be seen as a pioneer in globalisation theory and strategy. States had built their authority structures upon a principle of territoriality. State-theories were built upon assumptions that identified the scope of authority with territory. Functionalism proposes the building of a form of authority based on functions and needs, linking authority with needs, scientific knowledge, expertise and technology, i.e. it provides a supra-territorial concept of authority.

According to functionalism, international integration, i.e. the collective governance and material interdependence between states, develops its own internal dynamic as states integrate in limited functional, technical, and/or economic areas. International agencies would meet human needs that can be aided by knowledge and expertise. The benefits rendered by the functional agencies would attract the loyalty of the populations and stimulate their participation and expand the area of integration. There are strong assumptions underpinning functionalism: the process of integration takes place within a framework of human freedom; knowledge and expertise are currently available to meet the needs for which the functional agencies are built and; states will not hinder the process.

Functionalism further developed to neo-functionalism and became a theory of regional integration. It was built on the work of Ernst B. Haas ${ }^{10}$ an American political scientist and leading authority in the field of International Relations theory. Unlike previous theories of integration, neo-functionalism presents a non-normative approach and tries to describe and explain the process of regional integration based on empirical data. Integration is regarded as an inevitable process, rather than a desirable state of affairs that is introduced by the political or technocratic elites of the states involved. Its strength, however, is also its weakness: while it understands that regional integration is only feasible as an incremental process, its conception of integration as a linear process makes an explanation of any setbacks impossible. It nonetheless remains an important theory in the study of international relations.

Neo-functionalism assumes a decline in the importance of nationalism and the nation-state; it argues that the pursuit of the welfare objective by the executive power and the interest groups within states is best satisfied by the integration of EU states. The thought behind neofunctionalist theory is best understood by explaining the three mechanisms which neo-functionalists see as key to driving the process of integration forwards: positive spillover, transfer of domestic allegiances and technocratic automaticity.

10 Haas, Ernst B., Beyond the Nation State, Stanford: Stanford Univ. Press, 1964. 
The positive spillover effect is the concept that integration between states in one economic sector will quickly create strong incentives for integration in further sectors; and finally fully capture the benefits of integration in the original sector.

The mechanism of a transfer in domestic allegiances can be best understood by first noting that an important assumption within neofunctionalist thinking is of a pluralistic society within the relevant nation states. Neo-functionalists claim that, as the process of integration gathers pace, interest groups and associations within the pluralistic societies of the individual nation states will transfer their allegiance away from national institutions towards the supranational European institutions. They will do this because they will, in theory, come to realise that these newly formed institutions are a better placed conduit through which to pursue their material interests than the pre-existing national institutions.

Finally, technocratic automaticity describes the way in which, as the process of integration develops, the supranational institutions set up to oversee that integration process will themselves take the lead in sponsoring further integration, as they become more powerful and more autonomous of the member states.

In its application to European integration neo-functionalism argues that the supranational institutions of the European Union themselves have been a driving force of European integration, by expanding EU rule-setting and decision-making into new and more diverse areas. Moreover, the theory of neo-functionalism explains much of the thinking and acting behind the early proponents of the European Community. Jean Monnet's approach to European integration, which was aimed at integrating individual sectors in the hope of achieving spillover effects to further the process of integration, has clearly followed a neo-functional path: an increased European integration was perceived as the most important driving force to a peaceful Europe.

The increasing complexity of international relations has led to a theory of transnationalism, a field of study which argues that states are not the only significant actors, and whose focus is cross-boundary political space. This theory transgresses the traditional boundaries of sovereign territory, emphasising instead the direct linkages across international boundaries. It is an international process grown out of the heightened interconnectivity between people all around the world and the loosening of boundaries between countries.

As an economic process it involves the global reorganisation of the production process, in which various stages of the production of any product can occur in various countries, with the aim of minimising costs. Economic transnationalism was spurred on in the latter half of the 
20th century by the process of (economic) globalisation. Multinational corporations can be seen as a form of transnationalism because of their operational organisation irrespective of political boundaries.

In practice, transnationalism refers to increasing transborder relations between individuals, groups and firms and to mobilisations beyond state boundaries. Individuals, groups, institutions and states interact with each other in a new global space where cultural and political characteristics of national societies are combined with emerging multi-level and multinational activities.

Proponents of transnationalism seek to facilitate the flow of people, ideas, and goods between states and regions. They believe that it has increasing relevance with the rapid growth of globalisation. They contend that it does not make sense to link specific nation-state boundaries with migratory workforces, globalised corporations, global money flow, global information flow, and global scientific cooperation. The present financial crisis has shown the limits of this approach.

Very careful distinctions are now being made between international or multinational relationships, i.e. relations between and among nationstates or agents, and transnational relationships, i.e. interactions between and among individuals and other entities, regardless of nation-state boundaries. As a consequence, internationalism refers to a cooperation between nation states, and points to the affairs between nation-state governments, while transnationalism refers to a cooperation between people, and points to activities, which transcends national boundaries and in which nation-state governments do not play the most important or even a significant role. Furthermore, transnationalism often entails a vision of the obliteration of nation states to make way for a unified world government.

Examples of internationalism refer to broad United Nations institutional architecture, international treaties, international customs and tariff regulations. International organisations have an international scope on specific issues, are based on a treaty and subject to international law (e.g. IMF, World Bank, OECD, EU, etc.). Examples of transnationalism include NGOs such as Greenpeace or "Médecins sans Frontières" as well as global financial activities, global science research and global environmental concerns.

When we look further and deeper into the scientific analysis of the European experience in international relations, the present stage of the European integration process is more and more shaped by the ongoing conceptual and policy debate between intergovernmentalism and supranationalism. Two elements should be stressed: decision-making method and application to the European integration process. 
Intergovernmentalism is an approach to integration that treats states and national governments in particular, as the primary actors in the integration process. The power in international organisations is possessed by its member states and decisions are made by unanimity or coordinated consensus. Independent appointees of the governments or elected representatives have solely advisory or implementation functions. In short, in an intergovernmental organisation, member states keep power and the decision-making process is managed through unanimity/ consensus rules. Intergovernmentalism applies to most international organisations today such as the UN, UNICEF, UNESCO, OECD, Council of Europe, etc.).

As a theory of regional integration applied to European integration, intergovernmentalism rejects the idea of neo-functionalism. The theory suggests that governments control the level and speed of European integration. It is said that any increase in power at the supranational level results from a direct decision by governments. The theory rejects the concept of the spillover effect that neo-functionalism proposes, as well as the idea that supranational organisations are on an equal political level as national governments. Various intergovernmental perspectives have been offered in order to explain periods of radical change in the European Union (because of the converging governmental preferences) and periods of inertia (due to the diverging national interests).

Supranationalism, on the other hand, is a method of decision-making in multi-national political communities, wherein power is democratically entrusted to independent, experienced, appointed personalities or to representatives elected by the legislatures or people of the member states. Member state governments still have power, but they must share this power with others. Because decisions are made by majority votes, it is possible for a member state to be forced by the other member states to implement a decision. Unlike a federal state, member states fully retain their sovereignty and participate voluntarily, being subject to the supranational government only in the sectors agreed, according to those rules agreed for each sector. In supranationalism, as opposite to the decision-making method in intergovernmentalism, member states already agree on goals and the methods for making decisions together.

In supranational organisations a division/sharing of power between member states and central authority exists; the decision-making process is centralised and the executive power is held by civil servants. As to European supranationalism, Weiler ${ }^{11}$ distinguishes two main functional

11 Weiler, J.H.H., The Community System: The Dual Character of Supranationalism, in Yearbook of European Law, 1 (1), 1981, p. 267-306. 
dimensions: the executive dimension, in which the relationships and hierarchy which exist between Community policies and legal measures are on one hand and the competing policies and legal measures of the member states are on the other; and the legislative-juridical dimension, in which the institutional framework and decision-making by which such measures are initiated, debated, formulated, promulgated and finally executed.

\section{Emerging scientific context and content}

The scientific context and content of European developments are being challenged by various trends. It is therefore important to identify the major socio-cultural transformations which are challenging Europe's future in a globalising context, and shaping the emerging scientific context and content: the (neo-) liberalist thinking has resulted in an exclusively market-based society with subsequent commodification and monitarisation of exchanges and relations; democratic governance practices in politics are confronted with a plural vision of the world and human beings; the existence of multi-cultural societies implies the need for interdisciplinary concepts and approaches and for pedagogical tools to learn how to dialogue and to manage diversity towards interculturality; growing societal complexity leads to growing uncertainties and human (economic, social, political, etc.) insecurity, which produces a crisis of the sense of belonging at a social level (i.e. growing individualism, the principle of the predominance of "I", individual and collective egoism) as much as at the cultural level (i.e. cultural relativism, attitudes of indifference, neglect and intolerance); and the globalisation vs Europeanisation debate shapes the nature of internal and external relations within and beyond Europe, and requires specific European answers. In short, the ongoing interaction between these societal characteristics leads to increasing pluralism in scientific perspectives and analysis with a differing disciplinary and interdisciplinary focus on the challenges of the current fragmented postmodern societies.

Within this changing international economic and political landscape the role of the main shaping actors also influences the scientific perspective of the role of the State and the Society:

As to the role of the State, the modalities and targets as well as the capacity for state intervention have changed drastically in the global economy as a result of increased flexible accumulation. Increasing international competition forces all states to become more entrepreneurial to create a favourable business climate. Also, international organisations such as the IMF and the World Bank have gained policy importance in managing the global economy and 
international financial negotiations. The role of the state has become much more problematic in present times, being only one of the many shaping actors of the relationship between economy and society;

As to the role of Society, two seemingly contradictory trends seem to be at work. On the one hand, norms, habits, political and cultural attitudes have shifted since 1970 from collective norms and values towards a much more competitive individualism as the central value of entrepreneurship. On the other hand, at times of fragmentation and economic insecurity, the desire for stable values leads to an increased emphasis on the moral authority of basic institutions such as the family, religion, the state, the firm, etc. to manage the tension between flexibility and stability. The evolving individualising society seems to develop on a double basis: incentive-based at the economic level (globalisation) and value-oriented at the societal level (cultural assertivity). It seems that "flexi-security" represents the new working base for societal development.

Although exposure to extra-European social and economic forces is not new to European history, the new qualities of the globalisation process today are shaping the very nature of Europe's future: changes in the global location of production activities exceed any capacity of state regulation (e.g. social dumping, financial markets, regulation of the deregulation); and inward migration flows have an increasing impact on existing economic, social and cultural structures in European societies. This profound and worldwide global transition heralds a new phase of sociological analysis and urges the development of new approaches to capture these processes of transformation.

Sociologically, the process of modernisation describes the movement from traditionalism, in which religion, ascribed status, locally-rooted and small-scale, culturally-specific communities predominate, to rationalism in which science, achieved status, convergent, large scale organisation, and cosmopolitan urban societies take the lead. This notion has now collapsed because there are no longer any grand narratives or meta-narratives - there is no history. Themes of fragmentation and arbitrariness have led to a breakdown of social reforms, an increased heterogeneity and disorganised societies. We come across images and ideas that have little connection with the history of the areas in which we live, or with our own personal histories. This emerging post-modern society is highly pluralistic and diverse, much dominated by media and communication tools.

Post-modernism posits an increasingly decentred and fragmented society, lacking any overarching framework of social order and 
regulation. ${ }^{12}$ This notion of "decentredness" and fragmentation is linked with a perceived pluralism of cultural meaning and practice. It rejects universal cultural ideals and focuses on differentiation and cultural specificity away from the political and public sphere. Post-modernism implies a fragmentation of forms, rather than rational directness, randomness, chaotic variety, an end to unidirectional progress and a rapprochement between the modern and traditional world.

As a response to the economic and social changes in societies scientific literature is introducing new concepts to the policy debate These concepts refer to reflexive modernity ${ }^{13}$ (i.e. the essential characteristic of modern scientific thought of reflecting upon and constantly changing its conclusions: knowledge of the world contributes to its unstable or mutable character), risk society ${ }^{14}$ (i.e. risk implying a measured approach to the calculation of probabilities: by identifying and calculating risks and then making reasoned judgements about the probability. These global threats relate to unequal human development, environmental damage and rising crime) and globalisation ${ }^{15}$ (i.e. a sense of the interdependence of the entire world and of the interchangeable ability of many of its elements). The disintegrative trends in societies are signs of increasing difficulty and crisis in the management of tensions inherent to the social compromise model. Some of these trends will be further developed in the following chapters.

12 See Baudrillard, J., Simulacra and Simulation, Michigan University Press, 1994; Jean François Lyotard, The Post-Modern Condition: A Report on Knowledge, Manchester University Press, 1984, 110 p.; Harvey, D., The Condition of Postmodernity, Cambridge MA \& Oxford U.K.: Blackwell Publishers, 1990, 378 p.; Bourdieu, P., Outline of a Theory of Practice, Cambridge Studies in Social and Cultural Anthropology, Cambridge University Press, 1977.

13 Beck, U., Giddens, A. and Lash, S., Reflexive Modernization. Politics, Tradition and Aesthetics in the Modern Social Order, Stanford University Press, 1994.

14 Beck, U., Risk Society: Towards a New Modernity, London: Sage, 1992; Ibid., World Risk Society, Cambridge: Polity Press, 1998; Ibid., World at Risk, Cambridge: Polity Press, 2008.

15 See Beck, U., What is Globalization, Cambridge: Polity Press, 2001; Castells, M., The Information Trilogy: Econmiomy, Sociery and Culture, Vol. I, II, III, Cambridge MA \& Oxford U.K.: Blaclwell, 2000; Giddens, A., Runaway World: How Globalisation is Reshaping Our lives, London: Profile, 1999; Ibid., The Global Third Way Debate, Cambridge: Polity, 2001; Ibid., Europe in the Global Age, Cambridge: Polity, 2007; Habermas, J., The Postnational Constellation: Political Essays, Cambridge MA: MIT Press, 2001; Morin, E., La Complexité humaine, Paris: Flammarion, 1994. 


\section{Key Concepts}

\section{Integration}

(Economic, social, political) Integration refers to a variety of processes by which individuals and groups of people are incorporated into various social arenas and segments of society. Therefore, the essence of integration is the acceptance and tolerance of and respect for people who possess differing values and beliefs and who behave differently, while at the same time being committed to and working towards a common future, in which all will have a fair share.

Living with differences in societies requires the management of differences. Two areas of management are fundamental: the cultural field and the field of material resources, or rather, access to resources. In order to live together in a cohesive community with different cultures, synchronisation in public space is necessary in order to prevent open conflict and promote cooperation and a sense of belonging to the community. We perceive integration therefore not as a flattening process of assimilation but as a two-way process, based on a framework of basic values, i.e. the human rights paradigm, in which equal opportunity, cultural diversity and mutual tolerance are respected.

Furthermore, the European context implies that integration is understood from within its existing multicultural environment. Multiculturalism advocates that society allows and includes distinct cultural groups with equal status but differing cultural identities. A useful reminder of this perspective is the distinction Amartya Sen makes in his book Identity and Violence between the idea of cultural liberty, which focuses on the freedom either to preserve or to change priorities, and of valuing cultural conservation. ${ }^{16}$ In reality multicultural practices sometimes lead to an entrenchment of cultural identity, "ghettoization" of particular groups or a policy of separate development of ethnic minorities.

\section{Inclusion}

It is a two-sided process of people's capability to participate fully in economic, social, political and cultural life, based on a community of values (e.g. full respect for the dignity of each person, the common good, pluralism, non-violence, solidarity). It encompasses all aspects of social development and all policies. It requires the protection of the weak, as well as the right to differ, to create and to innovate (Copenhagen Declaration 1995).

16 Sen, A., Identity and Violence. The Illusion of Destiny, New York: W.W. Norton, 2006. 
The growing interest in the inclusion of wider social, cultural and environmental concerns into all areas and levels of policy-making, has led to the adoption of the now fashionable term of mainstreaming. As a consequence, policies have moved from a narrow basic human needs approach to a wider view of an inclusive and cohesive society. Such inclusive policies can be promoted through the participation of public bodies, social partners, NGOs and other relevant actors. Partnerships of community leaders and elected municipal politicians are emerging with the aim of strengthening the capacity of cities to create and sustain inclusive communities for the mutual benefit of all people and to ensure that community voices of diversity can be recognised.

\section{Diversity}

Diversity is a much more nebulous concept than inclusion or integration. Within the context of this paper, diversity is defined as recognising, appreciating, valuing and utilising the unique talents and contributions of all individuals regardless of their differences in values, beliefs and lifestyle, culture, language, religion, etc. Diversity means more than just acknowledging and/or tolerating difference. It develops in a globalisation context of various spheres of belonging and needs to be accepted, acknowledged, valued, promoted and managed in a balanced framework of rights and responsibilities.

The Human Development Report 2004 of the UNDP refers to a set of conscious practices that involve: ${ }^{17}$

a) understanding and appreciating interdependence of humanity, cultures, and the natural environment; b) practicing mutual respect for qualities and experiences that are different from our own; c) understanding that diversity includes not only ways of being but also ways of knowing; d) recognizing that personal, cultural and institutionalized discrimination creates and sustains privileges for some while creating and sustaining disadvantages for others; and e) building alliances across differences so that we can work together to eradicate all forms of discrimination.

The report concludes that an enriching effect of the recognition of diversity for democracy and progress can be obtained through building multicultural democracies and various forms of advanced democracy. ${ }^{18}$

\section{Governance}

Governance is a policy concept that tries to capture/respond to the challenges of the globalisation vs culture debate, set in the radical

\footnotetext{
17 UNDP, Human Development Report 2004: Cultural Liberty in Today's Diverse World, New York: Oxford University Press; 2005, Ch. 1.

18

Ibid., Ch. 3.
} 
transformation of our societies. We are moving from state-centric to human-centric structures to decide, influence and shape decisions. Governance describes the process whereby elements in society (institutions \& civil society) wield power and authority and influence and enact policies and decisions concerning public life, economic and social development. Global governance is then defined as the system of rules and institutions established by the international community and private actors to manage political, economic and social affairs.

Global governance, a shared communication tool, is a familiar concept in multidisciplinary literature, focusing on emerging decentralised and informal forms of governance and the declining forms of traditional institutionalised state-centric government. Understanding to what extent global governance could be driven by economic globalisation and complex interdependence will be crucial in defining the EU's future status as either a leader or a marginalised international player.

To respond to the increasingly interconnected internal and external challenges to societies, a rather innovative new policy concept is being introduced in the present debate, i.e. multi-level and multi-actor governance. The concept of multi-level governance ${ }^{19}$ refers to "the existence of overlapping competencies among multiple levels of governments and the interaction of political actors across those levels". It is the process whereby elements/actors/layers in society at various international, European, national, regional and local levels (institutions $\&$ civil society) wield power and authority and influence and enact policies and decisions concerning public life, economic and social development. The general policy characteristics refer to frequent and complex interactions between governmental actors and increasingly important dimension of non-state actors. In particular, multi-level governance crosses the traditionally separate domains of domestic and international politics.

The conditions for a proper multi-level governance structure can be summarised as follows: In the fields of economic governance rule setting is required for managing and controlling market economies; In the field of political governance the debate concerns the revisiting of some major policy themes (such as institutional efforts, the role of the state) on the origin of the rule of law, democratic institutions and working with social actors, in view of the fact that the nation state is only one of many actors in the international political system; In the

19 The concept was introduced by Gary Marks two decades ago, Structural Policy and Multi-level Governance in the EC, in Cafruny, A. and Rosenthal, G. (eds.), The State of the European Community, New York: Lynne Rienner, 1993, pp. 391-410. 
people and citizens oriented social/cultural governance, internal and external solidarity should be guaranteed as well as better proximity of the citizens to the institutional fabric. (e.g. a fairer framework for the movement of people and respect for cultural diversity are essential.)

The European expression of multi-level governance ${ }^{20}$ is exemplified by the EU, being a political system with a European layer (i.e. European Commission, European Council and European Parliament, etc.), a national and a regional layer. There is mutual interaction across different levels of government (i.e. a vertical dimension) and with other relevant actors within the same level (i.e a horizontal dimension). The policy results are frequent and complex interactions between governmental actors and an increasingly important dimension of non-state actors. In particular, multi-level governance crosses the traditionally separate domains of domestic and international politics. Its application to the practice of European governance suggests that the EU is considered a multilayered system of decision-making in dealing with complex societal problems where the institutional redistribution of competences is not based on a territorial dimension but on functional and issuerelated criteria.

\section{Guidelines}

In proposing a critical overview and analysis of the relation between globalisation and Europeanisation from a human-centric approach in the various parts and chapters of this book, we have adopted the following major working hypotheses.

The new post-modern conceptualisation of governance, citizenship and (social, civic, intercultural and interreligious) dialogue in European and global relations requires a multiplicity of citizenship as a politicallegal status (i.e. post-nationalism), a recognition of diverse and multiple identities (i.e. multiculturalism and interculturalism) and a citizens' participation on all levels of sovereignty (i.e. transnationalism).

The current multidimensional process of globalisation has a paradoxical impact on the external and internal relations of states. The dominant spatial paradigm of territoriality and identity-building is being undermined by globalising forces. But the power of the territorial narrative remains strong through the re-emergence of communal, nationalist and ethnic identities, the misconceived interpretation of sovereignty and the exclusive focus of locally based communities for sustaining social solidarity. Its seemingly contradictory nature reveals new opportunities for institutional structures along with new forms of

20 See European Governance, 2001 White Paper. 
politics and civility and, as a consequence, offers a reading of sustainable statehood from a cosmopolitan and public goods perspective. (See Part II, in particular Chapters 5 to 7.)

Europe today is characterised by a seemingly contradictory process of increasing diversity, unifying governance and undermining credibility in a globalising context. However, it is not fully equipped with the proper institutional architecture to cope with the economic, political, social and cultural challenges of the current systemic crisis and to inspire a motivational drive to its future. In Part III we try to analyse some specific areas of human-centric development in the ongoing Globalisation versus Europeanisation debate. 


\section{PART I}

Contextual Europe 



\section{CHAPTER 2 \\ The Idea of Europe: an Historical Perspective ${ }^{1}$}

\section{Introduction}

History illustrates that Europe is a dynamic and evolving entity with many faces, multiple identities, multiple expressions and experiences and diversified cooperation forms. ${ }^{2}$ Europe is a two thousand year civilisation with a multiplicity of cultures; it is also a socio-economic model and exhibits a unique integration process. The whole of European history is characterised by forms of and attempts at economic, political, military and cultural cooperation, as part of the search for equilibrium between integration and diversity within certain contours. Europe is, however, in the first place a community of shared values, based on values such as the centrality of the human being, freedom, equality, respect for human rights, and acceptance of diversity as an asset, tolerance, justice and solidarity. Europe is also a political project trying to unite people while respecting their diversity. Today, however, Europe is struggling to keep its diversified societal model alive in the midst of complex and interconnected issues of globalisation vs Europeanisation. ${ }^{3}$

In his essay "The Crisis of the Mind" Paul Valéry, ${ }^{4}$ the French poet and philosopher, describes the common characteristics of Europe. It is a Europe of the spirit which is shaped by the legacies of Rome, Athens and Jerusalem, has made humanism its foundation and is rooted in Christianity. This means that Europe is a world of historical

\footnotetext{
Parts of this contribution have benefitted from Andrea Chiarello, European Identity beyond the Nation State. Plurality and Inclusion for a new Democratic Space, Thesis, June 2012, University of Padua.

2 An innovative analysis of ideas about Europe from an interdisciplinary perspective is given by Dainotto, R.., Europe (in Theory), Durham: Duke University Press, 2007.

3 Giddens, A., Europe in the Global Age, Cambridge: Polity Press, 2007; Habermas, J., Europe. The Faltering Project, Cambridge: Polity, 2009.

4 "The Crisis of the Mind" was written at the request of John Middleton Murry. "La Crise de l'esprit" originally appeared in English, in two parts, in The Athenaeum (London), April 11 and May 2, 1919. The French text was published the same year in the August number of La Nouvelle Revue Française (From History and Politics, translated by Denise Folliot and Jackson Mathews, Vol. 10, pp. 23-36.).
} 
references, memories and experiences shared by people. He defines the "Homo Europaeus" as:

a man in whom the European mind can come to its full realization. Wherever the names of Caesar, Caius. Trajan, and Virgil, of Moses and St. Paul, and of Aristotle, Plato, and Euclid have had simultaneous meaning and authority, there is Europe. Every race and land that has been successively Romanized, Christianized, and, as regards the mind, disciplined by the Greeks, is absolutely European.

In his book The Origins of European Civilisation ${ }^{5}$ Hendrik Brugmans identified two major elements of European civilisation: the active participation to its many spiritual heritages and a series of historical experiences from the Roman Empire onwards. He distinguished three phases: the Empire of Constantine or a Mediterranean Europe, Medieval or Christian Europe and the Europe of the Nation-State. It is in the broader space of today's Europe that the original virtues of the spirit of Europe, namely democracy, dialogue, respect for rights and harmonious development should be understood, sharing a common heritage and rooted in Christian values.

\section{Classical Origin}

The term "Europe" has many origins and interpretations. For some authors it derives from the Greek word "eurus" meaning "wide"; some others refer to the dualism in the Acadian language between "asu/acu" and "erib/erebu", where the first means "to rise" and would indicate the dawn, i.e. the East and Asia in particular and the second means "to enter" and stands for the sunset, so the West and specifically Europe. ${ }^{6}$

In Greek mythology "Europa" was the daughter of Agenor, the Phoenician king of Tyre. The God Zeus felt in love with her, transformed himself into a bull and brought her to Crete, where he assumed human form and had three sons by her. It can be argued that the opposition between the West and the East was illustrated in the Classical Age by the Greek and the Persian world, where the first was a symbol of democracy and freedom, opposed to the absolutism and despotism of Persian rule. According to Herodotus, the geographical boundaries of Europe were defined by the Mediterranean Sea in the south, the Sea of Azov and the River Don in the east, and Gibralter's

Brugmans, H., Europe: One Civilization, One Destiny, One Vocation, in Brugmans, H. (ed.), Dream, Adventure, Reality, New York: Greenwood, 1987, p. 11-39.

6 Mikkeli, H., Europe as an Idea and an Identity, Basingstoke: Palgrave Publishers, 1998. 
Pillars of Hercules in the west, which was also considered the limits of the human civilisation.

Following the historical path of the origin of Europe, authors such as Mikkeli and Braque argue that the Roman Empire cannot be defined as the first European superpower. ${ }^{7}$ According to Mikkeli, the principal aim of the Roman Empire was to control the main commercial routes, extending its territorial power to the southern coast of the Mediterranean and parts of Asia. However the impact of various philosophical and religious currents made it difficult to define Europe ideologically. Brague follows the same of line of reasoning, asserting that the constant confrontation with "the Other" during the Roman Era, represented the most significant element on which a European common cultural heritage could be understood. ${ }^{8}$ This perspective conceives the European culture not as a fixed set of values, but in terms of "cultural transmission". The myth of the "abduction of Europa" underlines the fact that its origins were constructed from an appropriation of what belonged to others, moving from the East to the West. ${ }^{9}$

It is clear that in the Ancient Age, Europe was not perceived as a political community with unifying characteristics, but rather as a geographical area with unstable borders. In spite of some mythological common origin, none of the citizens of the Roman Empire defined himself/herself as a European, preferring instead the image of Rome as caput mundi. After the schism in 395 AD, the term "Europe" became more and more used to identify the western part of the Empire, whose identity was strongly shaped by Christianity. ${ }^{10}$

\section{A Res Publica Christiana in the Middle Ages}

The period after the fall of the Western Roman Empire, which coincides with the enormous Arab expansion, was characterised by cultural fragmentation. The Frankish attempt to build a united political community is considered by many authors as the very origin of Europe. This term was used in the Middle Ages to create a sense of solidarity in addressing a common enemy, the struggle against Islam to preserve Christianity as the religion of Europe.

\footnotetext{
Ibid., p. 18.
}

8 Brague, R., Eccentric Culture: A Theory of Western Civilization, South Bend, Ind: St. Augustine's Press, 2002.

9 Boon, V. and G. Delanty, Europe and its Histories, in H. Persson and B. Strath, Reflections on Europe, Brussels: P.I.E. Peter Lang, 2007, pp.159-182.

10 Delanty, G., Inventing Europe. Idea, Identity, Reality, London: MacMillan Press UTD, 1995. 
During the battle of Poitiers (732 AD) the word "Europeenses" (meaning "Europeans") was used to refer to Charles Martel's coalition army against the Arabs. ${ }^{11}$ However, there are some criticisms to the alleged unifying role of the Frankish Empire, as it did not cover the whole of Europe and it co-existed with the remaining Roman territories in the East. For some authors, the Carolingian period cannot be defined as the starting point of the European integration process and would be better termed as the end of a specific historical era, characterised by the attempt of Charlemagne to combine the classical heritage of the Romans with Christianity. ${ }^{12}$ The Crusades need to be understood in this historical context. The beginning of the crusading period is generally attributed to Pope Urban II's calling of the First Crusade at the Council of Clermont in 1095 to an armed pilgrimage to the Holy Land to defend Europe from the Muslim invasion.

One of Christianity's important contributions to European unity was from the Catholic Church. Its aim was the creation of a community of independent states, under the spiritual guidance of the Pope. It promoted a policy of international mobility of students and lecturers, with Latin as the vehicular language. In the 9th century the term "christianitas" stood for the whole territory inhabited by Christian people, with a focal attention towards universalism. Pope Innocent III (1198-1216), one of the most powerful and influential popes of the Middle Ages, affirmed the existence of a Christian territory ("terrae Christianorum"), with specific borders ("fines Christianorum") and one single "populus christianus", under different political communities, but with the common need to defend its identity against non-believers.

A crucial historical moment in the identification of Europe with Christendom was the fall of Constantinople to the Ottomans in 1453. It resulted in a clear separation between the Christian Europe and the Muslim Asia. Although the fragmentation caused by the schism between the Orthodox and the Catholic Church was reduced, a sense of unity in the continent was not yet present. The crusaders went fighting for Christendom and not for Europe.

Still the importance of Christianity in Europe needs to be put into its proper perspective. It was an Asian religion, born in the Middle East, with a universal message that transcended European borders. Nonetheless it gave Europe its territorial grounding and became the symbol of European unity against the Islamic East. ${ }^{13}$ In Pagden's words,

\footnotetext{
11 Wilson, K. and J. Van der Dussen (ed.), The History of the Idea of Europe, Taylor \& Francis, 1995, p. 26.

12 See for example Mikkeli, H., op. cit. p. 27.

13 Delanty, G., Inventing Europe. Idea, Identity, Reality, op. cit.
} 
it means that "an abducted Asian woman gave Europe her name, a vagrant Asian exile gave Europe its political and finally its cultural identity; and an Asian prophet gave Europe its religion". ${ }^{14}$

To summarise, it is difficult to state that the idea of Europe in the Middle Ages assumed a strong political connotation; it was instead used as a vague geographical expression which covered the cultural and religious common heritage of Christianity and the Classical Roman Age. The unification of the continent was therefore merely an answer to external threats and internal common interests were not strong enough to favour a process of actual integration. ${ }^{15}$

\section{A Process of Secularisation towards a European Civilisation}

History shows that the idea of Europe assumed many different connotations throughout the centuries, according to political and cultural contexts. In the humanistic culture of the Renaissance during the $14^{\text {th }}$ and $15^{\text {th }}$ centuries, the word "Europe" regained a strong meaning, recognised as a common reference by the intellectual classes in most European countries. ${ }^{16}$ From the beginning of the 16th century Christianity gradually lost its central role in the conception of Europe. Both the outbreak of religious conflicts with the Protestant Reformation challenging the role of the Catholic Church as European cultural unifier, and the discovery of the New World with the colonisation of American territories, led to a process of secularisation. The ties with Christianity were loosened and the affirmation of a European civilisation emerged, exhibiting a high level of intellect and a differentiated culture. ${ }^{17}$ The Protestant Sebastian Münster describes Europe in Cosmographia Universalis as the most fertile and cultivated area despite its relatively small dimensions. The actual conceptualisation of a "European civilisation", however, was made during the Enlightenment (17th-18th century).

From the political point of view, the Peace of Westphalia in 1648 marked the beginning of a new European era, where the balance of power between sovereign states came to be a central element. The term "Europe", detached from its religious connotations, came into common usage among political decision-makers. Moreover it constituted the

\footnotetext{
14 Pagden, A. (ed.), The Idea of Europe from Antiquity to the European Union, Cambridge: Cambridge UP, 2002.

15 Mikkeli, H., op. cit. p. 36.

16 Wilson, K. and J. Van der Dussen (eds.), op. cit. p. 36.

17 Mikkeli, H., op. cit. p. 44.
} 
basis of political projects that aimed to achieve an internal peaceful organisation of the continent.

On the cultural side, Europeans believed in the universal value and superiority of their civilisation. It was seen as a process leading towards a virtuous and ideal state ${ }^{18}$ and finally to eternal peace. ${ }^{19}$ The highest expression of civilisation was represented by the nation-state, which was to be legitimised in the context of "methodological nationalism". ${ }^{20}$ The idea of different yet equally valuable forms of society was not taken into consideration, and so other populations were labelled as "barbarians" who needed to be civilised by having European values imposed upon them. This concept of civilisation is thought to be the secular substitute for Christendom as the unifying element for the continent. Norman Davies notes that in the early phase of the Enlightenment "it became an embarrassment for the divided community of nations to be reminded of their common Christian identity; and 'Europe' filled the need for a designation with more neutral connotations".

Another contribution recognising the European common culture came from the French philosopher Voltaire. He argued that, in spite of political fragmentations, Europeans share the same religious background and the same civil principles. Strong focus was put on arts and natural sciences, which create close ties among nations and result in a "République littéraire". This was, in his view, the decisive element that made Europe the most civilised continent in the world. It should be added, however, that the feeling of belonging to the same cultural community was shared only by the closed circles of intellectuals with the same classical education, without much influence on ordinary people; for them, the privileged reference was to their closer local community and the idea of Europe was seen as abstract. ${ }^{22}$

\section{Conclusion}

As previously mentioned, the idea of Europe has mainly emerged out of a constant confrontation with otherness. However, this process is more complex and cannot be reduced to a mere clash or rigid distinction from the "Other". Hobson argues that Europeans have always had intense interaction and exchanges with the Eastern countries. In fact,

\footnotetext{
18 Wilson, K. and J. Van der Dussen (eds.), op. cit. p. 64.

19 Kant, I., Perpetual Peace: A Philosophical Sketch, 1795.

20 Beck, U. and E. Grande, Cosmopolitan Europe, Cambridge: Polity Press, 2007, p. 94-97.

21 Davies, N., Europe: a history, London: Oxford University Press, 1996.

22 Burke, P., Did Europe exist before 1700?, in History of European Idea, Vol. I, 1980, p. 21-29.
} 
some elements of European culture are originated and borrowed from outside Europe. It is worth reminding that the mathematical models used by Copernicus were invented by Ibn al-Shatir and that the typical British tea-drinking comes from the Chinese tradition. ${ }^{23}$ The distinctive feature of European culture is often the appropriation, acculturation and reworking of elements of other cultures.

The fundamental ambiguity accompanying European identitybuilding throughout the centuries has been the constant effort to provide its identity with a kind of substance, ${ }^{24}$ referring to an alleged common geographical belonging, ethnic origins, or to a common cultural heritage. This effort has often implied the demonisation of the "Other" and the refusal to build constructive forms of dialogue with them, looking instead for unity in the form of a common opposition to an enemy. History shows however that every attempt to purify Europe from the presence of an alleged hostile "Other" has always turned into tragedy.

Understanding the historical trajectory of how the idea of Europe has evolved and how its identity has built over the years into a common cultural heritage, is fundamental to interpretting today's scenarios and to making policy assessments for Europe's future. Some of the cultural specificities of Europe can therefore be related to: 1) the rescue of history from memory to focus on ideas that travel irrespective of borders; 2) the move beyond assimilation and multiculturalism towards interculturalism to management of diversity and living with differences; 3 ) the acceptance of change so that dialogue and mutual listening becomes the driving social force and 4) the learning from humility so that Europe can draw from its religious and non-religious traditions and from its Christian roots when learning how to practice humility. We consider these characteristics major components of the European spirit.

In order to valorise these components, a cosmopolitan perspective of the European integration process might be helpful in recognising plural and multifaceted identities in Europe, accepting its constitutive otherness and benefiting from its diversity. Stimulating intercultural dialogue $^{25}$ as an instrument and objective of building cohesive and sustainable societies might therefore create new forms of relationship

23 Hobson, J., Revealing the Cosmopolitan Side of Europe: the Eastern Origins of European civilisation”, in G. Delanty (ed.), Europe and Asia Beyond East and West: Towards a new Cosmopolitanism, London: Routledge, 2006.

24 Ibid., p. 180.

25 See Bekemans, L. (ed.), Intercultural Dialogue and Multi-level Governance. A Human Rights-based Approach, Brussels: P.I.E. Peter Lang, 607 p., 2012. 
Globalisation vs Europeanisation: a Human-centric Interaction

between the Self and the "Other", leading towards a democratic and inclusive Europe. 


\section{CHAPTER 3 \\ Identity-building in Europe}

\section{Introduction}

Identity and identity-building have been examined by numerous scholars from various disciplines and perspectives. Many have contributed to an understanding of the complexity and the dynamism of these terms and have even offered theoretical instruments to deal with their changing realities. However identity remains an open concept, increasingly shaped by growing interdependencies and transformations in the current international system. The globalising world is characterised by some asymmetry between the growing extra-territorial nature of power relations and the continuing territoriality of the ways in which people live their everyday lives.

The European Union can be perceived as a unique but complex system of governance with a policy mix of supranational and intergovernmental elements. After many centuries of rivalries and wars among European countries, the end of the Second World War paved the way for a peace-building process of integration. This process has followed a "neo-functionalist" step-by-step approach very much embodied by Jean Monnet, envisaging spillover effects from the economy to the political area and beyond. We are convinced that the only way of making people identify with Europe and build a sense of belonging without trying to replace national affiliations or marginalise regional or national identities, is the development of a communitydriven political project, embodied in a set of shared values and common principles. Such a political consensus might give coherence to its actions, legitimacy to its institutions and inspiration to the citizens of Europe.

\section{Concept of Identity}

Identity is related to the way individuals reach certain selfawareness, in relation to their family, social or ethnic group, language, culture, religious affiliation and political commitment. It is often expressed by the idea of "belonging". Therefore psychological and social factors play an important role in creating that awareness. As identity always implies both a strong interaction between the individual and the group and an affirmation of a group as distinct from other 
groups, its political implications are fundamental. This is especially the case in the different ways identity can be experienced or exploited.

However, identity determination is not a constant invariable process, but changes over time according to criteria such as birth, family, language, religion, territory, etc. Nowadays this has become more complex with the heightened mobility of people and the trespassing of visual and virtual borders; it has also become more disturbed by the growing individualisation and vagueness of the moral norms within society. In short, given the growing interdependent globalisation trends in today's world, a shift has been taking place from a more static definition of identity to a more contextual and dynamic understanding of identity.

Such a relational identity requires an open attitude towards "the Other". It requires a desire to listen to them and to induce comprehension of and benefit from dialogue with them. However many people are still afraid that intercultural encounters result in a loss of identity and create insecurity. Therefore, to overcome the perception of "the Other" as a potential threat, it is necessary to build the sense of belonging as close as possible to the citizen and to valorise local communities and cities as living places of intercultural conviviality. Subsequently, a spillover effect can support the building up of identities, characterised as belonging to a group differentiated but sharing a basic set of common values and interests.

\section{Concept of European Identity}

In search of the identity of Europe we have to accept that Europe presents a whole range of peoples and thus a great diversity of languages, cultures and religions. In theory and in practice Europe should be seen as an added (enriched) value to our multiple identities. The European identity relates to a community of shared values such as solidarity, the rule of law, respect for diversity, attention to the person and the human dignity. Debates about European identity have intensified in the context of EU enlargement and the EU Constitutional Treaty. Although the motto "unity in diversity" is generally seen as best describing the aim of the EU, opinions differ widely as to how it should be understood.

The point of departure of most discussions on European identity is the idea that a political community needs a common set of values and references to ensure its coherence, to guide its actions and to endow them with legitimacy and meaningfulness. With the fall of Communism in Eastern Europe in 1989 and the founding of the "European Union" in 1992 with the Maastricht Treaty, endowing the European Community with new and stronger competences in a wide range of areas (e. g. in the 
field of foreign affairs, security and defence), two questions gained renewed urgency: the definition of EU borders and that of the political legitimacy of the Union in the eyes of its citizens - the "glue" that unites all Europeans and keeps the Community together. However, despite fundamental differences, preconditions for the emergence of a European identity are linked to the strengthening of democratic participation at all levels of decision-making, the valorising of the European dimension in education and culture and achieving social and economic sustainable cohesion.

Still the nation-state continues to be the predominant reference for European citizens despite the growing Europeanisation of identitybuilding. The Eurobarometer surveys show that EU citizens continue to identify first of all with their own country. A relatively low political participation and weak attachment poses, of course, a legitimacy problem to the EU. ${ }^{1}$ Moreover, in the current period of dramatic transformations of societies within the globalising context, new (and different) political actors are shaping the world scene, undermining traditional forms of national statehood. ${ }^{2}$

\section{Models of European Identity-building}

Literature presents different models of European identity-building with various policy consequences.

\section{Europe of cultures}

The Communitarian view stresses the Europe of culture as a family of nations anchored in a common history and culture. It emphasises that European identity has emerged from common movements in religion and philosophy, politics, science and the arts and argues for a stronger awareness of the Christian (or Judeo-Christian) tradition. Therefore, they tend to exclude Turkey from the ranks of possible future member states. "United in diversity" is taken to refer to Europe as a "family of nations". On this basis, it is high time to define EU borders. It is evident that if what is considered as an original "culture" is a very complex phenomenon mixing a multitude of human traditions, characters and behaviours, then the way a group tries to express its own particular "cultural identity" is very often focused on one aspect of that complexity, because it is considered as the most essential element which reveals it. The selection of such an element is not always rational, but it finds its source in the recent history of the group, in sentiments and

Eurobarometer 71, The Future of Europe, January 2010, 169 p.

2 Papisca, A., Dallo stato confinario allo stato sostenibile, in Pace, Diritti dell'uomo, diritti dei popoli, Anno VI, numero 3, 1992 (1994). 
reactions born from a particular social or political situation, and also very often in what still appears to be presenting a problem, or a question raised when facing an uncertain future. However, opponents argue that this view is a form of "Euro-nationalism" that leads to exclusionary policies within European societies (as regards non-European immigrants) and the polarisation of global politics, with the "clash of civilisations" prophesied by the scholar Samuel P. Huntington as its worst possible outcome.

\section{Europe of citizens}

On the contrary, the Liberal and Republican view argues for a common political culture, or civic identity, based on universal principles of democracy, human rights, the rule of law etc. expressed in the framework of a common public sphere and political participation, a Europe of citizens or "constitutional patriotism". They believe that cultural identities and religious beliefs should be confined to the private sphere. For them, European identity will emerge from common political and civic practices, civil society organisations and strong EU institutions. It is said that cultural identities, religious beliefs etc. should be confined to the private sphere. According to this view, European identity "United in diversity", will emerge from the common political and civic practices of citizens sharing the same political and civic values, while at the same time adhering to different cultural practices. The limits of the community should be a question of politics, not culture. The liberal-republican view is often criticised for what is seen as the artificial distinction between the private and the public, the subjective and the universal. Democracy and human rights, according to critics, are not universal values, but themselves spring from specific cultural traditions. Problems related to cultural differences are ignored, rather than dealt with. Furthermore, solidarity and emotional bonds in societies can only result from cultural feelings of belonging together, never from purely abstract principles.

\section{Europe of encounters}

Constructivists believe that a "European identity" can only emerge as a consequence of intensive civic, political and cultural exchanges and cooperation. As identities undergo constant change, European identity would be encompassing multiple meanings and identifications and is constantly redefined through its relationships with others. According to this view, "United in Diversity" means a participation in collective

Habermas, J., The European Nation State. Its Achievements and Its Limitations. On the Past and Future of Sovereignty and Citizenship, in Ratio Juris, Vol. 9, Issue 2, June 1996, p. 125-137. 
political and cultural practices. It would be wrong and impossible to fix EU borders.

This view, according to critics, overemphasises people's ability to adapt to a world in flux and underestimates their need for stability. Too much diversity can eventually lead to the loss of identity, orientation and coherence, and can therefore undermine democracy and established communities. However, despite fundamental differences there are a number of factors that are seen by most as preconditions for the emergence of a European identity: politics: the strengthening of democratic participation at all levels and more democracy at the EU level; education and culture: strengthening of the European dimension in certain subjects (especially history), more focus on language learning, more exchanges etc.; and social and economic cohesion: counteracting social and economic differences.

\section{Process of European Identity-building}

The identity of the European Union has predominantly been defined politically. According to the Treaties, the EU is founded "on the principles of liberty, democracy, respect for human rights and fundamental freedoms, and the rule of law" (Article 6 TEU). Fundamental disagreements emerged in the work on the EU Constitutional Treaty about a reference to "God" or "Christianity" in the preamble. It now only refers to the "religious heritance" of Europe. In accordance with the principle of "unity in diversity", it shall promote the diversity of its cultures, while "bringing the common cultural heritage to the fore" (Article 151 TEU). Furthermore, the EU must respect fundamental rights, as guaranteed by the European Convention for the Protection of Human Rights and Fundamental freedoms and the Charter of Fundamental Rights of the Union.

As regards the accession of new members, any European state can apply for membership, while Europe and its borders are left undefined (Article 49, TEU). The Copenhagen criteria of stable and democratic institutions, a functioning market economy and adequate administrative structures, are to be interpreted in this process of European identitybuilding and possible membership. The prospect of Turkey's possible EU membership, as well as issues related to globalisation and immigration, have further added to the identity debates. Relatively low political participation and weak attachment pose a legitimacy problem to the EU. However, there is little agreement on how identification can be strengthened.

The recent developments in European identity-building very much refer to the EU legal context. The treaties from 1951 onwards, up to the Treaty of Lisbon, highlight the different contexted approaches which 
were used to strengthen the idea of Europe and European identity. During the first decades of the European integration process the only reference to the identity issue was made to distinguish Europe from other international political actors. From the second half of the 1980s, Europe has been conceived more and more as a community of shared values and a political space for active citizens, embodied in the Treaty of Lisbon and implemented in various EU programmes.

\section{The first years of European integration}

The end of the Second World War paved the way for the process of European integration. The French Foreign Minister Robert Schuman stressed in his Declaration on May 9th, 1950, that durable peace in Europe could only be achieved if the age-old rivalry between France and Germany was eliminated. The first period of an economic driven integration was thus characterised by a strong pragmatism and a "stepby-step" strategy aimed at building up a common economic space.

In this context, little space existed for debating about identity. The preamble of the treaty that established the ECSC in 1951 expressed the conviction that "the contribution which an organised and vital Europe can make to civilisation is indispensable to the maintenance of peaceful relations". The pursuit of common economic interests would create "the basis for a broader and deeper community among peoples long divided by bloody conflicts" or, as the Treaties of Rome suggest, "lay the foundations of an ever-closer union among the peoples of Europe".

The idea of Europe that emerges from the first treaties is deeply influenced by the historical tragedies of the First and Second World Wars. Economic areas were privileged for their cooperation, in accordance to the neo-functional approach. It was nevertheless always the objective to develop the process of integration beyond the European Economic Community. However, in the early years, most attempts to go beyond the mere economic orientation of the European integration process failed.

\section{The Declaration on European Identity (1973)}

The concept of European identity was introduced for the first time in the European political agenda with the "Declaration on European Identity" (Copenhagen, December 14th, 1973). It was said that cooperation among European peoples represented a real need to effectively face the current global threats. The action proposed was oriented to "defend the principles of representative democracy, of the rule of law, of social justice - which is the ultimate goal of economic progress - and of respect for human rights. All of these are fundamental elements of the European identity". 
A number of articles from the Copenhagen Declaration are illustrative for this changed (at least rhetoric) focus on European identity-building. Very interesting from this perspective is Article 3:

The diversity of cultures within the framework of a common European civilization, the attachment to common values and principles, the increasing convergence of attitudes to life, the awareness of having specific interests in common and the determination to take part in the construction of a United Europe, all give the European Identity its originality and its own dynamism.

Article 4 reaffirms the open nature of the Community, leaving space for further enlargements to peoples who share its same ideals. Another important aspect is the external dimension of identity, i.e. Europe's place and responsibility in the international landscape. Article 6 recognises that global problems can no longer be solved at a national level and consequently that Europe is to "speak increasingly with one voice" to other countries and regional areas. ${ }^{4}$

It has already been stated that in the first decades of integration, the issue of European identity was raised mainly in its external dimension, as an attempt to collocate the new supranational actor within the world context, or as a common project, founded on the search for "l'intérêt communautaire" in the coordination of national policies. But from the Single European Act onwards, the existence of a community of citizens was to be taken into consideration.

\section{Europe as a community of citizens}

The first attempt to push European integration beyond the notion of a common market dates back to 1976 with the Tindemans Report. In the chapter, "Europe of the Citizens", a community of citizens was proposed by raising European awareness through visible (symbolic) measures (e.g. the unification of passports, the vanishing of border controls, the common use of the benefits of the social security systems, the accreditation of academic courses and degrees, etc.). In 1984 the European Council of Fontainebleau set up the Adonnino Committee to address issues related to a "people's Europe". In spite of their ambitious goals, only some (modest) proposals were adopted to increase the sense of belonging to the European Community (e.g. the European flag, a unified passport and the anthem). ${ }^{5}$ In the same year, Altiero Spinelli advocated a more ambitious idea of the establishment of a political

Strath, B., A European Identity: To the Historical Limits of a Concept, in European Journal of Social Theory, Sage Publications, 2002.

5 Panebianco, S., European citizenship and European identity: from the Treaty of Maastricht to public opinion attitudes, JMWP no. 03/96, December, 1996. 
union, which wasn't, however, translated into a more political commitment.

The Treaty of Maastricht (1993) represents a milestone in the European integration process. It instituted the establishment of a "European citizenship", a legal status that guaranteed a set of rights to individuals possessing the nationality of one of Europe's member states. At last, a path had been forged that was headed towards an ever-closer relationship between the European institutions and their citizens. European identity was no longer exclusively addressed to the external dimension, but acquired a more specific internal meaning. It was no longer simply an instrumental usage for coordinating national policies. Instead it created a constitutional and founding value of the concept of a "Europe of citizens".

Still the debate on the existence of a European demos, which often refers to "the peoples of Europe" remains open to various interpretations. The construction of a single European subject is an ongoing process thanks to the direct application of EU norms to its citizens. The democratic base is no longer the representation of "the peoples of the European States brought together in the Community" (art. 189 TEC); in fact "Citizens are directly represented at Union level in the European Parliament" (art.10.2 TEU).

The Convention on the Future of Europe produced a draft for a Constitutional Treaty which expressed an intention to increase the level of participation from European citizens in the decision-making process. ${ }^{6}$ Despite its failure following the negative outcomes of the French and Dutch referenda in 2005, the Treaty of Lisbon (2009) has finally followed the same focused line on citizenship. Next to the principle of representative democracy, which is at the basis of the functioning of the Union (Art. 10.1 TEU), Article 11(1) states that "the institutions shall, by appropriate means, give citizens and representative associations the opportunity to make known and publicly exchange their views in all areas of Union action". The method chosen to put this general principle into practice is the "Citizens' Initiative", as formulated in article 11(4):

Not less than one million citizens who are nationals of a significant number of Member States may take the initiative of inviting the European Commission, within the framework of its powers, to submit any appropriate proposal on matters where citizens consider that a legal act of the Union is required for the purpose of implementing the Treaties [...].

6 Dauvergne, A., The Treaty of Lisbon: Assessments and Prospects as of Summer 2011, Notre Europe, Studies \& Researches, 2011. 
According to Article 24 of the Lisbon Treaty, the details and the conditions for an effective implementation of the Citizens' Initiative have been discussed by the Council and the European Parliament within the so-called "ordinary legislative procedure" and a specific regulation has been adopted. ${ }^{7}$ The ECI was finally launched on May $9^{\text {th }}, 2012$ with the registration of Fraternite 2020.

\section{The role of cultures and $E U$ founding values}

The aspect of the cultural and religious heritage of the European peoples is introduced in the treaties as an element of differentiation rather than unification. However, to imagine a Europe beyond the wellworn path of institutional, economic and political integration requires a value driven foundation of the search for the European identity. ${ }^{8}$ This is underlined by the words of Karel Verleye, one of the founders of the College of Europe in Bruges:

It is excluded that a European citizenship or a European commitment will be stimulated with the population, when no ample consideration will be given to a number of forgotten or undervalued factors in the construction of the new Europe, such as the cultural, regional, ethical, historical and spiritual dimensions.

European identity-building within the EU legal context is not based on a common linguistic nor cultural nor religious origin; the focus is instead on the necessity for EU institutions to "respect the equality of Member States before the Treaties as well as their national identities" (Art. 4.2 TEU). The Treaty of Lisbon includes the Title XIII on culture and clearly defines the role of the Union in cultural matters in its Article 167. It affirms that "The Union shall contribute to the flowering of the cultures of the Member States, while respecting their national and regional diversity and at the same time bringing the common cultural heritage to the fore" (Art 167.1). Furthermore, "The Union shall take cultural aspects into account in its action under other provisions of the Treaties, in particular in order to respect and to promote the diversity of its cultures" (Art 167.4).

A clear sign of the EU attitude is the lack of reference to Europe's Christian roots in the Constitutional Treaty. Despite a strong opposition from the Catholic Church, the preamble reads as follows: "Drawing inspiration from the cultural, religious and humanist inheritance of Europe, from which have developed the universal values of the

Regulation (EU) no. 211/2011 of the European Parliament and of the Council on the citizens' initiative, 16/02/2011.

8 Bouckaert, L. and J. Eynikel (eds.), Imagine Europe: The search for European Identity and spirituality, Leuven: Garant, 2009. 
inviolable and inalienable rights of the human person, freedom, democracy, equality and the rule of law (...)". The same formulation has been adopted within the Treaty of Lisbon, adding the intention "to deepen the solidarity between their peoples while respecting their history, their culture and their traditions".

In recent years, significant progress has been made in recognising the importance of fundamental rights within the European Union. The Amsterdam Treaty (1997) introduced for the first time a specific reference to human rights. The Treaty of Lisbon reinforced this perspective:

The Union is founded on the values of respect for human dignity, freedom, democracy, equality, the rule of law and respect for human rights, including the rights of persons belonging to minorities. These values are common to the Member States in a society in which pluralism, non-discrimination, tolerance, justice, solidarity and equality between women and men prevail (Art. 2).

It also stipulates that

the Union shall respect fundamental rights, as guaranteed by the European Convention for the Protection of Human Rights and Fundamental Freedoms signed in Rome on 4 November 1950 and as they result from the constitutional traditions common to the Member States, as principles of Community law (Art.6.2).

Moreover the Charter of Fundamental Rights of the European Union has been given the same legal value as the treaties. Its binding value commits the EU to building a political community within which human rights have the utmost importance as the ultimate reference. ${ }^{9}$ It illustrates a relevant qualitative shift in European integration, leading towards an inclusive community where the citizens can be the real protagonists.

\section{Conclusion}

The historical path of the idea of Europe shows that European identity-building is the result of a mixture of numerous elements coming from different contexts, set in a process of cultural appropriation and a continuous reworking of a dialogue of civilisations. The evolution of the European identity issue within the main European treaties highlights the fact that it was only in the 1980s, when the importance of the political legitimisation of EU institutions was clearly perceived, that the

9 Papisca, A., "Europe 2020": What Compass, What Soul, Which Kind of Architecture for the EU Governance? The Need for Human Rights Mainstreaming, in Pace diritti umani - Peace Human Rights, 3/2010, 22 p. 
European Commission started engaging in the cultural sphere. It defined EU founding values and officially embraced the universal human rights paradigm. The relative failure of the EU in its attempt to make people identify with the European project is partly due to the state-like "topdown" strategy and the lack of a genuine post-national identity.

Prospecting a sustainable European future today requires more advanced forms of supranational and multi-level governance, capable of managing complex and interconnected economic and political issues while strengthening a common sense of belonging. It is therefore important to understand the necessity for European identities to be inclusive and intrinsically plural, far from the exclusive national patterns of identity, nationality and citizenship. It would be undesirable, and rather impossible for the EU to return to the historical path of nationstate building. Europe does not represent an actual European "demos"; its borders are not fixed and it contains many different peoples and cultures. That's why the "Unity in Diversity" motto represents some big institutional and political challenges in today's Europe

Cosmopolitanism as a new way of conceiving cultural otherness opposes both hierarchical subordination and universal equality, recognising instead the existing (and undeniable) differences between peoples and giving them a positive value. Territorial boundaries, social groups and cultural barriers are transcended. The ultimate reference remains "the worldwide community of human beings" 10 where everyone is seen as both equal and different in order to expand the concept of the public beyond its national borders, opening it up to an emerging European space.

10 Nussbaum, M., Patriotism and cosmopolitanism, in Nussbaum M. et al. (eds.), For love of country: Debating the limits of patriotism, Boston: Beacon Press., 1996, p. 220. 

CHAPTER 4

\section{Europe's Challenges and Responsibilities in a Globalising World}

\section{Introduction}

What is Europe's relevance today? What is its cultural heritage, its values and norms, its societal model? The answers to these fundamental questions will shape the European future and the building of our European societies. Is Europe still an inspiring idea(l) of a value-driven society, worthwhile of pursuit? Themes such as the frontiers of Europe, European citizenship, cultural diversity, and the role and purpose of Europe in a global perspective all require a vision of what Europe is and should be.

Europe is at a cross roads between its past, present and future. We are now confronted by a number of (internal and external) challenges to the European model of socio-economic cohesion and cultural and regional diversity. Nonetheless, Europe still has a mission and responsibility in the globalising world.

Europe is at a crucial intersection in its history and at a decisive moment in the process of European integration. History illustrates that Europe is a dynamic and evolving entity with many faces, multiple identities and diversified cooperation forms. The recent enlargement (or re-unification) of 10 new member states reinforces this image.

Europe has an appointment with its destiny. Its model of society, based on fundamental human rights, culture as a vehicle of emancipation, on sustainable development and socio-economic cohesion, and on a multilateral vision of the world order, has been put under stress and pressure. In other words, we are experiencing a confrontation between the confusing actual European (political, economic, cultural and institutional) reality and Europe's global responsibility in the context of an ever-increasing globalisation.

The challenges are multiple and multi-dimensional within and outside the EU. It requires a new mobilising myth for Europe, i.e. a project for further European integration that guarantees institutional governing structures and financing mechanisms for European internal and external solidarity. Only such a vision may inspire the commitment of its citizens (and certainly of its young people), and strengthen the 
European role in the globalising world. However, recent political signals have not been very hopeful. Discussions on the European Constitution, the debate surrounding and methods being used to create the new Commission, are already very telling. And today's European approaches to policy and its answers to the global financial and economic crisis, demonstrate tension and incomprehension between the member states.

This chapter consists of three main sections: the first section briefly describes the historical context of Europe's future; the second section examines five main challenges to the European societal model (i.e. globalisation, Europeanisation, identity and specificity, culture and perception) and the final section presents three major European tasks for the future (i.e. the quest for meaning, favouring European citizenship and responsibility at the global level).

\section{Historical Context: Europe at the Cross Roads between Past, Present and Future}

Hendrik Brugmans, the first rector of the College of Europe, wrote many years ago:

Europe is not any longer an abstract concept, neither is it a mere geographical, difficult confining area. It is a culture circle/environment, a community. Now it is on the way to become an ordered society, with citizens who take up civil responsibility for the whole, although this is not yet clear for many. Transition times as ours are characterized by extrachaos. The hope is focuses on a change in continuity. But a radical change

Europe has to draw from the many lessons it has learnt from both its distant and more recent past. The whole of European history is characterised by forms of, and attempts at, economic, political, military and cultural cooperation, which attempted an equilibrium between integration and diversity within certain contours. However, Europe is first and foremost a diversified but coherent societal model shaped by vague geographical frontiers, fundamental values of freedom, solidarity and respect for the other, its common cultural heritage and shared historical experiences. In short, both the historic and recent development of the current European integration process is marked by an ongoing search for equilibrium between integration and cohesion on the one hand, and maintenance of diversity and regional and cultural identity on the other hand, within certain governance structures and institutions.

This radical change in continuity is not an objective in itself, but a process that prioritises the objectives of peace and sustainable development both within and outside Europe. The main lesson we can draw from the past is that Europe's reality and responsibility is to a multiplicity, a plurality of diversity, with positive and negative 
consequences. The solution is neither a dogmatic Euro-centrism nor a cultural relativism but a critical European-centrism based on what James Tully excellently describes as

practical identity; that is the aspects of citizens' identities that matter to them, transform our societies into multiple minorities contending and collaborating with a general ethos of forbearance and critical responsiveness and make our institutions diversity-aware.

\section{Challenges to the European Model of Socio-economic Cohesion and Regional Diversity}

The present European debate is animated and confronted by internal and external challenges. They shape the current and future wellbeing of Europe, i.e. the sustainability of the European model of society as a macro regional reality with global responsibility. I distinguish five fundamental challenges:

\section{Globalisation}

A first important challenge refers to the process of globalisation. This process leads to a radical decrease in the political-economic power of states in the management of socio-economic activities, an increasing domination of democratic societies by transnational plutocracies and to a slow depersonalisation of economic relations, which undermines our societies. Economic globalisation strongly influences territorial reorganisation and the process of state formation. The new regionalism causes a retreat of national states and a re-orientation of regional policy towards a more competitive approach between regions, and consequently leads to more active regions within Europe. Europe is however not an exclusive economic space, but is firstly a community of shared values, which is being forced to revisit itself as a result of the current globalisation debate.

This globalisation trend is increasing the tension with culture. Next to its economic and political dimension, globalisation is also a cultural phenomenon with consequences for cultures, peoples and persons. The intensification of communication systems and international mobility flows leads towards the kind of global culture that the French sociologist Pierre Bourdieu has warned of. Globalising cultural industries isolates men from their historically developed local, religious, moral and societal reference frames and leads to a further individualisation and commodification of values and human relations.

The homogenisation of cultural production and consumption patterns goes hand in hand with an increase in cultural assertivity and a growing consciousness of cultural differences. A kind of paradoxical process takes place. While in some, globalisation strengthens cultural assertivity 
and participation to global culture, a lack of comprehension of and respect for cultural differences has led others to develop a distrust of other cultures, and has increased the possibility of a clash between cultures and civilisations (Huntington). But it has certainly strengthened the clash of ignorance and increased stereotypical behaviour.

The impact of globalisation on cultures, societies, human relations and persons should be understood from a polycentric and pluricultural perspective. It implies that cultural differences are accepted and respected within a certain pattern of values without the domination of apriori superiority by any one culture. This requires a more compassionate globalisation or a cosmopolitan humanism. ${ }^{1}$

The greatest challenge is to look for governance structures that both create zones of common interests and shared values, as structures for civilised confrontation. Such structures should offer economic, social and cultural wellbeing, with a guarantee of internal and external solidarity and accessibility for all to the opportunities and advantages of globalisation. Certainly in a period when extra-national and extraterritorial transfrontier concepts and governance structures are gaining in importance, this represents a real challenge to global political governance. Currently the international community is lacking global political institutions and common values, which could replace a culture of competition, distrust and fear with a culture of cooperation, peace and mutual respect.

A second important impact of globalisation is the accelerated development towards an informed and knowledge-driven society. The accelerated use of new technologies during recent years has produced enormous productivity increases, as well as a progressive replacement of labour by capital. There is a real danger that these changes could lead to a further fragmentation and duality of the labour market if technological innovations are not complemented with social innovations. The rethinking and revalorisation of labour and education as a fundamental condition to full integration of the citizen into society is underway. The conclusions of the Lisbon Special European Council of 23-24 March 2000, for making Europe the most knowledge-driven economy by 2010 , or the objectives of the Bologna process, for realising a European university space, are obvious indications of this.

Another important development in the globalisation context is the revival of the civil society in institutionalised and non-institutionalised

Falk, R., The Decline of Citizenship in an Era of Globalization, in Citizenship Studies, Vol. 4, no. 1, 2000. 
forms. ${ }^{2}$ The civil society is a mixture of social forces with diverging agenda, means, scope and power. It is being perceived more and more as the place for answers to the challenges of economic globalisation and is becoming increasingly more involved in local, regional, national and international decision-making processes. The civil society supports the construction of social capital. The realisation of social common goods creates confidence and results in solidarity, which binds people and communities. People and citizens become more active and responsible at the grass roots level and are inspired by mobilising projects within formal and informal groups and communities. Although defining and protecting the common good is the responsibility of the state, from the local to the global action field, the active civil society has become, next to the market and the state, the third pillar of societal development at all governance levels.

\section{Europeanisation}

As well from the globalisation process, the Europeanisation process also shows clear internal and external tensions, which endangers the specificity of the European integration process, and European unity in diversity. The important challenge today is how the EU as a sui generis integration process, based on a common cultural heritage, common historical experiences and common and shared values, can maintain its specificity and particularity.

Firstly, there is the large societal debate concerning the values and vision of how the individual is related to his surroundings. The functional integration of thinking and acting, based on the principles of rationality, specialisation, competition, etc., has led to economic welfare within the European Community; but its underlying value patterns are increasingly coming under more pressure, because of the lack of persondriven answers in its complex institutional structure. Furthermore, the globalisation process undermines the European model and shakes its values of solidarity, good citizenship, tolerances and respect for diversity. The lack of direction, underpinned by political leadership, is leading to indifference and frustration and fundamental uncertainty as to how a rich Europe is to be further developed.

Within this general societal debate, the European model of unity in diversity is threatened by a number of specific challenges at the social, financial and political level: The European social model, i.e. the cohesion between economic and social objectives and between economic growth and social justice, is threatened. The danger of a

Mascia, M., Participatory Democracy for Global Governance, Civil society

Organisations in the European Union, Brussels: P.I.E. Peter Lang, 2012, 170 p. 
reduction of the individual life world and of cultural identity is real; The further development of the European integration process is undermined by modest financial support for carrying out European policies in some specific fields; There is a democratic distrust from the citizen towards society and the state and a clear lack of enthusiasm for the European Union. Europe is no longer inspiring as an ideal in the globalisation context. Enthusiasm for the largest single enlargement in terms of people and number of countries, may have been genuine in the 10 new member states on and around May $1^{\text {st }} 2004$, when it was celebrated with some festivities, but has since cooled down rather quickly. According to the recent Euro barometer, the confidence of the new Central and Eastern European member states has decreased to a mere $40 \%$. In the old member states it is a bit less than $50 \%$.

\section{Identity and specificity}

The debate concerning the concept of identity in Europe and of a European identity is crucial for further direction of the European integration process. To what extent is Europe part of our identity? The answer to this question is linked to the definition of European, national and regional identity in relation to nation, state and citizenship.

As stated in Chapter 2, identity refers to a particular value-sharing, a community of values which are decisive in the construction of an identity. This is formed at different levels by a process that changes over time according to criteria such as birth, family, language, religion, territory, etc. Nowadays this identity-building has become more complex and is now contextualised as multiple identity-building, as a result of people's heightened mobility and the trespassing of visual and virtual borders. It has also become more disturbed by the growing individualisation and vagueness of the moral norms/ethics within society.

In focussing on the European dimension of identity, we have recognised the presence of a whole range of peoples, expressing a great diversity of languages, cultures and religions throughout Europe. Therefore we insist on a departure from a unilateral determination of identity on the basis of birth, language, religion or territory because such a reduced interpretation often implies intolerance and distrust against other peoples. We have referred to this European dimension as a community of shared values that is part of our collective memory. However, for many, even more today, this is only a vague part of their historic memory.

Still we should embrace the idea of "Europe" as an added (enriched) value to our multiple identities. Identity does not have exclusive characteristics; multiplicity is the key characteristic of the European 
identity: multiple identities, containing compatible partial identities. This is certainly true for cultural identity, which binds and unifies countries, regions and groups of persons. They are the shared memories and shared expectations (the common subjective interpretation) of each group's own history and determines their future cultural identity.

The political meaning of the importance of identity lies in the fact that mutual respect for uniqueness can constitute the basis for more and certainly better collaboration and solidarity, both within and outside of the EU. Cultural and regional identity is therefore an important factor for further integration and a source of inspiration for the strengthening of the European model of society. It implies that the development of a European identity depends on the influence of common European institutions (i.e. the community structure) on daily life as well as on the commitment of the citizen to the European project. This is not only the task and responsibility of politics, but mainly of education. (See Chapter 13.)

\section{Culture}

A fourth challenge to the European societal model is presented by the role of culture. We start from an anthropological definition of culture as heritage, creativity and way of life. This point of departure is clearly applicable to European culture, which is not a mythical story or untouchable concept, but a dynamic interaction of historic, spiritual, intellectual, material and artistic characteristics and attitudes. These characteristics illustrate the multiplicity and wealth of European cultures, cultural expressions and traditions.

Culture is firstly a source of inspiration for further integration and socio-economic development. It certainly can encourage greater commitment in the citizen to the European project. Culture can be integrated in the economy and polity, not as a marginal factor, but as an intrinsic added value in societal development. Culture unfolds itself within society as a dynamic combination of spiritual, moral and intellectual elements, which are offered through education and formed through lifelong learning. Cultural multiplicity is also a source of wealth and strength. No culture can be missed out in the European cultural mosaic. Europe is pre-eminently a space of cultural diversity, but respect for cultural diversity does not mean a mere nationalistic or regional reflex/behaviour. The respect and stimulation of cultural diversity are a guarantee for further European integration and a renewed cooperation with other cultures.

Within the European context, culture is permanently placed in a tense relation between further market integration and the maintenance of cultural diversity (e.g. the book, film, audiovisual sector, etc.). The 
history of EU intervention in the cultural sector is characterised by a number of phases; from a political-rhetoric discourse, via a formalistic discourse, to finally a pragmatic discourse of cultural cooperation programmes; from negative to positive integration and to a communitarian integrism of the decisions of the Court of Justice; and from a focus on European cultural identity and unity, to a focus on cultural diversity.

Within this context, intercultural dialogue is of great importance. Intercultural dialogue can be instrumental in softening and avoiding the (negative) consequences of the globalisation process (i.e. the issue of minorities, migration, poverty, etc.). A dialogue between peoples and cultures can be constructive if we accept a number of common and moral values as points of departure (i.e. human dignity, respect for differences and diversity, solidarity, etc.). In the current framework of the tension between (economic) globalisation and internal and external solidarity, and between different religions, such a dialogue can be a vehicle for conviviality and multiculturalism in which cultures influence each other without destroying each other or clashing with each other.

Europe as a global player has an important voice in this dialogue, primarily from the value of its socio-economic model. The EU has made the first vital institutional steps under former president Romano Prodi to favour such an intercultural dialogue in the framework of the EuropeanMediterranean partnership, with its overall good neighbourhood policy.

\section{Perception}

Our final challenge is related to the perception of Europe and its reality in practice. Europe is being confronted with a general orientation crisis. There exists a stereotypical perception of the EU as a slow, nontransparent administration, with complex decision-making procedures, which shows a lack of determination and vigour at the vital moments of political decision-making. Recent statistics tell us that less than half of the population of the member states participated in the last European elections of June 2009. That this image is rather negative also comes from ignorance. Few people realise that the European Parliament is a fully-grown legislator, with European laws and regulations in many policy fields, which determine national policies in many fields.

This faulty perception reveals a clear problem of communication. The European jargon and language in the discipline of European studies doesn't always lead to a clear and simple message. For the media, Europe remains an isolated subject; what is no longer true in the daily reality. There is a growing interconnection between regional, national and European dossiers and European issues/problems are becoming more complex for the non-specialist journalist. For many politicians 
Europe remains a distant subject, sometimes a scapegoat for unpopular measures but mainly an important financial source for national dossiers. However, most of the time one is kept in ignorance of Europe's positive contribution in many domains. And often the (national) rhetoric of the member states is transparent and neglects the European common good. Europe is not selling itself very well; it communicates insufficiently with a rather technical and hermetic language and a complex bureaucracy.

In short, only a correct perception and the delivery of a positive image can lead to respect from the population and European partners. They are important for the legitimacy of and the involvement of the citizen to Europe.

\section{Europe's Task and Responsibility in the Globalising World}

This third section outlines the three major tasks for Europe in the globalising world.

\section{Quest for meaning}

We have to continue working towards a better Europe, one that is more democratic and social, which has respect for its multiple cultures. The European dream must be inspired by a purpose that goes beyond the existing economic, political and social frontiers. The question remains to what extent can a common vision, founded on global common goods, be developed in a context of economic globalisation and cultural relativism. Problems of social inequality and poverty, as well as nonaccessibility to the advantages of globalisation, take important forms from an economic and cultural perspective at the global level.

In short, the present situation refers to the need for an inspiring vision and a strategy that embodies such a vision. Europe cannot be sold as a technical project, but requires purpose and mobilisation. Structures and institutions don't constitute aims in themselves, and are only a means to achieving a sustainable model of society, based on the rule of law and opportunities, which can serve as an example.

Europe is tasked with being an actor for change and has a responsibility to revitalise its original project, and therefore has to mobilise the citizen, and particularly young people. How? By investing in knowledge, by creating a European industrial policy, by guaranteeing social protection, by stimulating a European democratic space and mainly by favouring the involvement of citizens and young people in the European political project. That is what the European and international 
information and training centre of Ryckevelde has been doing for nearly 50 years. In general, it is the mobilising task of genuine education.

\section{Favouring European citizenship}

Karel Verleye, one of the founders of the College of Europe in Bruges, wrote:

It is excluded that a European citizenship or a European commitment will be stimulated with the population, when no ample consideration will be given to a number of forgotten or undervalued factors in the construction of the new Europe, such as the cultural, regional, ethical, historical and spiritual dimensions.

There is a need for a large societal basis to support further European integration - the signs of which are not always hopeful. (European) Politics and the (European) administration do not always make an inspiring example. An overt support for more extreme tendencies in Europe may lead to intolerance and an undermining of the European societal model. Therefore, a drastic increase in the commitment of citizens and young people to the European project is necessary if Europe wants to be truthful to its destiny.

It is essential that with a bigger EU and greater political cooperation in fields such as social policy, employment, asylum, immigration, policy and justice, foreign policy and general security and defence policy, citizens are capable of expressing their cultural/regional identity within this changing environment. A further integration of the European continent requires continuous attention being attracted to traditional social, regional and cultural identities. The fundamental wealth of its diversity is not only geographic, but also institutional. Therefore, it is important that respect for diversity is encouraged and reflected in the institutions, the democratic processes and the policies of the EU. Furthermore the future of Europe is not the exclusive responsibility of its governments, but is also the responsibility of its citizens and their organisations. In order to valorise different dimensions of the cultural diversity and diverse forms of civil participation in Europe, various associations need to promote active European citizenship.

In short, the reference terms for a European citizenship require an inspiration that exceeds the existing economic, political and social boundaries. This insertion can give sense to a vision in which Europe may evolve to a multiple citizenship. New concepts and multi-level political structures are being developed that can give form to the complex European governance structure and make it transparent for the citizen. 


\section{Europe's responsibility at global level}

The globalisation of our increasingly unipolar world means Europe needs to claim a bigger role in global governance structures and needs to start speaking with one single voice. Europe has a responsibility to conduct a more daring and coherent common security and foreign policy and, subsequently, needs to actually favour a culture of peace, genuine dialogue, solidarity and sustainable development. This may not appear to be easy, given the present international developments and diverging viewpoints. Yet a modest institutional step towards this has made by the Treaty of Lisbon, which created the role of High Representative of Foreign affairs of the Union, who is also the vice-president of the European Commission.

With a courageous foreign policy Europe can grow to be a strong and trustful partner in a multilateral world order. The strategy of the European Commission of a good neighbourhood policy (i.e. "a ring of friends") is seen as an impulse towards such a broad international policy framework. This strategy should avoid the enlargement of the Union creating new divisions between the Union and its neighbouring countries. The European neighbourhood policy proposes to actually and financially strengthen the links of the Union with these partner countries, through a series of new cooperation structures.

\section{Conclusion}

We can now draw some conclusions. Europe is confronted with both the need and moral responsibility to maintain its own model of integration and diversity, within a strongly changing world system. This implies that Europe should defend its values and principles of solidarity, tolerance, democracy in the limited but open dialogue between cultures and peoples both within and outside of Europe. This requires a change in mentality, a broad imagination and proactive thought and action from the outset, but also political leadership and particularly an education that focuses on learning responsibility. However, the question has to be raised (even though the answer is unclear) whether Europe within a further unifying European economic space can guarantee an acceptable common institutional basis in which states, regions and communities can live diversely (with a guarantee of internal solidarity) and whether Europe can offer an open societal model within the process of further globalisation (a guarantee of external solidarity versus the European fortress).

The challenge facing further European integration is the search for a new equilibrium, between diversity and unity, in a globalising world. The European model should take into account the economic, historic, 
social and political changes which are taking place at the international level, but must still be faithful to its principles of internal and external solidarity. "Repenser l'Europe" implies recognition of a radical increase in the level of complexity within our societies, a further development of a multiple citizenship within multiple identities and the elaboration of multi-level governance. There is also the need for an enlarging and mobilising vision, which has the capacity to raise new spirit and regained enthusiasm in the citizen. Furthermore we must recall and build upon the enthusiasm and faith in the European project that was first embodied by the Founding Fathers of Europe.

In short, Europe needs bridge builders who can concretely complete the rhetoric of the European story, promote the European ideals of peace, unity in diversity, freedom and solidarity and mobilise young people towards the European model of society. The role of education is herein fundamental. In this model, new forms and places of dialogue, active citizenship and cooperation can develop outside of the existing institutionalised structures of representative representation. The European civil society becomes emancipated and develops opportunities in the globalising society through which persons, peoples and cultures, within and outside Europe can meet peacefully and respectfully. 


\section{PART II}

\section{RENEWING THE CONCEPTUAL FRAMEWORK FOR EUROPE'S FUTURE}



CHAPTER 5

\section{Sustainable Statehood: a Human-centric and Multi-level Governance of Europe's Transformation}

\section{Introduction}

This fifth chapter introduces a new conceptual reading of the globalisation versus Europeanisation debate. In the first section, an analysis is given of the state of affairs of EU/Europe's role in the world, focusing on the European dimension of the globalisation process, particularly on the European integration process in managing institutional, political, societal and cultural diversity. It tries to detect some major characteristics and trends of the transformation of European societies within the growing complexities of the broad field of international relations. The second section focuses on the conceptual content of sustainable statehood in a human-centric perspective.

\section{The Changing International Context: EU as a Regional and Global Power}

Long-term global trends are likely to affect the EU's ambition to be a global actor. Being or becoming a global power is not only determined by the internal and voluntary policy of that actor. Two ongoing transformations of the world are together weakening the position of the $\mathrm{EU}$ as an aspiring global power. The first trend is a shift in economic gravity from the East to the West. The second trend is a demographic decline in Europe. Both trends make it increasingly difficult for the EU to be a global power. But at the same time one can also identify a number of developments with regard to multilateralism that bear in them opportunities for the EU to increase its influence as a global actor. We are focussing on three major overlapping issues: the changing international setting, characterised by a globalisation process that is characterised by a multilateral and multipolar world; the weakening position of the EU/Europe as a global actor; and the EU as a reference model. 


\section{Changing setting: multilateralism and multipolar world order: characteristics and trends ${ }^{1}$}

Various dimensions of the Union's role as a global and regional actor exist. In the emerging multilateral world-order, states, international and regional organisations, transnational policy networks and nongovernmental actors are the building blocks of the multilateral system. ${ }^{2}$ In other words, states are no longer the "star players" but only players. Moreover, it is no longer possible to make a clear distinction between states and international organisations as some of the latter have statehood properties as well! Furthermore, the interactions between all these actors are not organised in a hierarchical way but in a networked way. This implies that there is no single "centre of the universe" in terms of governance. It also implies that there are sufficient "theatres" of multilateral relations.

A multilateralism that operates in a multipolar world could offer good prospects for generating a non-hegemonic world-order. Instead one can expect a fluid web of multi-stakeholder partnerships between different types of actors at different levels of governance including the regional level. According to Newman and Thakur, many multilateral processes work most effectively at the regional level, based upon their shared values, identity and regional leadership, ${ }^{3}$ So regions can become major nodes in the system. On the one hand they are to be considered as sub-global entities characterised by a dense intensity of economic and political relations that can be relatively autonomous of the rest of the world. On the other hand they have a centre of gravity that can act as a pole in the multipolar world.

The trend towards multipolarity is more than just a re-distribution of power at the global level. It is also about a change in who the players are and how the playing field is organised. A first characteristic of multilateralism is the diversification of multilateral organisations. In recent years there has been a dramatic rise in all kinds of international organisations and regimes. The number of intergovernmental organisations has grown from 37 to well over 400 in the period between

See Telò, M., The EU and global Governance, Routledge/Garnet series: Europe in the World, 2009, $354 \mathrm{p}$.

2 Van Langenhove, L., The EU as a global actor in a Multipolar World and Multilateral 2.0 Environment, Egmont Paper 36, March 2010.

3 Newman, T. and R. Thakur, Multilateralism under Challenge? Power, International Order and Structural Change, Tokyo: United Nations University Press, 2006, p. 539. 
1990 and $2000 .{ }^{4}$ They often operate on a network base. In line with a transnationalisation of policies, ${ }^{5}$ the emerging multilateral system implies the rise of transnational policy networks. ${ }^{6}$

Secondly, there is the growing importance of non-state actors in the international system. States have by now created a large number of global and regional institutions that have themselves become players in the international order. Some of these new players, although not states, do resemble states. An international organisation like the EU exemplifies this trend (e.g. its presence as observer in the UN, its voting rights at the IMF and its membership at the G8, etc.). Other regional organisations - although not to the same extent as the EU - are following suit. Van Langenhove argues that we are witnessing a transition from a world of states to a world of regions. ${ }^{7}$ This trend is further reinforced by the phenomenon of devolution, whereby state powers are in some states transferred to subnational regions. Both supraand subnational governance entities are created by states and can therefore be regarded as dependent agencies of those states. The suband supra entities have a tendency to behave "as if" they were states. All of this challenges sovereignty, as both the supranational and subnational regions have indeed to some extent statehood properties. The EU is exemplary as it is the only international organisation that grants citizenship to the citizens of its member states. Together this has weakened the Westphalian relation between state and sovereignty.

Thirdly, next to the increased relations between vertical levels of governance, there is a growing horizontal interconnectivity between policy domains. Finance cannot be divorced from trade, security, climate, etc. The boundaries between policy domains (and the organisations dealing with them) are becoming more and more blurred. Instead of clearly separated areas of policy concerns and separated institutions to deal with them, there are now communities of different

4 Schiavone, G., A Dictionary and Director, New York: Palgrave, 2001; Higgott, R., International Organisation, in R. Rhodes, S. Binder and B. Rockman (eds.), The Oxford Handbook of Political Institutions, Oxford: Oxford University Press, 2006.

5 Stone, D., Transfer Agents and Global Networks in the "Transnationalisation" of Policy, in Journal of European Public Policy, 11, 2004, pp. 545-566.

6 Djelic, M.L. and S. Quach, Globalisations and Institutions, Cheltenham: Edward Elgar, 2003.

7 Van Langenhove, L. and D. Marchesi, The Lisbon Treaty and the Emergence of Third Generation Regional Integration, in European Journal of Law Reform, X (4), 2008, pp. 477-496. 
actors and layers that together form a global gathering place of multiple publics and plural institutions. ${ }^{8}$

Finally, the involvement of citizens in the old multilateral system is largely limited to democratic representation at the state-level. The supranational governance layer does not foresee direct involvement of civil society or any other nongovernmental actors. There is increased room for nongovernmental actors at all levels. Organising multilateralism in a state-centric way has only been possible through the postulate of all states being treated as equal. This means that irrespective of the differences in territorial size, the size of population, military power or economic strength, all states have the same legal personality. Or in other words, the Westphalian principle of sovereign equality means that one state equals one vote. This postulate no longer corresponds with reality, therefore a more flexible form of multilateralism is needed, one which could eventually also lead to a more just system with a more equal balance of powers.

The reality is much more complex than a single bottom-up hierarchical line of governance. First of all, there is no single top level in the emerging new multilateralism. The $\mathrm{UN}$ and the Bretton Woods institutions, together with new fora such as the G20, stand for a plurality of top-levels. Secondly, at the regional level there is no perfect match between a regional territory and a regional organisation. On the contrary one can identify in most cases many different regional organisations that cover more or less the same territory. Thirdly, there is no fixed set of poles, but there are diverse and shifting poles at the level of continents, regions or states. Fourthly, as the multilateral system is no longer uniquely the playing-ground of states, the possibility is opened up for increased civil society participation in global governance. And finally, states are not necessarily the lowest level, as in some cases subnational entities can have their own direct relations with the regional or global level without passing through the state level.

\section{Assessment}

The changed global setting has moved a multipolar world towards a complex web of relations between four types of actors with statehood properties (i.e. global institutions, regional organisations, states and subnational regional entities) together with non-state actors such as NGOs or transnational policy networks. This new conceptualisation of governance, citizenship and dialogue in international/global relations requires therefore a multiplicity of citizenships as a political-legal status

Stone, D., Global Public Policy, Transnational Policy Communities and their

Networks, in Journal of Policy Sciences, 2008, 36(10), pp. 19-38. 
(i.e. post-nationalism), a recognition of diverse and multiple identities (i.e. multiculturalism vs interculturalism) and a citizens' participation on all levels of sovereignty (i.e. transnationalism). Furthermore, the growing awareness of the need for global knowledge and global planning to realise global goods and the recognition of a shared future, favours an interest in universal values of belonging and institutional expressions of global norms.

This current multidimensional process of globalisation also has a paradoxical impact on external and internal relations of states. The dominant spatial paradigm of territoriality and identity-building is being undermined by globalising forces. This paradigm has placed boundaries between some of the most fundamental characteristics of the modern world, notably community, nationality, identity and citizenship. Still the power of the territorial narrative remains strong through the reemergence of communal, nationalist and ethnic identities, the misconceived interpretation of sovereignty and the exclusive focus of locally-based communities for sustaining social solidarity. In summary, the globalising world is characterised by a partial asymmetry between the growing extra-territorial nature of its huge power and the continuing territoriality of the ways in which people live their everyday lives. Its seemingly contradictory nature reveals new opportunities for institutional structures along with new forms of politics and civility and broader perspectives on the process of European integration.

\section{A weakened position of the $E U$ as a global actor}

For a long time the EU has had the ambition and capacity to play a global role, especially in first pillar domains such as trade, development, environment and social issues. ${ }^{9}$ More recently, the EU has also been increasingly developing its security strategy and architecture with a focus on global ambitions. ${ }^{10}$ With the Lisbon Treaty, the EU has made an even more important step forward in realising its global aspirations. ${ }^{11}$ This can be called the process of Europeanisation, as a response to the globalisation process. Indeed, ever since the birth of the Industrial Revolution, Europe, and by extension "the West", has been the centre of the world. Along with the scientific and technological inventions that gave rise to unprecedented boosts in productivity, new institutional and political inventions arose in Europe, such as the birth of the liberal state

\footnotetext{
9 See for an overview Orbie, J., Europe's Global Role. External Policies of the EU. London: Ashgate, 2008.

10 See for an overview Tardy, T., European Security in a Global Context. Internal and External Dynamics, London: Routledge, 2009.

11 Van Langenhove, L. and D. Marchesi, op. cit.
} 
and the idea that peace and trade were interlinked. Combined with new ideas about sovereignty, legitimacy of state power and nationalism, this resulted in a system of interstate competition with dramatic economic and geopolitical consequences. Meanwhile, Western values and assumptions have been internalised to a great extent in almost every other major culture. ${ }^{12}$ Today, the international system is more complex, more interdependent and more and diverse actors are now involved.

Although the EU is still the world's leading exporter of goods, largest trader of services and biggest donor of development and humanitarian aid, the second largest foreign investor and the second largest destination for foreign migrants, there is now more competition in those areas. But, with the current global economic and financial crisis, one can easily speak of a European malaise and a decline of its economic and political power, even a systemic crisis. This can be related to a combination of various factors, which existed before the crisis: external factors of increasing competition at the global level and management of complexity and internal factors of demographic developments and EU governance deficit, in particular the lack of economic or fiscal governance.

In carefully managing the global crisis the EU is slowly taking measures for greater economic, fiscal and financial convergent policies, first in the framework of the previous Stability and Growth Pact and now, since January 1st 2013, with the Fiscal Compact (formally the Treaty on Stability, Coordination and Governance in the Economic and Monetary Union; or more plainly the Fiscal Stability Treaty). Much greater fiscal union, at least in the eurozone, is seen as a necessary solution to the current European sovereign debt crisis, as well as a natural next step in European integration.

\section{The EU as an international reference or a "model of society"}

Two essential and distinctive dimensions of the EU's contribution to global governance can be distinguished: the EU's internal/external influence as a model of national and supranational democracy and its impact on international democratisation. ${ }^{13}$ Since its creation in the 1950s, the European Community and now the EU has played a key role in underpinning and strengthening democratic processes throughout its several enlargements, from the Mediterranean to the Central and Eastern enlargements. Furthermore, the EU as a regional democratic political

\footnotetext{
12 Roberts, J.M., The Triumph of the West. The Origin, Rise and Legacy of Western Civilisation, London: Phoenix Press, 1985, p. 278.

13 Magnette, P. and K. Nicoalaïdis, The European Union's Democratic Agenda, in M. Télo, op. cit., p. 43-63.
} 
system in the making is a reference for its near and far international environment. The EU is not only an intergovernmental association of democratic states but also a new kind of non-state supranational political system at the macro-regional level, illustrating a unique process of integration sui generis. Its regional democratic polity is already offering a twofold international reference of democratic practise: for democracy within the state and for democracy between states.

Finally, for centuries the global implications of European contribution towards peacebuilding has been addressed by political thought, from Immanuel Kant to Jürgen Habermas. Jean-Marc Ferry analyses the modern cosmopolitan perspective in light of the European structural peace and democratic transnationalism. ${ }^{14}$ Even for realist scholars, such as Christopher Hill, the EU is already a regional form of international society, ${ }^{15}$ marked by reconciliation, recognition and deep cooperation among former enemies. Some idealist social scientists, such as Ulrich Beck, have professed the EU to be a cosmopolitan Empire within a Westphalian world ${ }^{16}$ (see Chapter 6). All these views imply new challenges in terms of the distinctive, international European identity, its external policy-making, and its innovative notions of power.

\section{The way forward for the $E U$}

There is overwhelming evidence that the world is going through a process of change that is unprecedented and that has resulted in an acceleration of all kinds of uncertainties. Not only are we thus witnessing tremendous societal changes, there is also a growing awareness of the need for changes at the political level. The scientific community has seemed to respond to the challenge. During its four year mandate, the European Research Area Board (ERAB), established in $2008,{ }^{17}$ has provided independent and authoritative advice to the European Commission on research and science policy, with a view to creating the European Research Area. In May 2012 it published its third and final strategic report, "The new Renaissance: will it happen? Innovating out of the crisis". ${ }^{18}$ Central to its thinking has been addressing the "Grand Challenges" such as climate change, energy

\footnotetext{
14 Ferry, J.-M., Europe, La Voie kantienne: Essai sur l'identité post-nationale, Paris: Cerf, 2005.

15 Télo, M., op. cit., p.11.

16 Beck, U. and E. Grande, op. cit. .

$17 \mathrm{http}: / /$ ec.europa.eu/research/erab/pdf

$18 \mathrm{http} / /$ ec.europa.eu/research/erab/pdf/3rd-erab-final-report_en.pdf
} 
supply, water resources, ageing societies, healthcare and sustainable prosperity for all. ${ }^{19}$

In short, if Europe wants to respond adequately to the global challenges and to the newly emerging world order, it needs a strengthened vision and a new storyline. ${ }^{20}$ One can point to many possible issues that could become part of such a new storyline. Given the working hypotheses of this first section, one can think of two (interrelated) tracks that could further strengthen Europe's position in the multipolar world of tomorrow: (1) deepening Western integration and (2) acting as a change-agent within the multilateral system.

\section{1) Deepening Integration: the road to European federalism}

Europe and the EU in particular, has a serious handicap to its ambition of being a global actor. As size matters, both for economic and political power, being divided into a multiplicity of small actors does not help. Of course, it has come a long way since the start of the integration process, after the First World War. But much more needs to be done. Notwithstanding the Euro as common currency, economic policy is still, to a large extent, the national policy of the member states. The same holds for security policy. Although there are EU-wide security policy documents, the major member states still have their own national security strategies.

Increased European integration seems therefore to be the only way forward. Only then will the national interest of all member states become part of the overall European interest. But perhaps an increased European integration will not be enough to counterbalance the fact that Europe's relevance in the world is shrinking. Perhaps even a fully integrated Europe will not be enough to allow the realisation of its global ambitions. In this context, transatlantic relations gain importance.

\section{2) Acting as a change-agent in the international system}

In the emerging new international system world order, states, international and regional organisations, transnational policy networks and non-governmental actors are the building blocks of the multilateral

19 See also Preparing Europe for a New Renaissance. A Strategic View of the European Research Area, First Report of the European Research Area Board, 2009, available at http://ec.europa.eu/research/erab/pdf/erab-first-annual-report-06102009_en.pdf;

Realising the New Renaissance, Second Report ERAB, 2010, available at http://ec.europa.eu/research/erab/pdf/erab-2nd-final-report_en.pdf); See also $E U$ 2020 Strategy and Report Reflection Group Europe 2030, May 2010, available at http://www.consilium.europa. eu/uedocs/cmsUpload/en_web.pdf.

20 Fritz-Vannahme, J., Europe's Bold New Story, Spotlight Europe, Bertelsmann Stiftung, no. 4, 2009, p.1-8. 
system. In other words, states are merely players amongst others. Moreover, it is no longer possible to make a clear distinction between states and international organisations as some of the latter have statehood properties as well. Furthermore, the interactions between all these actors are not organised in a hierarchical way but in a networked way. This implies that there is no single "centre of the universe" in terms of governance. It also implies that there are no sufficient "spaces of multilateral relations". Instead one can expect a fluid web of multistakeholder partnerships between different types of actors at different levels of governance including the regional level.

As Europe is the most regionalised region in the world, with a regional organisation (EU) that aspires to be a global power, it could play a central role in transforming the current multilateral system. Actually, it might also be that Europe needs to play that role in order to safeguard its own position and not to be reduced to a mere spectator in global affairs. ${ }^{21}$ The EU's plea for a more "effective multilateralism" is heading towards that direction and can be seen as a (timid) attempt to influence the multilateral playing field. But there is still a long way to go. At the level of the WTO, the EU is talking with one voice: it is the EU Commissioner for Trade who negotiated at the Doha Development Round on behalf of all EU member states. But at the IMF or the World Bank, Europe is not yet at that point. Giving a bigger role to regional organisations in the multilateral system might be the innovation to pursue.

\section{Conceptual Content: Sustainable Statehood of a Human-centric EU Governance}

In this second section, we propose a number of concepts and approaches that might help to better understand the changing statehood being built within Europe. This is done in view of European governance building, in particular Europe's contribution to good multi-level governance.

\section{Sustainable statehood}

\section{1) Point of departure}

The social sciences' debate on governance implicitly or explicitly remains connected to a specific type of modern statehood, exhibiting full domestic sovereignty and the capacity to make, implement and

21 Renard, T., A BRIC in the World: Emerging Powers, Europe and the Coming Order. Brussels: Academic Press for the Royal Institute of International Relations, 2009, p. 7. 
enforce decisions. This traditional statehood consists of five monopolistic dimensions, i.e. security, territory/borders, (national) citizenship, the practice of democracy and cultural identity. However, the traditional monopoly of statehood exhibited by the national sovereign state has historically been broken down into de facto e de jure, as shown in the first section of this chapter.

The new statehood dimensions are the international legal recognition of human rights, the development of intergovernmental and nongovernmental international organisations, the era of planetary interdependence and plural citizenship. These properties seem to have a greater governance capacity, both on a macro and a micro level of the multipolar system. Yet the available conceptual apparatus, i.e. referred to as "methodological nationalism", is not adequately equipped to deal with governance issues in the rapidly changing international system. Although the Western governance discourse assumes modern statehood and a fully functioning state as a background condition, the contemporary international political system introduces multiple sovereignties with changing statehood. The nation-state is no longer the place for coping with global and transnational problems. Governance in areas of changing statehood refers to multi-level governance, which links inter- and transnational actors to local ones in a variety of rule and authority structures.

The European Union, as previously stated, proposes itself as a new form of statehood at the international level, in which the adaptation process seems ongoing. Still the architecture of new global and European governance can only be structured according to a scheme of multi-level and supranational governance, linking the territorial and vertical dimension of subsidiarity with its functional and horizontal dimension. In this sense, the EU can be conceived as a container of sustainable statehood, exhibiting a double responsibility, i.e. an internal responsibility to guiding the member states in the process of adaptation and an external responsibility to being a civil actor promoting global governance.

The multi-directional building process of formal and informal governance building in the European and international system assumes various levels of governance (up, down, across and beyond) with institutional, political, educational, sociological and legal consequences. In Europe a four-fold process of cooperation/integration can be observed: the building up of a joint management of pooled sovereignty; the building down to regions within Europe, including some border regions; the building across, that is the fostering and consolidating of ties between groups on a transnational basis, often with an important functional and thematic connotation; and finally the building beyond, in 
the form of a variety of cooperation agreements in the European and global landscape. These interlinkages have an impact on changing statehood and governance.

\section{2) Conceptual framework}

The nucleus of the conceptual framework of the sustainable statehood refers to the theories of federalism, human development, public goods and multi-level governance. The driving forces in societal development, shaped by seemingly contradictory globalising and localising trends, challenge the characteristics of traditional statehood. Hence, they induce new paradoxes which, due to their magnitude of scale and intensity, are unprecedented and require new insights and innovative approaches to deal with complex issues such as territorial sovereignty vs responsibility of the international community, the need for global rules vs the need of local enforcement, global world culture vs local identity, the universality of human rights vs the particularity of their application, etc. It is clear that these manifestations all have an implicit tendency to generate conflict and constitute driving forces for change.

The reconversion of the nationally defined and border-based statehood passes through the structural reform of the modern state. The principles and structural conditions which make up the constitutive elements of a sustainable state are: (1) the recognition of the primacy of International Law of human rights over Internal Law; (2) the strengthening of the principles of the rule of law in view of their interdependence with the requirements of the welfare state: all human rights (i.e. civil, political, economic, social and cultural) are in fact interdependent and indivisible; (3) the realisation of forms of large functional autonomy, which implies the application of the principle of pluralism in the case of political parties and trade unions, as well as in the case of other legitimate formations of civil society (nongovernmental associations, voluntary groups, ethical banks, etc.); (4) the realisation of pronounced and diffused forms of territorial autonomy: more functions and powers to communities, provinces, regions, Länder, etc. based on the principle that local autonomy is originating, not derived from above; (5) the application of the principle of pluralism beyond the market economy principles; (6) the active belonging to supranational systems of collective security: strengthening the UN system; and (7) the protection and valorisation of the natural environment and cultural goods as a transversal objective of various public policies. 


\section{A Human-centric approach to sustainable statehood}

\section{1) Diagnosis of departure}

The underlying paradigm of a human-centric approach to international relations is the qualitative inadequacy or capacity deficit of the state-centric structure of the international system, and the reference to the human rights paradigm as a parameter for a human-centric transformation of the system. This approach focuses on the forms of humanly sustainable statehood.

The old national, sovereign-armed, border form of the state is no longer capable of exclusively covering and managing the contents of statehood. This criticism is based on the fact that law-enforcing power is no longer an exclusive sovereign function of the state. Other lawmaking structures of authority exist beyond and above the state, which makes laws, even containing constitutional norms and adopts lawbinding decisions. As a consequence, the current status of traditional statehood, also concerning its territorial dimension, presents characteristics of pronounced porosity in respect to variables that are external to the traditional domain reserved to the state.

The diagnosis of departure also invests a crisis of democracy, the main cause of which is linked to the limits of the space in which its experience has been previously circumscribed, i.e. domestic jurisdiction of a space reserved to a single state. A democracy that is only internally defined is therefore an insufficient democracy, and in the end useless, because it runs senseless in the presence of the undeniable fact that big decisions are often made beyond a single state. It is to these enlarged international and transnational frameworks that the democratic experience has to be taken. Of particular relevance in this respect are the political and normative implications that derive from the recognition of the international legal subjectivity of the human person.

Starting from the vital needs of persons and human communities, legal obligation and rational convenience seem to complement each other to realise a new division of politics, going from the micro-local context to the macro-planetary level. The functional space of sustainable statehood finally coincides with the constitutional space of human rights. In virtue of the international recognition of fundamental rights, the operational space is widened from the internal legal sphere to the global legal sphere.

In short, the International Law of Human Rights, with the applied support of subsidiarity, is the compass that guides the transfer and distribution of functions and structures of democratic statehood along the scale of sustainable statehood, moving from the city, the village, the region, the state, Europe and finally to the supranational institutions. 
Human rights need therefore to be situation-specific. In other words, they have to be localised or as locally relevant as possible. The contribution of local communities to the interpretation and further normative development of human rights is therefore conceived as essential.

\section{2) Basic fundamentals}

The mutually reinforcing conceptual building blocks of a humancentric approach to sustainable statehood building, applied to the European setting, are the universality and indivisibility of the human rights and the cosmopolitan perspective of multi-level governance in relation to its local relevance and the importance of global public goods in relation to transnational democratic practices.

(a) Human rights paradigm

The universality of human rights rests on the recognition of the equal importance and interdependence of civil, political, economic, social and cultural rights. Within the current globalisation debate this implies localising human rights as much as developing a common responsibility across borders of states. The human rights paradigm is conceived as a powerful and universal transcultural and transnational facilitator for human-centric governance and sustainable statehood. This recognition will favour a move from the (increasingly) conflicting stage of multiculturality to the dialogic stage of inter-culturality in globalising societies.

Anchored to the paradigm of human rights are human security and human development. ${ }^{22}$ They are the new frontiers of global multi-level governance. Both hold the human being as their primary subject. In broad terms, human security shifts our focus from traditional territorial security to that of the person. Human security recognises that an individual's personal protection and preservation comes not just from the safeguarding of the state as a political unit, but also from the individual's access to welfare and quality of life. The security policies of states should be instrumental to the objectives of human security and human development.

22 Papisca, A., International law and human rights as a legal basis for the international involvement of local governments, in V. Musch, Van Der Valk, Sizoo, Tajbakhsh (eds.), City Diplomacy. Conflict Prevention, Peace-building, Post-conflict Reconstruction, The Hague, 2008. 
(b) Cosmopolitan perspective of multilevel governance in Europe $\mathrm{e}^{23}$

The globalising world is characterised by some asymmetry between the growing extra-territorial nature of abundant power and the continuing territoriality of the ways in which people live their everyday lives. This seemingly contradictory nature reveals new opportunities for institutional structures along with new forms of management of politics and dialogue at various levels of the globalising landscape This perspective refers to a cosmopolitan shaping and understanding of the emerging European polity of multi-level governance structures. Point of departure is the weakening of the spatial paradigm of territoriality and identity-building by globalisation forces. The next chapter goes deeper into the cosmopolitan perspective of multi-level governance in Europe.

European integration has developed into a much more complex and mixed political project, evolving into a "common citizenship" and a transnational democracy. It is characterised by a flexible spatial structure, composed of vertical and horizontal links between models of sovereignty in a transformative interdependence. The European integration process presents an asymmetrical integrative order based on a mixture of intergovernmental and supranational forms of cooperation, in which civil society is becoming a shaping factor and a meeting place of social and political aggregations.

(c) Global public goods and transnational democracy ${ }^{24}$

A global public goods approach takes into account the core systemic features of globalisation, being spatial extension and compression, increasing interconnectedness, temporal acceleration and a growing awareness. It recognises multiple locations of governance, multiple dimensions of integration, multiple modes of interaction and an increasing institutionalisation of the process of globalisation. Such an approach contributes to a better analysis of global policy challenges, including sustainable statehood for good human governance and may recommend strategies for true global policy-making. New opportunities

23 Useful references are Archibugi, D. and D. Held (eds.), Cosmopolitan Democracy: An Agenda for a New World Order, Cambridge: Polity Press, 1995; Archibugi, D., The Global Commonwealth of Citizens: Toward Cosmopolitan Democracy, Princeton: Princeton University Press, 2009; U. Beck and E. Grande, op. cit.; Held, D., Democracy and the Global Order: From Modern State to Cosmopolitan Governance, Cambridge: Polity Press, 1995.

24 See research undertaken by Inge Kaul, UNDP and Global Studies Centre; Reference publications are: Kaul, I. and Grunberg, M.A. Stern, Global Public Goods: International Cooperation in the 21st Century, New York, Oxford: University Press, 1999; Kaul, I., P. Conceicao, K. Le Goulven and R.U. Mendoza (eds.), Providing Global Public Goods: Managing Globalization, New York, Oxford: University Press, 2003. 
for enhanced networked governance have been created among states, regions and civil society actors.

The public goods perspective departs from the need of international democracy for internal democracy in a deterritorialised (global) space. Therefore, today's open and interdependent world requires a principle of responsible sovereignty that encompasses both the internal and the external dimensions of governance responsibility. This implies a remodelling of the role of the state that encompasses collective selfinterest. A research consequence of this perspective is a focus on the creation, protection and management of global public goods, the subsequent dimensions of global democracy and global democratic community or society, the institutional diversity to promote the common good; and the importance of regional and international organisations as the building blocks of a global community, i.e. a re-inventing of democracy in a global context. This is further elaborated in Chapter 7.

\section{Conclusions}

\section{State-centric vs human-centric development}

The changing political landscape is now occupied by more local actors significant in both domestic and international politics. States are no longer the exclusive actors in international politics. But are local governments legally entitled to act in the system of international relations on dramatic issues like peace and security? These issues traditionally pertain to state foreign policies. The question can be answered with strong arguments. The first of these is that the legal field has undergone a genetic mutation. The international legal recognition of human rights has changed the driving force, the rationale of international law, from state-centric to human-centric. This has many implications. The process is the outcome of a long historic movement marked by peoples' suffering and reacting, intellectual endeavour, mass mobilisations, and political commitment, which has brought democratic processes inside states. With the UN Charter and the Universal Declaration of Human Rights the constitutional rationale has been extended to the world level, overreaching the borders of state sovereignty. For the first time in the history of humanity, the human being as a person has been recognised as the subject, and not as merely the object, of international law. So the human-centric rationale is constantly being reinforced by the new international law, or pan-human law, which is developing as a coherent body of principles and norms that both complement and update the first part of the UN Charter. 


\section{States as derived entities}

The next argument is that the human-centric position means that states and international organisations are simply derived entities, instrumental to pursuing the primary aims of human rights and fundamental freedoms. To underline the primacy of the human being over derived systems, Article 28 of the Universal Declaration proclaims the right to positive peace as a fundamental right. If we extend the argument on state-centric and human-centric law, a revolutionary implication follows. The "right to war" and the "right to peace" are the strongest claims of state sovereignty. But if peace is a human right, the right to war cannot help but disappear from the dictionary of state claims, endowments and inter-state relationships. And to positively confirm this position, the right of states to peace must be complemented by a duty to peace. When a legal system is founded on human rights, it enters a new stage of human-centric maturation. We are passing beyond the phase of international relations as a primary system; we are no longer in the Westphalian era that was formally based upon nationbased sovereignty.

\section{Renewing citizenship}

A last concluding remark refers to the impact on sovereignty, citizenship and democracy. ${ }^{25}$ States have borders. This involves an exclusionist territorial rationale of sovereignty and domestic jurisdiction. Conversely, local governments run territories that are not surrounded by borders, but they do minister to people in them. Local governments are closer to the source of sovereignty - people - than the state. Sovereignty belongs to the people because each of its members has inherent rights, and fundamental rights should be respected and protected where people live. National citizenship, based on the principle of exclusion, is consistent with the philosophy of states. Universal citizenship, based on the principle of inclusion, is consistent with the natural identity of local government. The international legal recognition of human rights obliges us to re-construct citizenship starting not from state institutions (traditional top down citizenship), but from its original holder, the human being, with his/her inherent rights internationally recognised (bottom-up citizenship).

25 Papisca, A., International law and human rights as a legal basis for the international involvement of local governments, in V. Musch, Van Der Valk, Sizoo, Tajbakhsh (eds.), op. cit.. 


\section{1) Citizenship from below}

A useful way of addressing this situation is to reconceptualise citizenship starting from below. That is from the roots of the political community up to the institutions of governance. The latter must then be seen in the light of their purpose and democratic legitimacy before considering them as sources of authority, power and capability. Such a bottom-up view is even more urgent if we consider the conflicts in many territories (regions, cities, streets) where different ethnic, religious and cultural groups live, where xenophobia and discrimination may be growing, and where migrant people of different cultures rightly advocate the same citizenship rights as nationals.

Sovereignty based on the nation-state has proven to be insufficient in protecting the true elements of democracy. Nation-states were the fertile kindergarten of democracy, but they do not suffice today when faced with worldwide interdependence and globalisation. The practice of democracy, in its twofold articulation of representative and participatory democracy, should be extended and deepened: upward for international and cosmopolitan democracy and downward in local direct democracy. By extending democratic practice beyond its historical territorial space, the local territory becomes a new frontier. Being so close to and involved with democracy, local governments are the primary stakeholders in good global multi-level governance.

A relatively recent and promising perspective regarding the legal development of the role of local governments in international politics is the European Grouping of Territorial Cooperation (EGTC). ${ }^{26}$ The EGTC as established in 2006 by the EU can be considered not only an advanced achievement but also a good starting point for further formal and substantive progress in recognising the international role of local governments. It could be envisaged that, within the framework of the $\mathrm{UN}$, an international framework convention be adopted to establish the "International" Grouping of Territorial Cooperation.

\section{2) International-transnational democracy}

Today's passionate and creative reality of civil society organisations and social movements, and of local governments acting across and beyond state borders, demonstrate that civic and political roles, that is active citizenship, are no longer limited to the intra-state space, and the geometry of democracy is extending and growing in the world space. The traditional inter-state system has always been an exclusive club of "rulers for rulers". Now it is citizens, especially through their

26 See special issue on Territorial Cooperation, in Pace Diritti Umani - Peace Human Rights, 3/2010. This is further elaborated in Chapter 14. 
transnational organisations and movements, who are claiming a legitimate role, and showing their visibility in the world's constitutional space. Democratising international institutions and politics in the true sense of democracy - this does not mean "one country, one vote" (a procedural translation of the old principle of state sovereign equality), but more direct legitimacy of the relevant multilateral bodies and more effective political participation in their functioning - has become the new frontier for any significant human-centric and peaceful development of governance. Advocating an international-transnational democracy is already putting new citizenship into practice.

\section{3) A new concept of citizenship}

This mobilisation is further being legitimised in a specific and innovative way by the UN Declaration "on the right and responsibility of individuals, groups and organs of society to promote and protect universally recognised human rights and fundamental freedoms". By virtue of this instrument, known as the "Magna Carta of Human Rights Defenders", "everyone has the right, individually and in association with others, to promote and to strive for the protection and realization of human rights and fundamental freedoms at national and international levels" (Article 1). Emphasis is put on the right to overfly domestic borders. Article 7 further states; "everyone has the right, individually and in association with others, to develop and discuss new human rights ideas and principles and to advocate their acceptance". Article 18, points 2 and 3, continues:

Individuals, groups, institutions and non-governmental organizations have an important role to play and a responsibility in safeguarding democracy, promoting human rights and fundamental freedoms and contributing to the promotion and advancement of democratic societies, institutions and processes. Individuals, groups, institutions and non-governmental organizations also have an important role and a responsibility in contributing, as appropriate, to the promotion of the right of everyone to a social and international order in which the rights and freedoms set forth in the Universal Declaration of Human Rights and other human rights instruments can be fully realized.

The new concept of citizenship implies huge changes in legal systems at all levels. In fact, internationally recognised human rights are the rights of every human being, not of the human being as a simple citizen of a given state. The big challenge that lies ahead is for politics and education to help change culture, harmonise national legal systems with the international law of human rights, carry out proper national and international social policies, and foster the inclusion of all in the framework of a multi-level architecture of governance. 
In the meantime, a new frontier for human promotion and democracy development has been launched. Since "the recognition of the inherent dignity and of the equal and inalienable rights of all members of the human family is the foundation of freedom, justice and peace in the world" (Universal Declaration), respect for human dignity and human rights should be guaranteed where people live. New citizenship, in tandem with the impact of the necessary intercultural dialogue aimed at democratic inclusion, can revitalise the public sphere in a perspective of multi-level and supranational governance. And it is in fact the phenomenology "in the plural" of citizenship, dialogue and inclusion that obliges institutions to redefine themselves and therefore to open up and develop multiple channels of representation and democratic participation.

Finally, in order to further contextualise the debate on the new concept of citizenship, it might be helpful to briefly identify various models and processes of citizenship that can be observed in current international and national affairs: (1) Ideological Monolithic Citizenship: there is an ideology of a monolithic national identity and static public values with no place for diversity and no intermediate level between the citizen and the state: a melting pot process; (2) Humanistic Citizenship: there is a holistic understanding of humanity with respect for individual uniqueness, but there is no intermediate level between the citizen and the state: a glocal identification process; (3) Communitarian Citizenship: only one culture is recognised as reference for the public sphere with no chance for real intercultural relations and contribution to public life; citizenship and political participation are understood in an antagonistic approach: a communitarian - discrimination process; (4) Multicultural Citizenship: a recognition of the cultural dimension of the citizen's identity with respect for cultural diversity and tolerance from the mainstream national community towards minorities, but without much possibility for participation: at risk of a ghettoisation and communitarian process and the tyranny of a minority over its followers; (5) Intercultural Citizenship: a recognition of the cultural dimension of the citizen's identity, beyond tolerance with a recognition of the contribution of each culture to the society: the citizenship culture is built through an ongoing intercultural dialogue and identification of shared public values. 

CHAPTER 6

\section{A Cosmopolitan Perspective of Multi-level Governance in Europe}

\section{Introduction}

The European integration process is, to date, the world's most advanced post-national constellation of states. As such, it has become a laboratory for scholars and philosophers of political theory and international relations interested in studying and developing workable models of supranational and/or global and multi-level governance. Prominent among these scholars are those who view the European Union from a cosmopolitan perspective, analysing integration for its potential to realise a cosmopolitan Europe in which the concept of citizenship is crucial.

The new post-modern conceptualisation of governance, citizenship and dialogue in international/global relations requires a multiplicity of citizenship (i.e. post-nationalism), the recognition of diverse and multiple identities (i.e. multiculturalism and interculturalism) and citizens' participation at all levels of sovereignty (i.e. transnationalism). On the other hand, the growing awareness of the need for global knowledge and global management to realise global goods and the recognition of a shared future favours an interest in universal values and the institutional expression of global norms.

The current multidimensional process of globalisation has a paradoxical impact on the external and internal relations of states. The dominant spatial paradigm of territoriality and identity-building is being undermined by globalising forces. This paradigm has placed boundaries around some of the most fundamental characteristics of the modern world, notably community, nationality, identity and citizenship. Still the power of the territorial narrative remains strong through the reemergence of communal, nationalist and ethnic identities, the misconceived interpretation of sovereignty and the exclusive focus of locally-based communities for sustaining social solidarity. In summary, the globalising world is characterised by a partial asymmetry between the growing extra-territorial nature of power and the continuing territoriality of the ways in which people live their everyday lives. Its seemingly contradictory nature reveals new opportunities for institutional structures along with new forms of politics and civility and, 
as a consequence, offers a reading of the process of European integration from a cosmopolitan perspective.

Chapter 1 described the history of the European integration process as a development from a (neo-) functional, utilitarian and largely economic project to a more complex and mixed political undertaking, set in a globalising context and now based on the institutional structure of the Treaty of Lisbon. The first decades of the European integration process functioned on the political paradigm of the Westphalian system. A democratic approach to international life outside of the national borders was not at all required. There was equality between nationality, identity and citizenship. The Treaty of Maastricht (1992) breaks down that linear perspective and establishes a political framework for a broader and deeper integration of European states and regions. In addition to consolidating the single market and opening the way for greater cooperation on internal and external affairs, it introduced the concept of European citizenship, i.e. a common citizenship applied to many nationalities and covering a multiplicity of identities. ${ }^{1}$

Such a broadly defined European citizenship does, however, not replace national citizenship but rather complements it. Moreover, it enhances the legitimacy of the process and promotes a stronger European identity. It is claimed that European citizenship provides equal access to the individually-based legal status of union citizenship to all nationals, and universal civic protection to all nationals and residents, to be translated into a transcendent European identity. It also means that an active citizenship can develop within a new framework, not that of a closed state on a limited territory, but open beyond national borders and respecting diversities. Europe is therefore evolving towards a social and political body in which one will be able to distinguish a common European citizenship, multiple state and regional citizenships and governance structures, within which there exists a growing awareness of multiple and different cultural identities.

Europe is indeed involved in favouring the development of a "transnational democracy". The process of European integration strongly contributes to changing the mentality and conception of the state system. The role of the state becomes less essential in many sectors of economic life through the "supranational" transfer of decisionmaking powers to common authorities; similar developments affect its role regionally through the need to adapt to multiple demands of autonomy, identity recognition, and decentralisation. In short, it seems obvious that with the process of globalisation, demands for the recognition of particular identities and minority rights will strongly

This is further elaborated in Chapter 12. 
develop within national and regional structures, while at the same time requests for more citizen participation at the supranational or transnational levels will become more evident, in the name of new European citizens' rights.

This chapter argues that a cosmopolitan shaping of the European Union using a complexity of multi-level governance structures is conducive to its underlying objective of legitimating the emerging European polity. The major working hypothesis is that the concept of cosmopolitanism can contribute to the understanding of the transformation of modern societies and of Europeanisation, in particular, by creating an integrated European public and European space. A cosmopolitan reading of Europeanisation and, in particular, of the process of European integration is proposed, to understand and assess the viability of a "cosmopolite" Europe and its policy implications as an idea and reality within a European and global context.

\section{Cosmopolitanism and Post-modernity in the Context of Globalisation}

By globalisation we mean the phenomenon and process of the growing concrete interdependence of economic, political, social and cultural relations and of a greater consciousness of the world. Globalising processes involve variable but usually significant shifts in the spatial ordering of personal and social relationships, as well as in organisational political forms and functions. It is an enacted process, in which the transformative capacity of globalisation reshapes the contours of social action and redefines the political and identity spaces of individuals and collective actors.

In the extensive literature on globalisation studies ${ }^{2}$ three conceptual stages can be distinguished. In the first stage, the impact of globalisation on national economies was investigated, and concluded that a neoliberal world economy government and homogenous world society were on the rise and the national state was in demise. In the second stage the cultural aspects of globalisation were studied, with criticism on the convergence thesis and arguments for a fragmented and multidimensional worldview. National communities were seen as one of

See amongst others Beck, U., What is Globalization?, Malden (Mass.): Polity Press, 2000; Brodie, J., Introduction: Globalization and Citizenship Beyond the National State, in Citizenship Studies, Vol. 8, no. 4, 2004; Stiglitz, J., Making Globalization Work, London: Penguin, 2006; Giddens, A., Runaway World: How Globalization Is Reshaping Our Lives, op. cit.; Bauman, Z., Globalization: The Human Consequences, New York: Columbia University Press, 1998; Held, D., Governare la Globalizzazione, Bologna: il Mulino, 2005. 
the multiple places of human organisation. The current third phase brings together a multidisciplinary and multidimensional analysis of globalisation, with particular focus on its political manifestation. It concludes that globality and globalism represent the dual character of globalisation, in that they simultaneously generate the conditions of universalism and particularism.

In the following, we first briefly identify the major characteristics and developments of contemporary cosmopolitanism; next we focus on an analysis of a major contribution to the universalist interpretation of cosmopolitanism, i.e. the cosmopolite democracy and, finally we conclude with an assessment of the critique presented by constitutional patriotism.

\section{Multifaceted cosmopolitanism}

In the first place we want to clarify the concept of cosmopolitanism, which is often used as a synonym for globalisation, globality, glocalism, globalism, universalism, multiculturalism, pluralism and imperialism. The term goes back to the Cynics and Stoics of antiquity. It acquired central importance in the philosophy of the Enlightenment and has regained conceptual strength in the current debates on globalisation against the organising power of the market and the nation-state. In summary, the concept of cosmopolitanism has a very old meaning that points to the future; it is both pre-national and post national.

Its core premises are the recognition and appreciation of difference of thought, social life and practice, both internally and towards other societies. It rests on the "both/and" principle of regarding others as both equal and different and, consequently calls for new concepts of integration and identity that affirm coexistence across borders without requiring that difference be sacrificed by supposed national equality. It therefore relies on a framework of uniting and universally binding norms that should prevent deviation into postmodern particularism.

Ulrich Beck uses the concept as a social scientific concept to deal socially with cultural differences, distinguished from hierarchical subordination, universalistic and nationalistic sameness and postmodern particularism. ${ }^{3}$ It is important to recognise that cosmopolitanism aims to overcome the dualities of the global and the local, the national and the international. It is not specified in spatial terms and can therefore be applied to regional geographical units such as Europe. Viewed in this way, cosmopolitanism should not only integrate different national traditions and norms, it should at the same time balance various ways of

Beck U. and E. Grande, op. cit., p. 12. 
dealing with cultural differences, determined by the "both/and" principle. As such, it is both a theoretical and empirical concept.

\section{Contemporary cosmopolitanism}

From the above definition it is clear that contemporary cosmopolitanism provides a suitable ideological framework to respond to the conditions developed in the third phase of globalisation. ${ }^{4}$ It represents a way of dealing with the differences and similarities within the changing societies of a globalised world. Scholars concerned with the impact of globalisation have come to a common understanding that the modernist premises of the national state have been eroded. The Westphalian state is no longer a singular unit of political power with absolute sovereignty. There is now the emergence of regional and local democratic entities and communities. Moreover, in multicultural Europe the nation is neither culturally homogenous nor the primary expression of collective identity; national and regional communities are diverse and identities are multiple.

The contemporary expressions of cosmopolitanism seem to represent a logical accommodation of the postmodern challenges to citizenship and dialogue. They represent post-national, multi- and inter-cultural models of political community that preserve identities and facilitate global, regional, local and municipal loci of legal status and political membership. Moreover, they are transnationalist, in that they promote an active citizenry that is empowered within an emerging global civil society and enabled to shape political, social and cultural developments.

A common reference point for contemporary cosmopolitan theory is Immanuel Kant's cosmopolitan theorem, built around the vision of world peace and a global ethical regime. ${ }^{5}$ In his 1795 essay Perpetual Peace Kant puts forward an ius cosmopoliticum as a universal guiding principle to protect people from war. It is evident that Kant's theorem was grounded in the modernist understanding of citizenship. In the absence of inter- and supranational legal and institutional frameworks

4 Archibugi, D., D. Held and M. Kohler (eds.), Re-imaging Political CommunityStudies in Cosmopolitan Democracy, Stanford: Stanford University Press, 1998; B. Axford, Globalization and the Prospects for Cosmopolitan Society, in V. Gennaro Lerda (ed.), Which "Global Village"? Societies, Cultures and Political-Economic Systems in a Euro-Atlantic Perspective, Westport: Praeger, 2002, Ch. 18; D. Archibugi, The Global Commonwealth of Citizens: Toward Cosmopolitan Democracy, Princeton: Princeton University Press, 2009.

5 Kant, I., Perpetual Peace: A Philosophical Sketch, in M. Forsyth, M. Keens-Soper and P. Savigaer (eds.), The Theory of International Relations, London: Allen \& Unwin, 1970; I. Kant, Idea for a Universal History with Cosmopolitan Purpose, in H. Reiss (ed.), Kant's Political Writings, Cambridge: Cambridge University Press, 1991. 
for citizenship, it falls short of post-nationalism. As it is focused on universal awareness it does not recognise the notion of cultural diversity.

In the current globalised context, cosmopolitan thought has flowed out into several directions, one of which is universalism. The universalist position promotes the expression of global morality in the form of supranational legal systems and political institutions, implying an extension of the modern national state-based theory of citizenship. In the Kantian tradition of universal, trans-cultural authority, Martha Nussbaum $^{6}$ pleads for a humanistic cosmopolitanism, insisting that rights, obligations and commitments do not stop at national borders. She suggests a primary allegiance to the worldwide community of human beings, in which educative processes gradually narrow the gap between particular and broader loyalties, and between the local and humanity as a whole.

\section{Cosmopolitan democracy}

One major contribution to the universalist stream is the theory of cosmopolitan democracy centred on David Held's idea of global governance. ${ }^{7}$ Held argues that the realisation of the cosmopolitan vision, that of lasting world peace and universal equality of individuals, cannot rely on the states' democratic capacity only. As a result of globalisation, the idea of a political community can no longer be exclusively located within the boundaries of the territorial nation-state and secondly, the locus of effective political power has shifted from national governments to international regimes and forums, international and regional organisations, and a variety of transnational corporations. Consequently, it is argued that democracy must be strengthened within and beyond borders and effective democratic law internationalised. An institutionalisation of cosmopolitan principles based on cosmopolitan democratic law is therefore more than welcome. Moreover, in resolving conflict situations between national sovereignty and international law, he very much advocates a democratisation of the intergovernmental international organisations, in particular granting operational power to the UN. In his version of a cosmopolitan democracy, in addition to the existence of overlapping and spatially variable sovereignties, there exists a multitude of political communities with multiple citizenships and different agendas.

Nussbaum, M., Patriotism and Cosmopolitanism, in Boston Review, OctoberNovember 1994.

7 Held, D., Democracy and Globalization, in Global Governance, Vol. 3, no. 3, 1997. 
Daniele Archibugi ${ }^{8}$ elaborates on Held's new democratic condition and examines the prospects for cosmopolitan democracy as a viable and humane response to the challenges of globalisation. He argues that democracy has to function simultaneously on domestic, international and global levels of political authority in order to generate a lasting normative framework. He therefore proposes a renewed model for global citizenship, i.e. institutional cosmopolitanism. He argues that democracy can be extended to the global political arena by strengthening and reforming existing international organisations and creating new ones. Furthermore he calls for dramatic changes in the foreign policies of nations to make them compatible with global public interests and, consequently, advocates giving a voice to new global players such as social movements, cultural communities, and minorities. Finally, he proposes building institutional channels across borders to address common problems and encourages democratic governance at the local, national, regional, and global levels.

In short, Archibugi's vision of the cosmopolitan world order is one of a multi-level system of democratic governance, i.e. a cosmopolitan democracy in which democratic participation by citizens is not constrained by national borders and where democracy spreads through dialogue and incentives. ${ }^{9}$ He applies the cosmopolitan logic to concrete issues such as humanitarian intervention, institutional reform at the UN and democratic transitions.

For both scholars, the linkage of democratic institutions outside the boundaries of the state is indeed necessary in order to complement the inadequate democratic capacities of the postmodern state and to monitor the internal state affairs. ${ }^{10}$ Andrew Linklater talks about the necessity to create a post-Westphalian community, in which citizens have the right to participate in the decision-making processes of international organisations. ${ }^{11}$ The cosmopolitan argument for a federative development of the global landscape and a global legislative institution should therefore be conceived above all as a framework-setting institution. $^{12}$

Archibugi, D., D. Held and M. Kohler (eds.), op. cit.

9 Archibugi, D., Principles of Cosmopolitan Democracy, in ibid. (eds.), pp. 207-209; ibid., Cosmopolitan Democracy and Its Critics: A Review, in European Journal of International Relations, Vol. 10, no. 3, 2004.

10 Archibugi, D. and D. Held (eds.), op. cit..

11 Linklater, A., The Transformation of Political Community, Cambridge: Polity Press, 1998; ibid., Citizenship and Sovereignty in the Post-Westphalian European State, in D. Archibugi, D. Held and M. Kohler (eds.), op. cit., pp. 113-137.

12 Held, D., Democracy and the Global Order: From Modern State to Cosmopolitan Governance, Cambridge: Polity Press, 1995. 
Such a cosmopolitan approach to democracy of course has policy consequences. ${ }^{13}$ Firstly, it implies an active membership of individuals in the global community. Global issues, such as human rights, the environment and poverty have a universal impact on all individuals and as such transcend regional, national and international frameworks of cooperation. If global challenges are to be addressed in line with basic democratic principles, citizens should therefore have political representation at various levels of decision-making, from the local neighbourhood up to the international level. Secondly, it involves the institutionalisation of a universal and global citizenship status, which contains a mandatory core of rights, laid down in the Universal Declaration of Human Rights. Finally, the expression of cosmopolitan citizenship as the empowerment of a nascent global civil society denotes the transnational dimension of the cosmopolitan democracy theory. All these policy consequences require the management of global public goods $^{14}$ and the establishment of global bodies that are designed to manage global issues and individual interests in multi-level and multiactor governance structures.

In short, global citizenship means the transfer of specific elements of national citizenship into the global domain, so that specific global issues can be tackled. The cosmopolitan democracy thesis focuses on the institutional establishment of the cosmopolitan ideal and on the multilevel nature of the emerging system of governance by subscribing to the condition of multiple post-nationalism. The introduction of a global cosmopolitan citizenship status complements national as well as regional and local loci of citizenship and complies with the multiple denational and de-territorial conditions of citizenship.

Richard Falk offers a pertinent and interesting account of the impact of globalisation on democracy. ${ }^{15} \mathrm{He}$ argues that the growing importance of transnational relations is weakening national citizenship and reducing the importance of social capital at the level of the nation-state. Because of the fact that the logic of market opportunity no longer coincides with the logic of territorial loyalty, the tendency is likely to create links and solidarities across borders rather than within them. Falk proposes a polity of a globalisation from below for offsetting the tendency for

13 Archibugi, D., Cosmopolitan Democracy and Its Critics, op. cit., p.456; ibid., Principles of Cosmopolitan Democracy, op. cit., pp. 216-217. See also N. Dower and J. Williams (eds.), Global Citizenship - A Critical Introduction, New York: Routledge, 2002; D. Held, Democracy and Globalization, op. cit.

14 For the literature on global public goods see I. Kaul, I. Grunberg and M.A. Stern, Global Public Goods, op. cit. and I. Kaul et al. (eds.), Providing Global Public Goods: Managing Globalization, New York: Oxford University Press, 2003.

15 Falk, R., The Decline of Citizenship in an Era of Globalization, op. cit. 
national governments to be shaped by market-oriented forces pressing globalisation from above. In his human governance approach ${ }^{16}$ Falk therefore focuses on the realisation of a system of human government, based on a globalisation from below and beyond national borders, which is rooted in civil society and developed in a practice of transnational democracy. He believes in the creation of a normative global democratic structure, but constructed from below and rooted in the global civil society. As a consequence, the task of transnational social movements is to disseminate a global ethics that surpasses the identity of state sovereignty. Marco Mascia shows that the growing importance of civil society in Europe exemplifies integration from below and supports the hypothesis that this participative dimension provides a new democratic horizon for the EU. ${ }^{17}$ This is very important for understanding the practice of a multi-level governance of intercultural dialogue and the role of civil society.

\section{Constitutional patriotism}

A comprehensive critique of the cosmopolitan democracy thesis is provided by Jürgen Habermas. ${ }^{18} \mathrm{He}$ endorses the requirement of supranational democratic institutions and transnational civic activity but criticises the premises of the theory. First, Habermas rejects the prospects of a world state, away from a multilayered post-national system of governance. Instead he envisions a dynamic picture of interferences and interactions between political processes at national, international and global levels.

Second, he claims that cosmopolitan democracy ignores the multicultural dimension and favours an all-inclusive and a priori sameness at the cost of multicultural particularism. ${ }^{19}$ In short, he asserts that cosmopolitan democracy cannot reconcile universalism and particularism $^{20}$ and therefore re-establishes the competitive relationship between the national and cosmopolitan domains of collective belonging. Habermas stresses the importance of a new community-building logic in

16 Ibid., On Human Governance, Cambridge: Polity Press, 1995. See also UNDP, Human Development Report 1999. Globalization with a Human Face, at http: //hdr.undp.org/reports/global.

17 Mascia, M., Participatory Democracy for Global Governance, op. cit.

18 Habermas, J., The Postnational Constellation: Political Essays, in T. McCarthy (ed.), Studies in Contemporary German Social Thought, Cambridge: Polity Press, 2001.

19 Ibid., Struggles for Recognition in the Democratic Constitutional State, in A. Guttman (ed.), Multiculturalism: Examining the Politics of Recognition, Princeton: Princeton University Press, 1994.

20 While universalism refers to the individuals' commitment to abstract principles and rights, particularism refers to the context of a historically specific political culture. 
national and global domains. He argues that the cohesiveness of a community cannot be guaranteed by fostering an exclusionary ethnocultural identity. Instead, he pleads for the building of a civic form of identity, i.e. "constitutional patriotism". He reasons that rationally chosen commitments to a common set of constitutional principles, fundamental rights and democratic institutions, can provide a common normative framework that is culturally neutral and therefore sufficiently inclusive for binding a multicultural society together.

Habermas' third critique regards the democratic character of the cosmopolitan democracy thesis. ${ }^{21} \mathrm{He}$ criticises the so-called pre-existing global morality that holds humans together in a global community. In this context, cosmopolitan rights are understood as pre-defined and universal. Democracy, according to Habermas, is the self-defined and self-legislated power of the public. That is, identity, rights and their institutional expressions are organic and negotiated categories.

In order to overcome the democratic deficiency of the cosmopolitan democracy theory, Habermas suggests moving away from a representative and towards a deliberative notion of democracy, internally and externally, domestically and globally. In particular, he asserts that deliberative democracy promotes channels of interactive and discourse-based civic activity in addition to the formalised institutional representation and participation of the citizen. ${ }^{22}$ Such a deliberative democracy further facilitates a comprehensive notion of the public sphere as a space where individuals can engage in rational critical discourse about common political interests. This might create a socially constructed collective identity that is constantly reproduced and generates legitimacy from below.

Habermas's final criticism of the cosmopolitan democracy thesis refers to its empirical foundations. According to Habermas, it is mistaken to base a cosmopolitan view on the developments of the international domain, the evolution of an international human rights regime and the UN system. He posits the European Union as a viable model of democracy beyond the nation-state. ${ }^{23}$ Despite this positive outlook, Habermas admits that the European Union is not yet adequately equipped to deliver this promise. He insists that the integration must incorporate the vehicles of constitutional patriotism and deliberative

21 Habermas, J., The Postnational Constellation, op. cit.

22 Ibid., The European Nation State - Its Achievements and Its Limits. On the Past and Future of Sovereignty and Citizenship, in G. Balakrishnan (ed.), Mapping the Nation, London: Verso, 1996; Ibid., The Postnational Constellation, op. cit., p. 76.

23 Ibid., Making Sense of the EU: Toward a Cosmopolitan Europe, in Journal of Democracy, Vol. 14, no. 4, 2003, p. 94. 
democracy so that the EU's democratic capacity can be strengthened while the multilayered nature of the European polity is maintained. Producing a common ethical framework of shared political values, moral norms and legal rights should transcend but not erode national and cultural particularism, in order to provide a viable and meaningful basis of solidarity for the public. ${ }^{24}$ In this perspective, the Treaty of Lisbon offers a modest step forward to creating a "European public space" in advancing deliberative capacity of the supranational institutions of democracy, simplifying decision-making and favouring active citizenship. ${ }^{25}$

\section{A Cosmopolitan Perspective of Europeanisation}

The second part of this chapter applies the cosmopolitan perspective to the process of Europeanisation. The analysis relies on Ulrich Beck's interpretation on cosmopolitanism, as it was developed in "Cosmopolitan Vision", in which Beck develops the concepts of second modernity, risk society and reflexive sociology into a radical new sociological analysis of the cosmopolitan implications of globalisation. The application of this vision is then further assessed within a "Cosmopolite Europe", ${ }^{27}$ mainly focussing on the content, policy implications and global setting of the European integration process.

\section{Beck's political and sociological cosmopolitanism}

Understanding Europe in cosmopolitan terms means defining the European concept of society as a regionally and historically particular case of global interdependence, i.e. a Europe of accepted, recognised and regulated difference, in a new era of border transcending and border effacing cooperation. This historically unique and distinctive mixed form of inter-governmental, supranational and inter-societal community, escapes the traditional categories and concepts. The development of the EU exemplifies particularly how political and theoretical concepts of the social sciences have become trapped in what Beck calls the conceptual straight jacket of methodological nationalism. ${ }^{28}$ Societies can no longer

24 Ibid., Citizenship and National Identity: Some Reflections on the Future of Europe, in R. Beiner (ed.), Theorizing Citizenship, Albany: University of New York Press, 1995.

25 See the declaration by J. Habermas, J. Derrida, After the War: The Rebirth of Europe, in Frankfurter Allgemeine Zeitung, 31 May 2003.

26 Beck, U., Cosmopolitan Vision, Cambridge: Polity Press, 2006.

27 Beck, U. and E. Grande, op. cit.

28 Ibid., p. 17. 
be conceived in exclusively territorial terms in which cosmopolite relations are reduced to mere international relations while the reality develops beyond borders in a framework of plural belongings.

In Power in the Global Age ${ }^{29}$ Beck explores the legitimacy of political authority under conditions of global interdependence. The major answer to a redefinition of concepts such as power, dominance and authority from a cosmopolitan perspective is to include globalisation in the analysis of politics, society and identity-building. Nationalism is about exclusive distinctions and loyalties; cosmopolitanism is about inclusive distinctions and loyalties, being citizens of the cosmos and the polis. It is therefore possible to develop meaningful affiliations without renouncing one's origins.

As previously stated, globalisation processes signal a rupture with past developments with profound internal and external consequences. In Cosmopolitan Vision ${ }^{30}$ Beck recognises the need to gear national (and regional) objectives towards global ends and acknowledges the global civil society as an advocatory movement that generates global values and norms with a self-legitimating power. He proposes a critical democratic cosmopolitanism achieved through reforms that include new transnational organisations and normative frameworks as well as remodelled multilateral institutions, the democratisation of human rights and enforcing of citizens' rights in the globalising context. According to Beck, the cosmopolitan state is both a political answer and a useful tool for managing political identities and ethnic fragmentation in the era of globalisation and pluralism.

Applied to the European context, Europe is then seen as a new kind of transnational, cosmopolitan, quasi-state structure, which draws its political strength precisely from the affirmation and management of diversities. In other words, he conceives Europe as a cosmopolitan state that cooperatively domesticates economic globalisation and guarantees the otherness of the others. In reality, this requires a political Europe that seeks to reconstitute its power at the intersection of global, national, regional and local systems of governance.

His new concept of cosmopolitan critical theory is placed in direct opposition to traditional nation-state politics. His political and sociological cosmopolitanism acknowledges the otherness of those who are culturally different, the otherness of the future and the otherness of nature. In that sense, cosmopolitanism shares some aspects of universalism, namely the globally acceptable notion of human dignity,

29 Beck, U., Power in the Global Age, Malden (Mass.): Polity Press, 2005.

30 Beck, U., Cosmopolitan Vision, op. cit. 
which must be protected and enshrined in international law. Thus, if we are to understand cosmopolitan Europe we must radically rethink the conventional categories of social and political analysis.

\section{Cosmopolite Europe}

\section{1) Content}

In Cosmopolitan Europe ${ }^{31}$ Ulrich Beck and Edgar Grande further elaborate the cosmopolitan vision in a global age, as it was presented in Beck's two previous books. They propose an analytical and political vision for rethinking Europe, based on the narrative of Europeanisation, defined as a permanent process of transformation which goes beyond the conceptual horizon of national societies and states. Beck calls Europe the last politically effective utopia, ${ }^{32}$ i.e. both an idea and a reality. Europe is neither a state nor a nation; hence it cannot be thought of in terms of the nation-state. Beck criticises the methodological nationalism practiced by social sciences in the usual national conceptual horizon, which neglects Europe's complex realities. As a consequence, a sociological cosmopolitanism ${ }^{33}$ is proposed, with a positive definition of Europe based on the "both/and" principle: expansion of power at the supranational level is not equated with loss of power at the lower level; rather the opposite holds, namely power as a whole increases and, as a consequence, nationality, transnationality and supranationality reinforce and complement each other.

A cosmopolitan Europe means simultaneously both difference and integration. It offers an alternative to the existing concepts of European integration, which either locate Europe above the states and combat national particularities as obstacles to European integration, or want to subordinate Europe to the nation-states and national interests. This also calls for expanding the concept of the public beyond its national borders and opening it up to an emerging European space. However, such cosmopolitanism also needs political mechanisms for institutionally producing and stabilising collective difference within given spaces. The novel concept of multi-level governance offers support for this cosmopolitan perspective.

The concept of multi-level governance, introduced by Gary Marks ${ }^{34}$ more than a decade ago, refers to "the existence of overlapping

\footnotetext{
Beck, U. and E. Grande, op. cit.

Ibid., p. 2.

Ibid., pp. 17-21.

34 Marks, G., Structural Policy and Multi-level Governance in the EC, in A. Cafruny and G. Rosenthal (eds.), The State of the European Community: The Maastricht Debate and Beyond, Boulder (Co.): Lynne Rienner, 1993, pp. 391-410.
} 
competencies among multiple levels of governments and the interaction of political actors across those levels". Its application to the practice of European governance suggests that the EU is considered a multilayered system of decision-making in dealing with complex societal problems where the institutional redistribution of competences is not based on a territorial dimension but on functional and issue related criteria. ${ }^{35}$

Following this line of thought, the idea of a cosmopolitan Europe is at once radically new and yet forms part of the continuity of European thought and politics. Beck defines Europe both as a social construct and an open political project, guided by vision and political principles as well as by the logic of side effects. ${ }^{36}$ The principle of cosmopolitanism offers a new perspective for understanding Europe and opens up new possibilities of social organisation and political participation, though not based on a homogeneous and uniform model of European demos or European polis, but characterised by an institutionalised process of permanent change instead.

This does not imply that Europe has to be completely reinvented. On the contrary, the European process of integration involved a cosmopolitan momentum from its beginning, in that it transcends the idea of the nation and transforms national sovereignty. Cosmopolitanism has been formalised in Europe by a step-by-step approach to the simultaneous institutionalisation of two seemingly competing and conflicting principles, i.e. supranationalism and inter-governmentalism. This process has proceeded in two directions: inwards, through constant extensions of the power of the EU and the resulting structural adaptations in the member states; and outwards, through the constant enlargements and the export of its norms and rules in the exercise of mainly soft power politics.

We agree with Beck's thesis that the process of Europeanisation has reached a critical threshold. ${ }^{37}$ Internally the EU has been confronted with intensifying criticism from its citizens for its lack of transparency, credibility and accountability. Externally there is much talk of the Balkanisation of Europe within the international political landscape. The real European crisis, as Beck argues, may be the inability to see the contradictory events as part of a common European undertaking. Both the internal and external contexts of European politics and governance are being fundamentally shaped by the opportunities and threats of

\footnotetext{
35 A short analysis of the concept is given by F. Delmartino, The Paradigm of Multilevel Governance, in Committee of the Regions, Towards a Multi-level Governance in Europe?, Cahiers of the CoR, Vol. 1, 2009, pp. 33-36.

36 Beck, U. and E. Grande, op. cit., p. 30.

37 Ibid., p. 4.
} 
globalisation. Under these conditions, the institutional reforms in the Treaty of Lisbon alone do not go far enough. Much more is called for to rethink Europe.

\section{2) Policy implications of a cosmopolite Europe}

What is European can be termed by forms of identity, ways of life, means of production and types of interaction that go beyond national or regional frontiers. It is about continuous border-crossing. Horizontal Europeanisation has taken place in all sectors of human life. Science, polity and economy are becoming globalised and Europeanised at the same time. This intertwining has various policy consequences and produce different lines of thought and action.

- The dismantling of national borders in Europe has an impact on the European dynamic of socio-economic inequalities. One thing is sure, the nation-based limits to people's perceptions of social inequality have slowly begun to dissolve as Europeanisation moves forward. The recognition of the importance of the social dimension for the European integration process has policy implications within and beyond European borders, in particular in relation to internal and external solidarity and a sense of belongingness.

- Europeanisation is initiating an historically new positive sum game: joint solutions serve the national interest. In some occasions and policies, the EU is better placed to solve problems than nations or regions could possibly be by acting alone. In other words, the EU is an arena where formal sovereignty can be exchanged for real power, cultures nurtured and economic success improved. A cosmopolitan Europe is first and foremost a Europe of difference and of recognised particularity. From a cosmopolitan perspective, this diversity (whether in languages, economic systems, political cultures, or forms of democracy) appears primarily as an inexhaustible source of Europe's cosmopolitan self-concept and not as an obstacle to integration. If we understand Europe's actual distress mainly as an inability to grasp and understand the historically new kind of reality that Europeanisation represents, different "both/and" policy alternatives may be envisaged.

- A third line of thought and action is that Europeanisation requires a collective memory culture that spans borders. Beck calls it a Europeanisation of perspective. A cosmopolitan approach to the opening up of communications, the acceptance of interdependence through inclusion of "the other" for the sake of common interests and to the management of cultural diversity, goes beyond tolerance or multiculturalism. It may lead to genuine intercultural dialogue and mutual learning, conceived as an enrichment of one's own integral human development. Such cosmopolitanism is intended to rest on 
cohesive and reciprocally binding norms, moving away from postmodern particularism and closer to Europe's true identity of an open, dynamic, diversified, multicultural and democratic entity.

- The fourth line is the understanding of European society as a regional world risk society. ${ }^{38}$ To avoid the danger caused by a European replica of methodological nationalism, Europeanisation should not be defined and analysed purely in endogenous terms, but in exogenous terms in relation to the frame of reference determined by world society. In this context, Becks refers to the theory of reflexive modernisation ${ }^{39}$ in which the experience and dynamics of modernity bears risks in the sense that along with its success modernity also contains negative consequences. This requires policy coordination and rule setting of both obstacles and opportunities in the European and global context.

- The fifth concluding line concerns the understanding and shaping of new forms of political authority that have emerged in Europe beyond the nation-state. The management of globalisation effects, specifically the problems related to the flows and crises of global finance and the neglected European dimension of current socio-political developments, requires a more courageous approach, in respect of the various levels and actors involved in the process.

\section{3) Cosmopolite Europe in a world risk society}

In the development of modern societies, Beck distinguishes a first and a second modernity and applies this distinction to the process of Europeanisation: the "either/or" model of society and politics of the first modernity is being replaced by the"both/and" model of society and politics of the second modernity. The relation between the two is conceived in inclusive, rather than in exclusive terms. Beck defines Europe as a society of societies, an "empire" composed of states and finally as a product of the secondary modernisation. ${ }^{40}$ The transition from first to second modernity is then perceived as a self-transformative meta-change. As such, Europeanisation is understood and analysed as part of a comprehensive process of reflexive social modernisation, a structural and epochal break in the development of modern societies, often as the result of the success of primary modernisation and internal dynamics.

In agreement with this line of argument, cosmopolite Europe cannot be reduced to a territorial expression of a "fortress" Europe, but is a

\footnotetext{
38 Beck, U., World at Risk, Cambridge: Polity Press, 2008.

39 Beck, U., A. Giddens and L. Scott, Reflexive Modernization: Politics, Tradition and Aesthetics in the Modern Social Order, Cambridge: Polity Press, 1994.

40 Beck, U. and E. Grande, op. cit., p. 53.
} 
component of the second modernity that is embedded in the world risk society. ${ }^{41}$ The conceptual link is clarified by the theory of reflexive modernisation, ${ }^{42}$ which is characterised by three constitutive elements, namely, the theorem of risk society, the theorem of forced individualisation and the theorem of multidimensional globalisation.

It is argued that the dynamics of reflexive modernisation poses numerous challenges for the nation-state. The nation-state as one of the basic institutions of the first modernity is being transformed by the emergence of a plurality of diverse new forms of transnational governance beyond the nation-state, but remains an integral component of the creation of post-national Europe. In other words, states become integrated in a variety of ways into new international regimes and organisations, new supra national institutions, new forms of regionalism, etc.

The result of this development is new complex systems of (global) governance and policy networks. In addition there is the increasing role of private actors in solving collective problems and providing public goods. ${ }^{43}$ The new basic institutions of the second modernity manifest themselves in these emerging transnational political regimes, of which Europe is at once the result and the driving force of this process. The theory highlights the fact that the different regions in the world are affected unequally not only by the consequences of failed processes of modernisation, but also by the consequences of successful processes of modernisation.

In this context, Beck refers to the interesting notion of a regime of side effects. ${ }^{44} \mathrm{He}$ argues that an inner globalisation of European societies has gradually and largely been taking hold through side effects independently of the political agenda, in the form of a self-propelling meta-change in European social, cultural and individual life worlds. Although the process of Europeanisation, i.e. "the realisation of an ever closer union of peoples of Europe" was intended as the result of the political decisions of the founding fathers, its institutional and material consequences were often unintended. This is well explained by the thesis of institutionalised cosmopolitanism. ${ }^{45}$

\footnotetext{
41 Ibid., pp.197-218.

42 Ibid., pp. 28-49.

43 Baudot, J., Building a World Community, Globalisation and the Common Good, Seattle-London: Royal Danish Ministry of Foreign Affairs Copenhagen and University of Washington Press, 2001; A. Héritier, Common Goods: Reinventing European Integration Governance, Lanham (MD): Rowman \& Littlefield, 2002.

44 Beck, U. and E. Grande, op. cit., pp. 35-40.

45 Ibid., pp. 19-20.
} 


\section{Cosmopolitan perspective of the European integration process: a European "empire"}

Reality is becoming cosmopolitan. As previously stated, de facto Europeanisation has already developed over the past fifty years. The real process of becoming cosmopolitan is taking place through secondary effects that are often undesired, unseen and usually occuring by default. Scholarly literature agrees that the EU is not a "state" or a "superstate" that has assimilated the sovereignty rights of the member states, nor is it a federal state with a clear division of powers, or a confederation, an international organisation or an international regime. In the context of recent research on Europe in political science, the EU has been defined a network, set of networks, network form of governance, a multi-level system, a multi-level system of governance or as a multi-level state. ${ }^{46}$

Ulrich Beck and Edgar Grande have proposed a redefinition of the term empire for an appropriate analysis of the political rule in Europe. ${ }^{47}$ It is argued that the cosmopolitisation of the state in Europe has created a new political system; they call it a post imperial empire. This European empire is not based on national demarcation and conquest, but on overcoming national borders, voluntarism, consensus, transnational interdependence and on the political added value accruing from cooperation.

The cosmopolitan empire of Europe is notable for its open and cooperative character at home and abroad. Its real power lies in the socio-economic model of a cooperative future and in its special form of soft world power. It is characterised by the following constitutive features: $:^{48}$ an asymmetrical political order subdivided into power zones according to the intensity of cooperation and the number of countries involved; an open variable spatial structure; a multinational societal structure; an integration through law; a consensus and cooperation behaviour; a welfare vs security objective; a horizontal and vertical institutional multi-level system of governance; a network power marked by non hierarchical forms of decision-making and participation of a large number of societal actors in integrated negotiating systems and political decision-making processes; a complex cosmopolitan (internal and external) sovereignty; an ambivalence of delimitation and limitation; and finally an emancipatory vs repressive cosmopolitanism.

The impact of a cosmopolitan perspective on European integration should be clear by now. For a long time, the key concept of the

\footnotetext{
46 Ibid., pp. 50-52 and pp. 69-70.

47 Ibid., pp. 50-92.

48 Ibid., pp. 62-72.
} 
integration process consisted primarily of the abolition of national and local differences. This policy confused unity with uniformity or assumed that uniformity is required for unity. In this sense, uniformity became the supreme regulatory principle of modern Europe. By contrast, cosmopolitan integration is based on a paradigm shift in which diversity is not the problem but rather the solution. Europe's further integration should therefore not be oriented to the traditional notions of uniformity inherent in a European federal state. On the contrary, integration should instead take Europe's inherent diversity as its starting point, in order to link the call for recognition of differences with the call for the integration of divergences. Understood as a historically tested political model for a post-imperial empire of consensus and law, Jeremy Rifkin's European Dream ${ }^{49}$ of a soft world power is a fascinating alternative of a forward-looking vision of a state structure firmly based on recognition of the culturally different other.

In this context, nationalist and regionalist ideas are unsuitable for unifying Europe. A large European super-state frightens people. Beck's cosmopolitan Europe offers the idea of uniting European citizens today because it quietens Europeans' fears of losing identity, makes interaction, dialogue and mutual learning tolerant among the many European nations, regions and peoples enshrined in the treaties and opens up new political spaces and options for action in a globalised world. However, the persistence of nations and regions remains an important condition of a cosmopolitan Europe. The more secure and confirmed Europeans feel in their national, regional and local dignity, the less they will shut themselves off in their territories and the more they will stand up for European values and take responsibility in the world.

\section{Conclusion}

By proposing multi-level governance structures and applying dialogue's frameworks and mutual learning for managing differences, a cosmopolitan perspective outlines a new post national model of democracy for Europe that no longer marginalises citizens but gives them an active role in European decision-making processes. ${ }^{50}$ Europe can be understood through the concept of cosmopolitanism because it fully reflects its nature, history and future possibilities. A cosmopolitan Europe guarantees the coexistence of different ethnic, religious and political forms of life across borders, based on the principle of cosmopolitan tolerance and dialogue. Throughout different eras of

\footnotetext{
49 Rifkin, J., The European Dream, Cambridge: Polity Press, 2004.

50 Mascia, M., Participatory Democracy for Global Governance, op. cit.
} 
European history, this concept has been transformed from an ethicalnormative ideal of community and open mindedness into the hybrid patterns of integration. In summary, cosmopolitanism is evolving from a categorical imperative and a rational project into a new modality of practice-oriented awareness. In this way, it acquires an empirical and analytical value inside a reality that seems to become structurally cosmopolitan. This allows a broad applied thinking about the democratic transformation of the EU and its role in view of the present and future challenges.

The cosmopolitan perspective also implies a fading of physical, mental and disciplinary borders. It is shaped by fluxes of capital, information and persons and by processes of spatial-temporal compression, de-territorialisation and de-nationalisation. The new fluxes go beyond traditional borders and refer to the concept of a network of interconnections. Cosmopolitanism becomes the possibility to recognise diversity as a constitutional element of multiple identities. At the practical level, this new consciousness determines the creation of a civilised confrontation sphere where identities are built in dialogue, in relation to a reality of (global) risks that requires collective solutions.

For many sociologists, the EU represents the result and the challenge of social transformation. It is said to be characterised by a flexible spatial structure, composed of vertical and horizontal links between models of sovereignty in a transformative interdependence. It presents an asymmetrical integrative order, based on a mixture of intergovernmental and supranational forms of cooperation, in which civil society is becoming a shaping actor and meeting place of social and political aggregations. This might lead to a new model of the supranational and transcend democracy which, of course, poses the problem of searching for new forms of management of politics and dialogue at various levels of the globalising landscape.

To think and act Europe along a cosmopolitan perspective means recognising the EU as a laboratory of plural democratic forms and analysing the European integration process as a dimension of cosmopolitisation and transformative cooperation. It is therefore necessary, on the one hand, to consider nation-states in relation to the transnationalisation of their interests and, on the other hand, to understand various forms of governance and dialogue within a context of risk interdependence. ${ }^{51}$ The EU is then conceived as a new space in which federalism, intergovernmentalism and neo functionalism are interconnected through a multi-level governance structure that opens up to a participative process and plurality of decision centres. Apparently,

51 Beck, U., Power in the Global Age, op. cit. 
the paradigm of multi-level governance contributes to the understanding of the complex political reality in the European and global context. ${ }^{52}$

Following this policy line, Europeanisation as cosmopolitisation is analysed in the discursive interaction between segmented publics, which favours integrative dynamics and transformative efficient solutions. In a transnational deliberative democracy, the form of multi-level governance emerges with the realisation of a public sphere that is open to the discursive process and diverging expressions. The legitimacy of subsequent political decisions comes then from the inclusion of knowledge, interests and actors at the various levels of the participative process.

This is not an easy discourse. ${ }^{53}$ The multiplicity of links and cultural perceptions stresses the premises of a valorial community. Europe should not only find its democratic form through the principle of responsibility in managing (global) risks, but should also apply the principle of reflexivity to the dynamics it puts to work. It is important that the recognition of universal rights remains the point of departure for democratic politics in multi-level and multi-actor governance.

Next to a societal reflection, a meta-reflexive person is also therefore needed to valorise the transformation of society in a European and global context. The capacity of transformation and realisation depends on the historical experience of the society as well as on the level of social practices of persons. The reflexivity of persons applies to memory, knowledge and action, and links the individual's prospects with that of society's. Therefore it is necessary to re-conquer a space of recognised and accepted differences, which is not limited to cultural relativism but favours a community of cultures and makes intercultural dialogue possible. The fundamental question relates to the objective of the integral human development of a person who is conscious of his/her universal rights. Europe should therefore present itself as an open public space, where institutional and non-institutional actors, formal and informal, meet, recognising their proper rights and obligations. Such a European perspective transforms demands and identity in a constructive way, but requires a respect of personal and collective identities and memories.

52 Examples of European multi-level governance are offered by European Commission, White Paper on European Governance, 25 July 2001, COM (2001), 428 (final); Committee of the Regions, Whiter Paper on Multi-level Governance, 17-18 June 2009, CoR 89/2009, final and Committee of the Regions, Towards Multi-level Governance in Europe?, op. cit.

53 Taglioli, A., Il volto cosmopolita dell'Europa, in Società Mutamento Politica, Vol. 1, no. 1, 2010, pp. 189-201. 
Cosmopolitanism is thus not an external credo or an ideological slogan of a normative and political universalism, but more an internal dimension of reflexive action, which stretches beyond a nostalgic defence of territorial sovereignty as well as beyond a utopia of universalistic centralism. Cosmopolitanism is mirrored in the diversified and similar history of Europe, a permanently changing multi-faceted Europe, situated at a crossroads between past, present and future. A cosmopolitan vision of the process of European integration may contribute to identifying and clarifying the conceptual and empirical characteristics of a multi-level governance of intercultural dialogue, bridging the gap between past and present contradictions in international democratic politics and strengthening the process of Europeanisation. 


\section{CHAPTER 7 \\ Global Public Goods and Human Development}

\section{Introduction}

We all increasingly live in one world, so that individuals, groups, nations and continents become interdependent in a so-called "global village". Various political, economic, cultural and social factors are shaping this process of globalisation, with drastic consequences on the human development relations between nations, peoples and persons. However, globalisation means different things to different people and its meaning has changed over time from mere technological progress and economic dynamism to a more mixed approach about pervasive and complex global policy challenges such as poverty, climate change, equity and justice, peace and security, etc. This is mainly due to the increasing importance of cross-border spill over from country to country and from countries to the global commons. Many of these global challenges and threats result from the under-provision of global public goods such as international financial stability, equity, health, environmental sustainability, respect for human rights, etc. This chapter explores the possibilities of applying the idea of public goods to human development, human security ${ }^{1}$ and human rights, ${ }^{2}$ seen from within a global context.

Not only is the list of common global policy challenges growing in current international relations, but many domestic policy objectives are increasingly beyond the reach of individual governments. The openness of today's global economy has changed the traditional scope of national sovereignty and is requiring increased international cooperation, multi-

For a very interesting discussion on the concept of human security as a global public good see Altvater, E., Public goods for human security, in Papeles del Este 14, 2007, p. 1-19; Des, G., The Idea of Human Security, Institute for Social Studies, The Hague, Garnett Working Paper, no 28, Jan. 2008, 36 p.; Grayson K.A., Human security in the global era, in Drache D. (ed.), The Market or the Public Domain? Global Governance and the Asymmetry of Power, New York: Routledge, 2001, p. 229-252; and Reich, S., Human Security as a global public goods, in The Courier $A C P-E U$, Dossier n ${ }^{\circ}$ 202, January-February-March 2004.

2 Andersen, E.A. and B. Lindsnaes, Towards New Global Strategies: Public Goods and Human Rights, Martinus Nijhof Publishers, 2007. The book presents a very timely and comprehensive publication on global public goods and human rights, seen as two mutually supporting concepts. 
level governance mechanisms and new policy tools to cope with the challenges of globalisation.

Globalisation is defined as a phenomenon and a process, which presents many faces, multiple voices and different interpretations with diversifying, often dramatic impacts on persons, cultures and societies. ${ }^{3}$ It cannot be reduced to a mere economic expression of growing interdependence and international agreements in an exclusively marketoriented and competitive environment. It is to be understood and analysed as a multidimensional phenomenon involving private and public domains of activity and interaction across borders and across continents, including the economic, political, socio-cultural, technological, ethical, environmental and personal domains. The UNDP has developed a Human Development Index (HDI), reflecting achievements in the most basic human capabilities (i.e. life expectancy, educational attainment and income), to measure the impact of globalisation on countries and peoples. ${ }^{4}$

Therefore our analysis of a global public goods approach to human development and human rights takes into account the core (systemic) features of globalisation, being spatial extension and compression, increasing interconnectedness, temporal acceleration and a growing awareness. ${ }^{5}$ The proposed global public goods approach recognises multiple locations of governance, multiple dimensions of integration, multiple modes of interaction and an increasing institutionalisation of the process of globalisation. It is argued that a vision and policy strategy based on global public goods may contribute to a better analysis of global policy challenges, including human development and may recommend strategies for true global policy-making.

In the first part of the chapter we redefine the concept of public goods and set it in a wider conceptual context. In the second part, this analysis is further applied to the case of global public goods. The final part deals with the policy relevance of global public goods in describing and analysing global challenges and policy responses.

From the very extensive literature on globalisation we mainly rely on following authors: Bauman, Z., Globalization: The Human Consequences, op. cit.; Beck, U., What is globalisation?, Cambridge: Polity Press, 2000. Giddens, A., Runaway World: How Globalization Is Reshaping Our Lives, op. cit.; and Stiglitz, J., Making Globalization Work, op. cit.

4 UNDP, Human Development Report 1999, available at http://hdr.undp.org/ reports/global 


\section{Conceptual Context: Rethinking the Definition of Public Goods}

In the first part of the chapter we explain the conceptual framework of our analysis. Following recent works on public goods theory an expanded and more realistic notion of public goods is suggested. The second section presents a brief policy assessment concerning this conceptual shift.

\section{A widened concept of public good}

Although the literature on public goods is extensive and diverse, there is a standard definition of public goods based on Samuelson's conditions of non-rivalry and non-excludability. ${ }^{6}$ Figure 1 presents the traditional approach to public goods. In the literature, goods with rival and excludable benefits are often automatically defined private goods (Quadrant 1). Goods that are non-rival and non-excludable in consumption, possibly supplied in variable quantities, are often called pure public goods (Quadrant 4).

In reality, however, the properties of goods do not always correspond to this standard definition. The main reason is that society can modify the (non) rivalry and (non) excludability of a goods' benefits. Goods often become private or public as a result of deliberate policy choices. That is why Kaul and Mendoza ${ }^{7}$ propose an expansion of the definition: they recognise that in many if not most cases, goods exist not in their original forms but as social constructs, largely determined by policies and other collective human actions. According to this revised definition, public goods are non-exclusive or, put differently, de facto public in consumption. The expanded concept of public good is illustrated in Figure 2.

Samuelson (1954).

7 Kaul, I. and R. Mendoza, Advancing the Concept of Global Public Goods, in Kaul, I., P. Conceição, K. Le Goulven and R. Mendoza (eds.), Providing Global Public Goods: Managing Globalization, New York: Oxford University Press, 2003, p. 78111. 
Figure 1. The basic properties of goods

\begin{tabular}{|c|c|c|}
\hline & RIVAL & NON-RIVAL \\
\hline $\begin{array}{l}\text { E } \\
\text { X } \\
\text { C } \\
\text { L } \\
\text { U } \\
\text { D } \\
\text { A } \\
\text { B } \\
\text { L } \\
\text { E }\end{array}$ & $\begin{array}{l}\text { QUADRANT 1 } \\
\text { Private goods } \\
\text { Examples } \\
\text { - Milk } \\
\text { - Land } \\
\text { - Education }\end{array}$ & $\begin{array}{l}\text { Examples: } \\
\text { - Research and development } \\
\text { - Non-commercial knowledge } \\
\text { - Norms and standards } \\
\text { - Property rights regimes } \\
\text { - Respect for human rights } \\
\text { - Television signals }\end{array}$ \\
\hline $\begin{array}{l}\mathrm{N} \\
\mathrm{O} \\
\mathrm{N} \\
- \\
\mathrm{E} \\
\mathrm{X} \\
\mathrm{C} \\
\mathrm{L} \\
\mathrm{U} \\
\mathrm{D} \\
\mathrm{A} \\
\mathrm{B} \\
\mathrm{L} \\
\mathrm{E}\end{array}$ & $\begin{array}{l}\text { Examples } \\
\text { - Atmosphere } \\
\text { - Wildlife }\end{array}$ & 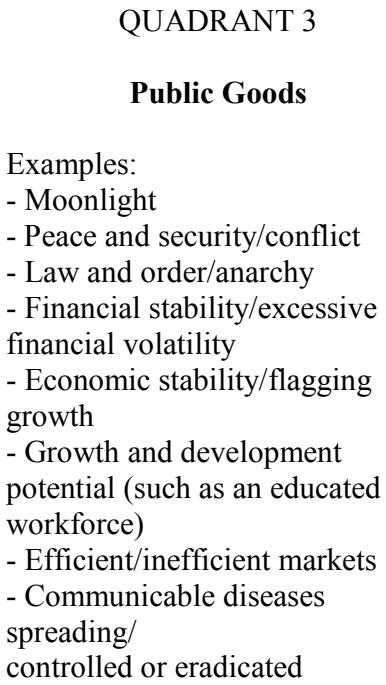 \\
\hline
\end{tabular}

Source: Kaul and Mendoza (2003), p. 82. 
Figure 2. The socially determined status of goods

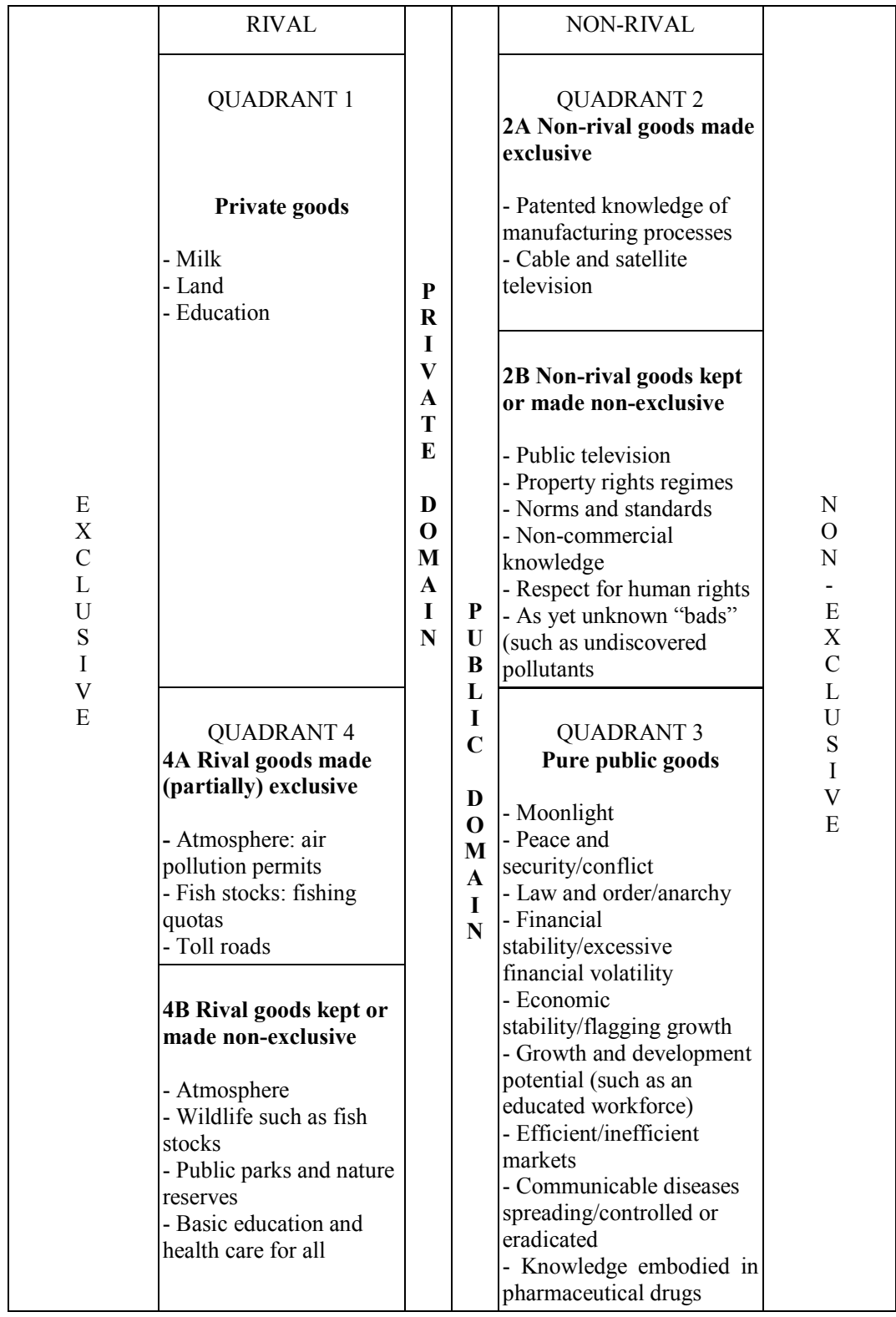

Source: Kaul and Mendoza (2003), p. 83. 
This enlarged definition requires some further explanation. Society can choose to make non-rival goods more public (non-exclusive) by policy design (quadrant 2B). In some cases it may even be compulsory to consume such goods. For example, people are usually required to respect property rights. Similarly, growing policy attention is being paid to encouraging respect for human rights, including gender equality. Still, many countries have some way to go in making respect for human rights fully non-exclusive, ensured for all groups. In other cases (e.g. universalising technical norms and standards, certain traffic rules, etc.) results have been much easier to achieve.

Rival goods can also be kept or made non-exclusive (quadrant 4B). Public parks and nature reserves are examples. Another is to make rival goods available in such plentiful quantities that there need not be any competition over who gets to use them. Many societies have chosen this policy route for basic education and health services. This approach is usually taken for two reasons. First, goods such as education and health are often seen as human rights and as having intrinsic value. Second, an educated and healthy population generates important private and public benefits. Educated people tend to be more productive and to contribute more to economic growth and development. Thus many countries have made basic education not just free and universal but compulsory as well.

The goods in quadrant 3 are technically non-excludable and therefore exist de facto in a non-exclusive form. The main goods are policy outcomes or overall conditions such as peace, law and order, financial stability, efficient markets, and communicable disease control and eradication. Once these conditions exist, all people can - and sometimes must - consume them. The goods' benefits are indivisible, so they exist for all in the same amount and with the same characteristics. These goods are often more evident when undersupplied. For example, conflict is more noticeable than peace, which is often taken for granted.

Some policy consequences are connected to this redefined concept of goods. It often takes a long time and a lot of effort to anchor a good firmly in the public domain. This is for example the case with equity or respect for human rights. Similarly, it often takes a policy decision to make a good private. And it takes an elaborate institutional and organisational framework to define, assign, and monitor private property rights, and update and enforce them. In short, societal norms and decisions of what is and is not private often reach deeply into what many perceive as the private sphere of people's lives. On a much broader level, state borders can no longer be used as shields behind which to curtail human rights, practice corruption, cause air pollution, etc. 


\section{A policy assessment}

The previous section has suggested a rethinking of the main notions underpinning the theory of public goods. First, it has shown that properties of (non) rivalry in consumption and (non) excludability of benefits do not automatically determine whether a good is public or private. "Public" and "private" are in many - perhaps most - cases, a matter of policy choice: a social construct. Some goods lend themselves more easily to being either public or private. Nevertheless, it is important to distinguish between a good having the potential of being public (i.e. having non-rival and non-excludable properties) and being de facto public (non-exclusive and available for all to consume). Second, public goods do not necessarily have to be provided by the state. All actors can, and increasingly do, contribute to their provision. And third, a growing number of public goods are no longer just national in scope, having assumed cross-border dimensions. Many have become global and require international cooperation to be adequately provided.

Rethinking the concept of public goods along these lines has a number of implications for the theory of public goods and opens up an important new research agenda. This includes the question of how in various cases publicness in consumption is matched with publicness in decision-making and with equity in the distribution of a goods' benefits. Kaul and Mendoza call that the triangle of publicness. ${ }^{8}$ Furthermore, recognising the provision of public goods as a multi-actor activity calls for a reconsideration of the current concept of optimal provision as well as for a renewed analysis of the provision process of public goods.

The standard definition of public goods has illuminated many important issues in the provision of such goods, including free riding and the prisoner's dilemma. But that definition does not fully capture the policy approach needed when dealing with the novel nature of many of these goods. As a result, many public goods are still analysed in an almost passive manner. Too often it is assumed that a non-rival and nonexcludable good must be public or that a rival and excludable good must be private and is best left to the market. That approach ignores the changing context and the new realities caused by increasing globalisation. Before goods appear in the market or are part of state competences, policy choices have been made or norms established to make the goods private in the sense of being exclusive, or public in the sense of being non-exclusive.

The excludability or non-excludability of goods often facilitates or hampers such public policy choices. In any event, the defining

$8 \quad$ Kaul and Mendoza (2003), p. 92. 
characteristics of many public goods are not inherent and are often socially endogenous. Public goods are therefore goods that are in the public domain: they are there for all to consume. Goods are in the public domain because: they cannot be made excludable (i.e. benefits cannot be withheld from the public), because doing so would be too expensive or technically impossible (the sun rays); they have been made public by design (e.g. a country's justice system, street signs, basic education for all); and finally; they are public by default, due to policy neglect (e.g. air pollution, crime and violence) or due to lack of relevant information (e.g. on food security). However, in most instances it is a matter of policy choice whether and to what extent goods have either public or private properties. In summary, the expanded definition of a public good can be formulated in a two-tier way: 1) goods have a special potential for being public if they have non-excludable benefits, non-rival benefits or both; and 2) goods are de facto public if they are non-exclusive and available for all to consume.

A further policy consequence of public goods is that they are not only public in consumption, but often also public in provision. Their supply may depend on collective action, i.e. cooperation among a number of individual actors. Different reasons can be given for such joint action: the provision of the good may require concerted action by all (e.g. all have to stop smoking in order to achieve a smoke-free environment), necessitating some sort of voluntary agreement, an enforceable form of regulation or the provision of financial incentives (e.g. subsidies or taxes) to encourage private actors to align their private interests with those of society; or no one person may be interested in providing services (such as birth or death registration) that offers few, if any, readily appropriable private benefits, making tax collection or another form of burden-sharing necessary to finance its state provision in the longer-term interest of all; or finally, no one person can enjoy the legitimacy to play a particular role (e.g. dispensing justice), so that again state provision and joint financing is called for.

Thus, the state often plays an important role in the supply of public goods by fostering collective action. However, private initiative and markets are also important. In recent years, more and more public goods are being provided through public-private partnerships of different types. Clearly, the balance between private goods and public goods cannot be equated with that between markets and states. Private goods can be provided through the state; and firms and markets can play a major role in public goods provision, in particular where both markets and state institutions are well developed. 


\section{The Case of Global Public Goods}

So far, public goods have been discussed without specifying the geographic or jurisdictional reach of their benefits, i.e. local, national, regional, or global. The second part of this chapter focuses on global public goods. ${ }^{9}$ We explore whether and to what extent the concept of global public good is useful in describing and analysing global challenges such as human development, human security and human rights. In the current process of globalisation, the public domain has been expanded and a diversity of actors at various levels of decisionmaking are now active on the international scene, being the state, civil society, business and households.

Global public goods are in a dual sense public: they are public as opposed to private; and they are global as opposed to national. An interesting issue is the extent to which some goods are global naturally and others have become global by policy choice. For example, capital controls or trade barriers are often being removed based on governmental and/or intergovernmental decisions. Or, greenhouse gases must not rise and burden the atmosphere to the extent they do. In the process of globalisation two main findings have emerged: first, globalised national public goods are an important class of global public goods and secondly global public goods require and create commonality in a world of extreme disparities.

\section{Understanding global public goods: definitions and typologies}

The discussion here builds on the definition of global public goods proposed by Kaul, Grunberg and Stern: ${ }^{10}$ Global public goods are goods whose benefits extend to all countries, people, and generations. Goods can be potentially public as well as potentially global. That is, many goods can be made public or global (or both) through human actions or public policies (or both). Global public goods are nothing new. Many,

9 For relevant studies on global public goods see, among others, Andersen, E.A. and Lindsnaes, B., Towards New Global Strategies, op. cit.; Ferroni, M. and A. Mody (eds.), International Public Goods: Incentives, Measurement, and Financing, Washington, D.C.: Kluwer Academic Publishers and World Bank, 2002; Kaul, I., I. Grunberg and M. Stern (eds.), Global Public Goods: International Cooperation in the 21st Century, New York: Oxford University Press, 1999; Kaul, I.,. P. Conceição, K. Le Goulven and R. Mendoza (eds.), Providing Global Public Goods: Managing Globalization, New York: Oxford University Press, 2003; Kaul, I., Global Public Goods: A Key To Achieving The Millennium Development Goals, Office of Development Studies, UNDP, January 2005; Stiglitz, J., The Theory of International Public Goods and the Architecture of International Organizations, Helsinki: United Nations University and World Institute for Development Economics Research, 1995.

Kaul, Grunberg and Stern, op. cit. 
notably the global natural commons, predate human activity. They include the atmosphere, the geostationary orbit, the electromagnetic spectrum, and the high seas. And as long as human beings have existed, there have been externalities.

With the running process of globalisation the volume of externalities and intentionally created goods of global reach has been growing exponentially: new technologies increasingly enhance human mobility as well as movement of goods, services, and information around the world; economic and political openness has stimulated cross-border and transnational activity; systemic risks, including global climate change; integrated financial markets, environmental degradation and poverty eradication require collective action on an international level, etc.

In other words, growing socio-economic inequities call into question the legitimacy of the global system. International regimes are becoming more influential, although often formulated by small groups of powerful nations yet often claiming universal applicability. Nations and groups see their public domains become interlocked and their living conditions become interdependent. The current global financial crisis well illustrates the domino effect of global risks. Lax food safety standards in one area can create health problems in many distant places through international travel or trade. And new global public platforms, such as the Internet, blunt many conventional public policy tools, including those for controlling such public "bads" as tax evasion, money laundering, drug trafficking, commercial fraud, and child abuse. The public and policymakers all over the world increasingly find that public goods they would prefer to have locally - or for "bads" not to have cannot be produced solely through domestic action. As a consequence, a growing number of national public goods have gone global.

Figure 3 classifies global public goods primarily according to their human-made (social) properties. As already said in part 1 of this paper, various goods have moved or are moving within or across quadrants. These changes in status show that global public goods are public because they are not private and global because they are not national. However, the impact of globalisation trends in economics, politics, social and cultural affairs makes international collective decisions on whether and to what extent to make certain goods public or private, more than necessary. Still, agreeing on policies at the global level can be difficult, as indicated by the discussions of the World Trade Organisation's agreement on Trade-Related Aspects of Intellectual Property Rights (TRIPS) or the debate on climate changes in the Copenhagen Conference.

This mixture of national goods and global public goods implies policy action at the international and global level. The goods in 
quadrants 2 and 4 of Figure 3 require harmonisation of national policies. Policy harmonisation is often intended to encourage countries to internalise cross-border externalities, i.e. to help generate positive ones and to reduce negative ones. Several goods in quadrant $2 \mathrm{~B}$ involve such efforts. Efforts to increase the inclusiveness of such goods as international communication and transport systems are aimed at improving the worldwide availability of network externalities. The same intention usually drives initiatives to increase adherence to norms and standards, including respect for human rights. Most of the goods in quadrant $2 \mathrm{~B}$ involve transnational policies that aim at providing global benefits. By contrast, many of the goods in quadrant 4 involve the internalisation of negative cross-border externalities. The promotion of basic human rights, shown in quadrant $2 \mathrm{~B}$, is an example.

Quadrant 4A lists goods that require policy responses that involve defining and assigning new (national) property rights, such as national pollution allowances or the exclusive economic zones created by the 1982 UN Convention on the Law of the Sea. Quadrant 4B includes goods involving measures similar to those in the national context; they are aimed at making certain crucial goods, such as basic education, health care, eradication from poverty, universally available. Moral and ethical concerns often motivate the international community to undertake such measures.

A further policy message relates to the pure public goods listed in quadrant 3. Many of the goods in this quadrant are the same as those in Figures 1 and 2. As national borders become open and cross-border economic activity increases, these goods become indivisible across borders, or transnational. In other words, all nations face the same international economic conditions, the same conditions in international financial markets and the same risk of global climate change. In the case of environmental sustainability, fundamental changes are needed in global provision and consumption patterns to avoid irreversible environmental damage, and hence require global governance action. 
Figure 3.

The de facto mix of national goods and global public goods

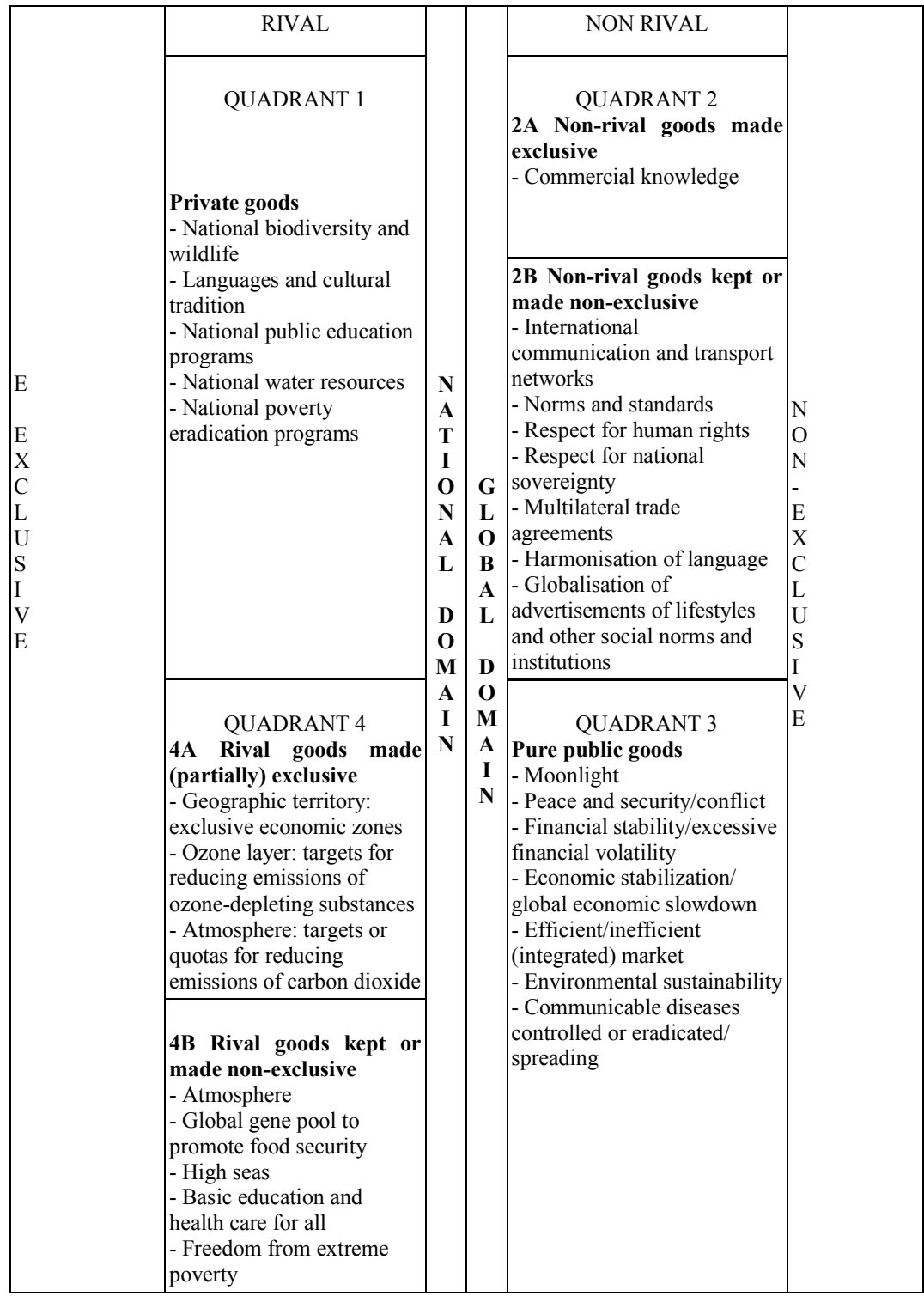

Source: Kaul and Mendoza (2003), p. 98

The considerations in Figure 3 make it possible to develop a typology of global public goods (Table 1). This typology differentiates 
between goods based on the nature of their benefits and the degree of their publicness. By examining global public goods through the triangle of publicness (i.e. public dimension of consumption, decision-making and distribution of benefits) Kaul and others ${ }^{11}$ have shed new light on some of the political tensions accompanying globalisation. For example, in the case of multilateral trade regime, the distribution of benefits is not completely public, but consumption and formal decision-making are. Or in the case of the international financial architecture, distribution of benefits and decision-making are not completely public but consumption is. These cases show that understanding the nature of the publicness of global public goods requires assessing globalisation not just for cross-border private economic activity but also for what is happening to goods in the public domain.

Table 1

A typology of global public goods by the nature of their publicness

\begin{abstract}
Class of good
Global natural commons

(e.g. the atmosphere or the high seas)

\section{Global human-made} commons

(e.g. global networks, international regimes, norms, and knowledge)
\end{abstract}

\section{Nature of publicness}

Free (managed) access: In their original state these goods are typically rival and non-excludable. Some global natural commons (e.g. the ozone layer) have taken on the social form of a managed access resource. They are usually still available for all to consume, though sometimes only in limited measure.

Free access: Non-commercial knowledge, for example, is often accessible to all. It is non-rival and difficult to exclude. It typically has limited (if any) commercial value but can be important to people's daily lives or to economic and political governance.

Limited access: Patented knowledge, for example, may be in the public domain but its use is restricted, at least for a period. The rationale is that

11 Kaul, I., P. Conceição, K. Le Goulven and R. Mendoza, (2003), op. cit. 
providing incentives to private producers of knowledge will enhance the economy's growth and its dynamic efficiency.

Inclusiveness being promoted: Many efforts are under way to enhance the inclusiveness of goods with network characteristics and whose expansion promises "additional user" benefits or positive network externalities.

Examples include international regimes (multilateral trade regime, Universal Declaration of Human Rights), global communication and transport systems, and informal norms. Efforts to increase the inclusiveness of these goods will widen the range of users, globalising the benefits and costs. Globalisation of public goods includes both top-down (from international to national) and bottomup efforts.

\section{Global policy outcomes/} conditions

(e.g. global peace, financial stability and environmental sustainability)
Universalisation of essentially private goods:

Examples include (global (national and international) efforts aimed at "for all" goals: basic education, health care, and food security.

Indivisibility of benefits and costs: Goods in this category have indivisible benefits that form the core of the interdependencies among countries and people. These goods tend to be technically non-excludable and so de facto inclusive and public.

Source: Kaul and Mendoza (2003), p.100.

An important conclusion from this expanded understanding of global public goods is the recognition of a new class of global public goods, which have been called "global policy outcomes". Kaul argues that the emergence and growing importance of these goods requires that international cooperation moves from dealing just with between or at- 
the-border issues to also managing a growing number of issues of behind-the-border convergence in national public policy. This requires a strengthened role of the UN in better managing the provision of global public goods. ${ }^{12}$ It presents a selective but very useful typology of global concerns as global public goods. ${ }^{13}$

Such a public goods typology has consequences for collective action. International cooperation seems essential for global policy outcomes or conditions. For global human-made commons, the international community has more flexibility in pursuing international cooperation. In addition, international cooperation can often take the form of more concerted national policy action to supply human-made global public goods. Yet for global policy outcomes or conditions and the shaping of their indivisible benefits there is often a need for truly common action at the global level.

\section{Provision of global public goods: politics and provision}

If so many global public goods are human-made, key questions need to be asked to determine how well the three dimensions of publicness are met for global public goods. That global public goods are largely national public goods that have gone global has important implications for the social aggregation strategies used to provide them.

\section{1) Politics}

Although the world is globalising, states still exhibit many political, economic, social and cultural differences. The impact of the systemic features of the globalisation process on peoples' developments varies very much from country to country as to scope, pace, timing and intensity of the global public goods. The question is whether the global scope of these goods' benefits and costs has been accompanied by a corresponding publicness in national and international policymaking. This question is urgent because publicness in consumption is often a requirement, not an option.

A stronger voice for the provision of global public goods, such as human development, human security and human rights, is often sought in the interest of democracy and pluralism. When international cooperation is required to curtail costly, inefficient global public "bads", an effective voice for all is also critical. This is particularly evident in cases where international institutions are assigned to implement

\footnotetext{
12 Kaul, I., The Changing Role of the United Nations: lessons for multi-level governance, in H. Enderlein, S. Wälts and M. Zürn, Handbook on Multi-level Governance, Cheltenham, UK: Edward Elgar, 2010, p. 323-342.

13 Kaul, I., I. Grunberg and M. Stern (1999), op. cit., p. 454.
} 
international standards to promote certain public goods (such as international security and international financial stability), often resulting in incursions on domestic policymaking and lawmaking. The legitimacy of such interventions depends on more participatory decision-making. Hence it is important to assess the main global public goods, notably those involving high interdependence, against the ideal triangle of publicness. Here an important role is set for global civil societies, which might serve as global consciousness.

\section{2) Provision}

Few global public goods are "readymade". Even the natural global commons often require international management regimes for their sustainable use. Most global public goods follow a complex, multidimensional, multilayered and multi-actor provision path of cooperation. Notwithstanding the importance of international cooperation, the issue of subsidiarity needs to be raised in view of choosing national policy harmonisation or joint provision at the international level. There is a diversified vision and a differentiated impact of globalisation across the globe on countries' and people's visions and conditions. ${ }^{14}$ As a consequence, increasing the provision of a global public good often requires a community of shared values and a respect for diversity. Therefore policy pluralism should be more acceptable than the centralisation and standardisation of policy making, conditioned to debate on the best approach to providing certain goods. However, policy pluralism increases the transaction costs involved in providing global public goods because it may entail more management support, monitoring, and reporting. In summary, given the complexity of providing global public goods, there is no easy or standard formula for ensuring their adequate provision.

As argued in the case for public goods provision on a national scale, similarly on the global scale the actors most likely to ensure that the process moves beyond narrow national self-interests are no longer only governments, because they are territorially bound. Actors include more and more transnational businesses, civil society organisations, and members of the public. As $\operatorname{Sen}^{15}$ points out, these actors often pursue interests and concerns independent of their nationalities. The growing de-territorialisation of national public goods makes concerted public goods provision on the international level (or global policy-making) a policy priority in the global era.

\footnotetext{
14 ILO, A fair globalization: creating opportunities for all, World Commission on the Social Dimension of Globalization, February 2004, p. 1-128.

15 Sen, A., Development as Freedom, Oxford: Oxford University Press, 1999.
} 


\section{A policy assessment}

The issues mentioned in our first part are even more urgent at the international level, particularly when one considers international cooperation in support of global public goods. The reasons are that at the international level there is no real equivalent to the institution of the state and that the global public has far more diverse interests and preferences than any national public. Furthermore, many people indeed, entire countries - often find themselves in "no exit" situations. Under these conditions, a decision-making and provision process for global public goods that is more participatory and "bottom up" is perhaps most ideal. Therefore, the debate on global public goods cannot simply build on the existing theory of public goods. It should be updated to reflect current realities following the suggestions of Kaul and others.

Global public goods provision is today more than ever a matter of policy choice. First, few global public goods are global and public by nature. The ozone layer is one of these few naturally global and public goods. Most other global public goods are national public goods that have become interlinked in the wake of increasing openness of borders and as a result of increasing international regime formation and policy harmonisation behind national borders. In summary, the wellbeing of people within the globalising context depends on private goods and public goods. Together, the available public goods create an enabling framework for economic growth as well as for human development.

Secondly it is argued that, in the wake of global trends and threats, the importance of global public goods has grown. Significant advances have been achieved in terms of openness of national borders and behindthe-border policy harmonisation. Coupled with progress in transportation and communication technologies as well as enhanced political openness, these trends have not only encouraged a high volume of transborder economic activities but they have also led to an interlocking of national public domains. The result has been the globalisation of a growing number of public goods. Financial stability, public health, the control of crime and violence, including terrorism, or food safety, are examples.

Thirdly, some global public goods remain today severely underprovided, such as international financial architecture or the international regime for knowledge management, and others are ill shaped, such as some dimensions of the multilateral trade regime. Still, the provision of global public goods has become crucial in the management of international relations and the survival of our planet. Many public goods can today no longer be adequately provided for national or local consumption through domestic policy actions alone. 
These goods now require international cooperation as an integral part of their provision path. ${ }^{16}$

\section{Policy Options and Strategies}

The third part of the chapter deals with feasible policy options and strategies that would guarantee a more reliable supply of global public goods from market efficiency to equity, health, environmental sustainability and peace. Without these global goods, genuine human development will be elusive.

\section{Global public goods and development: current trends and patterns}

The response of the international community to the rising importance of cross-border issues and activities has so far been primarily to forge a rapidly rising number of international regimes. However, these regimes have two critical shortcomings: they are often still incomplete, leaving important dimensions unsettled; and they more reflect the interests and concerns of the richer countries than those of the poorer. This is certainly true for the existing multilateral trade regime, the present international arrangements for knowledge management, the international financial architecture and the international arrangements for managing the natural global commons.

In today's complex reality, the international community is confronted with an expanded agenda of international cooperation. And even in the more conventional areas, such as peace and security, it faces new challenges, such as the problem of ethnic tensions, regional conflicts within nations, respect for human rights, etc. These challenges require new policy approaches but also new, additional resources for international cooperation. So far, the world has been rather hesitant to recognise this fact, despite the urgency of the matter. Often large sums of money are being spent on controlling the ill effects of the underprovision of certain global public goods. A plea can be made for better international governance capacities and patterns to provide some of today's global public goods. Moreover the international community at present lacks an effective forum for participatory global priority setting and policy oversight. Issues are mostly being addressed on an issue-by-issue basis, ignoring the various preferences for public goods in the global public domain.

Although the literature on global public goods points to many weaknesses, it also provides encouraging and constructive policy

16 See http://www.globalpublicgoods.org 
messages. Analyses suggest that it is desirable and feasible to correct many current problems. In particular, four main ways of improving the provision of global public goods and making globalisation more manageable are proposed. These are: refining the conceptual framework of the public goods approach to better reflect current realities in public goods provision; promoting collaboration between stakeholders and decision-makers to favour participation in global public goods debates; systematising the financing of global public goods to guarantee adequate private and public resources for these goods; and bridging borders, sectors, and groups of actors to foster institutional interaction and create space for strategic issue management.

\section{Global public goods and policy-making: policy options}

The analyses confirm that the reform of public policy-making is a key factor to managing globalisation better. In many global issue areas, countries increasingly find cooperation necessary to achieve national goals. Indeed, the fate of many nations has become increasingly intertwined, transforming what were once national policy issues into regional issues and regional issues into global ones. As issues such as financial stability, human development, peace and security bring nations into a shared fate, they should also bring them together in appropriately global public policy-making.

In order to identify policy options for global public goods provision three categories can be distinguished: global public goods can be overused, underused and undersupplied. The atmosphere and ozone layer are two overused global public goods. Information and knowledge are in adequate supply, but are underused. Peace, health, financial stability, human development and equity are all undersupplied. Kaul and others ${ }^{17}$ identify three major weaknesses in international cooperation that undermine the provision of the redefined concept of global public goods: a jurisdictional gap (i.e. the discrepancy between a globalised world and national, separate units of policy-making, i.e. the divide between foreign and domestic affairs); a participation gap (i.e. the gap between traditional intergovernmental cooperation and the emergence of new global actors, i.e. civil society and the private sector); and an incentive gap (i.e. the difference between various types of agreements and possible policy options). All three impede international cooperation and cause the under-provision of global public goods.

They argue that closing the three identified policy gaps requires a review of the fundamental principles of policy making in order to move beyond mere crisis prevention and management. A new approach is

17 Kaul and others (1999). 
therefore required, which recognises that the dividing line between internal and external affairs has become blurred with globalisation. Some policy options are recommended. As to the closing of the jurisdictional gap it is suggested that governments should assume full responsibility for the cross-border effects their citizens generate. In other words, the principle of "internalising externalities" should be applied to international spill over. This would strengthen the capacity of states to cope with global interdependence. National policy must therefore be closely linked to international cooperation. This can be done through strengthening regional cooperation, establishing national externality profiles and facilitating externality exchanges. The sharing of responsibility is important for the provision of global public goods across local, regional, national and global levels. This calls for actual multi-level governance. ${ }^{18}$

The closing of the participation gap concerns the horizontal distribution of opportunities among various actors, i.e. governments, people, civil society and business, to contribute to the provision, consumption and priority setting of public goods. Effective cooperation requires the equitable representation of all affected parties to obtain a fair provision of global public goods. Fairness and legitimacy can be built into the process by creating tripartite forums including governments, civil society and business that foster global multi-actor governance in international organisations. The world is already moving towards the fuller involvement of civil society and business in intergovernmental processes and international organisations. Still a more systematic approach to the representation of civil society and business in intergovernmental forums is urgently needed. In summary, enhancing participation in the decision-making, the provision and consumption of global public goods is critical to ensuring equity in international policy-making. Of particular importance is the building of new mechanisms to close the incentive gap by helping states to internalise the externalities they produce.

18 Marks, G., Structural policy and Multi-level governance in the EC, in A. Cafruny and G. Rosenthal (ed.), The State of the European Community: The Maastricht Debate and Beyond, Boulder, 1993, p. 391-411; Hooghe, L. and G.Marks, Unraveling the Central State, but how? Types of Multi-Level Governance, in Political Sciences Series 87, Institute for Advanced Studies, Vienna, Austria, March 2003; H. Enderlein, S. Wälts and M. Zürn, Handbook on Multi-level Governance, Cheltenham, UK: Edward Elgar, 2010. 


\section{Global public goods and the Millennium Development Goals (MDGs)}

In this perspective, the MDGs are an ambitious, international initiative. Their attainment calls for the focusing of our efforts and the using of available resources as efficiently as possible. This requires an adequate mix of national goods and global public goods as well as a fair structure of the public domain that offers human development opportunities to all (See Figure 3). However, as previously stated, some global public goods are either severely underprovided or badly provided, with distorted results on the global scene. The under-provision of global public goods is not an abstract problem. The security of states, the prosperity of economies, human development and the health of people and the planet all depend on the effective supply of global public goods. Enhancing the provision of these goods could be a decisive, costeffective and politically attractive step towards meeting the MDGs.

Global public goods whose provision is critical to the realisation of the MDGs are: preventing the emergence and spread of infectious disease; tackling climate change; establishing international financial stability; developing a fair and just international trading system; achieving peace and security; and the generation and dissemination of knowledge. Clearly, there is ample scope for reshaping and complementing the present international regimes in order to better align them with the intentions of the MDGs and avoiding a zero-sum game. Various incentives to initiate corrective action have been proposed.

Global and international inequity has assumed increasingly explosive dimensions. The MDGs themselves are an expression of the fact that the world now realises that the current policy course is in many respects unsustainable and needs correction. This is not only because extreme poverty is perceived as unethical or immoral but because it generates direct externalities such as the risk of failing states, exacerbated political turmoil and conflict, the spread of communicable diseases, or the interruption of commerce and investment flows. Although all nations and many actors would benefit from achieving the MDGs, the problem of freeriding, or at least easyriding, in the needed collective action and their financing is very present. In fact, enhancing the provision of the global public goods could have important redistributive effects and significantly improve economic growth and human development prospects. It certainly would be an important step towards the realisation of the MDGs.

Against this background, the Office of Development Studies has proposed a number of specific policy options to enhance the current 
provision status of some global public goods. ${ }^{19}$ Among the priority actions to be considered are the following: eliminating agricultural price and trade distortion in industrial countries; creating an independent Advisory Council for efficient knowledge management; streamlining and complementing the current international financial structure; differentiating systematically between the various international cooperation agendas, devising an efficient and fair international system to address global environment challenges; creating a body within the context of the United Nations to reflect on global trends and to suggest a balancing of global priorities; and strengthening the voice and negotiating capacity of developing countries. Many of the suggested corrective steps are of a regulatory, non-financial type: they would not require high investments; in fact, they would be relatively low-cost. It is said that such a rechannelling of resources might be more politically feasible than a direct transferring of resources.

An examination of the MDGs through the lens of a public goods approach reflects the embeddedness of the goals in the Millennium Declaration. It shows the links between peace, the environment, trade and finance, governance and human development. Ultimately, it is only through policy coherence across these various issue areas, nationally and internationally, that the development aspirations of the international community can be realised: attainment of the MDGs within the context of participatory, sustainable development, as well as peace and security for all. Achieving human development and human security requires both building on and going beyond the MDGs, by undertaking efforts to address the full range of critical and pervasive threats facing people.

\section{Conclusion}

This chapter explored the possibilities of applying the widened concept of public goods to human development, human security and human rights. It takes into account the globalising reality and the inherent global challenges. Global policy challenges are growing in current international relations and many domestic policy issues cannot be solved by individual states. This has changed the traditional scope of national sovereignty and requires more international cooperation, multilevel governance mechanisms and new policy tools. We argued that a global public goods approach contributes to a better analysis of global policy challenges, including human development, and may recommend strategies for true global policy-making.

\footnotetext{
19 Office of Development Studies, Global Public Goods: A Key to Achieving the Millennium Development Goals, New York, October 2003, 19 p.
} 
The expanded definition of public goods (i.e. public goods have a special potential for being public if they have non-excludable benefits, non-rival benefits or both; goods are de facto public if they are nonexclusive and available for all to consume) recognises the changing context and the new realities caused by increasing globalisation. It was said that the novel nature of many of these goods implies different policy choices and approaches to make the goods private in the sense of being exclusive, or public in the sense of being non-exclusive. These conclusions are even more urgent with the expansion in scope and actors of the international public domain, requiring policy choice and international cooperation in support of global public goods provision. A decision-making and provision process for global public goods should therefore be more participatory and "bottom up" in nature. The typology of global public goods according to the nature of publicness (i.e. global natural commons, global human-made commons and global policy outcomes) illustrates the need for an increasing international cooperation as an integral part of their provision path.

The response of the international community to the rising importance of cross-border issues and activities has so far been rather limited, incomplete and biased. The expanded agenda of international cooperation faces new challenges, which require new policy approaches and additional resources for international cooperation. We distinguished three categories of global public goods provision (i.e. public goods can be overused, underused and undersupplied) and identified three major policy weaknesses in international cooperation that undermine the provision of the redefined concept of global public goods (i.e. a jurisdictional gap, a participation gap and an incentive gap). It was argued that the closing of these policy gaps requires a review of the fundamental principles of policy-making and an approach that recognises that the dividing line between internal and external affairs has become blurred with globalisation. In this perspective, the realisation of the MDGs is an ambitious embedded international initiative, illustrating the interconnection between peace, the environment, trade and finance, governance and human development. Ultimately, it is only through policy coherence across these various issue areas, nationally and internationally, that human development and the human security of the international community can be efficiently realised. 

CHAPTER 8

\section{The Changing Content of European Studies: an Interdisciplinary Perspective and Practice}

\section{Introduction}

The European integration process is, to date, the world's most advanced post-national constellation of states. As such, it has become a laboratory for scholars from various disciplines in studying and developing workable models of supranational and/or global and multilevel governance from an economic, legal, political or historical perspective.

The Study of the European integration process shows a development from a (neo) functional, utilitarian and largely economic project to a more complex, mixed and unique political undertaking, set in a globalising context, today based on the institutional structure of the Treaty of Lisbon and characterised by an emerging European citizenship (i.e. a common citizenship applying to many nationalities and covering a multiplicity of identities) and the development of a transnational democracy. The Treaty of Maastricht (1992) has broken down the linear perspective between nationality, identity and citizenship and has established an economic, political and legal framework for a broader and deeper study and research of the European integration process. The contents, opportunities and challenges of this process have been studied from various disciplinary approaches, illustrated by the Jean Monnet Programme in the development of European integration Studies. ${ }^{1}$

The Jean Monnet programme aims to stimulate teaching, research and reflection in the field of European integration studies at the level of higher education institutions within and outside of the European Community. Launched in 1989, the programme is now present in 72 countries throughout the world. Between 1990 and 2011, the Jean Monnet Programme has helped to set up approximately 3,700 projects in the field of European integration studies, including 165 Jean Monnet European Centres of Excellence, 879 Chairs and 2,139 permanent courses and European modules. Since 2007 the Jean Monnet Programme has formed part of the new Lifelong Learning Programme 2007-2013; further information available at http://eacea.ec.europa. eu/llp/jean_monnet/jean_monnet_en.php 


\section{Contextual Points of Departure}

Trends and developments in European studies are set and should be understood within the current framework of interlocking crises and radical transformation of European societies. These crises cover various sectors and dimensions of society and challenge the place, role, content and future of European studies.

- Globalised economics: The present economic crisis, linked to a seemingly irreversible globalisation, threatens livelihoods and welfare state models, and undermines both internal and external solidarity as states struggle to protect themselves. Social inequalities widen between and within states, as unemployment rises sharply in some countries, and as youth unemployment becomes so devastating as to threaten the wellbeing of an entire generation. In this way, the financial and economic crisis has become a social and societal crisis.

- The environment: Many European regions and cities encourage environmental protection such as recycling and waste-management schemes, reclamation projects for polluted land and waters, the promotion of long-life electrical appliances, the inclusion of environmental studies in school curricula, etc. Yet despite its urgency and its potentially massive impact, the general crisis of the environment, and the specific crisis of climate change, receives far less political emphasis than the economic and financial crisis. Growth is proclaimed everywhere as the primary remedy for the economic crisis: but growth, even "sustainable growth" is a problematic objective in the face of the environmental crisis.

- Citizenship and belonging: The governments of single states are struggling to meet global challenges that far surpass their capacity for governance. People move across state borders, creating a truly multicultural society. Yet trust is not readily transferred from national to transnational bodies. Euroscepticism has expanded beyond supposed "nationalist" groups to touch large numbers of ordinary people, who are unconvinced of the value of the European project

- Focus on rights and responsibilities: The defence and promotion of human rights lies at the heart of our sense of citizenship. By definition, authentic human rights (civil and political, social and economic) can never legitimately be set aside. Yet the existence of rights in no way assures the quality of political participation. An exclusively rights-based approach would fail to recognise the realities and the demands of affiliation, communal loyalties and solidarity. From the European perspective, a narrowly rights-driven approach to citizenship has sometimes conceived the EU primarily as a tool to realise individual and 
national rights claims, whilst scarcely contributing to the European project.

- Education: Education systems transmit and shape the value systems of the societies in which they are embedded. European education, at all levels from primary schools to institutions of lifelong learning, now faces the critical challenge of reflecting and guiding the manifest plurality present among European cultures. Education should prepare people of different backgrounds and of varying talents for a life together. Yet many European education systems, at all levels, have increasingly embodied an overriding concern with specifically economic performance. This emphasis affects both the objects of study (a preference for scientific, legal, and economic subjects rather than for the traditional "humanities") and the methods of pedagogy and assessment.

These intersecting challenges require a response from all spheres of European society, and also from the field of European studies. The ongoing and radical process of transformation of European societies needs a proper contextualisation of European studies within the globalising, europeanising, regionalising and localising aspects of transformation. Questions about identity, citizenship, borders, economic, financial and fiscal governance, interconnecting institutional and legal levels, foreign relations, and human security, are in need of proper teaching, reflection and analysis.

Reasons for revisiting the role of European studies concern: 1) The EU's role in the world is rooted in its very existence, as an emerging form of multilateral governance of national and local diversities within an interconnecting legal framework. This implies a focus on the state of affairs of EU/Europe's role in the world, on the European dimension of the globalisation process, more particularly on the European integration process in managing institutional, political, legal, societal and cultural diversity; and 2) The intersecting challenges shape the learning content, levels and competences of European studies in a globalising context.

In Chapter 5 we identified three major overlapping characteristics and trends of the changing international context and the growing complexities of the broad field of international relations, particularly European studies. These contextual issues (i.e. a changing international setting shaped by a globalisation process characterised by a multilateral and multipolar world, a weakening position of the EU/Europe as a global actor and the EU as a reference model) have an important impact on the changing content of European studies in relation to its programmes, competences, methodologies, pedagogies, etc., in summary, in relation to its curriculum building in context and content. In short, the place of European studies in international relations has changed throughout the years from a separate study area to a more 
integral cross-cutting thematic area approach, recognising different levels and methods of learning about European specificity.

\section{Conceptual Guidelines for Strengthening, Deepening and Widening European Studies}

European studies should be based on a certain idea of Europe that is beyond mere information. Europe is a multi-faceted and multidimensional space exhibiting multiple characteristics. They have to be understood and translated within the globalisation context that often produces changing and paradoxical realities. These realities have an impact on current European identity, citizenship and solidarity building, the relations between Eastern, Central and Western European countries as well as on the widening gap between North and South. Therefore it is important for the future of European studies to clearly affirm the value premises of Europe as a community in dealing with the welfare and wellbeing (current and future) of its citizens.

1) Europe as a Community of Destiny: The process of European civilisation has led to an increasing interdependence between and complexity of the interactions and relations that shape our common destiny in a globalising world. The maintenance of peace, the conservation of the environment, and the means of enabling people to live their lives with dignity all demand common policies. Unifying Europe in diversity is the response to past sufferings and the challenges faced by history. All Europeans are called upon to work responsibly together to build a peaceful European order. The concrete realities of every day life however, illustrate a growing tension and differentiation amongst member and non-member states as to the role, responsibility and finality of Europe within the global context.

2) Europe as a Community of Values: The aim of European integration and inclusion is to carry out, test, develop and safeguard the community of shared values. These are rooted in common legal principles, acknowledging the freedom of individuals and social responsibility. Fundamental European values are based on human dignity, tolerance, humanity and fraternity. Building on its historical roots in classical antiquity and Christianity, Europe further developed these values during the course of history, which finally led to the development of democracy, the recognition of fundamental and human rights and the rule of law, which is now enshrined in binding legal frameworks. The great currents of culture and art, scientific discoveries and their application for the common good, as well as the critical analysis of accepted views and perceptions created an area of freedom, justice and democracy. 
These principles for international relations have opened the way to a free and peaceful future. However, Europe has repeatedly called these values into question, causing conflicts and wars. Therefore, in the name of preserving collective memory, intellectual, cultural and artistic built and non-built heritages need to be cherished and protected in treaties, programmes and projects. Potential conflicts can then be overcome through the European dialogues framework, peace-building and nonconflict initiatives, reciprocal understanding and mutual learning processes, thereby stimulating a sense of common purpose and an awareness of a shared European identity. European identity requires the free exchange of persons and ideas, and finds its expression in the common protection of our values. The 1950 Convention for Human Rights and Fundamental Freedoms, the EC Charter of Fundamental Social Rights of 1989, the creation of European Union citizenship by the Treaty of Maastricht and the European Charter of Human Rights, constitute important steps towards consolidating a European community of shared values. The promotion of European citizenship, however, should be conceived as part of global citizenship. A truly good European citizen, assimilating multiple identities, is therefore a good global citizen within cosmopolitan thought.

3) Europe as a Community of Life: In order for the European Union to become a citizens' Europe it must develop into a tangible, living community. To that end, citizens must be given the opportunity to participate more fully in the process of European integration. A unified Europe implies further developing European citizenship to the point at which all citizens in all member states have the same rights and duties. The democratic and federal structures must therefore be strengthened and individual decision-making procedures and policies made more transparent. All citizens must be informed of important proposals for reforms at an early stage, and be involved in the public debate.

Therefore, a cultural and education policy-fostering European identity is necessary for the Union and its member states. While drawing attention to common roots and values, as well as to Europe's diversity, the aims must be to develop a spirit of tolerance, dialogue and mutual learning towards other people and cultures, to convince all citizens of the European idea, and to enable them to play their part in the process of European integration. This should be favoured at formal, informal and non-formal levels of learning,

4) Europe as an Economic and Social Community: The first steps towards this were taken when six countries founded the European Coal and Steel Community, in which basic industries important for the conduct of war were placed under a common authority. This neofunctional approach resulted in the European Economic Community, 
and eventually the European Union, in a process that led to peace between the member states and a higher standard of living.

The driving force behind European integration was economic, though it has become clear that achievement in this field alone is insufficient for the development of a European identity. It implies that the social objectives of the economy must be identifiable. Therefore, a social community is an essential aspect of European identity and would lead - for reasons of internal and external solidarity - to sustainably cohesive societies. European governance on economic, fiscal, and environmental issues has become central to Europe's responsibilities in the present confusing times.

5) Europe as a Community of Purpose and Responsibility: In today's globalising and individualising world, the European Union carries a particular responsibility. The European continent has close economic, political and cultural ties with many regions of the world, set in various cooperation agreements. Conflicts and crises, whether within or beyond our continent, threaten all European states and citizens alike. Only through cooperation, solidarity and unity can Europe effectively help to solve world problems. Discord in European policies would be irresponsible and can only lead to chaos.

Global responsibility has various dimensions. It means responsible cooperation in conflict prevention and mediation within the scope of the common foreign and security policy, neighbourhood and development policy. However, it also includes conducting trade and ecological negotiations with other regions of the world in a fair and helpful manner. In accordance with its values and its policy of peaceful integration, the European Union should set an example, in particular in relation to upholding human rights and the protection of minorities. By this means, Europe can remain true to its own heritage.

6) Europe as a Community and Meeting Place of Multiple Identities: Freedom, peace, human dignity, equality and social justice are Europe's greatest common goods. To protect and further develop these aims, Europe needs a morally acceptable political structure and policies which strengthen the sense of common purpose while establishing the credibility of the European Union and making its citizens proud to be Europeans through the building of meeting places and the recognition of the wealth of its multiple identities. When that point has been reached, then a stronger, added European identity will also exist. In this perspective, the city dimension becomes more and more a space of recognition and true citizenship building. Reality shows how individuals are bound to territorial places to define and contextualise their identity, within the combined global-local aspects of globalisation. Cities have 
become laboratories of conviviality and living together with all the problems and opportunities multicultural societies offer.

7) Europe as a Community of Multicultural Learning: In order to build up a common European identity as an added value, a common background and future is needed, which takes into account the specific multilayered and diversified institutional and cultural European context. This however implies enough sharing to create a multicultural learning space that supports integration and human integral development. Although a legal framework exists in which education/learning is set in the European context, there is still the problem of a lack of information about the principles and practices of Europe, as well as there being only limited, basic knowledge of the European space and environment. These problems seem paradoxical when the living reality of daily experience refers to an unaware Europeanness, which could increase awareness of a European citizenship and the multi-faceted identity of Europe.

\section{Curriculum Impact in Teaching and Research: Good Practice}

\section{The Jean Monnet Programme of the EU}

The contribution of the European Jean Monnet Programme to the development of European integration studies can be considered a very interesting case study of curriculum building in European teaching and research. Still its potential importance lacks visibility and content impact in European decision-making processes. The Jean Monnet Action was launched in 1989 to stimulate teaching, research and reflection in the field of European integration studies at the level of higher education institutions within and outside of the European Community. In 2007 it has been turned into a Programme and became part of the Lifelong Learning Programme (2007-2013). ${ }^{2}$ It developed from a strict, limited and disciplinary focus (law, economics, history and politics) to a much more open and multiple focus that now covers a wide geographical reach and targets various groups. Today the programme illustrates a greater diversity and innovation in teaching, research and reflection on European studies.

The Jean Monnet Programme is now present in 72 countries and five continents. Between 1990 and 2011, it has helped to set up approximately 3,700 projects in the field of European integration studies, including 165 Jean Monnet European Centres of Excellence, 879 Chairs and 2,139 permanent courses and European modules. The Programme brings together a network of more than 1,500 professors,

2 http://eacea.ec.europa.eu/llp/jean_monnet/jean_monnet_en.php 
reaching audiences of 250,000 students every year. In short, the overall Jean Monnet programme is a successful practice in teaching, researching and reflecting on European integration, involving a wide variety of topics and target groups. An excellent example of applied academic and interdisciplinary work are the different Jean Monnet activities which have been developed within the Interdepartmental Centre on Human Rights and the Rights of people of the University of Padua for more than a decade.

\section{The Interdepartmental Centre on Human Rights and the Rights of People of the University of Padua}

The Interdepartmental Centre on Human Rights and the Rights of Peoples, established in 1982, is the structure of the University of Padua devoted to carrying out educational, training and research activities in the field of human rights. Within its existing pluridisciplinary structure and interdisciplinary approach (political science, economics, international law, international relations, philosophy and education sciences) the centre offers various teaching and research activities within the University and in collaboration with local, regional, national and international partners. Many of these activities focus on human rights, democratic citizenship, cultural diversity and intercultural dialogue in a European and international perspective. It has at its disposal a good regional, national and European network in the interdisciplinary area of intercultural dialogue, human rights and governance. Recent developments and events in Europe and the world have intensified the policy-oriented debate and necessitated an extended and deepened analysis of the relation between multi-level governance, intercultural dialogue and human rights within a European and global perspective.

The centre operates in an interdisciplinary and proactive synergy, within and outside university, and possesses a wide-ranging expertise in international relations, human rights, political sciences, intercultural dialogue and interdisciplinary studies with a focus on policy-oriented research programmes. Since 2000 the centre has been a Jean Monnet Centre of Excellence, which organises many teaching and research activities as well as conferences in the area of intercultural dialogue, human rights and multi-level governance. Its various activities benefit today from the international networking of three Jean Monnet Chairs and a pluridisciplinary staff, able to relate to the multidisciplinary and multidimensional programme of the centre. On 11 April 2013 the Interdepartmental Centre on Human Rights and the Rights of Peoples of the University of Padua became (the) "University Centre for Human 
Rights", implying an important added quality dimension to its academic and international profile.

\section{1) A Jean Monnet Transnational Research Project}

In 2006-2007 the centre successfully undertook the action-oriented interuniversity research project: "The role of intercultural dialogue in the development of a new, plural and democratic citizenship in Europe". The research lasted for eighteen months, involved four universities and more than forty researchers. The research work was carried out by four transnational teams respectively, at the Universities of Lodz dealing with "Intercultural dialogue and Democracy", Panteion Athens, dealing with "Governing a Multicultural Europe: a new Republican Approach", Malta, dealing with "Intercultural dialogue and EU-Mediterranean Partnership" and Padua dealing with "Intercultural dialogue and Human Rights, civil society and world order issues". It was promoted by a network of Jean Monnet Chairs, Centres of Excellence and European Community Studies Associations, and co-financed by the European Commission and the Region of Veneto.

This transnational research project resulted in a major publication ${ }^{3}$ that provided an important academic contribution to the European Year of Intercultural Dialogue, 2008. It resulted in some policy recommendations for further policy research in the specific field:

- The subject of intercultural dialogue is multi, inter and transdisciplinary by nature and affects many themes and issues in European societies. The current decade has witnessed a growing enlargement of the European Union and an increasing diversity in an era of opportunities and challenges. The EU represents more than ever an immense richness of cultural, social and linguistic diversity. In such a context, the shared values that hold together European societies, such as freedom, fairness, democracy, human rights, rule of law, tolerance and solidarity, become crucial for Europe's future.

- Authentic intercultural dialogue in Europe has an external and internal dimension. It is seen as a vehicle, a concrete space and place for conviviality between citizens, based on some economic and social prerequisites. It is also seen as a laboratory for innovative practices and new (formal and informal) forms of democracy from the local level upwards. Moreover, it is an actual space for building European citizenship and for accepting multiple identities in a European context

Bekemans, L., M. Karasinska-Fendler, M. Mascia, A. Papisca, C. Stephanou and P.G. Xuereb (eds.), Intercultural Dialogue and Citizenship. Translating Values into Actions. A Common Project for Europeans and their partners, Venice: Marsilio, March 2007, 665 p. 
that is against ignorance, intolerance and indifference. As a consequence, the management of intercultural dialogue should be done at all levels. Such a multi-layer approach includes trust-building activities (and not only institutional interventions) at the school, the city, the regional, European and international levels.

- But at the same time there was an urgent plea from the academic world to the EU for some serious investment in applied, long term and structured intellectual effort and research in intercultural dialogue, intercultural communication, intercultural knowledge and intercultural commitment, beyond rhetoric and single academic disciplines. A formal declaration was the outcome. Its purpose was the expression of a commitment from the academics involved in the research project to keep the Europe of ambitions, ideas and hearts alive. That's a political project beyond mere economics!

As a structured follow-up to this research, in 2007 the University of Padua created a Jean Monnet Chair on "Globalisation, Intercultural dialogue and Inclusiveness in the EU". It was initiated as part of the 2008 European Year of Intercultural Dialogue celebrations and has allowed the introduction of new degree and post-degree courses at the University and has contributed to extra-curricular training courses outside of the University.

\section{2) The Jean Monnet Centre of Excellence}

In 2009, the University of Padua, in particular its Interdepartmental Centre on Human Rights and the Rights of Peoples, set up the Jean Monnet Centre "Intercultural Dialogue, Human Rights and Multi-level Governance". It was launched, with the support of the European Union's Jean Monnet Programme in light of the broad political priorities of connecting Europe to its citizens and, in particular, following up on the policy suggestions of the transnational research project mentioned above. Its purpose was to strengthen and consolidate the European and international profile of the existing curriculum of teaching and research activities with a specific focus on capacity building and curriculum development in the area of intercultural dialogue, human rights and multi-level governance. It was argued that the confusing times necessitated an extended and deepened policy-oriented analysis of the relation between intercultural dialogue and human rights within a European and global perspective.

The vision, mission and workings of the centre are rooted in the "acquis" which has been gained from ongoing participation in various Jean Monnet activities, from contributions to structural reflection on the dialogue between cultures and peoples, activities in lifelong learning programmes in the territory of north east Italy, as well as from the 
existing network of international cooperation. The activities and events cover specific teaching modules, public lectures by international experts on policy-related topics and an action-oriented research programme focussed on the interconnecting fields of intercultural dialogue, human rights and multi-level governance. ${ }^{4}$

\section{Multi-level Governance and Intercultural Dialogue}

In 2009 the Jean Monnet Centre launched a three-year research project on the relation between intercultural dialogue and multi-level governance seen from a human rights based perspective. Various workshops were organised in the period 2010-2011. Contributions all dealt with the broad framework of the concept, the policy approach and the linkage between multi-level governance and intercultural dialogue, in particular dealing with governance of intercultural dialogue, education about intercultural dialogue and civil society participation in intercultural dialogue. It proposed approaches to the understanding of the complexities of current realities and of managing diversities, oriented towards a common destiny and future. It presented, analysed and assessed various aspects and dimensions of internal and external political, legal and institutional dimensions of intercultural dialogue, conceived as a fundamental and integral component of a human rights based approach to social cohesion and human security. Finally, the action-oriented research produced general and specific policy recommendations and illustrated good practices.

In short, the research offered a general applied reading to policyoriented academics, international relations and human rights scholars, regional, national and European institutions as well as civil society organisations dealing with human rights, governance, education and civil society issues. Its innovative, interdisciplinary and interconnecting approach dealt with crucial issues and challenges that address the European future from a human rights point of departure. In all its diversity of contributions, ranging from scientific reflections to policy papers and case studies, the main message of the research was clear: the fundamental importance of governance of institutional, political and societal diversity. This is rooted in respect for human rights, being a cross-cutting and cross-border building block for the Europe of the future.

\section{A Value-driven European Future}

Within the same period 2010-2011 the Jean Monnet Centre also initiated a structured and interdisciplinary indepth analysis of culturally

4 Bekemans, L. (ed.), Intercultural Dialogue and Multi-level Governance in Europe. A Human Rights based Approach, op. cit. 
oriented and value driven applied reflections on Europe's future. The research focussed on the current debate on the future of Europe, in particular on the complexities of transforming realities, oriented towards a common destiny of sustainable and cohesive societies in a globalised world, i.e. the building of a European future. ${ }^{5}$

The research first provided a conceptual framework for understanding and contextualising intercultural and interreligious dialogue, with a focus on an indepth institutional and international law approach. Secondly, it offered the value driven foundations of Europe, ranging from historical, value and human rights perspectives. Thirdly, it proposed applied reflections on the (future) perspectives of a valueoriented Europe in the world. Its interdisciplinary and interconnecting approach addressed crucial issues and challenges to a value based European future. The differing contributions all referred to the fundamental importance of a human-centric development, being the cross-cutting and cross-border compass for the Europe of the future.

\section{Conclusion}

\section{Policy impact}

The knowledge society requires an indepth development of lifelong learning, benefitting from a variety of interconnecting learning resources. However, today's policy towards a learning society implies a more innovative capacity to (re) design (new) institutions of political, economic, social and educational governance, which can respond properly to the challenges of the multi-faceted process of globalisation. As was said in Chapter 3 and 4, what is European can be termed by forms of identity, practices, ways of life, means of production and types of interaction that go beyond national, regional or disciplinary frontiers. It is about continuous border-crossing. The intertwining of globalisation and Europeanisation has various policy consequences and produces different lines of thought and action that need to be taken into account in European studies:

- The dismantling of national borders in Europe has an impact on the European dynamic of socio-economic inequalities. The social dimension for the European integration process has policy implications within and beyond European borders, in particular in relation to internal and external solidarity and a sense of belongingness.

- The Europeanisation process is initiating a historically new positive sum game: joint solutions serve the national interest. On some

Bekemans, L. (ed.), A Value-Driven European Future, Brussels: P.I.E. Peter Lang, 2012, 242 p. 
occasions and policies the EU is sometimes better placed to solve problems than nations or regions could possibly be by acting alone. From a cosmopolitan perspective, this diversity (whether in languages, economic systems, political cultures, or forms of democracy) appears primarily as an inexhaustible source of Europe's cosmopolitan selfconcept and not as an obstacle to integration. A cosmopolitan Europe is first and foremost the Europe of difference of recognised particularity.

- A third line of thought and action is that Europeanisation requires a collective memory culture that spans borders, an "Europeanisation of perspective". This might lead to genuine intercultural dialogue and mutual learning, conceived as an enrichment of one's own integral human development.

- The fourth line is the understanding of European society as a regional world risk society. Reference is made to the theory of reflexive modernisation, which is characterised by three constitutive elements, namely, the theorem of risk society, the theorem of forced individualisation and the theorem of multidimensional globalisation. This means that the experience and dynamics of modernity bear risks in the sense that along with its success, modernity also contains negative consequences. This requires policy coordination and rule setting of both obstacles and opportunities in European and global contexts.

- The fifth concluding line concerns the understanding and shaping of new forms of political authority that have emerged in Europe beyond the nation-state. The management of globalisation effects, specifically the problems related to the flows and crises of global finance and the neglected European dimension of current socio-political developments, requires a more courageous approach, in respect of the various levels and actors involved in the process.

\section{Renewing European Studies}

How can we renew, deepen and widen European studies without in any way abandoning the acquired excellence of the current approaches to European studies? It is our conviction that: education institutions should accept European lifelong learning as their collective responsibility; governments should invest in a broad European studies curriculum for all stages of informal, non-formal as well as formal education; and finally that Europe should strengthen its lifelong learning agenda to active and responsible citizenship.

Support for such a European oriented education about responsible citizenship and multiple identities would need to consider the following three elements: a differentiated and multi-leveled discourse; curriculum content; and a social and cultural relevance. 
- Discourse refers to people's internalised values and the way they behave. A deeper understanding of how people build up a self-image will help educators provide effective and adequate learning programmes for those most excluded from the mainstream. Educational inclusion for a responsible citizenship also means that different and alternative ways of knowing and doing within our mainstream learning programmes should be recognised.

- The development of a curriculum content in a European context would need: i) to contextualise the curriculum building in critical, reflexive learning experiences with the objective of understanding the role of the self is critical to learning how to contribute actively to a changing world; and ii) to introduce the idea of an alternative curriculum, alongside the conventional mode of disciplinarity, as a new mode of knowledge that is context specific, transdisciplinary, and created and transmitted largely outside of formal learning.

- The most common method proposed for democratising the selection and control of knowledge is through discussion and dialogue. There is need for a critical dialogic approach to learning, which recognises community experience as a contribution to knowledge and as a means of understanding its social and cultural relevance to the curriculum. This also implies recognising values outside the dominant perspective of the education system, in particular an education on intercultural dialogue, human rights and democratic citizenship. Consequently, the promotion of a European oriented education on responsible citizenship and multiple identities needs to be understood and realised in a wider societal context of the knowledge triangle.

\section{Possible trajectories}

In view of Europe's priorities within the globalising context (i.e. connecting Europe to the citizens; increasing the EU's visibility in the world; pursuing reflection on intercultural dialogue; providing analysis and guidance on economic, social and financial integration) European studies with the support of the Jean Monnet programme, could engage in following trajectories for deepening and widening European studies at various learning levels.

A balanced support for launching new projects and strengthening existing ones within a broader scope should become a priority of the Jean Monnet Programme's contribution to the field of European studies. The programme has been moving from a successful phase of introducing the European dimension to traditional university curricula to a phase where a consolidation, strengthening and deepening of the European dimension in teaching, research and disseminating activities within and beyond universities has become a quality label. This would 
imply granting continuous support (financial \& structural) on the basis of content and technical criteria of good practice, distinguishing short and long term perspectives and differentiating deepening and widening European issues. Such an approach will certainly strengthen the sustainability of a platform of competences and excellences in the field of European studies. It would also mean the adoption of a more horizontal approach for supporting transversal programmes and cooperation networks with a focus on the added (European) value in disciplinary and interdisciplinary approaches. Moreover, the creation of learning and research spaces within and beyond the traditional university landscape might be opened up to the society at large through curricular and extra-curricular activities embedded and rooted in the territory.

We are also convinced that a focus on a committed, balanced, diversified and plural structure of thematic networks will certainly strengthen the identity of the Jean Monnet brand. Recognising the diversity of approaches but searching for synergies between chairs and centres would imply a good mixture between: informative and formative tasks, disciplinary and interdisciplinary networks; broad areas and specific issues, traditional and innovative themes and approaches; local/regional embeddedness and European dimension. In short, the Jean Monnet Centres of Excellence are platforms and laboratories for issuerelated collaboration with different disciplines in the university and between universities.

Possible supportive tools range from: the development of Jean Monnet fellowships, joint degrees and Ph.D/Post-Ph.D support; the search for synergy with other EU programmes; benefitting from the mobilising capacity of individual Jean Monnet professors through the national associations of professors and researchers in European integration (ECSA); increasing internal and external visibility by using the Jean Monnet web space as an interactive tool; setting up strategic thematic knowledge clusters of transnational transdisciplinary transversal research networks, involving scholars from political science, economics, environmental studies, international affairs, international and EU law, sociology, and history (e.g. thematic networks on multilevel governance and international democracy, climate change, citizenship and human rights, the future of the EU for (good) global governance, etc.). 



\section{PART III}

\section{Policy Areas of European Human-Centric DEVELOPMENT}





\section{CHAPTER 9 \\ European Security and Foreign Relations}

\section{Introduction}

Since its birth in the 1950s, the European Union has been developing its relationship with the rest of the world through a common policy on trade, development assistance, and formal trade and cooperation agreements with individual countries and regional groups. It has become a global player in the changing international economic and political landscape. Its main strategic foreign policy objectives are the building of a stable Europe with a strong(er) voice in the world, securing its international competitiveness through promoting global commerce and consolidating its socio-economic model of society. In order to conduct its external relations the EU has a complex institutional and decisionmaking framework, now fully embedded in the Lisbon Treaty.

In the first section of this chapter, the EU foreign policy is contextualised in a European and global setting, focussing on the characteristics of its external relations, in particular the phased development of the EU common foreign and security policy. Secondly we assess the changes, perspectives and major elements of the EU foreign policy in view of the Lisbon Treaty. The last section proposes an assessment of the EU's external relations from the human-centric perspective, referring to the basic fundamentals of the human rights paradigm, the cosmopolitan perspective of multi-level governance and the global public goods approach.

\section{Context: EU Foreign Policy: a European and Global Commitment}

\section{Key characteristics of EU external relations}

\section{1) Developments of the acquis}

The EU promotes prosperity and supports democratic values around the world; at the same time it helps to consolidate stability and wellbeing for the citizens within its frontiers. The process of further integration has challenged its role on the international scene. The main traditional components of EU external activities have been trade, development cooperation humanitarian aid, foreign and security policy. 
The EU is a globally important trade power, still accounting for nearly $20 \%$ of global exports and imports and generating one quarter of global wealth. Open trade among members of the EU has led to the single European market with freedom of movement for people, goods, services and capital. The Union has always taken the lead in pushing for further trade liberalisation at the world level. Therefore trade sanctions (e.g. removing trade preferences or limiting or freezing trade with a partner in breach of human rights or other international standards of behaviour) have always been tools of European foreign policy.

The EU has always been a generous provider of aid to developing countries in various ways. Development assistance and cooperation, originally concentrated in Africa, was extended to Asia, Latin America and the southern and eastern Mediterranean countries in the mid-1970s. The special trade and aid relationship between the EU and the 79 countries of the African-Caribbean-Pacific (ACP) group dates from the Lomé Agreements of 1975. This relationship is being further developed through the "economic partnership agreements" (EPA), combining EU trade and aid in a new way. The ACP countries are encouraged to foster economic integration with their regional neighbours as a step towards their global integration, while more aid is focused on institutionbuilding and good governance. Under the EPA the development dimension has become the cornerstone of the EU-ACP relationship. Through its external aid programmes, managed by Europe Aid, the EU and its member states still provide more than half of all official development assistance and two thirds of grant aid. The primary objective of EU development cooperation is the eradication of poverty in the context of sustainable development, including the pursuit of The Millennium Development Goals.

The EU began providing humanitarian aid to those in need around the world in the 1970s. Assistance is unconditional: it does not matter whether the disaster is natural or man-made. The aim is to get help to the victims as quickly as possible, irrespective of their race, religion or the political convictions of their government. The EU channels emergency relief funding through the European Community Humanitarian Office, its humanitarian aid department (ECHO). Since it was set up in 1992, ECHO has been active in more than 100 countries around the world, getting essential equipment and emergency supplies to disaster victims as soon as possible. From its budget of more than $€ 700$ million a year, ECHO also funds medical teams, mine-clearance experts, transport and communications, food aid and logistical support.

As a mixture of intergovernmental and supranational institutional cooperation and decision-making, the EU serves as a model for cooperation and integration between countries in other regions. It tries to 
develop its internal and external relations in a dialogues framework, focussing on a strategy of soft power. It is now a world partner in a globalising context, engaged in various regional areas, regional groupings and partnerships and multilateral relations. ${ }^{1}$ With the latest treaties the Union has created a more pro-active foreign and security policy with the capacity to carry out crisis-management and peacekeeping missions within Europe and far beyond. In today's complex world, the EU has now added new tools to the traditional instruments of foreign policy in responding to global challenges that are in need of governance of global solutions. ${ }^{2}$

\section{2) A dynamic management of the EU's external relations}

The Union's external relations have developed slowly over the years from a trade and development-oriented (economic dominated) external policy to an emerging, more integrated common foreign and security policy. It has widened its scope within a limited institutional framework. Various aspects of an emerging EU external policy can be distinguished.

The need to develop its external relations sprang essentially from two sources. Firstly, as the original six EC countries removed internal trade barriers between them, they had to handle their trade relations with outside countries as a shared responsibility. This gave rise to the common commercial policy, being the key component of the EU's relations with the rest of the world. The EU's common trade policy has operated at two levels: within the World Trade Organisation (WTO), it is actively involved in setting the rules for the multilateral system of international trade and secondly, the Union negotiates its own bilateral trade agreements with countries and regions. Secondly, the EU's agreements with its partners around the globe go beyond trade and traditional development assistance. They cover support for economic reforms, health and education, infrastructure programmes and in some cases cooperation in areas like research and development and environmental policy. They also provide a framework for discussing political issues like democracy and human rights.

Another element of the strengthening of the EU's external relations has been the development of a coherent neighbourhood policy by moving to consolidate relations with neighbouring countries to the east and south. Under the driving force of the former EC president, Romano Prodi, the EU launched its European neighbourhood policy (ENP) in

The EU is now advisory or full member of the UN, OECD, Council of Europe, WEU, NATO, WTO, G7/G8, G10, G20, IMF, World Bank, European Bank for Reconstruction \& Development.

2 See Chapter 7 on Global Public Goods and Human Development. 
2004. This covers all the Mediterranean and East European countries plus the Caucasus, but not Russia. The ENP aims to bring about privileged economic and political relationships between the Union and each neighbouring country. The ENP underwent major changes in 20102011 due to the creation of the European External Action Service (EEAS), which was focused more on promoting deep and sustainable democratic practices, accompanied by inclusive economic development. Prior to the EEAS's creation, DG Relex in the commission dealt with the EU's neighbourhood policy from a non-political and technical perspective. Recently, the ENP is becoming more "political" as illustrated by the European Commission's regular progress reports covering all sixteen ENP countries. The shift to the EEAS can be seen as one explanation for a stronger political emphasis. The recent reports reflect a European agenda for good governance and democratic reform in its neighbourhood. They are therefore inherently politicised as the agenda reflects European values and interests.

However it was the Maastricht Treaty of 1992 that gave a major new dimension to the EU's external relations, by developing a more structured common foreign and security policy (CFSP). It established the Common Foreign and Security Policy (CFSP) of the European Union.

\section{Common Foreign and Security Policy (CFSP)}

\section{1) A phased development from political cooperation to a CFSP}

Progress over the years has been slow, but steady. For most of the post Second World War period, Europe's security was guaranteed in close cooperation with the US, and NATO was the predominant selfdefence institution. With the end of the Cold War, the picture has changed.

The first step was an ambitious but unsuccessful attempt in the early 1950s to create a European Defence Community among the six founding members of the EU. Then came a process called "European political cooperation", launched in 1970, which sought to coordinate the positions of member states on foreign policy issues. EU countries produced joint statements whenever they could. But on particularly sensitive issues, it was not always possible to reach the required unanimous decision. In the last 20 years, the Union has intensified efforts to play an international political and security role more in line with its economic status. The conflicts that erupted in Europe after the fall of the Berlin Wall in 1989 convinced EU leaders of the need for effective joint action. The fight against international terrorism has strengthened this conviction. The present global and financial crisis has 
put these action-driven common goals under continuous and severe tension.

The principle of a Common Foreign and Security Policy (CFSP) was formalised in 1992 with the Treaty of Maastricht. It defined the types of diplomatic and political activities the EU could undertake in conflict prevention and resolution. Five main objectives were identified: to safeguard the common values and fundamental interests of the EU; to strengthen the security of the Union; to preserve peace and international security in accordance with the UN Charter; to promote international cooperation; and the development of democracy and the rule of law, and respect for human rights and fundamental freedoms. Only a few months later, war broke out in former Yugoslavia. The EU tried unsuccessfully to broker a political solution to the crisis. As the EU had no military force of its own, its member countries could only intervene as part of UN and NATO forces.

\section{2) European Security and Defence Policy (ESDP)}

In the light of the Balkan wars, and of conflicts in Africa in the 1990s, the EU launched its European Security and Defence Policy (ESDP) within the overall framework of the CFSP. The Treaty of Amsterdam (1997) provided a limited upgrading of the CFSP. It spells out the objective "to strengthen the security of the Union in all ways" as one of the five fundamental objectives of the CFSP. This treaty incorporated the Western European Union's "Petersberg tasks" (humanitarian and rescue tasks, peacekeeping tasks and tasks of combat forces in crisis management, including peacemaking) into the treaty on the EU. This laid the treaty basis for the operative development of the European Security and Defence Policy (ESDP).

The ESDP completed and thus strengthened the EU's external ability to act through the development of civilian and military capabilities for international conflict prevention and crisis management. As regards military capabilities, the EU set up a force of up to 60,000 personnel, deployed within 60 days, to sustain it on the ground for at least one year, for the purposes of humanitarian and rescue tasks, peacekeeping, and crisis management, including peacemaking. At the European Council in Lisbon in June 2000, the EU member states launched the civilian dimension of the ESDP. They established four priority fields of civilian action: police, strengthening the rule of law, strengthening civilian administration and civil protection. In 2003, the EU deployed its first external mission under the ESDP with a military force to the former Yugoslav Republic of Macedonia. Since then, it has instigated more than 20 civilian and military missions and operations on three continents. 
An important decision in terms of improving the effectiveness and profile of the CFSP was the creation of the office of High Representative for CFSP (1999) whose role it was to coordinate EU foreign policy and, in conjunction with the rotating presidency, speak on behalf of the EU in agreed foreign policy matters. This post combines three functions: the EU's representative for the CFSP, the President of the Foreign Affairs Council and a Vice-President of the Commission. At the moment, this post is held by Catherine Ashton.

\section{3) European Security Strategy: a doctrine for Europe}

At a summit meeting in December 2003, EU leaders adopted the EU Security Strategy (2003) and the subsequent report on implementation (2008). The EU established a strategic approach and set clear objectives for advancing its security interests based on core European values. The strategy takes into account key concerns such as: proliferation of weapons of mass destruction, terrorism, regional conflicts and problems related to state failure, including organised crime. It recognised that citizens in Europe and elsewhere face potential threats from terrorism, the spread of weapons of mass destruction and illegal immigration. It was said that each kind of threat needs an appropriate response, often requiring international cooperation. The European Security Strategy was set in a document entitled "A more secure Europe in a better world". It assesses the security environment in which the EU operates in terms of global challenges and key threats; it sets out the EU's strategic objectives through a policy of conflict prevention and responding to complex problems with various solutions: response to challenges; security at its borders and an international order based on multilateralism; and draws up the policy implications for a Europe that has to become more active, more capable and more coherent.

\section{4) Assessment}

A common security and defence policy has been a European ambition ever since the aborted 1954 plan for a European Defence Community. However, the legal basis for such a policy was only laid down with the adoption in 1993 of the Treaty on European Union, which first established a common foreign and security policy, and speaks of "the progressive framing of a common defence policy which might lead to a common defence". Since the ratification of the Amsterdam Treaty, and spurred by external events such as the Kosovo crisis, an ESDP has developed rapidly. Following decisions taken by the EU leaders at the Helsinki and Nice European Councils in December 1999 and in December 2000, new and tailor-made structures in the

3 http://www.consilium.europa.eu/uedocs/cms_data/librairie/PDF/QC780 9568EN C.pdf 
military and political areas have been set up in Brussels to enable decision-making in crisis situations. Attempts have been made over the years to streamline the way CFSP decisions are taken. But key decisions still require a unanimous vote, which was hard when there were $15 \mathrm{EU}$ members and is even more difficult with 27. Despite their commitment to the CFSP, member governments sometimes find it hard to change their own national policy in the name of EU solidarity. Still a few first conclusions can be made assessing the past security and foreign relations aspects of the EU within the globalising context.

Firstly, the EU has adopted a wider concept of security. The fact that security is becoming a wider concept reflects developments underway since at least the energy crisis of the early 1970s. This evolution clearly accelerated after the end of the Cold War. Furthermore, traditionally, security has been analysed and managed from state and alliance perspectives. Now, the geographical relevance of security issues has widened to include both subnational and global levels. Similarly, the scope has widened from the purely military to include broader political, economic, social and environmental aspects. In 2004, the study group on Europe's security capabilities proposed A Human Security Doctrine for Europe. ${ }^{4}$ This calls for a comprehensive understanding and (new) legal framework of the internal/external security landscape from an EU perspective, implying a conception of the EU as a norms-promoter.

Secondly, global and regional coordination efforts have increased during the last decade. The awareness of an increasing fragmentation of security efforts has resulted in a series of efforts to a large extent undertaken by the international community to achieve coordination on a global level, through the United Nations, on a transatlantic level through the North Atlantic Treaty Organisation, and in Eurasia, through the Organisation for Security and Cooperation in Europe (OSCE).

Thirdly, the very existence of the EU has its origins in a peace project seeking to overcome historical divisions between France and Germany. Particularly after the Cold War, enlargement, both for the EU, the candidate countries and their neighbours, has been viewed as being part of an overall security endeavour on the European continent.

Fourthly, the institutional and legal framework for the governance of all the various programmes in the Union varies considerably. Within the EU the main focus for overall coordination is the European Council, which gives strategic direction to EU security policy on the basis of proposals from both the Council and Commission.

4 A Human Security Doctrine for Europe, Barcelona Report of the Study Group on Europe's Security Capabilities, September 2004. 
Finally, the link between EU internal and external aspects of security is becoming more and more obvious. There are many security-related components developed in several EU programmes. They may not relate specifically to CFSP/ESDP, but are relevant to the internal security of the Union and for cooperation with partners outside the EU. Relevant policy areas in this field include: security of supply and energy stock reserves, the Single European Sky, protection of critical infrastructure, air transport and aircraft security.

\section{The Lisbon Treaty and the EU Foreign Policy: Changes and Perspectives}

\section{Global context}

The complexities of the globalising world and various acute policy dilemmas challenge the pursuit of the five EU foreign policy objectives (the encouragement of regional cooperation, the advancement of human rights, the promotion of democracy and good governance, the prevention of violent conflicts and the fight against international crime, including terrorism). The world has increasingly become globalised and interdependent. There is a permanent tense interaction between the global trends (i.e. global politics, global economy and global culture) and global threats (i.e. economic and social inequality, ${ }^{5}$ environmental degradation, climate change and global warming ${ }^{6}$ and organised crime and terrorism). A new multi-polar world is emerging, where power is more diffuse, international dynamics more complex and management of global goods and bads the major challenge. It is within this context that the EU has to face up the world's dramatic transformations and develop its foreign policy. The thematic priorities refer to enhanced EU credibility in conflict prevention, crisis management and peacebuilding, a broad comprehensive policy of fighting against terrorism, a structured support for the International Criminal Court, a normative human rights policy, credible security guarantees for non-proliferation and stronger controls against arms export.

\section{Institutional reforms}

The Treaty of Lisbon (2008) has introduced some changes to the EU foreign policy as to the institutional structure, the actors involved, instruments and decision-making. One of the main objectives of the Lisbon Treaty is to increase the coherence and the efficiency of the EU's

See Human Development Reports.

6 See Human Development Report 2007/2008: Fighting climate change: human solidarity in a divided world. 
external action. It brings the external community policies together in a more comprehensive manner. All elements of the EU's external action are now covered by the same principles and objectives. These include inter alia human rights, good governance, environmental protection and sustainable development. What are the main provisions?

\section{A Single Union}

The Union is given a single legal personality. Before Lisbon, the European Community and the European Union had different statutes and did not operate using the same decision-making rules. This is one of the main simplifications introduced by the new treaty. This innovation has a significant impact on the Union's external action. The Lisbon Treaty allows the Union to act more effectively, coherently and credibly in its relations with the rest of the world. A Union with a single legal personality allows it to conclude international agreements and become a member of international organisations in its own right.

The EU's institutional framework has been adapted to the now 27 member states in general and external relations-specific terms. The Lisbon Treaty creates an enhanced institutional architecture and offers better opportunities for strengthened collective action. The innovations however do not challenge the essential inter-governmental nature of foreign and security policy decision-making. It remains a distinctive intergovernmental regime. It proposes a reorganising of the existing institutional framework and rationalises the EU actor competences in the field of external affairs. The following are the main institutional changes:

A more unitary European Union replaces the former three-pillar structure. Under the previous approach, the European Community was responsible mainly for the internal market and external trade relations (the "first pillar") while common foreign and security policy (the "second pillar") and police and judicial cooperation in criminal matters (the "third pillar") were dealt with by intergovernmental cooperation between EU member states. New provisions added to the former EC Treaty enumerate the policy areas in which the EU has exclusive, shared or supporting competence, together with its member states. The EU is responsible both internally and externally for all of these areas of EU policy, within the limits of its degree of competence, and has a single legal personality.

\section{A decision-making process}

Although the essential intergovernmental nature of decision-making in relation to CFSP and CSDP prevails, there are new provisions to facilitate that process in a Union of now 28 member states. By granting the Union a legal personality for the first time, the Lisbon Treaty 
enables it to sign treaties or international agreements. Nonetheless, the CFSP is still governed by specific decision-making procedures. However, it facilitates decision-making procedures by allowing for a qualified majority in some CFSP-related issues (e.g. the "passerelle" provision, constructive abstention).

The procedure has been simplified and made more democratic in order to enhance the EU's ability to act. Qualified majority voting in the Council of the EU has been extended to many new areas of policy. The general use of the co-decision procedure with the European Parliament makes decisions even more legitimate. Qualified majority voting, which is becoming the rule, has been redefined. It is based on the principle of double majority: in order to be adopted, Council decisions need the support of $55 \%$ of the member states, representing $65 \%$ of the European population. At least four member states are needed to form a blocking minority. This system will enter into force in November 2014. The number of areas in which the Council of the European Union decides by qualified majority has been extended to around 40 new policy fields, including police and judicial cooperation. The risk of stalemates is thus to be decreased.

The current system for the weighting of votes continues to apply until 1 November 2014. During a transitional period until 31 March 2017 , it is still be possible for a member state to request that the system of weighting under the current treaty be applied. Lastly, these arrangements are complemented by a mechanism that allows a group of member states with less than the required blocking minority to suspend decision-making for a limited period. In certain cases, decisions continue to be taken unanimously. This is the case for defence and tax matters in particular.

The Lisbon Treaty also brings the co-decision procedure into general use, thus giving the European Parliament the power to legislate jointly on an equal footing with the European Council. By way of this procedure, the decision-making of the European Union is based on the double legitimacy of citizens and member states.

\section{Strengthening the role of the European Parliament and National Parliaments}

The European Parliament and the national parliaments see their roles reinforced in the context of European decision-making. The European Parliament becomes the co-equal legislator with the European Council in almost all policy areas. Thus, the legislative process of co-decision is substantially extended and becomes the standard legislative procedure. It is extended to new policy fields, such as the areas of freedom, security and justice. This innovation reinforces the legislative power of the 
European Parliament. The European Parliament's powers are also stepped up in the area of the budget (i.e. approval of the multiannual financial framework, co-decision arrangement for laying down all obligatory and non-obligatory expenditure) and in the adoption of international agreements. The Lisbon Treaty creates a direct link between the results of elections to the European Parliament and the choice by the European Council of the candidate for President of the Commission. The voting system in the council will become simpler and better reflect the relative size of a member state's population within the EU. After a phase-in period from 2014 to 2017, a decision can be approved if voted for by council members representing $55 \%$ of member states, accounting for $65 \%$ of the EU's population, i.e. a double majority rule is introduced.

For the first time in the history of the European treaties, the national parliaments are directly involved in the European decision-making process. This reinforces the democratic legitimacy of the Union's decision-making. The Lisbon Treaty clearly lays down the rights and obligations of the national parliaments in the context of the European Union, including those relating to information, the monitoring of subsidiarity, the evaluation mechanisms in the area of freedom, security and justice, and the revision of the treaties.

The national parliaments will check whether European legislative proposals are in line with the subsidiarity principle. Using an early warning system, any national parliament is able to send reasoned opinion to the European institutions within eight weeks of communication of a European legislative proposal, explaining the reasons why it considers that the proposal is not in line with the principle of subsidiarity. If this reasoned opinion represents at least a third of the votes attributed to the national parliaments, the drafter of the proposal (usually the European Commission) will have to re-examine the text, and will then have to decide whether to retain, amend or withdraw it. If the legislative proposal is contested by a simple majority of votes attributed to the national parliaments and the European Commission decides to retain it nevertheless, a specific procedure will be launched. The European Commission has to argue, in a reasoned opinion, why it considers that the principle of subsidiarity has been respected. This will be brought to the attention of the legislator together with the reasoned opinions of the national parliaments. The legislator may then decide not to pursue the legislative procedure.

An expanded jurisdiction of the European Courts is also important. The European Court of Justice now has jurisdiction over all areas of EU activity, with the exception of foreign and security policy. Notably, this extends the European Court's jurisdiction to the police and judicial 
cooperation in criminal matters. National courts and tribunals will be able to refer questions relating to immigration, asylum, internal security and criminal law to the European Court. Acting unanimously, the European Council can further expand the European Court's jurisdiction to disputes arising under treaties that establish European intellectual property rights.

\section{Institutional changes}

The European Council has become a separate institution, headed by a president who is elected for two and a half years, renewable once. This permanent Presidency of the European Council is intended to lend greater consistency and continuity to the Union's actions and to increase its visibility. The President is responsible for ensuring the preparation and continuity of work, and for achieving a consensus. The European Council President also represents the Union on the world stage in matters relating to the common foreign and security policy (CFSP). This replaces the current system of a rotating presidency every six months among the EU Heads of State. Former Belgian Prime Minister Herman Van Rompuy was appointed the first President of the European Council, for a two and a half year term, renewable once; his second mandate expires at the end of 2014. This new position has given better visibility and stability in "the preparation and the continuity of the work of the European Council" and the external representation of the Union on the CFSP, certainly in the management of the ongoing financial and economic crisis.

The creation of the post of High Representative of the Union for Foreign and Security Policy is one of the major institutional innovations of the Lisbon Treaty. The combined post of High Representative of the EU for Foreign Affairs and Security Policy and External Relations Commissioner, currently held by Catherine Ashton, reinforces the visibility of the institutional actors involved in EU foreign affairs. Essentially, the purpose is to achieve greater coherence across the first and second pillars within the EU, combining the roles of the High Representative for CFSP in the Council and the Commissioner for External Relations in the Commission. This new expanded role for the High Representative has not only an increased role within the European Council, but also becomes a Vice-President of the Commission. It chairs the new External Relations Council, represents the EU externally, ensures consistency of the EU external policies, and is responsible for coordination of all external relations policies. The High Representative is assisted by the creation of a European External Action Service (EEAS), a diplomatic corps that has the objective of developing a genuinely European foreign policy. It was launched on December 1st 2010. The EEAS comprises of staff from the European Commission, 
European Council secretariat and from EU member states. In short, it seeks to streamline the EU external services by combining all those involved in foreign affairs. Article 27(3) TEU constitutes the legal basis for the European Council decision on the organisation and functioning of the EEAS.

\section{Clarification of competences}

A complex institutional design is set up to confine powers and competences for the European Commission and the European Parliament in the sensitive area of CSFP: "the provisions covering the Common Foreign and Security Policy do not give new powers to the Commission to initiate decisions nor do they increase the role of the European Parliament". Whereas the rotating presidency-in-office chaired all meetings of the General Affairs and External Relations Council, under the Lisbon Treaty, the council is split up into an External Relations Council chaired by the new High Representative, and the General Affairs Council, which continues to be chaired by the rotating presidency-in-office. Nevertheless, the European Parliament acquires a degree of additional democratic control over the new High Representative in her role as a commissioner. Through its creation of a new High Representative, the Lisbon Treaty has elevated the European Commission's voice in CFSP. However, the European Commission no longer has the right to submit proposals to the European Council.

The definition of the European Union's competences clarifies its relations with its member states. The European Union has at its disposal only those competences expressly conferred on it by its member states (the principle of conferral of competences). The Lisbon Treaty clarifies and categorises them as described below.

- Exclusive competences. In the following fields in particular, the Union is the only party with the power to act on behalf of all its member states: the customs union, the establishment of competition rules necessary for the functioning of the internal market, the monetary policy of the Euro area, the common commercial policy and the conservation of fishery resources.

- Shared competences. Here, the Union intervenes to support the action of its member states in the following areas in particular: the internal market, social policy, agriculture, consumer protection, the environment, transport, energy, and the area of freedom, security and justice.

- Competence to take supporting, coordinating or complementary action. Here, member states have a wide freedom of action and have primary responsibility. The Union acts only to coordinate or complement the action undertaken by member states. This is the case, 
for example, in the fields of health, sport, civil protection, industry, tourism, education and culture. It should be noted that the European Council takes decisions unanimously in the fields of culture, social services, education and health.

The Lisbon Treaty maintains a certain degree of flexibility, which is one of the keys of the Union's success. It allows the Union to take action where this is necessary to achieve one of its objectives, even if the treaties have not specifically provided for powers to that effect. In such cases, the European Council has to make decisions unanimously with the approval of the European Parliament.

\section{Enhanced cooperation}

Enhanced cooperation allows a group of member states to act together in the context of the Union. The Union is able to act without all member states necessarily participating. This mechanism allows the interests of all member states to be respected. The Lisbon Treaty retains the possibility of enhanced cooperation in specific policy fields and facilitates the implementation of this mechanism. This form of cooperation improves the Union's ability to act by permitting at least nine member states to move forward without the others, while leaving open the possibility for others to join in at a later stage. In this way, the EU can act without all 27 member states having to participate. At the same time, it allows member states to remain outside any enhanced cooperation initiative which they do not wish to join, without stopping other member states from acting together.

\section{The Common Security and Defence Policy}

The Lisbon Treaty stipulates more clearly that the EU's competence in matters of common foreign and security policy covers all areas of foreign policy. Member states can make available to the Union the civil and military capability necessary to implement the common security and defence policy. Unanimity remains the rule as far as decisions on defence issues are concerned. If a member state is the victim of armed aggression on its territory, other member states have the obligation to provide it with aid and assistance using all the means in their power, in accordance with Article 51 of the United Nations Charter. This does not prejudice the specific character of the security and defence policy of certain member states.

Member states have developed their defence policies and instruments outside the EU treaties, and defence remains a very sensitive topic touching on national sovereignty and opening up questions about transatlantic relations, for example. Although the Lisbon Treaty does not address these fundamental issues, it does nonetheless attempt to align 
the law with the practices in those areas where member states can agree. Hence, the Lisbon Treaty now better reflects the nature of ESDP missions, by extending the scope of the so-called Petersberg tasks to: "joint disarmament operations; military advice and assistance task, peace-making and post-conflict stabilisation; conflict prevention and post-conflict stabilization missions". It also contributes to combating terrorism "in supporting third countries in their territories". The European Defence Agency (EDA), created in July 2004, is inserted within the legal framework of the CSDP, thereby seemingly reinforcing the leading role that member states want to assign it in pushing forward the development of EU operational capabilities and the EU as a military actor on the international scene. The Lisbon Treaty also institutionalises the implementation of a mission by a group of member states that are "willing and have the necessary capability for such a task" on behalf of the Union and "entrusted" by the European Council.

The mutual defence clause and the solidarity clause are important innovations that promote the principles on which the EU is based i.e. solidarity with, and assistance to, other member states. It binds all member states to provide aid and assistance "by all means in their power" in the event of another member state becoming a victim of armed aggression, without prejudicing the neutrality or relationship to NATO that some member states may enjoy. The solidarity clause represents a new legal mechanism of assistance between member states when one of them is the victim of a terrorist attack, natural or man-made disaster. The EU will mobilise all the instruments at its disposal, including military resources made available by member states, to assist. This is in addition to the new provision on civil protection.

In order to allow Europe to fully play its role in the interests of peace, the new treaty extends the Union's powers in the area of defence to include among its tasks those of humanitarian and evacuation missions, peacekeeping operations and the stabilisation of post-conflict zones. The Lisbon Treaty creates the possibility of enhanced cooperation between those Member States with the necessary military capacity and that wish to cooperate more fully in the area of defence. These member states can establish a permanent structured system of cooperation in the context of the Union. The Lisbon Treaty extends the scope of "enhanced cooperation" to the defence and security field by encouraging permanent structured cooperation among willing and capable states. The introduction of such flexibility measures provides alternatives to the intergovernmental system and is a major innovation. However, one of the points against this new mechanism is that it might create a two-speed Europe excluding the smaller countries that may 
have the will but not the human or financial resources to achieve the stated objectives.

All questions relating to the Union's security might lead to a European vision of collective defence and a new European Security Model, in which internal and external security is perceived as a transnational public good. It presents key innovations specific to the defence field. CSDP (formerly called ESDP) has its own section within the Lisbon Treaty and is symbolically upgraded from an European to a Common Security and Defence Policy (while still being within CFSP). If this change indicates a greater willingness by member states to develop a military arm of the EU, it does not push it towards a more integrationist approach.

\section{The EU External Trade Policy}

The Lisbon Treaty introduces three main changes to its external trade policy or what is usually termed as Common Commercial Policy. First, the EU trade policy becomes an integral part of overall EU external action and its relations with third countries. This implies that the EU in formulating its trade policy not only considers the economic liberalisation agenda, but has to take into account other objectives. The treaty may therefore provide a basis for the use of conditionality in trade policy, and lead to a politicisation of trade policy, something that is not always welcomed by EU's trading partners.

Secondly, to increase the democratic accountability of the EU trade policy, the Lisbon Treaty gives more power to the European Parliament in scrutinising trade policy. The EU legislation for implementing trade policies now has co-decision power by the European Council and the European Parliament; the European Commission has to report regularly to the Special Committee of the European Parliament on the progress of trade negotiations, and more importantly, the European Parliament must now give consent before a trade agreement can be adopted. However, the power to engage in trade negotiations still belongs exclusively to the European Council. This implies that the EU's trading partners have to watch the European Parliament more closely when dealing with the EU on trade issues. It is also important that the enhanced role of the European Parliament increases the possibility of having non-economic objectives such as human rights and social standards issues being included in trade agreements. The increased role given to the European Parliament in the EU trade policy may therefore contribute to increased politicisation of future trade negotiations leading to uncertainties and possible delays in getting a trade agreement through.

Finally, the system of allocation of competences in the area of EU trade policy is clarified and contributes to a streamlining of the trade 
policy. Before the Lisbon Treaty, the allocation of competences between the European Community and member states was complex and difficult to comprehend. Trade in goods was an exclusive European competence. With the Lisbon Treaty, trade in goods and services, commercial aspects of intellectual property and foreign direct investment will now all fall under the exclusive competence of the European Union.

\section{Development cooperation}

The treaty identifies development cooperation as an independent policy area with EU competency providing the principal framework for the EU's relations with all developing countries. (Art 208 TEU). It sets out the eradication of poverty as the principal objective of this policy. Humanitarian affairs is included in the treaty for the first time (Art. 214 TEU). This requires ensuring the integrity of EU development policy. Such an integration in general EU external action favours the management of development cooperation as a public good at the European and global level. This of course has some institutional consequences.

Currently the EU's development cooperation with developing countries is managed by three directorates (i.e. DG Development covering development policy and relations with countries from the Africa Caribbean and Pacific (ACP) group; DG External Affairs responsible for cooperation with developing countries in Asia and Latin America, as well as those covered by the European Neighbourhood Partnership Instrument; and Europe Aid that is charged with implementation of the EU's development assistance). The treaty clearly makes development policy the principal framework for the EU's cooperation with all developing countries, and it is important that the single development service is given the capacity and status to pursue these interests.

\section{Humanitarian Aid}

One innovative aspect of the Lisbon Treaty is the specific legal basis given to humanitarian assistance and the possibility of creating a European voluntary humanitarian aid corps. Sustainable development becomes one of the main objectives of the Union in its relations with the rest of the world. The EU's humanitarian assistance is based on the principles of humanity, neutrality, impartiality and independence, made explicit in the European Consensus on Humanitarian Aid. As such, the Commission's European Community Humanitarian Office (ECHO) distributes humanitarian aid without political agenda, and seeks to help those in the greatest need, irrespective of their nationality, religion, gender, ethnic origin or political affiliation. 
As such, ECHO is a clear expression of European solidarity with people in need all around the world. In its 20 year existence it has provided $€ 14$ billion of humanitarian assistance to victims of conflict and disasters in 140 countries around the globe. Over the last five years ECHO's annual budget has averaged $€ 1$ billion. In 2011 alone these funds reached nearly 150 million of the world's most vulnerable people in over 80 countries. In 2004 ECHO became the Directorate-General for Humanitarian Aid before integrating Civil Protection in 2010 for a better coordination and disaster response inside and outside Europe.

Humanitarian intervention is always controversial, especially if it involves the use of repressive measures, be it through military means or sanctions. The human security approach undoubtedly provides an interesting blueprint for the EU to improve coherence in its external action, as it is better suited to translate the Union's founding principles (and its inherent emphasis on non-military conflict resolution) into policy practice. At the same time though, political considerations remain relevant, as demonstrated by the analysis of the EU's involvement in four human rights crises (Darfur, Zimbabwe, Gaza and Lebanon). In order to strengthen its credibility and consistency as a humanitarian actor, the EU should prioritise the protection of civilians, avoid double standards at all costs, and favour genuine multilateralism, which requires a real involvement of all parties. In this regard, therefore, the EU should refrain from posing "take it or leave it" conditions and recognise that real multilateralism might well lead to non-optimal outcomes for the EU's interests. Very close to the EU's humanitarian assistance is the EU's concern for human rights.

\section{A Human-centric Assessment}

The impact of the Treaty of Lisbon provisions on the EU foreign and security policy can be assessed, using the building blocks of the humancentric approach to sustainable statehood, i.e. the human rights paradigm, the cosmopolitan perspective and the public goods focus ${ }^{7}$ as reference points. The Lisbon Treaty strengthens citizen's rights from the human rights perspective, renews the democratic fundamentals of the European Union in a globalising world and introduces a greater concern for the public good.

\section{Human rights and citizenship}

The European Union sees human rights as universal and indivisible. It actively promotes and defends them both within its borders and when engaging in relations with non-EU countries. Human rights, democracy

$7 \quad$ See Chapter 5. 
and the rule of law are the core values of the European Union. Embedded in its founding treaty, they were reinforced when the EU adopted the Charter of Fundamental Rights in 2000, and strengthened still further when the charter became legally binding with the entry into force of the Lisbon Treaty in 2009. Article 21 of the Treaty on European Union reaffirmed the EU's determination to promote human rights and democracy through all its external actions. It implies that countries seeking to join the EU must respect human rights. Furthermore, all trade and cooperation agreements with third countries contain a clause stipulating that human rights are an essential element in relations between the parties. In other words, human rights have become an explicit EU foreign policy objective.

The Union's human rights policy encompasses civil, political, economic, social and cultural rights. It also seeks to promote the rights of women, of children, of those persons belonging to minorities, and of displaced persons. With a budget of $€ 1.1$ billion between 2007 and 2013, the European Instrument for Democracy and Human Rights ${ }^{8}$ supports non-governmental organisations. In particular it supports those promoting human rights, democracy and the rule of law; abolishing the death penalty; combating torture; and fighting racism and other forms of discrimination.

\section{Charter of Fundamental Rights of the European Union}

The Treaty of Lisbon recognises the rights, freedoms and principles set out in the Charter of Fundamental Rights. ${ }^{9}$ Whilst signifying progress in the defence of the fundamental rights of European citizens, the charter gives no new powers to the Union. Even though the Charter of Fundamental Rights is not part of the current European treaties, the Lisbon Treaty makes it legally binding. It is a highly symbolic document with a list of rights that every person should enjoy. In the context of the Union's law and competences, the charter provides further guarantees and rights as well as additional freedoms to European citizens.

The charter provides for new rights in addition to those enshrined by the European Convention on Human Rights (ECHR): ${ }^{10}$ the protection of personal data, the right to asylum, equality before the law and nondiscrimination, equality between men and women, the rights of children

8 On June 25, 2012 the EU adopted The Strategic Framework on Human Rights and Democracy: http://www.consilium.europa.eu/uedocs/cms_data/docs/pressdata/EN/ foraff/131181.pdf

9 http://www.europarl.europa.eu/charter/pdf/text_en.pdf

$10 \mathrm{http} / / / \mathrm{www} . \mathrm{echr}$. coe.int/NR/rdonlyres/D5CC24A7-DC13-4318-B457-5C9014916D7 A/0/Convention_ENG.pdf 
and elderly people and important social rights, such as protection against unfair dismissal, access to social security and social assistance. Other rights, already provided for in the ECHR, see their scope extended: the right to education, the right to a fair trial. The Court of Justice of the European Union enforces compliance with the charter where it is legally binding. However, a protocol restricts its application in the United Kingdom and Poland.

\section{Citizens' rights: freedom, security and justice}

The Lisbon Treaty represents a step forward in protecting citizens' rights. It confirms existing ones and introduces new rights, as well as mechanisms to ensure that these rights are respected within the Union. The principle of the democratic equality of its citizens is enshrined, which means that all citizens enjoy the same degree of attention from the institutions, bodies and organisations of the Union. The principle of participatory democracy complements the principle of representative democracy. This means that dialogue with the representative associations and civil society, churches and philosophical and secular organisations is regular, open and transparent. The Lisbon Treaty establishes the principle of citizens' initiatives. This allows at least one million people from a significant number of member states to petition the European Commission to submit to the European Parliament and to the European Council a legislative proposal which they consider to be necessary for the implementation of the objectives of the treaties. In the context of the right of access to information, citizens and national parliaments are able to see the decisions taken by their government.

The aim of the Lisbon Treaty is to establish an area of freedom, security and justice with respect for the fundamental rights and freedoms of its citizens. It ensures the free movement of citizens whilst guaranteeing a high level of security. It strengthens the means of preventing and combating crime and terrorism. The concept of an area of freedom, security and justice is present in the current treaties. However, the Lisbon Treaty moves this area forward in that virtually all important issues are subject to qualified majority voting and co-decision between the European Parliament and the European Council. The Union's undertaking to develop a joint immigration policy is confirmed. A consistent approach to immigration allows migration flows to be effectively managed, taking into account the economic and demographic development taking place in Europe. A common asylum system will be developed, with a standard asylum status and standard procedures for persons from third world countries needing international protection. Whilst ensuring that persons are allowed to cross its internal borders without checks, the Union puts in place an integrated system for the management of its external borders. 


\section{Cosmopolitan perspective of $E U$ foreign relations}

\section{The EU in the world}

The EU has to defend its interests in a changing world order. Defending responsible interdependence requires in turn a world where the major players support and agree to work within a system of multilateral governance. Therefore, the Union needs to become a much more assertive player on the international scene. From increasing Europe's economic competitiveness to advancing in the knowledge society and providing its citizens with freedom and security, the challenges at stake are global. It needs to become a driving force in shaping new rules of global governance. The Lisbon Treaty reinforces the principles on which the Union's action is based: democracy, the rule of law, human rights and fundamental freedoms, respect for human dignity and the principles of equality and solidarity.

The reinforcement of actors involved in EU foreign affairs might help to develop an EU approach to global governance reform. The creation of the position of High Representative of the Union for Foreign and Security Policy might lend greater consistency to the Union's external action and increase its visibility worldwide. The High Representative has access to an external action service. This service makes for a more effective implementation of the policies of the Union and its member states. The President of the European Council represents the Union at the international level on issues associated with the common foreign and security policy.

\section{European citizenship}

The Lisbon Treaty reinforces the principle according to which any person holding the nationality of a member state is a citizen of the European Union. Citizenship of the Union complements and does not replace national citizenship. The Lisbon Treaty clearly states the rights arising from citizenship of the Union: the right to move and reside freely; the right to vote and to stand as a candidate in elections to the European Parliament and in municipal elections; the right to diplomatic and consular protection; the right to submit a petition to the European Parliament and to appeal to the Ombudsman; and the right to write to the institutions in one of the languages of the Union and to receive a reply in the same language. The formalised European dimension to citizenship favours a more cosmopolitan perspective on the globalisation vs Europeanisation debate. This will be further explored in Chapter 12. 


\section{Global/European public goods and social democracy}

\section{Democratic values}

The Lisbon Treaty defines explicitly and clearly the values on which the Union is founded. These values must be respected by all member states. The Treaty of Lisbon lists the values on which the Union is founded: respect for human dignity, freedom, democracy, equality, the rule of law and respect for human rights, including the rights of persons belonging to minorities. These values are common to all member states in a society in which pluralism, non-discrimination, tolerance, justice, solidarity and equality between women and men prevail.

These common values must be respected by all member states. Respect for them is a condition sine qua non for any European country wishing to join the European Union. As in the previous treaties, sanctions may be imposed on any member state which persistently commits serious infringements of these values. The Union respects the equality of member states and their national identities, including local and regional autonomy. It also establishes the principle of protecting Europe's cultural and linguistic diversity. Any member state may decide to withdraw from the European Union in accordance with its own constitutional requirements. This is an important innovation.

\section{Renewing Europe's economic and social model}

The Lisbon Treaty steps up the Union's social objectives and introduces new social concepts in European law. At the heart of the European Community is a distinctive economic and social model, referred to as a highly competitive social market economy. The Union has to work towards the social dimension of sustainable development, based on balanced economic growth, price stability and a highly competitive social market economy, with the aim of achieving economic and social progress. The treaty has a horizontal social clause stipulating that, in all its policies and actions, the Union will take into account the promotion of a high level of employment, the guarantee of adequate social protection, the fight against social exclusion, and a high level of education, training and health protection.

The Union should therefore promote the role of the social partner at the European level, whilst respecting their autonomy and the diversity of the national systems. The tripartite social summit should contribute to the dialogue on growth and employment. Although the key role of economic services of general interest (e.g. public transport, telecommunications, postal services, gas and electricity supply, etc.) is recognised, the Union's powers in this area are limited. A great deal of room for manoeuvre is granted to the national authorities to supply, 
operate and organise services so as to respond as effectively as possible to the needs of users. The diversity of these services, depending on different geographical, social or cultural situations, is affirmed, and the need to ensure a universal, high-quality service is guaranteed. However, the Union has to refrain from any action detracting from the competence of member states in the provision, operation and organisation of noncommercial services of general interest (health, social services, police and security forces, state schools, etc.).

The Charter of Fundamental Rights of the EU expressly recognises the right to information and consultation within firms, the right to negotiate collective agreements and the right to strike, the right of access to a free job placement service and protection against unfair dismissal, the right to faired equitable working conditions, and access to social security and social assistance. Remuneration, the right of association and the rules for taking strike action and implementing lock-outs remain a matter for member states.

\section{New challenges}

The EU is also facing new challenges. Global warming is one of the main environmental, social and economic challenges facing humanity. The Lisbon Treaty identifies measures to tackle these problems. One of the Union's objectives is to promote sustainable development in Europe, based on a high-level of environmental protection and enhancement. An innovative aspect of the treaty is the promotion, at international level, of measures to tackle regional or global environmental problems, in particular climate change.

Europe also has to guarantee secure, competitive and clean sources of energy. The Lisbon Treaty clarifies and complements the rules governing energy policy in the current treaties with a new section on energy. There is a consensus in Europe among governments, citizens and the business community that global warming, linked mainly to emissions of carbon dioxide from the use of fossil fuels (i.e. coal, oil and gas), needs immediate action on the part of the EU. The EU has taken the international lead in seeking to limit the effects of global warming by cutting its carbon emissions and greenhouse gas emissions. In this area, the Union's objective is to ensure that the energy market functions well, in particular as regards energy supply, and to ensure energy efficiency and energy savings as well as the development of new and renewable energy sources. The Lisbon Treaty also establishes the principle of solidarity in the event of difficulties in energy provision in one or more member states. In such an event, other member states should offer assistance, in particular if one or more countries have to deal with a major stoppage in the provision of energy from outside the Union. 


\section{Conclusion}

The Lisbon Treaty, through its rationalisation of the EU institutional architecture, has dismantled the three pillar structure in order to create more policy coherence, effectiveness and visibility. However, the Lisbon Treaty does not challenge the essential inter-governmental nature of foreign and security policy decision-making. The divergences between the national policies of the now 28 member states on how best to manage common security concerns, and their reticence in seeing their sovereignty challenged by a supranational EU institution, are sufficient explanations for the gradualist approach adopted in the Lisbon Treaty. It represents an attempt by the member states to overcome the impasse caused by the failure of the Constitutional Treaty. It is hardly revolutionary. Instead it aims to create an enhanced institutional architecture and to offer better opportunities for strengthened collective action - leaving the door open for the member states to go further if they so wish.

Last but not least, the Lisbon Treaty provides a partial answer to the question long attributed to former U.S. Secretary of State Henry Kissinger: "Who do I call if I want to talk to Europe?" As of December 1st 2009, the answer is that the Secretary of State of the U.S. can phone the High Representative of the EU - Baroness Ashton. However, if U.S. President Barack Obama asks a similar question, the answer is not as straightforward. In a statement following their appointment, President Obama indicated he looked forward to working with European Council President Van Rompuy, EU foreign policy chief Ashton and Commission President Barroso, just illustrating that the Lisbon Treaty has not yet eliminated difficulties in identifying the leader of the EU.

In line with the report to the European Council by the Reflection Group on the Future of the EU $2030^{11}$ (May 2010) globalisation and rebalancing of power in the world provide an important new rationale for joint EU action on the global scene. This requires political courage, collective ambition, solid pragmatism and a clear sense of a community of shared values and ideals. The Lisbon Treaty has introduced some political and legal changes, which may be further steps towards the developments of the EU as a global, responsible and cosmopolitan player in the rapidly changing international political landscape.

11 Project Europe 2030, Challenges and Opportunities, A Report to the European Council by the Reflection Group on the Future of the EU 2030, May 2010, 60 p. http://www.consilium.europa.eu/uedocs/cms_data/librairie/PDF/QC3210249ENC.pdf 


\section{CHAPTER 10 \\ Globalisation vs Culture in Europe}

\section{Introduction}

In this chapter, the human-centric perspective is applied to the tense interaction between the process of globalisation and the various cultural expressions, developments and practices in Europe. Globalisation has brought the world closer together: distances between places have seemingly become shorter. As a result, people interact with cultural differences on a daily basis. In order to address some of the pressing issues of modern day life, it is vital to be able to navigate global networks. Therefore the importance of culture as a source of difference and demarcation should be examined within the context of globalisation. In the first part, the concepts and policy implications of the ongoing globalisation vs culture debate are briefly explained. ${ }^{1}$ The second part gives a succinct overview of the EU cultural practice from a legal and programme perspective.

\section{Conceptual Debate}

\section{Globalisation}

Globalisation is a phenomenon and a process, which presents many faces, multiple voices and different interpretations with diversifying, often dramatic impacts on persons, cultures and societies. ${ }^{2}$ It cannot be reduced to a mere economic expression of growing interdependence and international agreements in an exclusively market-oriented and competitive environment. It is to be understood and analysed as a multidimensional phenomenon involving diverse domains of activity and interaction across borders and across continents, including the

\footnotetext{
Bekemans, L., Culture vs globalisation in Europe: actual tension or possible dialogue?, in L. Anckaert, D. Cassimon and H. Opdebeeck (eds.), Building Towers. Perspectives on Globalisation, Leuven: Peeters, Oct. 2002, pp. 191-211; and ibid., Globalisation and Solidarity: Europe's duty in intercultural dialogue, in Intercultural Dialogue, European Commission DG EAC/ Jean Monnet Action, March 2002, pp. 152-168.

2 Anckaert, L., D. Cassimon and H. Opdebeeck (eds.), op. cit.; Beck, U., What is globalisation?, op. cit.; Giddens, A., Europe in the global Age, op. cit.; Stiglitz, J., Making Globalisation Work, op. cit.
} 
economic, political, socio-cultural, technological, ethical, environmental and personal domains.

Globalisation is a complex and selective phenomenon with varying effects. Globalisation offers opportunities and dangers. The world at large is experiencing the effects of multi-faceted globalisation with varying degrees of impact on cultures and peoples. In Western and nonWestern societies, seemingly contradictory tensions appear (modernisation vs indigenisation, universalism vs particularism, homogeneity vs heterogeneity, unity vs diversity).

Globalisation is also a cultural phenomenon with profound implications on the daily life of society. If there is economic globalisation there is also cultural globalisation, often implying a cultural imperialism of the West. It manifests a double paradoxical reality: on the one hand, it favours a greater capacity for communication, mobility and exchange on the international scale, whereas on the other hand, it creates a real danger of homogenisation and commodification, flat individualisation and increasing secularisation. Dangers are related to the globalising culture industries which are detaching people from their historically developed local, religious moral and societal reference frameworks and to the individualisation and commodification of values and human relations which lead to a creative destruction of solidarity ties and to societies only unified by commercial or contractual agreements.

In other words, the driving forces of the ongoing globalisation process (i.e. technological progress and liberalising of cross-border capital flows, the dominance of market forces) produce challenges, threats and social drawbacks, strain solidarity ties between and within countries and create a cultural (anti-global) backlash. Phenomena such as religious fanaticism, ethnic nationalism/cleansing, racism, terrorism, economic, social and cultural poverty, hunger, immigration, social exclusion, underdevelopment, ignorance, environment, etc. shape international relations and dominate the international policy agenda.

In short, globalisation is a selective phenomenon and process with varying interpretations as to its impact on culture (optimistic vs pessimistic view). While globalisation has increased cultural assertivity and participation for some, the lack of understanding or respect for cultural differences by others has however led to distrust and confrontation between cultures and reinforced tensions in multi-ethnic societies.

\section{Culture}

The question of how to define what we mean exactly when we talk about "culture" is not easy. There are so many different approaches and 
convictions that the answer does not appear to be a question of concept and knowledge, but rather a question of feeling and belonging. It is therefore proposed that culture should be considered as that mixture of values, norms and traditions that affects as much the moral dimension of life as the taste and vision of things. This follows the consensus embodied in UNESCO's 1982 Mexico City Declaration on Cultural Policies. ${ }^{3}$ It defined culture as the "whole complex of distinctive spiritual, material, intellectual and emotional features that characterise a society or social group including not only the arts and letters, but also modes of life, the fundamental rights of the human being, value systems, traditions and beliefs". This has the merit of neither adopting an excessively restrictive definition of culture nor focusing on a particular aspect (e.g. religion) in order to define a culture.

In today's globalising world, most human societies no longer live in isolated territories, so their cultures are no longer the specificity of a given society limited by closed boundaries. We live in contact with each other, more or less intensively, and therefore other cultures are part of our daily life. This is the result not only of increased migration flows, but also of modern technologies, which have transformed communication systems and rebuilt relationships. Various cultural interactions have become a way of living in today's world. Indeed, it becomes important in order to avoid conflict and even war to understand that others do not see their world as we see our own, do not follow the same values when judging similar situations, or do not use the same criteria as our own to identify themselves as different. The Council of Europe's White Paper on Intercultural Dialogue $(2008)^{4}$ claimed two distinct approaches to defining the way that different cultures relate to each other and manage cultural diversity: multiculturalism and interculturalism.

Multiculturalism relates to a policy approach which recognises various and diverse cultures within a society: it indicates that different cultures exist and may interact within a given space and social organisation. A multitude of expressions always implies diversity but is still perceived as a unity. Multiculturalism suggests therefore that human beings are able to merge diversity of cultures within one society on the same territory and that the remaining existing differences can be considered as a richness for all without being denied or eliminated. Culture, from this perspective, is not only a heritage that determines

\footnotetext{
3 http://portal.unesco.org/culture/en/files/12762/11295421661mexico_en.pdf/mexico_ en.pdf

4 http://www.coe.int/t/dg4/intercultural/source/white\%20paper_final_revised_en.pdf
} 
what we are and what we believe, but also what individual human beings are able to build together.

Interculturalism, on the other hand, presents itself as a dynamic policy approach that believes and affirms that cultures should be recognised for what they are, as different and separated as the social groups to which they belong. It endorses and encourages respectful and open interaction between and among individuals and groups from different cultural backgrounds, and it recognises the opportunities of various cultures within a given society and space. The important goal is to mutually benefit from intercultural encounters, while respecting each other's diversity, which in turn can help to promote tolerance and understanding, prevent conflicts and enhance social cohesion.

Regardless of the academic debate on this distinction, it is obvious that these two approaches are not the result of factual observations of reality, but rather modes of defining what could be the most desirable attitudes and policies to face the "fact of multiplicity". However, it is argued here that it is the way people approach and define the diversity of cultures in a given society which determines the nature of that diversity, and not the reality itself. It implies that the existing multiplicity needs to be understood from an "intercultural" point of view, recognising that we should move from a multicultural to an intercultural reality.

Therefore we propose an anthropological definition of culture along the line of the Mexican anthropologist Rodolfo Stavenhagen, ${ }^{5}$ distinguishing culture as heritage, creativity and way of life. In this perspective he makes a very useful distinction between culture as capital, as creativity and as a total way of life: culture as capital is made up of the accumulated manifestations of intellectual and artistic creativity, past and present; culture as creativity is the process of artistic, intellectual and scientific creation; and culture as way of life is a source of values, social energy, inspiration and ways of living together.

In other words, culture is defined as a system of shared beliefs, values, customs, behaviour and artefacts that members of society use to cope with their world and with one another and that are transmitted from generation to generation through learning. Culture, then, in its broadest sense is cultivated behaviour, i.e. the totality of a person's learned and

Stavenhagen, R., Cultural rights: a social science perspective, in Culture rights and wrongs, Paris, UNESCO, 1998. Rodolfo Stavenhagen is a Mexican sociologist. He is a professor-researcher at El Colegio de México and former Deputy Director General of UNESCO. In 2001 he was appointed by the United Nations Commission on Human Rights the first United Nations Special Rapporteur on the situation of the human rights and fundamental freedoms of indigenous people. 
accumulated experience, which is socially transmitted - or more briefly behaviour through social learning.

In policy-driven terms, it means that we need to distinguish three aspects of culture in the globalising context: i) conservation: culture as an asset, tangible or intangible and a carrier of local identity; ii) production: culture as a commodity which needs to be re-produced not only to reconstitute cultural capital but also as a source of economic development insofar it is embedded in production processes; and iii) valorisation: culture as a set of norms and capacities which enrich communities and are used as bridge builders and carriers of good relations for social and economic exchange. A dynamic and interactive process between these three aspects of culture implies not only a peaceful co-existence of different cultures within society but also a mutually influencing and open dialogue between cultures. Moreover, such a conceptual shift from multicultural co-existence to intercultural dialogue may avoid the trap of cultural relativism and provide the basis for true living together.

This also applies to European culture, which is not a mythical or untouchable concept but rather an ongoing interaction of distinctive historical, spiritual, intellectual, material and emotional features and attitudes. These features are expressed in language, images, sounds, symbols, lifestyles, etc. illustrating the pluriformity and richness of European societies. These diversified but shared cultural expressions finally make up Europe's social, cultural and human capital. Therefore, the embeddedness of culture in society implies introducing historical, social and ethical considerations into our analysis. ${ }^{6}$

Culture is in the first place a source of inspiration for social integration and socio-economic development. It certainly can give an impulse to greater commitment of the citizen to the European project. Culture can be integrated in the economy and polity, not as a marginal factor, but as an intrinsic added value in the societal development. Cultural multiplicity and diversity is also a source of wealth and strength. No culture is left out in the European cultural mosaic. Europe is pre-eminently a space of cultural diversity, but respect for cultural diversity does not justify a mere nationalistic or regional reflex/behaviour. The respect and stimulation of cultural diversity may guarantee further European integration and a renewed cooperation with other cultures.

It is only very recently that this cultural and paradigmatic divide between economy, society and culture has been questioned in relation to

6 Bekemans, L. (ed.), Culture Building Stone for Europe 2002, Brussels: European Interuniversity Press, 1994, $331 \mathrm{p}$. 
its underlying assumptions as well as to policy relevance. Certainly in present times the Atlantic (Western) tradition seems to be increasingly criticised for its a-historical and purely analytical and monetised focus. However, our value systems are increasingly confronted with specific cultural expressions of society that escape rational and quantifiable analysis. Culture, also in business economics, becomes again a shaping factor and added value in the societal process of creativity, institutionbuilding and market exchange. We sense a change from culture as mere material artefacts to culture as a process of shaping values, patterns and expressions of the human spirit.

Within the European context, culture has been the permanent thorn between increasing market integration and maintenance of cultural diversity. Cultural diversity is also applied to the external dimension of common European action. This is seen as a contribution to a world order based on sustainable development, peaceful co-existence and dialogue between cultures.

We are also experiencing a progressive confirmation of cultural diversity at the international level ${ }^{7}$ (e.g. G8, the Council of Europe with its Declaration on cultural diversity of December 2000, the UNESCO Universal Declaration and Action Plan dealing with the protection of cultural diversity, etc.) They all illustrate a growing concern for the maintenance of cultural diversity as a common heritage, promotion of living cultures and creative capacity. Often this concern is integrated with global strategies on sustainable development.

In today's world, the present situation illustrates the need for new approaches and new types of understanding and managing cultural diversity. Cultural differences are more and more seen as a treat for economic and social stability, although they are often an enrichment of one's own culture. The fundamental question here is how we can solve these opportunities and contradictions peacefully and humanly.

\section{Policy implication of the globalisation vs culture debate}

In order to deal responsively with this double impact, cultural differences should be accepted and respected on the basis of a common pattern of values without the domination of a-priori superiority of a certain culture and with a mutual respect for differences. Such a common horizon should be based on universalistic values, but with respect for applied diversification. This requires a more "compassionate

UNDP, Human Development Report 2004: Cultural Liberty in Today's Diverse World, New York, Oxford University Press, 2005; World Commission on Culture and Development, Our Creative Diversity, Paris, UNESCO Publishing, 1996. 
globalisation" or "un humanisme cosmopolite" against any cultural relativism.

There is a need for governance structures (policies, mechanisms and resources), which create zones of common interest and commonality as well as civilised frameworks of disagreement. These structures should provide the common good (of economic, social and cultural welfare) that favours solidarity and makes the opportunities and benefits of globalisation accessible to everyone. However, the question remains: to what extent can a common world vision based on global common goods be developed against the twin processes of globalisation and cultural relativism? In any case, problems of social inequalities and poverty as well as non-accessibility to the benefits of globalisation, have taken on dramatic proportions, not only in the economic sense, but also in the cultural perspective. The Copenhagen seminars for social progress, which took place between 1996 and 1999 following the UN World Summit for Social Development in March 1995, tried to spell out an ideology for the pursuit of the common good in a globalising world. ${ }^{10}$

We also are convinced that different cultures need to re-examine their own realities in the context of globalisation in order to re-locate themselves in this new reality. This implies the emergence of a global consciousness and the acceptance of multiple identities and multiple modernities. It implies that we take into account the existence of different "modernities" with their own histories and stories, which need not respond to the criteria and principles of Western modernity.

In order to re-direct the asymmetrical, unequal and contradictory character of globalisation as regards cultural diversity, various international organisations (UN, UNESCO, EU, etc.) on the international scene propose a constructive dialogue between cultures and peoples, in order to counteract the economic and political dominance manifest in current global processes. In this context, intercultural dialogue becomes a necessity not only for overcoming conflict but also for rethinking and responding to the global challenges faced by humanity. ${ }^{11}$ Henceforth, ethical discourse implies devising dialogues between cultures able to balance unity and solidarity with tolerance and diversity, whereby the person as individual and social being is the guiding norm.

\footnotetext{
8 Falk, R., Realizing the Copenhagen Vision: The Political Imperative, in J. Baudot, op. cit..

9 Plenel, E., La découverte du monde, Folio Actuel, Gallimard, 2004.

10 Baudot, J., op. cit.

11 See Chapter 12 for a further elaboration.
} 
Thus, between the universalistic (euphoric) rhetoric of the Western cultural model (i.e. autonomy of the individual, mechanistic concept of society) and the post-modern discourse of cultural relativism, some forms of cross-cultural judgements are appropriate worldwide. In this sense, cross-cultural moral claims are part of the intercultural dialogue, which is, as Amitai Etzioni ${ }^{12}$ argues, a point of departure radically different from that of the cultural relativist.

In summary, the area of culture has grown in salience in global development issues on account of the rising share of cultural goods, services and intellectual property in world trade as well as the threats to cultural diversities and identities associated with contemporary globalisation. Also there is increasing awareness that the protection and promotion of cultural diversity is vital to universal human rights, fundamental freedoms along with securing ecological diversity. This standpoint is premised on the view that sustainable development is only achievable if there is harmony and alignment between the objectives of cultural diversity and social equity, environmental responsibility and economic viability. In the globalising context the notion of culture becomes the fourth pillar of sustainable development along with the social, economic and environmental dimensions, trespassing existing borders. As a consequence, culture should be viewed as part of the whole social order.

\section{European Cultural Practice}

At the time of its foundation, the European Community was not competent in the field of culture. Economic (and eventually political) integration was to be achieved without standardisation or homogenisation of cultures. The uniqueness of the European model implied economic and political integration with the maintenance of cultural diversity.

\section{Legal aspects}

With the formation of the Treaty of Maastricht, culture was for the first time integrated into the formal competencies of the European Community. Articles 128 (art. 151 in the Treaty of Amsterdam) and 92 (art. 87) provide the legal basis for EU support in the cultural sector.

In 1993, the entry into force of the Treaty of Maastricht marked the member states' desire to "mark a new stage in the process of European integration", that of "an ever closer union between the peoples of Europe", expressed in particular via the creation of a European

12 Etzioni, A., The new golden rule: community and morality in a democratic society, New York: Basic Books, 1998. 
citizenship and by the granting of new powers to the European Community, including new powers in the field of culture, with the Treaty introducing a new article devoted to it. Cultural cooperation thus became a recognised aim of European Community action, with an appropriate legal basis (Article 128).

This article was included in its entirety in the Treaty of Amsterdam (1997) (article 151), apart from paragraph 4 which was amended to read as follows: "the Community shall take cultural aspects into account in its actions under other provisions of this Treaty, in particular in order to respect and to promote the diversity of its cultures". This paragraph calls for culture to be taken into account and for cultural diversity to be respected in all European Community policies, in compliance with European Community law. This is a legal obligation, and the European Community institutions must take on board the cultural implications of all European Community policies.

\section{Programmes}

\section{1) Ad-hoc programmes}

In July 1990, the European Commission published the selection criteria and conditions for participation in the "Platform Europe", which became in 1991 the first Kaleidoscope programme for supporting artistic and cultural events involving at least three member states. The programme was reorganised from 1994 in order to support cultural events more effectively, encourage artistic creation and cooperation in the form of a network, to promote better public access to European heritage and to improve artistic and cultural cooperation between professionals. Between 1990 and 1995, more than 500 cultural projects received European Community support.

Between 1996 and 1999, the EU launched three cultural programmes: Kaleidoscope (1996-1999), which aimed to encourage artistic and cultural creation and cooperation with a European dimension; Ariane (1997-1999), which supported the field of books and reading, including translation; and Raphaël (1997-1999), the aim of which was to complement member states' policies in the area of the cultural heritage of European significance.

\section{2) The first framework programme (2000-2006) in support of culture}

The objective of Culture 2000 was to promote a common cultural area characterised by its cultural diversity and shared cultural heritage. It combines the old "Raphaël", "Kaleidoscope" and "Ariane" programmes, and is an opportunity to implement a new approach to European Community cultural action, by clarifying the role and the place of 
culture in meeting the great challenges now facing the European Union. The programme identifies the broad scope of the European project, extending it to the entirety of European society and its citizens; it integrates the cultural dimension into other European Community policies and recognises the role of culture as an economic factor but also as a factor in social integration and citizenship.

The programme's objectives are achieved by specific innovative and/or experimental actions, integrated actions covered by structured, multi-annual cultural cooperation agreements and special cultural events with a European and/or international dimension. It is a single programming and financing instrument for European Community measures in the field of culture; only 167 million Euros have been assigned for a five-year period. The budget clearly illustrates a discrepancy between the plurality of policy objectives and the modest means available on the European Community level and subsequently the still rather symbolic value of European Community action in the cultural field. It seeks to encourage cultural creation and mobility, access to culture for all, the dissemination of art and culture, intercultural dialogue and knowledge of the history of the European peoples. It also accords culture a social integration and socio-economic development role. Three main categories are eligible: specific annual activities, multiannual activities forming the subject of cooperation agreements and special cultural events such as the European Capitals of Culture. The Culture 2000 programme already presents a more structured, integrated and outward looking approach anticipating a potentially more powerful role of Europe in the ongoing globalisation/culture debate.

3) The new culture programme (2007-2013): “Crossing borders connecting cultures" $" 13$

The general objective of the programme is to enhance the cultural area common to Europeans through the development of cultural cooperation between the creators, cultural players and cultural institutions of the countries taking part in the programme, with a view to encouraging the emergence of European citizenship. The specific objectives of the programme are: to promote the transnational mobility of people working in the cultural sector; to encourage the transnational circulation of works and cultural and artistic products; and to encourage intercultural dialogue.

13 http://ec.europa.eu/culture/documents/publications/doc1165_en.pdf 


\section{Assessment}

A certain development can be distinguished in the form of European cultural practice. The early years of European integration were dominated by a mainly political-rhetoric discourse. The preamble of The Rome Treaty refers to a closer union between the European peoples, quality of life and a guarantee of freedom and peace.

From the end of the 1960s, the plea to go beyond the mere economic dimension was made explicit in many solemn declarations of European summits (The Hague 1969, Paris 1972, Copenhagen 1973 and Stuttgart, 1983). This finally led to the concept of a truly European Union, which contained not only an economic, but also a political, social and cultural dimension and found its legal context in the Treaties of Maastricht, Amsterdam and Nice. Terms such as "European identity and consciousness", "Community cultural heritage", and "Europe of the citizen and culture", entered into European Community language. Still the actual result was meagre: the adoption of a rather minimalist approach with modest European Community action in the cultural sector and an even smaller budget.

In reality, between the rather utopian political-rhetoric discourse and the very limitative formalistic discourse, EU interventions in the cultural sector did follow a more pragmatic, fragmented ad hoc policy, applying a subtle mixture of cultural, economic and legal arguments (e.g. the Year of Music or Film, conservation of architectural heritage, cultural action programmes such as Ariane, Kaleidoscope and Raphaël, the European cultural cities, etc.).

Also, a content shift in the cultural programmes of the EU can be distinguished. The predominant objective of the cultural programme of the EC has been focussed on the elimination of (national) obstacles against the free flow of cultural goods and services and on the stimulation of the free movement of "cultural operators" within the European Community's territory. The formal interaction of culture was set within an economic framework, with an emphasis on the economic dimension of the creation of a European cultural space, i.e. a common market for cultural goods, activities and persons. Within this perspective national and regional cultural policies were governed by market integration rules. Possible conflicts between the open border economic objectives and cultural policy priorities were understood in view of the impact of integration policies on the cultural sector.

From this originally negative integration intervention by the EU, a move was made to more positive integration activities, referring to the economic benefits of the cultural sector through harmonisation of legislation or the launching of European Community action 
programmes. The expansion of the legal competence of the EU in the cultural sector was also favoured by European Community integrism in the Court of Justice, by adjudging exceptions on the basis of cultural considerations such as common interest, language, and cultural identity. In fact, actual European cultural practice has always been confronted with the ambiguous task of combining economic competence with cultural ambitions in a strict legal framework.

The EU also changed the discourse on the legitimisation of its cultural activities, less focus on European cultural identity and unity and more on cultural diversity. Cultural diversity was set in an institutional and legal context, stressing subsidiarity, autonomy of cultural policy as well as integration with European Community policies.

In other words, the cultural objective has been formally recognised as a European Community preoccupation, although with strong legal procedures, a weak legal instrument and a very modest budget. In short, a new synthesis between economic and political integration on the one hand, and preservation of cultural diversity on the other hand is being developed, whereby the EU will attempt to preserve the specificity of the European model with a formal and legal anchorage of European Community action in the cultural field. The actual challenge is therefore the creation of a more genuine link between culture and integration in a broader and more open context. 


\section{CHAPTER 11 \\ Intercultural Dialogue for Cultural Diversity}

\section{Introduction}

Dialogue is a vital tool for understanding and managing diversity. This chapter explores the opportunities and challenges of intercultural dialogue for understanding and managing cultural diversity. It should be clear that the prior goal of intercultural dialogue is not integration or assimilation of individuals and groups of different cultures within a given society, but an incentive to share universal values by/for living and doing together whilst respecting the other. Political and civic participation are fundamental features of inclusiveness at all levels; they may even give rise to a new civic identity, referring to the Europeanconstitutional motto "united in diversity".

In short, the EU can form the model framework for unity in diversity within and outside the Union, so that a common sense of citizenship based on shared responsibility for the achievement of the common good can be elaborated through joint decision-making and joint implementation of shared policies. Moreover, such a conceived civic transcendent identity is perfectly consistent with the space-specific developments of Europe, in which persons can interact peacefully in a given territory, unhindered by physical or mental borders.

We have structured this chapter in two main parts. In the first part we identify the general context by trying to define what we mean by cultural diversity and what we understand by intercultural dialogue as to its usages, practices, content, national and sector approaches. The second part focuses on institution-building in the area of intercultural dialogue; the intercultural dialogue practices of $\mathrm{UNESCO} / \mathrm{UN}$, the Council of Europe and the EU are reviewed together with an example of good intercultural practice.

\section{General Context}

\section{Cultural diversity}

Our cultural environment is changing quickly and becoming more and more diversified. New cultural influences pervade virtually every society, not only in Europe, but everywhere on the planet. Cultural diversity is an essential condition of human society. It is caused and 
fostered by many factors such as cross-border migration; the claim of national and other minorities to a distinct cultural identity; the cultural effects of globalisation and the growing interdependence between all world regions; and the advances of information and communication media. More and more individuals are living in a "multicultural" normality, i.e. facing the influences of different cultures in their daily life, and have to manage their own multiple cultural affiliations.

Cultural diversity is not only a fact and a right to be protected, but also an economic, social and political added value, which needs to be developed and adequately managed. Protection, promotion and maintenance of cultural diversity are factors of human development and a manifestation of human liberty, and they are an essential requirement for sustainable development for the benefit of present and future generations. In summary, cultural diversity is a rich asset for individuals and societies, which needs careful and gentle management attention.

On the other hand, increasing cultural diversity brings about new social and political challenges. Cultural diversity often triggers fear and rejection. Negative reactions - from stereotyping, racism, xenophobia and intolerance to discrimination and violence - can threaten peace and the very fabric of local and national communities. International conflicts, the socio-economic vulnerability and marginalisation of entire groups, and widespread cultural ignorance - including the lack of knowledge about one's own culture and heritage - provide fertile ground for rejection, social exclusion, extremist reactions and conflict.

The most fundamental challenge, therefore, is that of combining social cohesion and cultural diversity. So far, Europe has discussed this challenge under categories like "multiculturalism" and "assimilation". However, there is no consensus yet on the best long-term vision for living together peacefully in multicultural societies. It seems obvious that the right balance between social cohesion and cultural diversity cannot be achieved by compromising the core values that are at the very heart of the fabric of our societies - the universal human rights and fundamental freedoms, democracy, and the rule of law.

There are various ways to manage cultural diversity. Galtung, a Norwegian professor of peace studies, distinguishes four ways to deal with cultural diversity: ${ }^{1}$ Intolerance: "You are different from me, you are dangerous"; Tolerance: "You are different from me, that is your problem, live and let live". Human rights have their place here; Respect and Dialogue: "You are different from me, how fascinating! Let us sit down and talk it over". The other exists in its own right and is part and

Galtung, J., Peace by Peaceful Means: Peace and Conflict, Development and Civilization, Thousand Oaks, CA: Sage Publications, 1996. 
source of my own enrichment. Dialogue means asking questions; and Mutual learning: "You are different, let us learn from each other".

\section{Intercultural dialogue: an inventory of usages and practices}

There is no lexicon of accepted usages surrounding the notion of intercultural dialogue. In effect, we observe a range of practices and a multiplicity of (coded) terms almost as diverse as the notion of culture itself. We distinguish between current usages of the notion and categories of intercultural practice. Both uses and categories of intercultural dialogue are manifold and diversified.

\section{1) Usages}

"In our increasingly diverse societies, it is essential to ensure harmonious interaction among peoples and groups with plural, varied and dynamic cultural identities as well as their willingness to live together". This affirmation, drawn from the Universal Declaration on Cultural Diversity adopted by UNESCO in 2001, is relatively unambiguous and broadly accepted by all concerned organisations and individuals. However, the practice and implementation thereof is plural. The term tends to be used mainly by philosophers, cultural activists and public officials. It is strongly normative, as a pathway towards the goal of attaining ways of living together. It is used in at least the following ways:

At one extreme of generality, intercultural dialogue is interchangeable with the notion of dialogue among civilisations, the inverse of the clash of civilisations predicted by the American political scientist Samuel Huntington. ${ }^{2}$ Intercultural dialogue is also sometimes simply a new term for international cooperation in general, cultural cooperation in particular. This very general usage merges into that of a "politically correct" euphemism for traditional cultural diplomacy on the part of states, intergovernmental and supranational organisations.

In some current usages, intercultural dialogue is coterminous with inter-religious dialogue. Sometimes the term is used as an alternative to multiculturalism, in other words the recognition on the part of the public authority (as well as society at large) of the different values, practices and interpretative frameworks that characterise culturally diverse societies.

Increasingly, however, intercultural dialogue is advocated as an inherently normative and voluntaristic practice, an intercultural

2 Huntington, S., The Clash of Civilizations and the Remaking of World Order, A Touchstone Book, New York: Siman \& Schuster Inc, 1996. 
deontology. This has been nicely expressed by the Delors Commission ${ }^{3}$ as "learning to live together", a process whereby developing an understanding of others and their history, traditions and spiritual value and, on this basis, creating a new spirit which, guided by recognition of our growing interdependence and a common analysis of the risks and challenges of the future, would induce people to implement common projects or to manage inevitable conflicts in an intelligent and peaceful way.

A final meaning of the term "intercultural dialogue" is associated with a business-driven field of academic research, teaching and vocational training, and refers to intercultural communication. The term refers principally to the exchange inherent in international business, including such diverse concerns as negotiations and communications within multicultural organisations. It has long been part of the toolkit of multinational corporations, who were quick to understand the challenge of selling effectively across cultures.

\section{2) Categories of practice}

The varieties of intercultural dialogue are carried out in a number of different frameworks. A preliminary typology of possible models can be determined as follows: A dignitary model brings together heads of state or governments who tend to deliberate in terms of broad abstractions (in particular in reference to a dialogue among civilisations) and adhere to diplomatic norms; An inter-religious dialogue model brings together religious leaders whose subject matter is self-evident. (e.g. Assisi meetings); A representative intellectual figure model brings together leading academicians, journalists and opinion-leaders from different cultures in encounters based on rational debate, inspired by the liberal values of a shared commitment to an intercultural ethic; A transactional model (essentially in the business world) is based on the negotiation of diverging stakes against a backdrop of different cultural assumptions; An epistemic community model brings together specialists in a shared field, e.g. scientists, artists, the media, or a common age-set or category, e.g. young people, women; A local dialogue model brings together neighbours in a geographically defined location that is not yet characterised by intercultural tensions; A mediation or conflictprevention model brings together neighbours in situations of overt intercultural tension.

UNESCO, International Commission on Education for the 21st Century, Learning:

The Treasure Within, Paris: UNESCO Publishing, 1996. 


\section{Intercultural dialogue: content}

\section{Definition}

"Intercultural dialogue is an open and respectful exchange of views between individuals and groups belonging to different cultures that leads to a deeper understanding of the other's world perception". In this definition, "open and respectful" means based on the equal value of the partners; "exchange of views" stands for every type of interaction that reveals cultural characteristics; "groups" stands for every type of collective that can act through its representatives (family, community, associations, peoples); "culture" includes everything relating to ways of life, customs, beliefs and other things that have been passed on to us for generations, as well as the various forms of artistic creation; "world perception" stands for values and ways of thinking.

Dialogue between cultures is the oldest and most fundamental mode of democratic conversation, and is an antidote to rejection and violence. The cost of "non-dialogue" may therefore be high. Continued noncommunication, ignorance and mutual cultural isolation will lead to ever more dangerous degrees of misunderstanding, mutual seclusion, fear, marginalisation, and violent conflict.

\section{Objective}

In a very general sense, the objective of intercultural dialogue is to learn to live together peacefully and constructively in a multicultural world and to develop a sense of community and belonging. Intercultural dialogue can also be a tool for the prevention and resolution of conflicts through enhancing the respect for human rights, democracy and the rule of law.

More specifically, the following goals are mentioned: to share visions of the world, to understand and learn from those who do not see the world in the same way as we do; to identify the differences and similarities between different cultural traditions and perceptions; to achieve a consensus that disputes should not be settled by violence; to help managing cultural diversity in a democratic manner, by making the necessary adjustments to the existing social and political arrangements of all kinds; to bridge the divide between those who perceive diversity as a threat, and those who see it as an enrichment; to share best practice, particularly in the areas of intercultural dialogue, the democratic management of social diversity and the promotion of social cohesion; and to develop jointly new projects.

4 Council of Europe, White Paper on Intercultural Dialogue. Living together as Equals in Dignity, 2008. 


\section{Enabling factors}

Easier than a definition is a description of the conditions - the "enabling factors" - that characterise a true, meaningful intercultural dialogue. Based on existing experience, one can propose at least six crucial conditions that must be fulfilled from the very outset, or achieved during the process: equal dignity of all participants; voluntary engagement in dialogue; a mindset (on both sides) characterised by openness, curiosity and commitment, and the absence of a desire to "win" the dialogue; a readiness to look at both cultural similarities and differences; a minimum degree of knowledge about the distinguishing features of one's own and the "other" culture; and the ability to find a common language for understanding and respecting cultural differences.

In the international debate, intercultural and interreligious dialogue are sometimes seen as two separate, though interrelated issues; whereas others, like the Council of Europe, stress that religious beliefs and traditions - like agnostic, atheist or secularist convictions - are one dimension of culture. In the past, the Council of Europe has essentially dealt with religious beliefs under two aspects: the protection of the freedom of thought, conscience and religion, and of the freedom of expression as laid down in the Council of Europe Convention for the Protection of Human Rights and Fundamental Freedoms (Articles 9 and 10); and the role of religious beliefs as an important cultural fact, similar to other identity sources such as languages, history or cultural heritage.

Over recent years, religious issues have gained in importance in the Council of Europe activities. Since 2000, the Commissioner for Human Rights has developed a dialogue with religious communities on various practical issues related to human rights. At the same time, the role of religions in the context of social cohesion and mutual understanding has been increasingly acknowledged, which has led to initiatives e.g. on the relationship between religious diversity and intercultural education (including the teaching of religious facts in schools), and to a general encouragement - addressed to religious communities - to engage in inter-religious dialogue.

\section{Parameters}

The promotion of intercultural dialogue is characterised by three basic parameters: its value basis, its transversal nature and its different geographical dimensions. Intercultural dialogue is neither an expression of, nor does it lead to, cultural relativism. Dialogue must be based on the principles of the universality and indivisibility of human rights, democracy and the rule of law. It implies a rejection of the idea of a clash of civilisations and expresses its conviction that, on the contrary, increased commitment to cultural cooperation - in the broad sense of the 
term - and intercultural dialogue will benefit peace and international stability in the long term. It is conceived as an important pillar for sustainable development across the globe.

Secondly, the promotion of intercultural dialogue is not simply another theme, added to the list of other existing policies. Instead, it is conceived as a cross-sectoral, transversal approach, which influences the agenda of virtually all other policy domains and institutions.

Finally, we distinguish three levels that are important for a coherent policy of promoting intercultural dialogue: intercultural dialogue within European societies, such as dialogue between majority and minority cultures living within the same community (e.g. with a focus on immigrant communities, various religious beliefs, national minorities); intercultural dialogue between different cultures across national borders, e.g. dialogue activities in international cultural policy programmes, in cross-border exchange schemes, through international media; and intercultural dialogue between Europe and its neighbouring regions.

\section{National approaches to intercultural dialogue}

Two major policy approaches are used to promote intercultural dialogue at the national level:

\section{1) The instrumentally integrative approach}

In many EU member states, the social cohesion approach has gained ground. It aims at a more unified society with political stability, internal security, economic growth, and equal opportunities for all individuals and groups, regardless of their origin, to participate in both the work environment and social spheres. To this end, a common national identity, related values and the use of a main national language are being promoted and concepts or requirements in immigration/citizenship laws and policies are developed or tightened. On the other hand, some intercultural dialogue-related programmes or events are also part of this approach; they often aim at supporting the socio-cultural integration of groups or individuals with a migrant background.

This approach is found in countries, which: have ethnically diverse communities, which are often a result of their colonial past, such as Belgium, France or the Netherlands; have attracted, mainly during the last decades, large numbers of migrant workers from both in and outside of the EU, such as Austria, Denmark, Greece, Germany, Luxembourg or Spain; or used to be part of the former Soviet Union or Yugoslavia where certain groups with unclear legal status remain in the population, for example: stateless people (in some of the Baltic States) or so-called "erased people" (Slovenia). 
With reference to refugees and asylum-seekers, whose number has been on the rise above all around the Mediterranean; social fringe groups in the suburbs of large cities in Western Europe; or specific minorities such as the Roma in Central, Southern and Eastern Europe, priority is placed more on improving their basic socio-economic conditions than on intercultural dialogue. In fact, experts or speakers from these communities often argue that intercultural dialogue should not be seen as a replacement for policies related to basic social needs in housing, employment, education, health care, etc.

\section{2) The cultural equity oriented approach}

The second important approach focuses on the legal or political recognition of defined minority cultures and identities that coexist within a territorially defined area, be it that of a nation, region or locality. Minorities are provided with specific rights, some of which are accompanied by affirmative action measures in the fields of culture, education and the media. This approach has been traditionally prevalent in most of the Nordic countries and in the United Kingdom; it seems to gain ground in Belgium (FL), Ireland, Lithuania, Macedonia (FYROM) and Slovenia. For example, in Slovenia, a law defining the scope of special rights for the Roma community was passed in 2007.

\section{Sector approaches}

National approaches to intercultural dialogue are to be understood in a broader context and as a policy issue in the sectors of education, culture, youth and sport.

\section{1) Education: basis for understanding and respecting diversity}

National policy approaches to intercultural dialogue in the education sector range from a focus on civic education (throughout Europe) to intercultural education (in some countries). Intercultural dialogue activities are also found in higher education be it in specific courses or in the context of international academic exchanges. Still, the development of intercultural competencies and skills as part of an overall political vision or national strategy on life-long learning processes - starting from pre-schooling, extending into primary and secondary education and reaching far into the different areas of professional training and lifelong learning programmes - has yet to be achieved.

Acquiring civic competence through education means equipping individuals to fully participate in civic life based on knowledge of democracy, citizenship, and civil rights. There is no common approach to civic education across Europe or even within one country. One of the main issues of civic education from the point of view of intercultural 
dialogue is the content of educational materials, whether for social studies or history teaching.

Across Europe, one of the main objectives of educational policy to promote dialogue is by providing resources for language learning. This takes many forms. Informal intercultural learning activities are also pursued independently of educational institutions through media programmes, exhibitions of culture and heritage institutions, training and employment schemes, etc., which aim at providing multiple perspectives of the past, an understanding of the present and a diversified vision of a common future.

\section{2) Interculture: policies, institutional strategies and artist-led approaches}

Intercultural dialogue in the arts and related fields can take on many different meanings, ranging from promoting formal cultural relationships across national boundaries (i.e. cultural diplomacy) or artist-led partnerships within Europe or internationally (i.e. cross border cultural cooperation).

One of the main cultural policy approaches adopted to promote intercultural dialogue within countries has been to showcase different cultures and cultural expressions through support for one-off projects, events and media programmes. The objective is to give visibility to artists who are not part of the mainstream cultural landscape and as an educative strategy to inform the public about different cultures. On the other hand, there are many artists who reference their own cultural roots in their work, yet want to be recognised for their artistic talents irrespective of their ethnic background.

\section{3) Promoting integration through sports}

National approaches to promoting intercultural dialogue in the field of sports are often challenge oriented and/or target group oriented. As reflected in the 2007 EU White Paper on Sports, ${ }^{5}$ the major challenges are often identified with social inclusion and empowerment of excluded or marginalised individuals and groups; combating racism and xenophobia; or post war reconciliation.

While it is true that sport and its informal settings can provide shared spaces which are more interactive and face fewer barriers than in other parts of society, there is a heavy burden placed on local and voluntary associations to promote the social inclusion of specific target groups such as immigrants (cultural focus), children (age group focus), Muslim

European Commission, White Paper on Sports, 2007. http://ec.europa.eu/sport/whitepaper/the-2007-white-paper-on-sport_en.htm 
female teenagers (gender focus). Despite all these caveats, such approaches are prevalent in most countries.

\section{4) Youths: a challenging generation to target}

New generations of third culture kids (second and third generation immigrants) have been growing, and youths are reported to be the fastest growing group of mixed race in Europe; some of them feel alienated in their present home country and are looking to a return to their cultural roots. Multiple, hybrid identities and complexities are the norm and will determine the process of dialogue and communication in the future. This can be seen through many new hybrid forms of (inter)cultural expressions being created by youths with a migration background, particularly in pop music (e.g. hip hop in Paris or Turkish rap in Berlin). They have also created new forms of dialogue and intercultural links through the Internet, which is also displayed in the escalating number of youth blogs.

\section{Institutional Practices of Intercultural Dialogue}

\section{UN/UNESCO}

The United Nations (UN) has launched many formal initiatives in the last few decades to promote a culture of peace and a dialogue among civilisations. It declared 2001 the United Nations Year of Dialogue among Civilizations. In November 2001, the General Assembly adopted the UN Global Agenda for dialogue among civilisations. Since the adoption of the resolution, the need to promote dialogue has been underlined by UN members and by the UN itself. "Dialogue seeks to enable and promote the best in humanity". ${ }^{6}$

The Alliance of Civilizations was established in 2005, at the initiative of the Governments of Spain and Turkey, under the auspices of the United Nations. The UN Secretary General launched the Alliance of Civilizations initiative to improve understanding and cooperative relations among nations and peoples across cultures and religions and to counter the forces that fuel polarisation and extremism. A high level group of experts was formed by former Secretary-General Kofi Annan to explore the roots of polarisation between societies and cultures and to

6 UN Secretary General Kofi Annan wrote in 2001: "Dialogue is the oldest and most fundamental mode of democratic conversation. It is both a specific working method and an integral part of all other policies to manage cultural diversity today. It is an antidote to rejection and violence. It is a tool that can be used by everybody, by every local and regional authority, every government, every religious community, by migrants and host societies, minorities and majorities, civil society organisations and international bodies like the Council of Europe, in order to improve the situation". 
recommend a practical programme of action. The group's report provided analysis and put forward practical recommendations that have formed the basis for the implementation plan of the United Nations Alliance of Civilizations (UNAOC).

On April 26th, 2007, former President of Portugal, Jorge Sampaio, was appointed High Representative for the UNAOC by SecretaryGeneral Ban Ki-moon to lead the implementation phase of the alliance. The UNAOC Secretariat, which is based in New York, works with a global network of partners with states, international and regional organisations, civil society groups, foundations, and the private sector to improve cross-cultural relations between diverse nations and communities. It also works at the grassroots level, promoting innovative projects that build trust, reconciliation and mutual respect. The alliance works in four program areas to support such projects. These areas are: youth, media, education, and migration.

In 2011 the UNAOC launched the regional initiative "Reconciling diversity and cohesion: a human rights model to build inclusive and participatory societies in European countries". It recognised that migration and the growing mobility of people results in increased diversity in societies, thus leading to new challenges but also to untapped resources. Changing the narrative that most European societies have constructed around diversity seems a necessary move in order to start thinking of cultural diversity as an asset rather than a liability and to make it a full advantage for democracies in the 21 st century.

A wide process of consultations and hearings of a broad array of experts, policy and opinion-makers, local actors, academics, associations, faith-led organisations, corporations and community leaders was started. In the first meeting, members reflected on how best to construct optimal transformative policies that respond to 21 st century complexities. While stressing the positive value of pluralistic societies, the panel identified gaps and priority issues that need to be addressed to provide people with a modern sense of belonging. Thinking deeper about social cohesion, it drafted a number of practical recommendations that were further developed on the occasion of the UNAOC annual Forum in Qatar, in December 2011.

The most recent global initiative is the World Forum on Intercultural Dialogue. It is an initiative of the Government of Azerbaijan, supported by the Council of Europe, its North-South Centre, UNESCO and the UN Alliance of Civilizations. The Forum has taken responsibility for delivering the global agenda of the Dialogue Among Civilisations, adopted by the United Nations General Assembly (November 2001), the UNESCO Convention on Protection and Promotion of the Diversity of Cultural Expressions (2005), the Islamic Declaration on Cultural 
Diversity (2004), the Declaration and Action Plan of the Third Summit of the Heads of State and Government of the Council of Europe Member States, and the Council of Europe's White Paper on Intercultural Dialogue (May 2008).

The first World Forum on "Intercultural Dialogue - United through Common Values, Enriched by Cultural Diversity", took place in Baku (Azerbaijan, 7-9 April 2011). Representatives from many countries from all continents, many international organisations, NGOs, media representatives, scholars and experts participated in the forum. It addressed the universal governance and practical aspects of intercultural dialogue on a global scale ${ }^{7}$ and offered a platform for discussion and interaction between different ethnic, cultural, religious and linguistic backgrounds. The Baku Forum addressed challenges of intercultural dialogue in its various aspects regarding conceptual frameworks, governance, policy and practice. It tackled the barriers to dialogue and faced concretely how dialogue can best be pursued in diverse contexts. Moreover, it provided an opportunity for the sharing of good practices such as the Council of Europe's Intercultural Cities Programme, Artists for Dialogue Initiative, CultureWatchEurope and work on national cultural and youth policies. Two key commitments were made at the first Baku Forum: to turn the world forum into a regular event, and to use appropriate means to place cultural diversity and intercultural dialogue higher on the international agenda.

The 2nd World Forum on Intercultural Dialogue ${ }^{8}$ was held from May 29th to June 1st 2013 in Baku. The programme implied several plenary sessions such as "How to build the world future together?", "How to build the popular support for cultural diversity?" and "The New Era of Globalization: hybridity in culture in a changing world" and "How to build public support for cultural diversity". There were also some parallel roundtables and workshops as well as a ministerial conference. The insight-foresight approach of the 2nd World Forum retained the strong commitment to intercultural dialogue as a tool, a process and as a destination. It showed an applied reflection on how global awareness about the importance of cultural diversity and intercultural dialogue has become both a necessary and desirable characteristic of the contemporary world. The Baku Process is now understood as a process that comprises an open and respectful exchange of views between individuals and groups with different ethnic, cultural, religious and linguistic backgrounds and heritage, living in different continents, on the

\footnotetext{
7 Wilson, R., World Forum on Intercultural Dialogue, Concept Note, April 2011, Baku.

8 http://www.bakuforum-icd.az/
} 
basis of mutual understanding and respect. Still it remains a challenge for the promotion of intercultural dialogue to move from ideas to practice and to establish a platform in which today's challenges can be discussed in the spirit of intercultural dialogue and universal values.

The United Nations Education, Scientific and Cultural Organization (UNESCO) is a specialised agency of the United Nations that was founded on 16th November 1945. It has 195 members and 8 associate members with more than 50 field offices around the world. Using its specialised competencies, UNESCO works to create the conditions necessary for open dialogue among civilisations, cultures and peoples, all based upon a respect for commonly shared values and global visions of sustainable development. The organisation's mission is to contribute to the building of peace, the eradication of poverty, sustainable development and intercultural dialogue through education, the sciences, culture, communication and information. The internationally agreedupon development goals, including the Millennium Development Goals, underpin all of UNESCO's strategies and activities. The overarching objectives of the organisation are: attaining quality education for all and lifelong learning; mobilising science knowledge and policy for sustainable development; addressing emerging social and ethical challenges; fostering cultural diversity, intercultural dialogue and a culture of peace; and building inclusive knowledge societies through information and communication.

In the new, turbulent international globalised landscape, UNESCO is taking greater account of the close links between cultural diversity, dialogue, development, security and peace. From that perspective, the culture of peace imposes itself as the main strategic focus of UNESCO, along with sustainable development. Today, sustainable development calls for a rethink of our relationship to the economy, to society and the environment, bearing in mind that the emerging and future challenges of humankind do require collective responses, which implies the kind of solidarity that can result only from a culture of peace, non-violence and dialogue to bind cultures and societies to each other. In turn, a culture of peace fosters sustainable development since it is aimed at helping people cope resiliently and creatively with ethical, cultural, political, environmental and other social transformations.

Various recommendations, initiatives, actions and projects have been taken on by UNESCO since its creation, to promote intercultural practices within the broad view of culture, peace-building, human rights and sustainable development. The Declaration of the principles of international cultural cooperation in $1966^{\circ}$ clearly recognised mutual

$9 \quad$ http://portal.unesco.org/en/ev.php 
knowledge of cultures as a key to peace. Various medium term plans have been launched to respond to time specific needs; they were focusing on specific characteristics of cultures. ${ }^{10}$ The World Decade for Cultural Development (1988-1997) ${ }^{11}$ combined the specificity and universality of cultural values. Placing culture at the heart of development policy constitutes an essential investment in the world's future and a pre-condition to successful globalisation processes that take into account the principles of cultural diversity.

In 1966 The World Commission on Culture and Development produced the report "Our Creative Diversity". ${ }^{12}$ The report considered a commitment to pluralism to be of fundamental importance. Its message was that cultural pluralism is an all-pervasive, enduring characteristic of societies, and that ethnic identification is a normal and healthy response to the pressures of globalisation. Its central argument is that development embraces not only access to goods and services, but also the opportunity to choose a full, satisfying, valuable and valued way of living together, thus encouraging the flourishing of human existence in all its forms and as a whole. "Development divorced from its human or cultural context is growth without a soul. Economic development in its full flowering is part of a people's culture". This implies a clear shift from the purely instrumental role of culture to awarding it a constructive, constitutive and creative role. In line with the conclusions of "Our Creative Diversity", a thematic programme "Mainstreaming Cultural Diversity and Intercultural Dialogue in Education for Sustainable Development"13 was established in 2007 as a contribution to the UNESCO Decade of Education for Sustainable Development (20052014).

10 The Medium Term Plan 1977-1982 viewed culture at the service of development so that intercultural dialogue could be realised with respect to the value of cultural endogeneity; the Medium Term Plan 1990-1995 was concerned about the development of pluricultural societies and the complexity of cultural identities; it favoured the sense of belonging to a universal culture by stressing the interdependence of cultures and economies; the Medium Term Strategy 1996-2001 focused on the interlinkages of culture with development, democracy, peace and security by evidencing the need for active tolerance and creative diversity.

$11 \mathrm{http}: / / \mathrm{www}$.unesco.org/new/en/culture/themes/culture-and-development/

12 http://unesdoc.unesco.org/images/0010/001055/105586e.pdf

13 http://www.iemed.org/publicacions/quaderns/10/q10_185.pdf; Tilbury, D \& Mulà, I., Review of Education for Sustainable Development Policies from a Cultural Diversity and Intercultural Dialogue: Gaps and Opportunities for Future Action, Paris: UNESCO, 2009. 
The UNESCO Universal Declaration on Cultural Diversity ${ }^{14}$ (2001) presents a very important step towards the institutional building of intercultural dialogue. This is a legal instrument, which recognises, for the first time, cultural diversity as a "common heritage of humanity" and considers it's safeguarding to be a concrete and ethical imperative, inseparable from respect for human dignity. It affirmed the position that "no one may invoke cultural diversity to infringe upon human rights guaranteed by international law, nor to limit their scope". ${ }^{15}$ The connection between human rights and intercultural dialogue became crucial because of their mutually reinforcing of the creation of inclusive societies. And a global culture of human rights requires competence in holding intercultural dialogues.

In 2005, UNESCO provided a new international framework for the governance and management of culture with the Convention on the Protection and Promotion of the Diversity of Cultural Expressions. ${ }^{16}$ It is a legally-binding international agreement that ensures that artists, cultural professionals, practitioners and citizens worldwide can create, produce, disseminate and enjoy a broad range of cultural goods, services and activities, including their own. The focus was on the implementation of international law that would recognises the distinctive nature of cultural goods, services and activities as vehicles of identity, values and meaning; and that, while cultural goods, services and activities have important economic value, they are not mere commodities or consumer goods that can only be regarded as objects of trade. The convention recognised that culture can no longer be just a byproduct of development, but rather the mainspring for sustainable development. The 2009 UNESCO World Report on "Investing in Cultural Diversity and Intercultural dialogue", ${ }^{17}$ further elaborated on the importance of cultural diversity in different areas (languages, education, communication and creativity). This diversity is perceived as an essential dimension of intercultural dialogue for strengthening sustainable development, ensuring the effective exercising of universally recognised human rights and freedoms, and favouring social cohesion and democratic governance. It makes clear how crucial it is to acquire a cultural literacy to understand cultures in their creative diversity.

\footnotetext{
14 http://portal.unesco.org/en/ev.php-

15 UNESCO, 2001, Art. 4.

$16 \mathrm{http} / /$ www.unesco.org/new/en/culture/themes/cultural-diversity/diversity-of-culturalexpressions/the-convention/convention-text/

17 The UNESCO World Report, Investing in Cultural Diversity and Intercultural Dialogue, UNAOC, Paris, 2009; available through http://unesdoc.unesco.org/images/ 0018/001847/184755e.pdf
} 


\section{Council of Europe}

The Council of Europe, founded on May 5th 1949, is an intergovernmental organisation currently comprising of 47 member states. It seeks to develop common and democratic principles throughout Europe, and is marked by its resolute commitment to the promotion of the universally recognised human rights and fundamental freedoms. Numerous international conventions and other legal instruments, policy statements and programme documents have guided its policy. This basis has evolved over more than 60 years and will undoubtedly shape its future policy for the promotion of intercultural dialogue.

According to the European Cultural Convention, signed in 1954 in Paris, the Council of Europe action in the field aims at an intercultural approach based on the principles of equal dignity and promotion of universal values of human rights, democracy, and the rule of law. The purpose of this convention is to develop mutual understanding among the peoples of Europe and a reciprocal appreciation of their cultural diversity, to safeguard European culture, to promote national contributions to Europe's common cultural heritage respecting the same fundamental values and to encourage in particular the study of the languages, history and civilisation of the Parties to the Convention. It organises activities in peacebuilding and intercultural dialogue with training programmes for professionals and volunteers in NGOs dealing with conflict themes. A current 3-year programme focuses on conflict prevention and dialogue between civilisations (including the religious dimension).

\section{1) European legal framework for Intercultural dialogue ${ }^{18}$}

The European Convention on Human Rights (ECHR) ${ }^{19}$ (formally The Convention for the Protection of Human Rights and Fundamental Freedoms) is an international treaty to protect human rights and fundamental freedoms in Europe. It was drafted in 1950 by the then newly formed Council of Europe and entered into force on September 3rd 1953. It established the European Court of Human Rights which interprets and applies the convention and deals with complaints. The court's views on the governance principles and preconditions of

\footnotetext{
18 Wiater, P., Report Intercultural Dialogue in the Framework of European Human Rights Protection, White Paper Series, Volume 1, 2010. This report analyses the jurisprudence of the European Court of Human Rights in terms of the promotion of cultural diversity, as championed by the Council of Europe particularly through its White Paper on Intercultural Dialogue (2008).

19 http://conventions.coe.int/Treaty/en/Treaties/Html/005.htm
} 
intercultural dialogue - and particularly the case law on freedom of thought, conscience and religion, freedom of expression and freedom of association and assembly - provide guidelines for politicians, academics and practitioners alike.

The basic conditions of intercultural dialogue for authentic intercultural dialogue relate to: Democracy: the democratic governance of cultural diversity is one of the main policy approaches for the promotion of intercultural dialogue. Democracy is the foundation of the political system, and citizens are valued also as political actors and not only as social beings, contributors to or beneficiaries of the wellbeing of the nation; Rule of law: a main feature of democracy and a further condition for intercultural dialogue; Equal dignity and equal enjoyment of rights: general principles, ethnic equality and gender equality.

Articles 9, 10 and 11 of the ECHR relate to intercultural dialogue. We will briefly refer to the significance and key principles of these articles.

Article 9 - Freedom of thought, conscience and religion

Significance

1. Everyone has the right to freedom of thought, conscience and religion; this right includes freedom to change his religion or belief and freedom, either alone or in community with others and in public or private, and to manifest his religion or belief, in worship, teaching, practice and observance.

2. Freedom to manifest one's religion or beliefs shall be subject only to such limitations as are prescribed by law and are necessary in a democratic society in the interests of public safety, for the protection of public order, health or morals, or for the protection of the rights and freedoms of others.

Key principles related to intercultural dialogue deal with religious pluralism, tolerance, mutual respect and the principle of nondiscrimination and neutrality and impartiality of state authorities.

Article 10 - Freedom of expression

Significance

1. Everyone has the right to freedom of expression. This right shall include freedom to hold opinions and to receive and impart information and ideas without interference by public authority and regardless of frontiers. This article shall not prevent States from requiring the licensing of broadcasting, television or cinema enterprises.

2. The exercise of these freedoms, since it carries with it duties and responsibilities, may be subject to such formalities, conditions, restrictions or penalties as are prescribed by law and are necessary in a democratic society, in the interests of national security, territorial integrity or public 
safety, for the prevention of disorder or crime, for the protection of health or morals, for the protection of the reputation or rights of others, for preventing the disclosure of information received in confidence, or for maintaining the authority and impartiality of the judiciary.

Key principles related to intercultural dialogue concern pluralism of views and opinions, neutrality of state authorities and tolerance and mutual respect.

\section{Article 11 - Freedom of association and assembly}

\section{Significance}

1. Everyone has the right to freedom of peaceful assembly and to freedom of association with others, including the right to form and to join trade unions for the protection of his interests.

2. No restrictions shall be placed on the exercise of these rights other than such as are prescribed by law and are necessary in a democratic society in the interests of national security or public safety, for the prevention of disorder or crime, for the protection of health or morals or for the protection of the rights and freedoms of others. This article shall not prevent the imposition of lawful restrictions on the exercise of these rights by members of the armed forces, of the police or of the administration of the State.

The key principles related to intercultural dialogue concern the levels of intercultural dialogue. European societies are socially and culturally interconnected. They are embedded in a growing cultural diversification because of migration, asylum seekers and globalisation and because of the effects of revolutions in telecommunications and the media, Internet, development of transport and tourism.

\section{2) Intercultural dialogue as a political priority}

Intercultural education, communication and understanding have been themes of international cooperation for a long time, but the notions of "dialogue of civilisations" and "intercultural dialogue" have only recently begun to appear on the political agenda of international institutions. The policy of the Council of Europe for the promotion of intercultural dialogue has evolved through a long series of European ministerial meetings and expert conferences.

The Third Summit of Heads of State and Government of the Council of Europe (Warsaw, May 2005) in its Action Plan explicitly endorsed intercultural dialogue - together with political and interreligious dialogue - as a means of ensuring that the diversity of European cultures becomes a source of mutual enrichment. The summit also committed itself to a new dialogue between Europe and its neighbouring regions the southern Mediterranean, the Middle East and Central Asia. Since 
then, the promotion of intercultural dialogue has been a major political priority of the Committee of Ministers of the Council of Europe.

The Conference of European Ministers responsible for Cultural Affairs (Faro/Portugal, 27-28 October 2005) was an important milestone for the implementation of this policy. The Faro Declaration was adopted, which contained the Council of Europe's strategy for developing intercultural dialogue. The document placed the strategy for the promotion of intercultural dialogue in the context of the overall objectives to promote human rights, democracy and the rule of law, to strengthen social cohesion, peace and stability. The Declaration thus cleared the ground for the "mainstreaming" of intercultural dialogue in all working areas of the Council of Europe.

Important agreements were signed and declarations issued by the Council of Europe and different partners, charting future cooperation in the field of intercultural dialogue.

- The "Faro Open Platform", created with UNESCO, builds a flexible mechanism of cooperation with international partners, in order to support the development of a coordinated and efficient approach.

- The bilateral agreements signed by the Secretary General and the "Anna Lindh Euro-Mediterranean Foundation for the Dialogue between Cultures" and the Arab League Educational, Cultural and Scientific Organization (ALECSO) provide the Council of Europe with the possibility to engage in closer cooperation with the countries on the southern shores of the Mediterranean and in other regions.

- Declaration on cultural diversity, adopted by the Committee of Ministers of the Council of Europe on 7 December 2000.

- Declaration on intercultural dialogue and conflict prevention, adopted by the European ministers responsible for cultural affairs, Opatija (Croatia), 22 October 2003.

- Declaration by the European Ministers of Education on intercultural education in the new European context, Athens (Greece), 10-12 November 2003.

- Declaration on 50 years of cultural cooperation in Europe, adopted by the ministers responsible for culture, education, youth and sport of the signatory states of the European Cultural Convention, gathered at Wroclaw (Poland), 10 December 2004.

- Declaration on the Council of Europe's Strategy for Developing Intercultural Dialogue, adopted by the ministers responsible for cultural affairs in the States Party to the European Cultural Convention gathered in Faro (Portugal), 27-28 October 2005 ("Faro Declaration"). 
In practice, all component parts of the Council of Europe contribute to intercultural dialogue in various forms:

- As legal instruments that set certain standards for the interaction between majority and minority cultures, such as the Framework Convention for the Protection of National Minorities or the European Charter for Regional or Minority Languages;

- As statutory activities, like the case law of the European Court of Human Rights, or the reports of the European Commission against Racism and Intolerance (ECRI), monitoring the quality of intercultural interaction;

- As long-term action programmes, e.g. those focussing on education for democratic citizenship, teacher training for intercultural learning and history teaching, inter-community relations, the programme for the development of monitoring and communication tools of national programmes for Roma in South East Europe, or;

- As specific programmes run by the North-South Centre, the European Centre for Modern Languages and the two European Youth Centres of the Council of Europe;

- As distinct high-visibility initiatives like the ministerial conference in Faro (2005), the 3rd Intercultural Forum (Bucharest, March 2006) or the conference on "Dialogue of Cultures and Inter-Faith Cooperation" (Nizhniy Novgorod, 2006);

- As individual activities that are part of other programmes of activities but have a clear relevance for the promotion of intercultural dialogue, such as the "European Language Portfolio";

- Coherence was assured through the appointment of a "Coordinator for Intercultural Dialogue" and the creation of an inter-service Task Force on Intercultural Dialogue as a platform for the exchange of information.

- In 2006, the Committee of Ministers launched preparations for the White Paper on Intercultural Dialogue ${ }^{20}$ of the Council of Europe, which was published in May 2008, the first of its kind on this specific topic at least at the international level. The White Paper is drawn into the democratic management of cultural diversity at every level of governance - from local to regional to national to international.

Generally speaking, "white papers" are policy documents containing background information and proposals for action in a specific political area. The White Paper on Intercultural Dialogue argues that intercultural dialogue can help meet the challenges posed by cultural diversity.

20 White Paper on Intercultural dialogue: Living together as Equals in dignity: Dialogue-A Key to Europe's Future, CM (2008) 30, 2 May 2008. 
Dialogue will however only be effective if the dialogue partners share at least some basic values and cultural references and if they are willing to engage in dialogue on an equal basis; if the political environment is supportive and aiming at greater social justice, and does not work against intercultural dialogue; if there is coherence between the initiatives at local, national and international levels; if civil society is involved; and if the cultural industry supports dialogue.

- In 2011 the Council of Europe published the Report of the Group of Eminent Persons "Living together. Combining diversity and freedom in 21 st century Europe". ${ }^{21}$ It identified various threats that Europe is facing (such as rising intolerance, rising support for xenophobic and populist parties, discrimination, the presence of a population virtually without rights, parallel societies, Islamic extremism, the loss of democratic freedoms, possible clashes between "religious freedom" and freedom of expression). Reasons are related to insecurity, immigration, distorted image of minorities in the media and harmful stereotypes and a crisis of leadership. It offered guiding principles and strategic recommendations.

\section{3) Assessment}

The Council of Europe is committed to common values and principles, which are rooted in Europe's cultural, religious and humanistic heritage - a heritage both shared and rich in its diversity. The statutory mission of the organisation is the promotion and active defence of pluralist democracy, universal human rights and the rule of law. Values are important building materials for social cohesion. However intercultural dialogue, as a tool for the promotion of cultural diversity and social cohesion, can only be successful if the dialogue partners - independent of all differences - are sharing certain common values and cultural references.

The Council of Europe's approach to intercultural dialogue brings into focus all policy areas directly influencing the diversity of cultural practices and cultural identities. It concerns, to name just the most obvious, policies regarding citizenship and rights of participation, education, social cohesion, minority rights, immigration, foreign affairs, language, relations between the state and religions, the development of civil society and gender equality. Education, in all its forms, arguably plays the most important role of all, since the skills necessary for living peacefully together in a culturally diverse environment need to be acquired and can be taught; this includes for instance the important areas of the teaching of foreign languages and of history.

21 Council of Europe, Report of the Group of Eminent Persons Living together. Combining diversity and freedom in 21st century Europe, 2011. 
In a wider sense, however, coherence must be achieved also with other policy areas, i.e. with those that influence the material living conditions and the sustainability of cultural identities, such as social services, housing, labour markets, urban planning, public health and many more. A better integration of these policy areas is necessary for addressing the negative consequences of social fragmentation and the precarious social and economic positions of many individuals and groups.

The diversity and scope of policy areas concerned with intercultural dialogue presents a specific challenge, which cannot be addressed by ad hoc or sectoral measures without running the risk of neutralising the efforts in one domain by opposite or ill-conceived measures taken in another. In order to be effective, the principle of promoting intercultural dialogue must therefore become an integral part of policy-making and policy implementation in practically all other areas. This is usually called "mainstreaming".

This brings into focus the role of the different stakeholders of intercultural dialogue, who act in very different political and institutional contexts. At the local level, initiatives by individuals and civil society organisations, the activities of religious communities, the policies and services of local and regional authorities as well as neighbourhood media - they all play a very important role for the promotion of intercultural dialogue. Issues faced by cultural and religious minorities can often be best addressed at the local level. Parliaments, governments, administrations and NGOs at national level share this responsibility for fostering a culture of understanding. Also international organisations can contribute in various ways. Of course, all this works more effectively if they share the same priorities and convictions. A particular role is set for cultural industries in promoting intercultural dialogue (for example, through music, film, publishing, cultural tourism) and reflecting on society's diversity. This includes the media, referring to printed and broadcast media and the growing importance of new technologies, as tools of creation, information and communication.

\section{European Union}

\section{1) Conceptual premises}

The European Union (EU) is now a Europe of 28 member states and 500 million citizens. It is a Europe at the crossroads of its past, present and future. It is at a crucial point at the intersection of its history and a decisive moment in the process of European integration. History illustrates that Europe is a dynamic and evolving entity with many faces, multiple identities and diversified cooperation forms. 
Today the European reality is confronted with the frontiers of its pragmatic and functional integration process. The 21 st century is making new demands that call for a revision of the perspective of Europe. Today, its model of society, based on fundamental human rights, culture as a vehicle of emancipation, of sustainable development and socio-economic cohesion, and on a multilateral vision of the world order, is under stress. In other words, an intense conversation between the confusing actual (political, economic, cultural and institutional) European reality and Europe's responsibility in the context of an everincreasing globalisation, is clearly taking place.

Moreover, the EU is made up of multicultural societies. Conflicts do influence how people define their identities and how they perceive themselves in relation to their own culture and to others. Manuel Castell, ${ }^{22}$ the Spanish sociologist, sees economic, political, social or cultural exclusion as the main cause for conflicts. He believes in the power and necessity of communication to restore confidence and to formulate common projects. This implies that conflict prevention, building bridges between cultures and religions and extending the multicultural context require new concepts, approaches and tools.

A final conceptual premise refers to the fact that dialogue supposes equality. A healthy multicultural society can only be built on mutual respect. This is not a sufficient but an absolutely necessary condition for a successful policy of intercultural dialogue. For Edgar Morin, the French philosopher and sociologist, dialogue is only possible between individuals who recognise themselves as persons with the same dignity, rights and obligations. ${ }^{23}$

\section{2) EU legal framework for intercultural dialogue}

a) Articles 2, 3 and 6 of the current Treaty of the European Union provide the fundamental basis of the legal framework of the EU's activities in the field of intercultural dialogue. They read as follows:

Article 2, TEU: The Union is founded on the values of respect for human dignity, freedom, democracy, equality, the rule of law and respect for human rights, including the rights of persons belonging to minorities. These values are common to the Member States in a society in which pluralism, non-discrimination, tolerance, justice, solidarity and equality between women and men prevail.

22 Castells, M., The Network Society: A Cross-Cultural Perspective. Cheltenham, UK, Northampton, MA: Edward Edgar, 2004.

23 Talking to Edgar Morin, Dialogue assumes equality, interview by UNESCO, The New Courier, January 2004. 
Article 2, TEU: 1. The Union's aim is to promote peace, its values and the wellbeing of its peoples. [....] 3. The Union shall establish an internal market. It shall work for the sustainable development of Europe based on balanced economic growth and price stability, a highly competitive social market economy, aiming at full employment and social progress, and a high level of protection and improvement of the quality of the environment. It shall promote scientific and technological advance. It shall combat social exclusion and discrimination, and shall promote social justice and protection, equality between women and men, solidarity between generations and protection of the rights of the child. It shall promote economic, social and territorial cohesion, and solidarity among Member States. It shall respect its rich cultural and linguistic diversity, and shall ensure that Europe's cultural heritage is safeguarded and enhanced.

Article 6, TEU: 1. The Union recognises the rights, freedoms and principles set out in the Charter of Fundamental Rights of the European Union of 7 December 2000, as adapted at Strasbourg, on 12 December 2007, which shall have the same legal value as the Treaties. 2. The Union shall accede to the European Convention for the Protection of Human Rights and Fundamental Freedoms. [....]

b) The Preambule of the Charter of Fundamental Rights of the EU (annex of the Lisbon Treaty, 2009) reads as follows:

The peoples of Europe, in creating an ever closer union among them, are resolved to share a peaceful future based on common values. Conscious of its spiritual and moral heritage, the Union is founded on the indivisible, universal values of human dignity, freedom, equality and solidarity; it is based on the principles of democracy and the rule of law. It places the individual at the heart of its activities, by establishing the citizenship of the Union and by creating an area of freedom, security and justice. The Union contributes to the preservation and to the development of these common values while respecting the diversity of the cultures and traditions of the peoples of Europe as well as the national identities of the Member States and the organisation of their public authorities at national, regional and local levels; it seeks to promote balanced and sustainable development and ensures free movement of persons, services, goods and capital, and the freedom of establishment. To this end, it is necessary to strengthen the protection of fundamental rights in the light of changes in society, social progress and scientific and technological developments by making those rights more visible in a Charter.

Articles 10, 11 and 12 of the EU Charter of Fundamental Rights are of particular importance to intercultural dialogue. They address equality (e.g. non-discrimination and cultural, religious and linguistic diversity), freedoms (e.g. freedom of expression, of thought, conscience and religion), and citizen's rights (e.g. of movement and residence, to vote).

Article 10: Freedom of thought, conscience and religion 
1. Everyone has the right to freedom of thought, conscience and religion. This right includes freedom to change religion or belief and freedom, either alone or in community with others and in public or in private, to manifest religion or belief, in worship, teaching, practice and observance. 2 . The right to conscientious objection is recognised, in accordance with the national laws governing the exercise of this right.

\section{Article 11: Freedom of expression and information}

1. Everyone has the right to freedom of expression. This right shall include freedom to hold opinions and to receive and impart information and ideas without interference by public authority and regardless of frontier. 2 . The freedom and pluralism of the media shall be respected.

Article 12: Freedom of assembly and of association

1. Everyone has the right to freedom of peaceful assembly and to freedom of association at all levels, in particular in political, trade union and civic matters, which implies the right of everyone to form and to join trade unions for the protection of his or her interests. 2. Political parties at Union level contribute to expressing the political will of the citizens of the Union.

\section{3) EU initiatives}

The enlargement of the European Union, coupled with increasing mobility linked to the common market, new and old migratory flows, the new trade ties with the rest of the world, and education, leisure and globalisation in general, have led to increased contact between cultures, religions, ethnic groups and languages. Against this backdrop and in the context of an increasingly multicultural EU, the development of intercultural competences and the promotion of intercultural dialogue have been a driving force for related EU initiatives.

The promotion of intercultural dialogue became high on the political EU agenda after the attack on the Twin Towers of 9/11. Various EU activities and conferences were organised in the aftermath to support the importance of intercultural dialogue, often in collaboration with the academic world and the Jean Monnet Programme of the EU. ${ }^{24}$ The March 2002 Jean Monnet conference on "Intercultural dialogue" 25 focused on the centrality of the human rights paradigm and its practical implications as to the place of Europe in the world, interreligious dialogue, democracy and globalisation. Its conclusions have given input to the Euro-Mediterranean conference of the Ministers of Foreign Affairs in Valencia, April 22nd-23rd 2002, in order to re-launch the

\footnotetext{
24 See Chapter 8.

25 European Commission, Intercultural Dialogue, Luxembourg: Office for Official Publications of the European Communities, 267 p., 2002.
} 
Barcelona Process. An action program resulted from the conference with an important section on the dialogue between cultures/civilisation. The European Commission also supported an international conference in Beyrouth in September 2002 on "Cultures, Religions and Conflicts" and organised another Jean Monnet Conference in December 2002 on "Peace, Security and Stability: an international dialogue and the role of the EU". In 2003, Romano Prodi, the then president of the European Commission, created a high level advisory group, "The Dialogue between peoples and cultures in the Euro-Mediterranean area". ${ }^{26}$ Its report finally led to the creation of the Anna Lindh Euro-Mediterranean Foundation for the Dialogue between Cultures in Alexandria (Egypt). ${ }^{27}$ As mentioned in Chapter 8 the Jean Monnet programme financed the Interuniversity European research project "Intercultural Dialogue for the development of a new (plural, democratic) citizenship" 28 in 2007-2008, resulting in the launch of a Jean Monnet Centre of Excellence "Intercultural Dialogue and Multi-level Governance" at the University of Padua (I) in 2009. ${ }^{29}$

\section{4) Assessment}

Intercultural dialogue contributes to a number of strategic priorities of the European Union, such as respecting and promoting cultural diversity; favouring the European Union's commitment to solidarity, social justice and reinforced cohesion; allowing the European Union to make its voice heard and realising new efficient partnerships with neighbouring countries. Indeed, the European Union has for the last two decades encouraged intercultural dialogue, both inside and outside of the European Union, through various programmes and initiatives.

However, to realise this objective and to reinforce European Community action, a first step is to identify, promote and exchange experiences and best practices that would illustrate the possibility, value and efficiency of intercultural dialogue. The European Commission has initiated this process of valorisation via projects supported by European Community programs. A second step is to treat intercultural dialogue as a horizontal priority for all relevant European Community programs, especially for those related to culture, education, youth and citizenship;

26 High-Level Advisory Group, European Commission, Dialogue between peoples and cultures in the Euro-Mediterranean Region, 2003, 45 p.

27 See The Anna Lindh Report Euromed Intercultural Trends 2010; http://www.euromedalex.org/sites/default/files/AnnaLindhReport2010.pdf

28 Bekemans, L., M. Karasinska-Fendler, M. Mascia, A. Papisca, C.A. Stephanou and P.G. Xuereb (eds.), op. cit.

29 Bekemans, L. (ed.), Intercultural Dialogue and Multi-level Governance in Europe. A Human Rights Based Approach, op. cit. 
Finally, 2008 was declared the Year of Intercultural Dialogue. Since then, intercultural dialogue events have complemented existing community programs and raised the awareness of citizens, especially the youths, as to the importance of intercultural dialogue. ${ }^{30}$

\section{Intercultural cities: a good practice towards a model for intercultural integration $^{31}$}

One very interesting initiative is the Intercultural Cities project, a joint initiative of the Council of Europe and the European Commission, which was launched in 2008. It supports the conceptual development, implementation and assessment of urban diversity strategies and has introduced the model of intercultural integration, i.e. a new model of local governance and policy in the age of diversity. It explains what intercultural integration means in practice: how it affects policies, governance and citizenship, public discourse, media relations, public services and the urban environment. It reviews the processes that facilitate the development of intercultural strategies and presents a wide range of examples. Intercultural integration models are now being applied in 60 cities across Europe as well as Mexico, Canada, and cities in Japan and Korea. ${ }^{32}$

It has stimulated an inclusive debate and policy-making in pilot cities, taking an intercultural approach to migration, integration and social cohesion; encouraged pilot cities to develop comprehensive intercultural strategies to manage urban diversity and acted as an inspiration for other cities in Europe. It proposes practical policies and methods to help cities review their policies through an "intercultural lens", including tools like expert reviews, study visits, city-to-city mentoring, thematic workshops and public events.

In short, intercultural integration calls for a review and reshaping of urban policies on education, spatial planning, safety, culture, economic development, employment, etc. with a view to identifying the skills and competences of migrants, giving them access and empowering them to be full participants in city life. It presents a vision for the future by identifying the characteristics of an intercultural city: diversity is a source of dynamism, innovation, creativity and growth; diversity is accepted as the norm and the heritage and identity of all people is affirmed; public spaces, schools, homes, workplaces and cultural forums

\footnotetext{
30 Decision $N^{\circ} 1983 / 2006 / E C$ of the European Parliament and of the Council of 18 December 2006 concerning the European Year of Intercultural Dialogue in 2008.

31 Wood, Phil (ed.), Intercultural Cities. Towards a model for intercultural integration, Council of Europe, 2010.

32 See www.coe.int/interculturalcities
} 
are designed to enable people from different cultural backgrounds to mix, exchange and interact productively and creatively; public consultation, debate and decision-making reflect the community's cultural mix. To make this vision a reality, cities must develop an intercultural strategy to transform their policies, public spaces, institutions and partnerships. As a consequence, politicians and the media should therefore encourage citizens' participation in creating a shared identity.

The development of an Intercultural City Index is, in this perspective, very interesting. It is based on a questionnaire involving 66 questions grouped in 14 indicators with three distinct types of data. Indicators have been weighed for relative importance. For each indicator, the participating cities can reach up to 100 points (which are consolidated for the general ICC Index). These indicators comprise of: intercultural commitment; education system; neighbourhoods; public services; business and labour market; cultural and civil life policies; public spaces; mediation and conflict resolution; language; media; international outlook; intelligence/competence; the welcoming of new arrivals and governance. Some of these indicators - education system; neighbourhoods; public services; business and labour market; cultural and civil life policies; and public spaces are grouped in a composite indicator called "urban policies through the intercultural lens" or simply "intercultural lens".

In 2013 The Council of Europe published a Practical guide for applying the urban model of intercultural integration. ${ }^{33}$ The guide is designed for city leaders and practitioners wishing to learn from the intercultural cities pilot project in developing an intercultural approach to diversity management and integration. This approach has been built on the basis of the experience of dozens of real-life cities in redesigning their policies and reshaping their governance to ensure equal opportunities and realise a diversity advantage. It recommends steps and measures to help develop an intercultural strategy and monitor its implementation.

\section{Evaluation}

An authentic EU intercultural dialogue calls for a conceptual framework that deals with diversity on a European and global scale; requires a socio-cultural setting that combines globalisation with cultural assertivity and assumes a moral dimension that favours commonly shared values worldwide. The proposition of such a

33 Council of Europe, The intercultural city step by step - Practical guide for applying the urban model of intercultural integration, 2013. 
framework requires a few additional explanatory and voluntaristic observations, which refer to some of the previous chapters.

\section{Culture as a driving force for genuine intercultural dialogue}

We recognise cultural pluriformity as the main character of European civilisation. It is a source of wealth and strength. No culture can be missed out in the European cultural mosaic. Protection of cultural diversity, however, does not imply nationalistic or regionalist isolation or a European fortress, inside or outside the EU.

We recognise a tension between culture and integration in European developments. Therefore, we have to be careful not to turn Europe into a global cultural area, which resembles a melting pot in which all diversity would be lost. Different cultures should not be separated; but enter into dialogue with and influence each other and transform themselves while remaining diversified.

We favour mutual learning as an agenda for intercultural dialogue. It would be a grave mistake to save the originality of particular cultures by isolating them from dialogue with other cultures or to accept a cultural relativist approach on the global scale. Moving away from the Western sense of superiority and the rise of cross-cultural relativism, there is indeed a growing recognition that some forms of cross-cultural judgements can be appropriate worldwide. We assume that a dynamic cultural sector helps to ensure real participative democracy and activates democratic empowerment, by inspiring citizens to become active, creative and responsible.

Intercultural dialogue is an important way of overcoming some of the negative consequences of globalisation (i.e. minorities, migration, poverty), condition to the recognition of common and moral values (i.e. human dignity, respect for difference and diversity, solidarity, etc.). As such, intercultural dialogue is an important instrument in governance building, creating mutual understanding, trust and confidence. It is a vehicle for a more active, consensus building citizens' participation to create tolerance and respect between different cultures and peoples and to overcome ignorance, arrogance, fear and mistrust. Such a dialogue should be perceived as a path to conviviality and interculturalism in which cultures influence each other without destroying themselves or entering into clashes or conflicts. It is therefore a crucial path for peace and genuine sustainable development and may lead to a conversation among equals with respect for the difference and the diversity of each other. 


\section{Europe's responsibility to favour a dialogue between diverse cultural discourses}

Europe as a global actor has an important responsibility in intercultural dialogue. It should take up its role as an enabler and facilitator. Europe should be a communicative bridge builder and a boundary breaker in such a dialogue. The EU has a valid socioeconomic foundation that is based on democracy, human rights, solidarity and above all diversity, meaning respect for different cultures, languages, religions, traditions, etc. This implies mutual understanding and learning and an open dialogue.

Europe should play a proactive role in defusing the tension between universalism and particularism in a globalising world, combining difference and identity in novel ways of dialogue and cooperation. Europe is called upon to meet the challenge of crossing its boundaries, respecting the right to diversity and difference but preserving fundamental values. The actual realisation of related programmes and partnerships therefore requires an imaginative and courageous approach to Europe's destiny in the world.

In view of the process of globalisation and its consequences on cultural exchanges and cooperation worldwide, Europe is required to take up its moral responsibility to contribute to a strengthening of an intercultural dialogue among equals in a globalising world, while firmly supporting its commonly shared values at all possible policy levels. The maintenance and promotion of the global common good of economically, socially and culturally sustainable development worldwide, the common practice of mutual learning and the centrality of the individual citizen as a person within a community and a coherent internal and external policy are to be Europe's guiding principles in promoting globalisation with a human and cultural face.

\section{Human rights paradigm: the basic point of departure for intercultural dialogue}

Human rights are at the core of any suitable approach to intercultural dialogue. The International Law of Human Rights has extended its constitutional space from inside the nation state to the entire world. The human rights paradigm is assumed as a powerful transcultural facilitator in moving from the (increasingly) conflicting stage of multi-culturality to the dialogic stage of inter-culturality.

Such a universal human rights approach to intercultural dialogue also requires a European policy interpretation. Public policies are absolutely necessary to pursue the strategic goal of the inclusion of all individuals and groups living in the EU. A major coordination with the other 
European institutions engaged in this field, in particular with the Council of Europe and the OECD, is desirable; also a major focus and continuity to partnerships with other regions in the world and to strengthen the support to the UN. The European Union should give an example of how to apply (first of all within its territorial and institutional space) universal human rights into its internal and external policies. The challenge is to make the European space, marked by a process of increasing multiculturalisation, a real yardstick for interculturality and a policy environment responsible for the appeal of shared responsibilities in the globalised world.

\section{From policy to practice}

Sources of good practice projects are multifold. ${ }^{34}$ Successful intercultural dialogue projects are to be found in "shared spaces"; both institutional spaces and non-institutional spaces. Moreover, diversity can be fostered at all stages of cultural/artistic production, distribution and participation. The educational challenges are to develop intercultural competences and skills among all members of society and to stimulate transnational cooperation activities. Finally, interactive communication processes stimulate empowerment or development of self-confidence in individuals, and a sense of collective responsibility.

A number of guidelines of intercultural practices can be identified for sharing diversity within and between cultures: Recognise that intercultural dialogue depends upon the full implementation of human, civic, economic, social and cultural rights; Acknowledge intercultural dialogue at the heart of citizenship and integration strategies; Approach intercultural dialogue as a transversal issue which is part of a complex system of governance based on diversity, equality and participation; Develop strategies which view intercultural dialogue as a process of interactive communication within and between cultures and; Open up institutional structures and international cooperation for intercultural dialogue. In summary, interculturality should become a practice of plural citizenship, favouring an alliance of civilisations above a clash of civilisations.

\footnotetext{
34 http://www.coe.int/t/dg4/intercultural;

http://www.interculturaldialogue2008.eu;

http://ec.europa.eu/dgs/education_culture/dialogue/catal_dial_en.pdf;

http://www.culturalpolicies.net/web/intercultural-dialogue-database.php
} 


\section{Conclusion}

\section{Intercultural dialogue and identity}

Intercultural dialogue requires an open attitude towards "the other", a desire to listen to them and to induce comprehension. However, many people are still afraid that intercultural encounters result in a loss of identity and create insecurity. So, to overcome the perception of "the other" as potential threat it is necessary to build the sense of belonging as close as possible to the citizen, to create small and local communities where "the other" can become an accepted neighbour. Subsequently, a spill over effect can support the building up of identities, not defined in a negative way as being opposed to something, but characterised as belonging to a group differentiated but sharing a basic set of common values and interests.

It should be clear that the prior goal of intercultural dialogue is not integration or assimilation of individuals and groups of different cultures, but an incentive to share universal values by/for "doing together". Political participation and laicality are fundamental features of inclusiveness at all levels; they may give rise to a new civic identity, referring to the European-constitutional motto "united in diversity".

The following policy conclusions are proposed: The policy of local authorities should encourage and provide the material basis for the building up of local communities of civic society; Citizen participation should be promoted locally where the basic needs are met to create a sense of community between those sharing basic interests; Various fora for intercultural dialogue other than those usually associated with interculturalism and dialogue. In the case of infrastructure projects, the integration of local community stakeholders in debates over the common good may lead to intercultural "learning by doing" at the regional and local level and in daily life; The cross-border cooperation programmes and programmes addressed to the third countries with the participation of EU member states should take into account the intercultural element; and finally, a focus on educating about intercultural dialogue is fundamental for sustainable results. However, the coherence between school education, aimed at intercultural dialogue, and home education, which sometimes propagates opposite attitudes visà-vis "the others", is not always present. It seems that a stronger involvement of families with schools could result in a peaceful coexistence, building up the environment for shaping open identities and inclusive societies. 


\section{Intercultural dialogue and citizenship: universal basis, European dimension and plural character}

The European integration process is aiming at the building of an ever-closer Union between the peoples of Europe. The idea and institution of European citizenship should therefore be the framework in which the European peoples identify themselves as the European demos, living in a broad cultural space and belonging to a large and differentiated polity. ${ }^{35}$

Universal citizenship is the grant provided by the "new" International Law, which is rooted in the United Nations Charter and in the Universal Declaration of Human Rights. In virtue of this Ius Novum Universale, all human beings are endowed with the same legal statute in the world constitutional space. The rationale of universal citizenship is to include all, i.e. ad omnes includendos.

A new European citizenship appears as a model for democratic community where all citizens are treated equally, exhibiting universal rights as well as rights relevant to their group differences. European citizenship also means plural and active citizenship, being the core of any credible policing of intercultural dialogue. Its immediate implication is that all residents in a given territory, as human beings having the same legal status internationally recognised, should enjoy the same fundamental political, civil, economic, social, cultural rights and liberties. In this perspective, plural and active European citizenship is strictly linked to democracy in its different political, economic and social dimensions, in its various representatives, participatory and deliberative forms and in its local, national and international expressions.

The following policy recommendations are suggested: A new model of European citizenship is needed which includes universal and multicultural rights; European citizenship should be based not only on nationality, but also on legal residence. This means that legal long-term third country nationals should be recognised as Union citizens.

\section{Intercultural dialogue and democracy: major challenges and participatory characteristics}

The challenge to current politics is the search for a coherent combination of all dimensions of democracy and, at the same time, an extension of democratic practices up to the international institutions. Strengthening and democratising the United Nations should hopefully become a fundamental common goal for the actors in dialogue. It is

35 The concept of citizenship is further elaborated in Chapter 12. 
assumed that an intensification of intercultural dialogue and a reinforcement of deliberative democracy might contribute to the development of a new European policy of greater inclusiveness, rejecting a distinction between insiders and outsiders, and increasing a sense of belonging. Such a dialogue constitutes a solid basis for the European active citizenship, strengthens empowerment and contributes to the deepening of the European identity.

I am convinced that intercultural dialogue may contribute to an intercultural society that brings a new and advanced type of democracy to the growing diversity of the European political, social and cultural space. Preconditions for such an intercultural dialogue are: the acceptance of the human rights paradigm as a solid basis for mutual respect; an intensification of intercultural communication; a recognition of cultural pluralism; greater citizens' participation; inclusive policies at all levels and within all sectors; and the development of a culture of dialogue and an education of intercultural dialogue. Democracy needs intercultural dialogue for the exploitation of its full potential as much as intercultural dialogue needs democratic practices.

\section{The structural/institutional setting for intercultural dialogue: the European Dialogues' framework}

Structures for effective and sustainable intercultural dialogue are important for the policy implementation of the key concepts of identity, citizenship and democracy. A relevant question concerns the EU policy for political dialogues, discussions, cooperation, and the human rights clause in EU treaties with third countries. The purpose of sharing a precise world order model is missing in this approach. Dialogues provide a clear framework for EU policy-making and would increase the democratic legitimacy that is needed to gain the vital support of the European civil society and public opinion. Intercultural dialogue has (still) not formally entered into the EU dialogues' agenda, but informally it is very present.

Indicators of an "inclusive Europe", taking into account the principle of subsidiarity, should include: a revision of the EU citizenship, in accordance with the EU Charter of Fundamental Rights; a human security (and human rights) approach for the chapter on "Justice and Home Affairs"; a legislation on asylum and immigration in accordance with the International Law of Human Rights; welfare policies for economic and social rights; a real and consistent commitment to contribute to build up a world order based on the UN Charter and the international law of human rights; and a larger and more substantive space for the role of civil society organisations and local institutions in the various forms of dialogue and communication. 
Intercultural dialogue is therefore of the utmost importance to meeting the challenges of globalisation and living together peacefully in a diverse world. It contributes to the recognition that difference exists between peoples and societies, and addresses the need to encourage mutual trust and understanding between diverse peoples. Moreover the environment in which intercultural dialogue takes place is marked by difference, proximity and interconnectedness.

Approaching cultural diversity requires that the broadest possible range of competences be identified and promoted. Hence the growing awareness that intercultural competences constitute a very relevant resource and become a requisite response to help individuals negotiate cultural boundaries throughout their personal encounters and experiences. The UNESCO and the Council of Europe have been addressing the growing interest in intercultural competences by proposing strategies, guidelines and handbooks in view of the realisation of true intercultural dialogue. ${ }^{36}$ Placing cultural diversity and intercultural dialogue higher on the international agenda is therefore critical for human security and a prime responsibility for the 21st century to safeguard the survival, livelihood and dignity of individuals.

36 UNESCO, Intercultural Competences, Conceptual and Operational Framework, 44 p., 2013; Council of Europe, Intercultural competence for all: Preparation for living in a heterogeneous world, Pestalozzi Series no. 2, Strasbourg: Council of Europe Publishing, 2012. 



\section{CHAPTER 12}

\section{Citizenship-building in EU}

\section{Introduction}

The notion of citizenship refers to an active and responsible participation of individuals in the society in which they live. Without going back to the Greek and Roman roots in our Western culture, we should underline that it is only through the recognition of the status of citizenship that our societies actually became "civil" societies and authentic democracies. There is indeed no democracy without full, free and active participation of citizens in the decisions that concern them. Thus, one understands that the possession of the "nationality" of a state does not by itself create a democratic system; this is why one should not confuse the notions of citizenship and nationality.

Since the 1990s, citizenship has become one of the key issues of the political debate. The notion of citizenship is changing at a great pace because of the great economic, social and political changes that occurred while the 20th century moved into the 21 st century. In short, citizenship refers to attitudes, awareness and behaviours based on civil, political, social and cultural rights in a geographical space within a socio-political framework (i.e. city, region, country, Europe and the world).

\section{Process of European Citizenship-building}

\section{The classical concept of citizenship}

The classical concept of citizenship relates to a legal and political status that allows the citizen to acquire some (civil, political, social...) rights as an individual and some duties (taxes, military service, loyalty...) in relation to a political community, as well as the ability to intervene in the collective life of a state. The latter right arises from the democratic principle of the sovereignty of people. Citizens of a state have a series of rights, granted by their constitutions, but also have obligations, with regard to their national community. In a democratic state, the citizen must fulfil those obligations since they were passed by the representatives they voted in, using one of the main citizen political rights - suffrage. Citizenship is restricted to people who have that condition. People that live in a territory but lack the status of citizen are deprived of the rights and duties that citizenship involves. Every state 
has laws to regulate the way an individual can acquire its nationality, that is to say, their citizenship.

This concept of citizenship dates back to a historical period initiated by the great liberal revolutions of the late 18th century, linked to the granting of civil rights. The institutions most directly associated with them are the Courts of Justice. Political rights mainly developed in the 19th century, and the corresponding institutions are parliament and local councils. Social rights mainly developed in the 20th century, and the institutions most closely connected with them are the education and social public service systems. ${ }^{1}$

It is a notion characterised by the pre-eminence of the state-nation as the political community that comprises the individuals. Citizenship is tantamount to nationality. In fact, in the traditional thinking of the nation-states which have dominated the political scene of Europe for the last two centuries, and because of people's ideological identification with the idea of a nation, there existed a kind of intellectual confusion between the three notions of identity, nationality and citizenship. "People" were traditionally defined and identified by the nation-state ruling over them; they were defined as "national" because they belonged to their country. It was through this national status that they acquired their citizen's rights.

The dominant political paradigm was the so-called Westphalian system, which originated in the 17 th century. Five principles ruled the relationship between states in that system: 1) Governments of nationstates (kings in the past, parliament and executives in modern times) are the exclusive owners and holders of sovereignty; 2) This sovereignty covers a well-defined and limited territorial space; 3) Governments (whatever their internal political system) are the only political actors on the international and world levels, holders of all recognised rights outside of their territory; 4) There is no pre-existing international order, or legal order, outside of treaties signed by sovereign nations; and 5) Wars between nations are a legitimate instrument to solving conflicts. In other words, a democratic approach to international life, which would have implied an active and direct participation of citizens outside of the borders of their nation, was not at all required.

\section{Challenges to the nation-state and the citizenship equivalent to nationality}

The concept of citizenship has evolved from the classical ages to the present time. In the 21 st century, we are witnessing a quite different

Heater, D., What is Citizenship?, London: Polity Press, 1999. 
kind of citizenship, in particular in the European context. Although the nation-state continues to be the key element of the world political map, changes are taking place that illustrate an evident challenge to this kind of political organisation.

Two major transformations are questioning the role of the contemporary nation-state and the concept of citizenship that it embraces. Firstly, the process of globalisation implies that the central and strategic economic activities are integrated on a world scale through electronic webs of capitals, goods, and information exchange. A key element of this globalisation is the development of the Internet and the information society. This globalisation of markets is the decisive factor that impelled further steps to be made towards European integration, from the Economic and Monetary Union to a stricter Financial and Budgetary Union. The nation-state is less and less able to cope with the challenges of globalisation. Secondly, the existence of more multicultural societies, which breaks up the theoretical homogeneity of the nation-state. Regional or national diversity in many European countries as well as multiculturalism and multi-ethnicity brought about by growing immigration are key aspects of the new European society. European citizenship departs from this new European society.

\section{Historical development}

The history of the European integration process shows a development from a (neo) functional, utilitarian and largely economic project to a more complex and mixed political undertaking. It is set in a globalising context and is today based on the institutional structure of the Treaty of Lisbon, characterised by an emerging European citizenship and the development of a transnational democracy. The first decades of the European integration process functioned on the political paradigm of the Westphalian international system. A democratic approach to international life outside of the national borders was not at all required. There was equality between nationality, identity and citizenship. The Treaty of Maastricht (1992) breaks down that linear perspective and establishes a political framework for a broader and deeper integration of European states and regions, built on a European dimension of citizenship.

\section{1) Road towards a European citizenship}

The right to the free movement of persons inside the European Community was introduced in the constituent treaty of the EEC, signed in Rome in 1957. This freedom did not appear bound to any citizenship concept but was closely linked to the conduct of an economic activity. In consequence, the right of residence was accorded to workers and their families, linked to the right to exercise a labour activity in another 
member state of the EEC. Although in a meeting of the European Council, held in Paris in 1974, the necessity to grant special rights in the EEC to the citizens of the member states was put forward.

It was only in 1976, however, when the Tindemans Report was issued, that for the first time, the object of proceeding beyond a common market and creating a community of citizens, was clearly proposed. This report, edited by the Belgian prime minister at the request of the Summit of Paris 1974, had no success with the governments, though it had an important influence on later steps towards integration. In a chapter, titled "Europe of the Citizens", Tindemans proposed the enactment of different measures that made perceptible, by means of outward signs, the rise of a European awareness: unification of passports, the vanishing of border controls, the common use of the benefits of the social security systems, the accreditation of academic courses and degrees, etc.

In 1976 a second step took place, when elections to the European Parliament by universal suffrage were conducted. Although Parliament's competences were meagre, for the first time, one of the key elements of citizenship, democratic participation, appeared. Later on, after the Fontainebleau European Council in 1984, a Committee of Europe of the Citizens, presided over by the Italian Euro MP Adonnino, was established. This committee approved a series of unambitious proposals leading to the constitution of a European citizenship. More audacious was the Project "Treaty of European Union", passed by the European Parliament in February 1984, and presented by the Euro MP Alterio Spinelli (The Spinelli Project). In spite of its restraint, the Single European Act (1986) hardly included any of the Spinelli project proposals, although it adopted, and this is fundamental, the objective of a political European Union. In this manner, a few years later, two intergovernmental conferences were convened to reform the treaties. One of them focused on the Economic and Monetary Union, the other solely on the Political Union.

A meeting of the European Council, which took place in Rome in October 1990, in the course of establishing the Intergovernmental Conference (IGC) guidelines, introduced the notion of European Citizenship as an essential element of treaty reform, and with some characteristics and similar rights to those that were later included in the Treaty of the European Union and the Treaty of Maastricht. In October 1990, it was the Spanish delegation that first presented a text on the European citizenship to the IGCs. After diverse negotiations, and with the enthusiastic support of the European Parliament that passed two favourable resolutions in 1991, the Treaty of the European Union came finally to institutionalise European citizenship. 
The first steps towards the construction of European institutions did not make any changes to the political paradigm. The first decades of the European unification functioned on that basis. The Treaty of Rome, for instance, stipulates that its main purpose is the creation of a stronger Union among European people, but these people remained abstract and were in no way democratically involved in it. The real legal subjects of the treaty, the members of the European economic community it created, i.e. the legal personalities acting within the treaty, were the states and "only" the states. The action of the citizen was accepted only within their national boundaries, never outside, because citizens had neither an identity nor a nationality outside of their dependence on a particular state, and there could be no "citizenship" without the two other notions. This is the origin of what has been rightly called the "democratic deficit" of the Union.

The Treaty of Maastricht breaks down that perspective. In establishing a European citizenship, it introduces the idea that it is no longer necessary to establish an interdependence of the three notions as in the past. Sure, it is specified that the new European citizenship should be recognised exclusively for those individuals possessing the nationality of one of the member states, but the fact that there is now a common citizenship applying to many nationalities establishes a fundamental shift between the two.

\section{2) Implications}

The Treaty of Maastricht represents a first step towards the end of the necessary interdependence of these notions. But this also means that an active citizenship will develop within a new framework - not of a closed state on a limited territory, but open beyond the borders of nations. Europe is definitely involved in favouring the development of a transnational democracy, a completely new concept in the history of human society. The scope of what is traditionally called the "civil society" will therefore take on a completely new dimension. It seems that the institutions of the nation-states as well as those of the European Union are not yet fully adapted to that new reality. The very idea and acceptance of a European citizenship is breaking new mental barriers.

Furthermore, a similar consequence will apply to the notion of identity. If one imagines that the idea of citizenship can relate to a multiplicity of nationalities, it is also feasible that a multiplicity of identities could be envisaged under the traditional notion of nationality. In spite of the fact that each nation inherited from history its own typical political culture, this constituted only part of their national identities. In fact, these are composed of many other aspects and internal differences including languages, traditions, expressions of art and regional and local originalities, which together constitute a larger internal diversity in each 
of the nations themselves. The unity of a nation is not necessarily contradictory to the idea of a multiplicity of identities within it.

The further integration of Europe will indeed strongly contribute to changing the mentality and conception of the state system as it has developed over recent centuries. While its role becomes less essential in many sectors of economic life through the supranational transfer of decision-making powers to common authorities, similar developments affect its role infra-nationally by the need to adapt to multiple demands of autonomy, identity recognition, and decentralisation. In the coming decades it is obvious - this being accentuated by migration and mobility of work forces within the Union - that demands for the recognition of particular identities and minority rights will strongly develop (founded on languages, cultures, religions, ethnicity, gender, sexual behaviours, etc.) within national structures, while at the same time requests for more citizen participation at the supranational or transnational levels will become current, in the name of new European citizen rights that the traditional states can no longer master. This has been exacerbated globally by the current financial and economic crisis.

In short, Europe is therefore evolving towards a social and political body in which one will be able to distinguish a common European citizenship, multiple state citizenships and political systems, within which there will develop a growing awareness of multiple different cultural identities. Of course, this path of destiny is interpreted differently by different European member states.

\section{European citizenship}

\section{1) Universal basis}

Universal citizenship is the grant provided by the "new" International Law, which is rooted in the United Nations Charter and the Universal Declaration of Human Rights. In virtue of this Ius Novum Universale, all human beings are endowed with the same legal statute in the world constitutional space. The rationale of universal citizenship is to include all, i.e. ad omnes includendos.

\section{2) European dimension of citizenship}

The European integration process is aiming at the building of an ever -closer Union between the peoples of Europe. The idea and institution of European citizenship should therefore be the framework in which the European peoples identify themselves as the European demos, living in a broad cultural space and belonging to a large and differentiated polity.

A new European citizenship, combining the post-national and multicultural form, appears as a model for democratic community where all citizens are treated equally, exhibiting universal rights as well as 
rights relevant to their group differences. Therefore, the European Union is required to quickly harmonise the present "EU Citizenship" rationale with the correct citizenship rationale that stems from the EU Charter of Fundamental Rights.

European citizenship also means plural and active citizenship. Its immediate implication is that all residents in a given territory, as human beings having the same legal status internationally recognised, should enjoy the same fundamental political, civil, economic, social, cultural rights and liberties. In this perspective, plural and active European citizenship is strictly linked to democracy in its different political, economic and social dimensions, in its various representative, participatory, deliberative forms and in its local, national and international expressions.

The immediate implication is the building of a new model of European citizenship, which includes universal and multicultural rights. European citizenship is based not only on nationality, but also on legal residence. It means that legal long-term third country nationals should be recognised as Union citizens. It also implies that economically nonactive citizens of the EU member states should enjoy free movement and residence rights, which are not conditioned by their possession of the sufficient means for subsistence and health insurance. It should also result in the abolishment of all transitional periods concerning the free movement of workers for citizens of new member states of the EU.

\section{3) Legal statute of the citizenship of the Union: citizens' rights}

The Treaty of the European Union or Treaty of Maastricht established the citizenship of the European Union. The foremost purpose of the institutionalisation of this new legal status was, according to European Community institutions, to strengthen and enhance the European identity and enable European citizens to participate in the community integration process in a more intense way.

European citizens condition was reserved to every person that had the nationality of a member state. The European citizenship did not substitute but rather supplemented the citizenship of each state. In consequence, the laws of each state - quite different in many cases were to regulate access to the Citizenship of the Union:

Citizenship of the Union is hereby established. Every person holding the nationality of a Member State shall be a citizen of the Union. Citizenship of the Union shall complement and not replace national citizenship (Treaty of Amsterdam, 1997).

Member states citizens already enjoyed a series of rights on account of the application of the laws that regulated the European common market (free movement of goods and services, consumer protection, 
public health, equal opportunities...). The Citizenship of the Union added some rights that are summarised in the following articles:

The right to free movement of persons in the member states territory. Article 18 (ex Article 8a):

Every citizen of the Union shall have the right to move and reside freely within the territory of the Member States, subject to the limitations and conditions laid down in this Treaty and by the measures adopted to give it effect (Treaty of Nice, 2001).

The right to vote and stand in local government and European Parliament elections in the country of residence. Article 19 (ex Article $8 b)$ :

(1) Every citizen of the Union residing in a Member State of which he is not a national shall have the right to vote and to stand as a candidate at municipal elections in the Member State in which he resides, under the same conditions as nationals of that State.

This right shall be exercised subject to detailed arrangements adopted by the European Council, acting unanimously on a proposal from the Commission and after consulting the European Parliament; these arrangements may provide for derogations where warranted by problems specific to a Member State;

(2) [...] every citizen of the Union residing in a Member State of which he is not a national shall have the right to vote and to stand as a candidate in elections to the European Parliament in the Member State in which he resides, under the same conditions as nationals of that State [...] (Treaty of Amsterdam, 1997).

The right to have diplomatic and consular protection from the authorities of any Member State where the country of which a person is a national is not represented in a non-Union country; Article 20 (ex Article 8c):

Every citizen of the Union shall, in the territory of a third country in which the Member State of which he is a national is not represented, be entitled to protection by the diplomatic or consular authorities of any Member State, on the same conditions as the nationals of that State. Member States shall establish the necessary rules among themselves and start the international negotiations required to secure this protection (Treaty of Amsterdam, 1997).

The right of petition to the European Parliament and appeal to the European Ombudsman. Article 21 (ex Article 8d):

Every citizen of the Union shall have the right to petition the European Parliament [...]; Every citizen of the Union may apply to the Ombudsman [...] (Treaty of Amsterdam, 1997). 
To these rights, the Treaty of Amsterdam added other two less important new rights: (1) The right of writing to the European institutions in one of the official languages (Spanish, Portuguese, French, Italian, English, Gaelic Irish, Dutch, German, Danish, Swedish, Finnish and Greek) and being answered in that same language; and (2) The right to access European Parliament, Commission and Council documents, except in the cases legally agreed. These last two rights, as well as petition rights to the European Parliament and application rights to the Ombudsman, are also applicable to every resident in the member states, despite not being nationals of them.

So far, citizenship of the Union, contrary to national citizenship, does not impose any duties on the citizens of the member states. Citizenship of the Union is considered as a legal status to be developed. Every three years, the European Commission's reports on citizenship of the Union assess the application of European Community rules on citizens' rights and propose concrete measures to further their complete and effective implementation. ${ }^{2}$ One of the initiatives to improve this information on European citizens' rights has been the setting up of a web site for citizens. ${ }^{3}$ This site provides practical information.

Next to the new legal statute of the Citizenship of the Union, the Treaty of Amsterdam introduced some advances with regard to human rights. Other rights guaranteed within the Union are: (i) equality of all citizens to access the civil service in the institutions of the European Union; (ii) the non-discrimination principle by reason of nationality. Article 12 (ex Article 6): "Within the scope of application of this Treaty, and without prejudice to any special provisions contained therein, any discrimination on grounds of nationality shall be prohibited". (Treaty of Amsterdam, 1997); and (iii) the non-discrimination principle by reason of sex, race or ethnic origin, religion or belief, disability, age or sexual orientation. Article 13 (ex Article 6a):

Without prejudice to the other provisions of this Treaty and within the limits of the powers conferred by it upon the Community, the Council, acting unanimously on a proposal from the Commission and after consulting the European Parliament, may take appropriate action to combat discrimination based on sex, racial or ethnic origin, religion or belief, disability, age or sexual orientation.

Finally, it is necessary to highlight that the European Commission has emphasised the fact that education will be the key element for building up the European citizenship. The rights introduced in

\footnotetext{
2 http://europa.eu/legislation_summaries/justice_freedom_security/citizenship_of_the _union/123031_en.htm

3 http://eudo-citizenship.eu
} 
Maastricht and included in the Treaty of Amsterdam constitute the beginnings of a process that, from a pro-Europe view, will lead to a citizenship of the Union in which rights and duties will be connected to daily life and will be the basis on which Europeans will support a significant part of their identity.

In 1995, the European Commission set up a Group of Reflection on Education and Formation, comprising of 25 independent experts of the then fifteen member countries and presided over then by a French member of the commission, Edith Cresson. In December 1996, this panel subscribed a report titled "Building Europe by means of Education and Training". The following year, in December of 1998, the commission approved a document titled "Learning for active citizenship". ${ }^{4}$ Edith Cresson claimed in the foreword:

The fostering of competencies and convictions capable of enhancing the quality of social relations rests on the natural alliance of education and training with equality and social justice. Citizenship with a European dimension is anchored in the shared creation of a voluntary community of peoples, of different cultures and of different traditions - the creation of a democratic society which has learned to embrace diversity sincerely as a positive opportunity, a society of openness and solidarity for each and every one of us.

The future of the citizenship of the Union will depend on the evolution of the public opinion of its members states regarding national and European citizenship. For many, the rights included in the citizenship statute are limited. The most significant is, with no doubt, the free movement and residence of persons. Although there has been remarkable progress since the Treaty of Rome, where free movement was strictly bound to labour activity, there are still some serious limitations that should be eliminated. Despite the different agreements reached, any country can re-establish control of its border whenever its security is considered threatened and residence freedom continues to have different sorts of restrictions.

Also other rights only affect the daily life of European people in a negligible way: the right of appeal to the European Ombudsman only deals with matters under EU jurisdiction; the right of petition to the European Parliament already existed and has to do with a parliament with very scarce competences; the right to vote and stand in local government and European Parliament elections in the country of residence affects a minority of Europeans, the right to have diplomatic and consular protection from the authorities of any other member state

4 http://ec.europa.eu/education/archive/citizen/citiz_en.html 
concerns solely those Europeans who visit a country in which there are no embassies or consulates from its own state.

In short, European citizenship lies still midway between the more theoretical or soft conception of citizenship (exhibiting a sense of belonging to a community with shared common goals and values) and the practical or strong citizenship with real rights that can be claimed from juridical institutions to protect the exercising of these rights. Still, Europe is evolving towards a social and political body in which one will be able to distinguish a common European citizenship, multiple state citizenships and political systems, within which there will develop a growing awareness of multiple and different cultural identities. An important step in this direction was the inclusion of the European Charter of Fundamental Rights in the Treaty of the European Union.

\section{Connection between Identity, Nationality and Citizenship}

Citizenship of the Union is not a consolidated reality; rather, it is part of a long process that will shape the European integration process by interconnecting identity, nationality and citizenship. To fully develop a meaningful European citizenship it is therefore necessary that a sort of European identity emerges beyond nationality. Just like the compulsory educational systems had the main task of building up national identities, the role of schools and universities in fostering a sense of belonging and European identity is of the utmost importance.

Nationality expresses how individuals are connected to a particular political entity or state, based on a given and well determined territory, and to the authority which governs that state. It expresses the recognition by a state towards the individuals it considers as its own members. This recognition is acquired by birth (i.e. natural nationhood) or through a process of naturalisation given by a state according to its own law of nationality.

Nationality is also a kind of belonging, but one that individuals do not really master; they are more subjects, subjected to and depending on a particular state. To have a nationality however, gives some rights and guarantees of being protected by the state. But the fact of restricting the right of nationality to state powers can be a source of discrimination and exclusion, and often of intolerant attitudes. This could indeed become an instrument of legalising certain prejudices of identity when migration and asylum policies in the EU become stricter. 


\section{Inclusion or exclusion}

Since its birth in ancient Greece, the concept of citizenship has experienced dramatic changes. But citizenship has always been based on an exclusion rule of defining clearly who are and mainly who are not citizens.

The only way to access citizenship of the Union is by having one of the member state nationalities. This causes a paradoxical situation: the same person coming from a third country with the same circumstances will be treated in a very different way. In some states, this person would acquire their nationality and, therefore, would become a European citizen; whereas in other states, this individual would be excluded from their nationality and European citizenship. This diverse treatment is related to a different legal base for citizenship acquisition, i.e. "ius sanguinis" or "ius soli".

Citizenship of the Union excludes third country nationals that live within its frontiers. In fact, the permeability of the interior frontiers introduced by the Agreement and Convention of Schengen has been accompanied by raising more barriers in the Union's external frontiers and by hardening the asylum right procedures. One great dilemma that Europe currently faces is how to build a Union based on national identities while excluding third country nationals who already make up a conspicuous part of Europe's human landscape. These peoples are a significant element of Europe and, therefore, of the European identity, which European citizenship is based on. Since the tragic events of September 11th 2001 in New York, a more conservative and reductive view on what is Europe has been adopted by most EU member states.

\section{Democratic participation}

After the signature of the Treaty of the European Union in 1992, the democratic deficit became more manifest. Important competences have been transferred from national institutions that are elected and democratically legitimated, to European institutions that are not always legitimised by people's votes. Members of the European Commission are named by their national governments. The Council of the European Union, despite a growing number of decisions adopted by a majority, continues to be an intergovernmental institution. Finally, the European Parliament, the sole institution legitimated by suffrage, has scarce competences and its decisions and debate are mostly ignored by public opinion. All those institutions are quite distant from the European citizens, who largely consider them as ruled by a technocratic bureaucracy. 
The only way to build up a genuine European citizenship should be based on solving this democratic deficit. Citizenship is not a passive condition, based on an enjoyment of a series of rights and freedoms - it should be an active citizenship, based on political and civic participation. National citizenship has been constructed historically through this kind of social participation. This involvement has often adopted the shape of clashes and conflicts, which, in the long term, have developed a set of civil, political and social rights and duties, and a conscience of identity. The Lisbon Treaty has made some progress in the European citizenship building process.

\section{Emergence of a European identity}

The concept of the European identity is, at the least, problematic. To some extent, a great number of EU citizens feel themselves to be Europeans, but the majority feel more intensely their belonging to France, Portugal, Spain, or Catalonia, Scotland or Flanders. ${ }^{5}$ Identities are not easily separated and often, different feelings of affinity to ethnic or racial groups, genders, political ideas, cultural affinities, etc. are mingled.

A genuine European Union requires an added European identity, based on a community of shared values, rooted in legal texts and applied with a European specificity to the challenges of today's globalisation. As explained in Chapter 3, a European identity will not arise from an impossible cultural uniformity; neither should it be built against other civilisations but it should be fully embedded in the conceptual driving forces of the European process of integration as explained in Chapter 8 . One of the most suggestive theories in this field comes from Jürgen Habermas. According to Habermas, citizens should not be identified with a common cultural identity, but with some constitutional principles that fully guarantee their rights and freedoms. This proposal is very suggestive, because it comes from the best liberal and tolerant traditions of Europe, and escapes from and fights against ethnic nationalism, the great foe of peace and freedom in early 21 st century Europe.

\section{European Citizenship in a cosmopolitan perspective}

In Chapter 6 the cosmopolitan perspective of multi-level governance in Europe was analysed in general terms; here it is used to assess European citizenship. European citizenship not only includes a set of rights and responsibilities, but also contains an important symbolic value. Even if the concept remains linked to national belongingness, the existence of a common citizenship applying to many nationalities and covering

5 Flash Eurobarometer 217, Intercultural dialogue in Europe. 
multiple identities establishes a fundamental shift in the relation between identity, nationality and citizenship. This innovative legal status produces political implications as it favours transnational democracy and the development of a European public sphere. ${ }^{6}$

Moreover, the recognition of a multiplicity of identities can be simultaneously envisaged under the traditional notion of nationality as well as under the notion of European citizenship. Amartya Sen's argument on the multiplicity of identities ${ }^{7}$ finds in this context a possibility of implementation, even if European citizenship is only addressed to member state nationals. However, if European identity could be based on the principle of inclusiveness, EU citizenship should also be obtained by legal long-term third country nationals. Antonio Papisca argues that the sense of belongingness to a European political community can be achieved if individuals and peoples will be its principal actors. ${ }^{8}$ Sharing projects and participating in the decisionmaking process is therefore the only way for Europeans to be inspired, motivated and committed to Europe.

In the cosmopolitan view, ${ }^{9}$ European citizenship is a step towards a global citizenship. Europe is conceived as a political laboratory for a new supranational and transcendental democracy, but the outcome of this process cannot be a mere translation of functions from the national to the European level.

The horizon for active citizenship is the European and world space of internationally recognised human rights. The EU provides the evolutionary context and spatial horizon in which plural citizenship and inclusion practices can be implemented. Citizenship rights therefore must be exercised in a broader constitutional space, expressing both legitimisation of decisionmaking and citizen's participation in the formation of a global civil society.

With this approach, the universal human rights paradigm is the fundamental point of departure for conceiving of a citizenship "ad omnes includendos" ${ }^{10}$ It is therefore worthwhile to focus both on the set of values adopted in the treaties as constitutive of European identity and on the process of codification of human rights.

\footnotetext{
6 Bekemans, L. and L. Morganti (eds.), The European Public Sphere. From critical thinking to responsible action, Brussels: P.I.E. Peter Lang, 300 p., 2012.

7 Sen, A., Identity and Violence: The Illusion of Destiny, op.cit.

8 Papisca, A., Riflessioni in tema di cittadinanza europea e diritti umani, Padova, in Pace Diritti Umani, 1/2004, pp.39-58.

9 Beck, U. and E. Grande, op. cit.

10 Papisca, A., Citizenship and Citizenships Ad Omnes Includendos: A Human Rights Approach, in L. Bekemans, M. Karasinska-Fendler, M. Mascia, A. Papisca, C.A. Stephanou and P.G. Xuereb (eds.), op. cit.
} 


\section{Conclusions}

\section{Conceptual guidelines}

What is European can be termed by forms of identity, ways of life, means of production and types of interaction that go beyond national or regional frontiers. It is about continuous border-crossing. The intertwining of globalisation and Europeanisation has various policy consequences and produce different lines of thought and action.

The dismantling of the national borders in Europe has an impact on the European dynamic of socio-economic inequalities. The social dimension of the European integration process has policy implications within and beyond European borders, in particular in relation to internal and external solidarity and the sense of belongingness.

Europeanisation is initiating a historically new positive sum game: joint solutions serve the national interest. In some occasions and policies the EU is sometimes better placed to solve problems than nations or regions could possibly be by acting alone. From a cosmopolitan perspective, this diversity (whether in languages, economic systems, political cultures, or forms of democracy) appears primarily as an inexhaustible source of Europe's cosmopolitan self-concept and not as an obstacle to integration. A cosmopolitan Europe is first and foremost a Europe of difference of recognised particularity.

A third line of thought and action is that Europeanisation requires a collective memory culture that spans borders, an "Europeanisation of perspective". This might lead to genuine intercultural dialogue and mutual learning, conceived as an enrichment of one's own integral human development.

The fourth line is the understanding of European society as a regional world risk society. Reference is made to the theory of reflexive modernisation. ${ }^{11}$ Beck distinguishes three constitutive elements, namely, the theorem of risk society, the theorem of forced individualisation and the theorem of multidimensional globalisation. It means that the experience and dynamics of modernity bear risks in the sense that along with its success, modernity also contains negative consequences. This requires policy coordination and the rule setting of both obstacles and opportunities in European and global context.

The fifth concluding line concerns the understanding and shaping of new forms of political authority that have emerged in Europe beyond the nation-state. The management of the globalisation effects, specifically

11 Beck, U., The Theory of Reflexive Modernization: Problematic, Hypotheses and Research Programme, in Theory, Culture \& Society, April 2003 20: 1-33. 
the problems related to the flows and crises of global finance and the neglected European dimension of current socio-political developments, requires a more courageous approach, in respect of the various levels and actors involved in the process.

So Europe is indeed involved in favouring the development of a "transnational democracy". The process of European integration strongly contributes to changing the mentality and conception of the state system. The role of the state becomes less essential in many sectors of economic life through the supranational transfer of decision-making powers to common authorities; similar developments affect its role regionally through the need to adapt to multiple demands of autonomy, identity recognition, and decentralisation. In short, it seems obvious that with the process of globalisation, demands for the recognition of particular identities and minority rights will strongly develop within national and regional structures, while at the same time requests for more citizen participation at the supranational or transnational levels will become more evident, in the name of new European citizens' rights.

\section{Policy suggestions}

In this perspective we may conclude that (1) European citizenship provides the framework in which the European peoples identify themselves as the European demos, living in a broad cultural space and belonging to a large and differentiated polity; (2) the European citizenship appears as a model for a democratic community where all citizens are treated equally, exhibiting universal rights as well as rights relevant to their group differences; and finally (3) that European citizenship refers to a plural and active citizenship. Its immediate implication is that all residents in a given territory should enjoy the same fundamental political, civil, economic, social, cultural rights and liberties.

In practice, this would mean a strengthening of the policy of local authorities to encourage and provide the material basis for a building up of local communities of civic society and supported with the subsidiarity principle. The integration and participation of citizens in urban contexts should be encouraged and supported with the exploitation of accessible community programmes but also with the greater involvement of local/regional authorities and actors of the territorial multi-level governance system.

Citizen participation should be promoted locally where basic needs are met to create a sense of community between those sharing basic interests. A dialoguing element should not only be stressed in the areas related to education and culture but in all areas where the common interest in basic community needs may turn into common purpose, thus 
creating an integrating societal factor by setting common purposes beyond ethnic, mental and cultural borders within local communities.

There exists more potential fora for citizenship building than those usually associated with interculturalism and dialogue. In the case of infrastructure projects, the integration of local community stakeholders into debates over the common good may lead to intercultural "learning by doing". This potential should be reinforced horizontally among various European Community action programmes beyond those administered by DG Education and Culture. They may create added value of promoting dialogue, tolerance and solidarity exactly where it should happen, i.e. at the regional and local level and in daily life.

The cross-border cooperation programmes and programmes addressed to the third countries with the participation of EU member states should take into account the intercultural element while providing for the transfer of knowledge and best practices in the fields not necessarily directly linked to culture, education, media or social policy issues. The sharing of common goals offers the first steps to communication with others, while working together may lead to increased understanding and mutual respect and trust.

In the next chapter the focus is on education of citizenship. This is fundamental for peaceful coexistence and the building up a sustainable environment for shaping open identities and inclusive societies. 

CHAPTER 13

\section{Education for European Citizenship-building}

\section{Introduction}

In this chapter, the conceptual framework of human-centric sustainable statehood is applied to the field of education, conceived as a priority policy area of value-oriented European citizenship building. The first section deals with the crucial role of education in citizenshipbuilding, focussing on the responsibility, objectives, competences and aspects of education for integral human development. The second section concerns education policies in Europe, with a focus on the European lifelong learning agenda of citizenship building.

\section{The Crucial Role of Education in EU Citizenship- building}

\section{Points of departure}

\section{1) The right to education}

Education is a fundamental human right and important for the exercise of other human rights. It promotes individual freedom and empowerment and yields important development benefits. Freedom of education has been guaranteed in international and European law. Following articles constitute the universal, international and European legal framework for the right to education.

The right to education has been universally recognised in Article 26 of the Universal Declaration of Human Rights (1948):

(1) Everyone has the right to education: Education shall be free, at least in the elementary and fundamental stages. Elementary education shall be compulsory. Technical and professional education shall be made generally available and higher education shall be equally accessible to all on the basis of merit. (2) Education shall be directed to the full development of the human personality and to the strengthening of respect for human rights and fundamental freedoms. ${ }^{1}$

Article 2 Protocol 1 of the Convention for the Protection of Human Rights and Fundamental Freedom (Rome, 1950) says,

1 http://www.un.org/en/documents/udhr/ 
that no person shall be denied the right to education. In the exercise of any functions which it assumes in relation to education and to teaching, The State shall respect the right of parents to ensure such education and teaching in conformity with their own religions and philosophical convictions. ${ }^{2}$

Article 13 paragraph 1 of the International Covenant on Economic, Social and Cultural Rights (1966) clearly states that education

shall be directed to the full development of the human personality and the sense of its dignity, and shall strengthen the respect for human rights and fundamental freedoms [and] that education shall enable all persons to participate effectively in a free society, promote understanding, tolerance and friendship among all nations and all racial, ethnic or religious groups, and further the activities of the United Nations for the maintenance of peace. $^{3}$

Henceforth, rights, respect and participation are bound firmly together. Education in this full sense embraces personal formation, not merely the transmission of information, or professional training. It thus enhances social, cultural and economic development, active citizenship and fundamental moral values. The impact of the global economic downturn on education systems if the right to education is not fully protected has been dramatically illustrated by UNESCO, in its "Education for all - Global Monitoring Report 2010. Reaching the marginalized". ${ }^{4}$

Article 14 of the Charter of Fundamental Rights of the EU (2000) defines the right to education as follows:

1. Everyone has the right to education and to have access to vocational and continuing training; 2 . This right includes the possibility to receive free compulsory education; 3 . The freedom to found educational establishments with due respect for democratic principles and the right of parents to ensure the education and teaching of their children in conformity with their religious, philosophical and pedagogical convictions shall be respected, in accordance with the national laws governing the exercise of such freedom and right. ${ }^{5}$

As well as being a right in itself, the right to education is also an enabling right. If people have access to education they can develop the skills, capacity and confidence to secure other rights. Education gives people the ability to access information and to grow in knowledge. It supports people in developing the communication skills to demand these

\footnotetext{
http://www.hri.org/docs/ECHR50.html

http://www2.ohchr.org/english/law/cescr.htm

http://www.unesco.org/en/efareport

5 http://www.europarl.europa.eu/charter/pdf/text_en.pdf
} 
rights, the confidence to speak in a variety of forums, and the ability to negotiate with a wide range of authorities and power holders. In other words, some preconditions are needed to make education a meaningful right. Katarina Tomasevski, the former UN Special Rapporteur on the Right to Education developed the concept of the 4 A's: ${ }^{6}$ education should be available, accessible, acceptable and adaptable. Of course these conditions are to be cherished, elaborated and strengthened, in respect of the key objectives of education.

\section{2) The key role of education in human integral development}

Education plays a central role in the development of both human beings and modern societies as it enhances social, cultural and economic development, active citizenship and ethical values. Education is to build peace, foster dialogue and enhance understanding in order "to build peace in the minds of men" as enshrined in UNESCO's Constitution (1945) and further developed in its various recommendations, declarations, resolutions and initiatives. ${ }^{7}$ To be educated is to learn and to be able to feel free of any kind of dependence, submission or fear. It is to be able to create, to think, to imagine, to dream - all distinctive and decisive capacities of the human condition. This ideal is summarised in the Delors Report, "Education for 21st Century. Learning: the Treasure Within" (1996) which argues that the education process rests on four pillars: learn to know; learn to do; learn to be; learn to live together. ${ }^{8}$

6 http://www.right-to-education.org/

7 It is useful to recall the major general UN contributions to education since 1990: Education for All (1990); Agenda 21 for the Environment (1993); World Plan of Action for Education on Human Rights and Democracy (1993); Vienna Conference on Human Rights (1993); The Contribution by Religions to the Culture of Peace (1994); Declaration of Principles on Tolerance (1995); Copenhagen Declaration on Social Development (1995); Fourth World Conference on Women, Beijing Declaration (1995); International Decade for a Culture of Peace and Non-violence for the Children of the World (1998); Declaration and Programme of Action on a Culture of Peace (1999); UN Millennium Declaration (2000); The Earth Charter of Amsterdam (2000); Universal Declaration on Cultural Diversity (UNESCO, 2001); Declaration on Dialogue among Civilizations (2003); Culture of Peace (UN Recommendations A/Res/63/113, 26 February 2005); The Hague Agenda on City Diplomacy (2008); Charter for a World without Violence (2009); etc.

8 Delors Report, Education for 21st Century Learning: the Treasure Within, Report to UNESCO of the International Commission on Education for the Twenty-first Century, Paris: Unesco Publishing, 1996. The report focuses on the relationship between education and the six subject areas of development, science, citizenship, culture, social cohesion, and work. The report focuses on the relationship between education and the six subject areas of development, science, citizenship, culture, social cohesion, and work. 
The current crisis of socialisation and value transmission has made the task of education difficult but vital for society building. ${ }^{9}$ The crucial role of education should therefore be reset within the dramatic acceleration in the speed of social change brought about by the process of globalisation. Reference can be made to the works of sociologists such as Zygmunt Baumann, Ulrich Beck and Anthony Giddens, writing about education in a liquid society, a risk society or a reflexive modernity. ${ }^{10}$ In such a changing context of processes of transformation at the global level, we are being urged to rethink the meaning of education, as well as the uses and practices of teaching and learning, the opportunities for communicating interaction offered by new technologies and the dangers of commodification of human relations caused by the new relation between culture and economy.

\section{Objectives and competences}

Education is a dynamic process of learning, which creates added value and forms a person's integral development. It should transmit possibilities and opportunities with conviction, intuition and motivation. It is always a meeting with the other: hence the role of teachers as key agents for change and the need to accompany and respect their role in the educational landscape. Also, Europe and the international context are an integral part of the general educational project as well as of each individual learning path. This implies the need to transmit in an open and critical way ideals and principles that valorise the person at the centre of education systems and national curricula, recognising the European and international context.

Education's first task is to form (young) people into responsible citizens, and to provide them with information, knowledge, competences, skills and an open-minded behaviour, in line with fundamental values such as peace and tolerance of diversity. Key competences refer to knowledge, skills and attitudes that serve personal fulfilment, social inclusion and active citizenship. These include the traditional competences but also the more transversal ones such as

See Education together in Catholic schools, published by the Congregation of Catholic Education, Rome, September 2007.

10 Bauman, Z., Liquid Modernity, Cambridge: Polity, 2000; Ibid., Europe: An Unfinished Adventure, Cambridge: Polity, 1994; Ibid., Liquid Times: Living in an Age of Uncertainty, Cambridge: Polity, 2006; Giddens, A., Europe in the Global Age, op. cit.; Habermas, J., Europe. The Faltering Project, Cambridge: Polity, 2009. 
learning to learn, social and civic competences, cultural awareness and expressions. ${ }^{11}$

Intercultural competences are becoming an integral part of what the UNESCO report directed by J. Delors (1996) had termed as "learning to live together". Intercultural competences are abilities to effectively and appropriately interact in complex environments marked by growing diversity of peoples, cultures and lifestyles. ${ }^{12}$ It implies that the scope of intercultural competences goes beyond formal education and school learning. The UNESCO World Report Investing in Cultural Diversity and Intercultural Dialogue ${ }^{13}$ introduced the term of cultural literacy, i.e. a fundamental resource for benefitting from multiple learning places (from family and tradition to the media, and to informal groups and activities) and an indispensable tool for transcending clashes of ignorances. The Intersectoral Platform for a Culture of Peace and NonViolence of UNESCO published in 2013 a very useful conceptual and operational framework for addressing intercultural competences. ${ }^{14}$

Therefore, intercultural competences empower participating groups and individuals and enable them to interact with cultural others with a view to bridging differences, defusing conflicts and setting the foundations of peaceful conviviality. In this context, reference to Edgar Morin, the French sociologist, is essential. He proposes four objectives in the transmission of knowledge and the activities of teaching: ${ }^{15}$ (i) to form a well-developed mind (better than a too full mind); (ii) to teach the human condition; (iii) to educate to live (learning does not mean only the acquisition of knowledge, techniques and productive modes, but also an interest in the relations with the other and with oneself); and (iv) to learn the dignity of the citizen.

\footnotetext{
11 The European dimension of such an education is well captured by Zani, A.V., Formare l'uoumo europeo: sfide educativie e politiche culturali, Roma: Città nuova, 2005.

12 Fantini, A. and A. Tirmizi, Exploring and assessing Intercultural Competence, World Learning Publications, Paper 1, 2006.

13 UNESCO, Investing in Cultural diversity and Intercultural dialogue, 2009.

14 UNESCO, Intercultural Competences.Conceptual and Operational Framework, Paris: UNESCO, 2013.

15 Morin, E., Réforme de la pensée et éducation au $\mathrm{XXI}^{\mathrm{e}}$ siècle, in Les Clés $d u$ $X X I^{e}$ siècle, J. Bindé (ed.), Paris: UNESCO/Seuil, 2000, pp. 271-275.
} 


\section{Citizenship education: education to active and responsible citizenship in a plural Europe}

\section{1) Definition: a dynamic concept}

If education has the priority task of transmitting knowledge and competences that give scope and responsibility to the development of each person, ${ }^{16}$ some fundamental questions need to be addressed concerning citizenship education. These relate to (i) education of and for all; (ii) education of humanity: this involves cross-cutting the dichotomy between an "humanistic" education and a "professional" education; (iii) education for change: this deals with the meaning of creativity and the use of a critical mind; (iv) education to master a variety of languages; and finally (v) permanent education in the search of values: this implies surpassing the so-called contradiction between tradition and innovation.

In the education processes and transmission of knowledge it is not sufficient to affirm the principle of the centrality of the person. The educator and the teacher have to act within the socio-cultural context, responding to the challenges of global interconnectedness and complexity, cultural disintegration and the dispersion and fragmentation of knowledge. This requires an integration of a diverse range of learning sources and levels.

As stated above, Europe is part of such a learning process. The question however remains open as to what extent a common vision, founded on common goods, can survive in a context of economic globalisation and cultural relativism. The problems of social inequality and poverty, values of solidarity, responsibility and respect for differences, as well as the non-accessibility of the benefits of globalisation, have to be tackled by various forms of learning.

In short, the current situation requires an inspiring vision and a strategy that embodies such a vision. Europe cannot be taught as a technical project, but demands breadth of vision and engagement. Education has the task of being an agent of change and has the responsibility to revitalise Europe's original project and consequently, mobilise its citizens, particularly its youth. This can only be done through (formal, informal and non-formal) education to active citizenship which stimulates the commitment of (young) people to the European project, a plural Europe, a Europe of dialogue and an intercultural Europe.

\footnotetext{
16 Commission of the European Communities, Schools for the 21st century, Staff Working Paper, Brussels, 11/07/07.
} 
The notion of responsible citizenship includes an awareness and knowledge of rights and duties. It is closely related to civic values such as democracy and human rights, equality, participation, partnership, social cohesion, social justice as well as the knowledge and exercise of rights and responsibilities. This goes beyond the legal status and judicial relationship between citizen and state. A citizen is a person who coexists in a society.

As was explained in Chapter 12, societies have changed in recent decades and, with them, the theoretical conceptions and practical implementation of citizenship. The concept is steadily broadening and changing, as lifestyles and patterns in our relations with others become more diversified. Far from being limited to the national context, the notion of harmonious coexistence among citizens relates to the concept of a community embracing all contexts - local, regional, national and international - in which individuals live. Much work has been done in this regard by the Council of Europe. ${ }^{17}$

The link between citizenship and education is very close. Today's challenge is to strengthen citizenship building in societies and develop learning modes that respond to the citizens' need for information, knowledge, capacity and quality, to deal with the societal developments of today's world. This is the core of the pedagogical approach to citizenship. However, the teaching of citizenship is not sufficient; it is the learning of citizenship that is essential. This consists of the development of intercultural skills in context, by acquiring operating, social and communicative competences through practice, experience and dialogue in formal and non-formal instruction. As a consequence, the concept of citizenship could (and should) be integrated into the educational process in a very integrated way with a horizontal focus from different perspectives.

Moreover, active and responsible citizenship is a lifelong process. Learning citizenship is interactive and deeply embedded in specific formal, non-formal and informal contexts. Support should therefore also be given to citizenship learning within civil society as well as within the informal setting of the family. Teaching people to learn to become active citizens implies giving them access to the capacities and skills

17 We refer to: Final Declaration Second Summit of Heads of State and Government of the Council of Europe (Strasbourg, 10-11 October 1997); Committee of Ministers' Declaration and Programme on Education for Democratic Citizenship, Based on the Rights and the Responsibilities of the Citizens (Strasbourg, 1999); Recommendation on Education for Democratic Citizenship (Strasbourg, 2002); Recommendation on the Charter on Education for Democratic Citizenship and Human Rights Education (CM/Rec (2010)7), etc. 
they need to participate efficiently in economic, political and social life. This also means the knowledge of languages.

In fact, the educational dimension of European citizenship has as much to do with rights as with responsibilities and duties. Accordingly, European citizenship cannot be merely reduced to forms of individual participation in political life or to bilateral economic relations, but should take into account the acquisition of skills that have been previously acquired during the formal and non-formal process of education. This process should be favoured from below by concrete projects at the local and regional citizens' level with exchanges between schools, students and teachers. Extra-curricular opportunities for citizenship learning should therefore also be encouraged through international exchanges. ${ }^{18}$ In summary, the concept of citizenship education relates to educating (young) people to become responsible citizens, who are capable of contributing to the development and wellbeing of the society in which they live. ${ }^{19}$

Education traditions and approaches to citizenship vary across Europe. The basic idea of democratic citizenship in a modern society is the active participation and engagement of each. Although the sense of citizenship is embedded in each individual's life history and their relationships with others, no standard model for developing citizenship can be applied. ${ }^{20}$ Until recently, the concept of citizenship was conceived in mainly state and institutional terms. ${ }^{21}$ In today's Europe the concept of citizenship has become more fluid, dynamic and contextual, linking it to the multiple identities of Europe. This means that learning to live together positively with differences and diversity is becoming the central dimension of practising citizenship in Europe. Therefore, citizenship education is a modern and dynamic concept with a European dimension.

18 See EU Citizens' Programme.

19 See the definitions given in O'Shea, K., Developing a Shared Understanding. A Glossary of Terms for Education for Democratic Citizenship, Strasbourg: Council of Europe, 2003.

20 Holford, J. and R. van der Veen (eds.), Lifelong Learning, Governance and Active Citizenship in Europe, ETGACE project, European Commission, EU Research on Social Sciences and Humanities, Luxembourg: Office for Official Publications of the European Communities, 2006, 206 p.

21 Steele, T. and R. Taylor, Citizenship and global Chaos - Education, Culture and Revolution, in Wildemeersch, D., V. Stroobants and M. Bron (eds.), Active Citizenship and Multiple Identities in Europe. A Learning Outlook, Frankfurt am Main: Peter Lang, 2005, pp. 88-97. 


\section{2) Objectives of responsible citizenship}

While its aims and content may be highly diversified, key objectives of responsible citizenship education in today's complex world should relate to (1) political and (multi)cultural literacy, (2) critical thinking and the development of certain attitudes and values and (3) active participation.

(1) The development of political and cultural literacy may involve: learning about social, political and civic institutions, as well as human rights; the study of the conditions under which people may live harmoniously together; teaching young people about national constitutions so that they are better prepared to exercise their rights and responsibilities; promoting the recognition of cultural and historical heritage; and promoting recognition of the cultural and linguistic diversity of society.

In this perspective, increased literacy should favour active communication and participation in democratic societies, finally leading to responsible citizenship building. Moreover, the impact of globalisation on our lives necessitates a growing awareness of the existence of different cultures, religions and political systems in order to develop respect for the otherness. In other words, increasing the diversity of peoples in European societies requires a reconceptualisation of literacy towards a political and multicultural literacy, which might be a vehicle to mutual understanding and learning in European multicultural societies and beyond. In summary, political and cultural literacy requires a life-long and a life-wide education.

(2) The development of critical thinking and the adoption of certain attitudes and values may entail: acquiring the skills needed to participate actively in public life; developing recognition of and respect for oneself and others with a view to achieving greater mutual understanding; acquiring social and moral responsibility, including self-confidence, and learning to behave responsibly towards others; strengthening a spirit of solidarity; the construction of values, with due regard for differing social perspectives and points of view; learning to listen and resolve conflicts peacefully; learning to contribute to a safe environment; and developing more effective strategies for fighting racism and xenophobia.

(3) Finally, the active participation of youngsters may be promoted by: enabling them to become more involved in the community at large (at international, national, local and school levels); offering them practical experience of democracy at school; developing their capacity to engage with each other; and encouraging pupils to develop project initiatives in conjunction with other organisations (such as community 
associations, public bodies and international organisations), as well as projects involving other communities.

In short, it should be clear that citizenship education is not just concerned with imparting theoretical knowledge to enhance political and (multicultural) literacy in issues such as democracy, human rights, the functioning of political institutions, the cultural and historical heritage, etc. It is crucial for integral human development that positive civic attitudes and values are developed and active participation be promoted - be it at school level or in society at large.

\section{3) The European dimension of citizenship education ${ }^{22}$}

Citizenship always has a territorial connotation, whatever its scale and limits. However, education processes should take account the fact that future citizens identify with different entities and dimensions, whether local, regional, national, European, international or global. Four aspects should be considered in developing the European dimension of education: curriculum building, teacher education, and support for teachers and teaching materials and extra-curricular activities involving mobility and exchanges.

(1) Curriculum building: The European/international dimension of citizenship should be part of the overarching general aims of various levels and phases of education to stimulate a sense of involvement with and belonging to Europe. Aspects which could be addressed in education/learning paths are: the rights and obligations of EU citizens; the contemporary history of European nations, the EU integration process, the functioning of European/international institutions, economic, political and social issues in European/international cooperation, knowledge and promotion of socio-cultural diversity; learning about European culture/literature/values guidelines, etc. From the curricular standpoint, citizenship education can be offered as a

2 The European Commission has published various White Papers and studies on European citizenship education such as: White Paper on "Teaching and Learning: towards the Learning Society" (1995); Memorandum on Lifelong Learning (2000)); Resolution on Lifelong Learning (2002)); European Commission: Open Learning Environment, Active Citizenship and Social Inclusion. Implementation of Education and Training 2010 Work Programme: Progress Report, Brussels, November 2003; European Commission: The Future of Education and Citizenship Policies: The Commission adopts Guidelines for Future Programmes after 2006, Brussels, 2004; Learning for Active citizenship. A significant Challenge in Building a Europe of Knowledge: Education and Active Citizenship in the European Union (2006); Programme in the field of lifelong learning 2007-2013. Interesting policy-oriented studies were made by GHK, Study on Active Citizenship Education, commissioned by DG Education and Culture, Feb. 2007, 151 p. and Eurydice, Citizenship Education at School in Europe, May 2005, 91 p. 
separate stand-alone compulsory or optional subject, or integrated into one or more other subjects (such as history, social studies, geography or philosophy), or as a cross-curricular educational theme, so that the principles of citizenship education might be present in all subjects of the curriculum. These different approaches are not mutually exclusive.

(2) Teacher education: The European dimension of citizenship education should be taken into account in the initial teacher education as well as in the provision of in-service teacher training.

(3) Support for teachers and teaching materials: Teacher support measures relevant to the European dimension of citizenship education may exist in a wide variety of forms and bodies. They may be devised by the education authorities of a particular country, public research institutes, institutions for teacher education, associations and NGOs as well as by a variety of European institutions, such as the European Commission or the Council of Europe. They may involve materials or facilities intended directly for teachers, or information materials on the European Union for the general public.

(4) Activities in the wider school context: Learning about the European dimension of citizenship means acquiring formal knowledge and developing awareness about a set of societal and political issues. However, this learning process also requires above all that students should be able to gain experience of a practical nature from simulation games or various exchange programmes. Many European, national and regional education programmes and schemes exist for promoting the European dimension and awareness.

If Europe wants to fulfil its destiny, a drastic increase in the engagement of citizens and (young) people to the European project is necessary. Strengthening a holistic and integral approach to the concept and practice of citizenship enriches the possibility of promoting active citizenship together with the European dimension. From the Tindemans Report "Europe of Citizens and Peoples" (1976) onwards many community action programmes have been launched to contribute to the building of active citizenship, mainly in the fields of education, training and youth (e.g. Socrates, Leonardo, Culture 2000, the Lifelong learning programme, "Youth on the Move").

In short, the European dimension of active citizenship goes beyond economic, political, social and cultural boundaries. Such integration can lead to the recognition and acceptance of a European citizenship covering multiple identities and nationalities. This is not the exclusive responsibility of governments, but also the responsibility of citizens and their organisations. Consequently, diversified forms of civil society participation emerge and develop in Europe, to concretise active citizenship at local and regional levels. However, a certain level of 
common identity is needed to strengthen European citizenship. This identity exists in different complimentary forms, creating a multilayered identity. It is a process that should be enhanced, as long as it goes along with the recognition of diversity. Intercultural learning could be key to this strengthening.

\section{4) The conditions for active citizenship learning in plural Europe}

The conditions for such an integral human development in education and learning can be summarised as follows: (1) The development, not only of an analytical mind and understanding, but also of a synthetic and creative capacity to applied learning in concrete training projects. There is the need for capacity and skills to confront and go beyond isolated subjects, disciplines and frontiers. This favours tolerance and avoids stereotypical behaviour and prejudices; (2) The formation of general and specific knowledge, particularly thinking and acting with respect for diversity and differences within and outside Europe. This requires a knowledge acquisition with an open and critical spirit in an historical perspective; but conscious of basic values; (3) Education to listening, tolerance, comprehension and respect for other cultures and other peoples and education to responsibility. Therefore, knowledge of one's culture and language, of other cultures and languages is an important key for actual communication; (4) A pedagogy is embedded in the regional and educational specificity: it implies territorial inclusiveness in order to create formal and informal spaces of learning, set within a European context; and (5) The development of programmes for learning to live together and life skills at the grass roots level, which stimulate participation, respect and dialogue.

\section{5) General education practices to European citizenship}

Active citizenship in a European context should be applied to general and specific education/learning processes by focussing on: (1) Attention to European themes/topics in the educational project, not as a residual factor but as a crucial and permanent reference with the help of numerous European, national and regional programmes; (2) Building a curriculum of formal and informal learning that includes interdisciplinary learning, workshops, and exchanges of good practice in a comparative perspective; (3) Transmission of collective memories, confirmation of common values and the formation of an open mind and tolerant, respectful, interested behaviour towards other cultures through experience, examples and exchange programmes and permanent learning; and (4) Financial support for concrete projects to develop networks of regional, national, European and international collaboration among schools and teachers. 
Various programmes of education for democratic citizenship are organised by international organisations ${ }^{23}$ as well as by governmental and non-governmental organisations. They all offer training, education and learning activities targeted towards teachers, students or specific groups such as minorities or handicapped persons, often with a focus on the local implication. They all illustrate the importance of the societal role of education for integration and inclusion purposes in democratic and multicultural societies. The main challenge remains however the implementation of these education activities in formal and non-formal curriculum building at local and school levels.

\section{Education Policies for Citizenship-building in Europe}

\section{The legal basis}

At the European level, education in general and higher education in particular are not subjects of a common European policy. With the principle of subsidiarity each member state maintains full responsibility for the content and the organisation of its education system. The European Commission's work in the field of education and training rests on two pillars: (1) policy cooperation and work with the member states; and (2) funding programmes, such as the Lifelong Learning Programme. The basic principle is that member states are in charge of their education and training, and the European Commission works together with the member states to help achieve common goals.

Education was formally recognised for the first time in the treaty establishing the European Community signed in Maastricht in 1992. The Maastricht Treaty set the scene for education and vocational training in the EU. The legal basis for citizenship education is now set in Articles 165 and 166 of the Lisbon Treaty.

\section{Article 165}

1. The Union shall contribute to the development of quality education by encouraging cooperation between Member States and, if necessary, by supporting and supplementing their action, while fully respecting the responsibility of the Member States for the content of teaching and the organisation of education systems and their cultural and linguistic diversity. The Union shall contribute to the promotion of European sporting issues, while taking account of the specific nature of sport, its structures based on voluntary activity and its social and educational function.

23 See the education programmes of the UN, UNESCO, Council of Europe, the education, youth and citizens' programmes of the EU, etc. 
2. Union action shall be aimed at:

- developing the European dimension in education, particularly through the teaching and dissemination of the languages of the Member States,

- encouraging mobility of students and teachers, by encouraging inter alia, the academic recognition of diplomas and periods of study,

- promoting cooperation between educational establishments,

- developing exchanges of information and experience on issues common to the education systems of the Member States,

- encouraging the development of youth exchanges and of exchanges of socio-educational instructors, and encouraging the participation of young people in democratic life in Europe,

- encouraging the development of distance education,

- developing the European dimension in sport, by promoting fairness and openness in sporting competitions and cooperation between bodies responsible for sports, and by protecting the physical and moral integrity of sportsmen and sportswomen, especially the youngest sportsmen and sportswomen.

3. The Union and the Member States shall foster cooperation with third countries and the competent international organisations in the field of education and sport, in particular the Council of Europe.

4. In order to contribute to the achievement of the objectives referred to in this Article:

- the European Parliament and the Council, acting in accordance with the ordinary legislative procedure, after consulting the Economic and Social Committee and the Committee of the Regions, shall adopt incentive measures, excluding any harmonisation of the laws and regulations of the Member States,

- the Council, on a proposal from the Commission, shall adopt recommendations.

\section{Article 166}

1 The Union shall implement a vocational training policy which shall support and supplement the action of the Member States, while fully respecting the responsibility of the Member States for the content and organisation of vocational training.

2. Union action shall aim to:

- facilitate adaptation to industrial changes, in particular through vocational training and retraining, 
- improve initial and continuing vocational training in order to facilitate vocational integration and reintegration into the labour market

- facilitate access to vocational training and encourage mobility of instructors and trainees and particularly young people,

- stimulate cooperation on training between educational or training establishments and firms,

- develop exchanges of information and experience on issues common to the training systems of the Member States.

3. The Union and the Member States shall foster cooperation with third countries and the competent international organisations in the sphere of vocational training.

4. The European Parliament and the Council, acting in accordance with the ordinary legislative procedure and after consulting the Economic and Social Committee and the Committee of the Regions, shall adopt measures to contribute to the achievement of the objectives referred to in this Article, excluding any harmonisation of the laws and regulations of the Member States, and the Council, on a proposal from the Commission, shall adopt recommendations.

These two articles mean that the European Community may contribute to the development of quality education and training by encouraging cooperation between member states, through a wide range of actions, such as promoting the mobility of citizens, designing joint study programmes, establishing networks, exchanging information or teaching the languages of the European Union. The treaty also contains a commitment to promote life-long learning for all citizens of the Union. Therefore, the European Community has a complementary role to play: to add a European dimension to education and training, to help develop quality education and training and to encourage life-long learning.

\section{Overview of the European lifelong learning agenda in relation to citizenship}

1) The European Union ${ }^{24}$

In Chapter 12 we explained that the European Union introduced the notion of European citizenship in 1992 and completed its understanding in the updates of the Treaty on European Union. After having stressed

24 Lifelong Learning Programme of the EU covers the sectoral programmes of Erasmus for higher education Leonardo da Vinci for vocational training, Comenius for school education, Grundtvig for adult education, Transversal programme and the Jean Monnet Programme for European integration. See more details at http://eacea.ec. europa.eu/llp/index_en.php 
the representative and the participatory dimensions of the democratic character of the EU, the concept of active citizenship was promoted, especially by insisting on the "rights" linked to citizenship, neglecting somehow the responsibilities attached to citizenship. It was said that the concept of citizenship also entails responsibilities. In the European context, this means becoming "actively involved [...] to develop a sense of European identity, [thus] enhancing mutual understanding between Europeans".

However, there is no doubt that today's citizen is much more attached to rights than obligations, implying a sort of "clientelistic citizenship". If citizenship is only expressed in a legal/political relationship between the citizen and his/her polity (as a community/ political system), then today's citizen seems to be a consumer of the rights, treating their obligations to the community as less important. Therefore, today such responsibilities should be taught in a dynamic process of formal, informal and non-formal learning. It is however important to recall that citizenship building has become an integral part of the EU education and training agenda.

Since the mid-1990s the EU and the member states have attached great importance to lifelong learning in the knowledge society. Various White Papers, Memoranda and Resolutions illustrate the impact of lifelong learning on citizenship building:

- The White Paper of the European Commission on "Growth, Competitiveness, and Employment" (1993) ${ }^{25}$ proposed for the first time that: "Lifelong learning is, therefore, the overall objective to which the national educational communities can make their own contributions". It further said that:

All measures must, therefore, necessarily be based on the concept of developing, generalizing and systemizing lifelong learning and continuing training. This means that education and training systems must be reworked in order to take account of the need [...] for the permanent recomposition and redevelopment of knowledge and know-how.

- In 1995, the European Commission published the White Paper on "Teaching and Learning: towards the Learning Society"26 and declared 1996 the European Year on Lifelong Learning. The 1997 Amsterdam Treaty officially adopted lifelong learning as the basic principle for its education and training policies. The subsequent policy paper "Towards

\footnotetext{
25 White Paper, Growth, Competitiveness, Employment: The Challenges and Ways Forward into the 21st Century, COM (93) 700 final, in Bulletin of the European Communities, Supplement 6/93, December 1993.

26 http://ec.europa.eu/languages/documents/doc409_en.pdf
} 
a Europe of Knowledge" developed the principles of lifelong learning in order "to promote the highest level of knowledge for its people through broad access to education and its permanent updating". It confirmed the emergence of lifelong learning as the core policy strategy of the EU for the 21 st century. Institutional recognition of lifelong learning was expressed in the creation of the Lifelong Learning Policy Unit within Directorate XXII in Brussels.

- In 2000, the EC published the "Memorandum on Lifelong Learning ${ }^{927}$ which defined lifelong learning in terms of:

[...] all learning activities that are undertaken throughout life, with the aims of improving knowledge, skills and competence, within a social, civic, social and/or employment-related perspective.

It was finally published as a Commission Communication in 2001: "Making a European area of Lifelong Learning reality", ${ }^{28}$ making explicit its four broad objectives of active citizenship, personal fulfillment, social inclusion and employability. The taking into consideration of the full range of formal, non-formal and informal learning was important.

- In June 2002, the European Council of Heads of State and Governments adopted the Resolution on Lifelong Learning. ${ }^{29}$ It was to be the guiding principle for the reform of education and training in the member states. It contained a declaration that by $2010,15 \%$ of the working population must be engaged in educational activity. It argued that

Education and training are indispensable means for promoting social cohesion, active citizenship, personal and professional fulfilment, adaptability and employability.

It further affirmed that:

Lifelong learning facilitates free mobility for European citizens and allows the achievement of the goals and aspirations of the European Union countries (i.e. to become prosperous, competitive, tolerant and democratic). It should enable all persons to acquire the necessary knowledge to take part as active citizens in the knowledge society and the labour market.

It also agreed that lifelong learning should in future play a key role in:

$27 \mathrm{http} / / /$ www.bologna-berlin2003.de/pdf/MemorandumEng.pdf

$28 \mathrm{http} / / /$ europa.eu/legislation_summaries/education_training_youth/lifelong_learning /c11054_en.htm

29 http://eurlex.europa.eu/LexUriServ/LexUriServ.do?uri=OJ:C:2002:163:0001:0003:

EN:PDF 
[...] the actions and policies developed within the framework of the European employment strategy, the action plans for skills and mobility, the Socrates, Leonardo and Youth programmes, the e-learning initiative, and in the research and innovation actions among others.

The previous developments and various policy documents finally resulted in an integrated action programme in the field of lifelong learning 2007-2013:30 the new programme replaced the existing four sectoral programmes on school education (Comenius), higher education (Erasmus), vocational training (Leonardo da Vinci) and adult education (Grundtvig). The budget earmarked for this new integrated programme was $€ 6.97$ billion for the seven year period. They were further concretised in September 2006 with a recommendation that identified the key competences in lifelong learning and a recommendation on the establishment of the European Qualifications Framework for lifelong learning. ${ }^{31}$

The Lisbon Strategy: The development of lifelong learning as the EC's strategic policy for education and training does not stand alone. Since 2000, lifelong learning policies have become increasingly integrated as a core dimension within the broader economic and social policies of the EU with regard to the knowledge economy, employment, mobility and social inclusion. The Lisbon strategy was agreed in March 2000, when the European Council of Heads of State and Government formulated the new strategic objective for the EU as follows:

The EU must become the most competitive and dynamic knowledge-based economy in the world capable of sustainable economic growth with more and better jobs and greater social cohesion.

In order to achieve this ambitious goal, the European Council demanded

[...] not only a radical transformation of the European economy, but also a challenging programme for the modernization of social welfare and education systems. ${ }^{32}$

For the first time, agreement was reached on shared targets to make education and training policies central to the knowledge economy. A ten-year work programme was adopted to be implemented through the sharing of experiences, working towards common goals and learning from what works best elsewhere through the open method of coordination. This new instrument paved the way for a more coherent

\footnotetext{
30 http://ec.europa.eu/education/lifelong-learning-programme/doc78_en.htm

$31 \mathrm{http}: / /$ ec.europa.eu/education/lifelong-learning-policy/eqf_en.htm

$32 \mathrm{http} / / /$ www.europarl.europa.eu/summits/lis1_en.htm
} 
policy in education, where a common policy is not feasible but where there is a real need for a European educational area.

This programme constituted the new and coherent Community strategic framework of cooperation in the fields of education and training. Three major goals were to be achieved by 2010: (i) to improve the quality and effectiveness of EU education and training systems; (ii) to ensure that they are accessible to all; and (iii) to open up education and training to the wider world.

These ambitious goals were complemented by more specific objectives covering various types and levels of education and training (formal, non-formal and informal) aimed at making lifelong learning a reality, including citizenship education. "Education and Training 2010" integrated all actions in the fields of education and training at the European level, including vocational education and training (the "Copenhagen process") as well as the development of the European Higher Education Area (the "Bologna process") implying the introduction of the three cycles (Bachelor/Master/PhD), a quality assurance and the recognition of qualifications and study periods. However, the results of the Lisbon strategy and the achievement of the targets set for 2010 were not totally successful and a more realistic strategy for the current decade has been proposed.

The EU 2020 Strategy: The Lisbon Strategy has been replaced by the EU 2020 Strategy. ${ }^{33}$ It is the EU's growth strategy for the current decade. In a changing world, the EU wants to become a smart, sustainable and inclusive economy. These three mutually reinforcing priorities are said to help the EU and its member states deliver high levels of employment, productivity and social cohesion. Key priorities are (i) creating value by basing growth on knowledge; (ii) empowering people in inclusive societies; and (iii) creating a competitive, connected and greener economy. The key tasks are a successful exit from the crisis and an advanced strategy for convergence and integration within a multi-level governance setting and global context.

Concretely, the Union has set five ambitious objectives - on employment, innovation, education, social inclusion and climate/energy - to be reached by 2020. Seven flagship initiatives were launched to boost growth and jobs: Smart growth (i.e. Digital Agenda for Europe, Innovation Union and Youth on the Move), Sustainable growth (i.e. Resource Efficient Europe and an Industrial Policy for the globalisation era) and Inclusive growth (i.e. the agenda for new skills and jobs and the European Platform against Poverty).

33 http://ec.europa.eu/europe2020/index_en.htm 
Specific challenges for education and training are addressed: to achieve the target of a reduction in school drop-out rates to below $10 \%$ and of at least $40 \%$ of $30-34$ year-olds completing third level education; to strengthen the social embodiment of education (i.e. rethinking the role of university in knowledge and research generation in society); and the development of competences and skills adapted to the needs of an emerging new economy and society. The Church and Society Commission of the Conference of European Churches adopted an education strategy (Haguenau, $28^{\text {th }}$ May- ${ }^{\text {st }}$ June 2010) ${ }^{34}$ for monitoring and influencing the ET 2020 and for promoting education for democratic citizenship.

A further boost to European citizenship building has been given by the regulation on the European Citizens' Initiative (ECI) (2012). With the ECI, part of the Lisbon Treaty, EU citizens are being given the opportunity to play a part in the democratic process for the very first time. Although the ECI is not a legislative instrument, it can be a tool for participative cross-border democracy and a vehicle to bring Europe a little closer to its citizens. The proposed new "Europe for Citizens" programme 2014-2020 aims to enhance remembrance and civic participation in Europe. ${ }^{35}$

\section{2) The Council of Europe}

The Council of Europe is particularly active and productive in the areas of education, citizenship and intercultural dialogue. It has been dealing with these issues for several years, mainly through its programme "Education for Democratic Citizenship and Human Rights" $(\mathrm{EDC})^{36}$ and by formulating expert groups on education and democracy. The EDC is a set of practices and activities designed to help young people and adults play an active part in democratic life and exercise their rights and responsibilities in society. It encompasses concepts such as peace and intercultural education. Human rights education (HRE) is the core and indivisible part of democratic citizenship education. It introduces the conception of an international civism, being a new concept of citizenship, based on a major consciousness and responsibility.

In this context we refer to the Council of Europe's "Charter on Education for Democratic Citizenship and Human Rights Education"

\footnotetext{
34 Conference of European Churches, Church and Society Commission, Education Strategy, adopted at the Commission meeting in Haguenau, 28th May-1st June 2010. http://www.europarl.europa.eu/committees/en/studiesdownload.html?languageDocu ment $=$ EN\&file $=75891$, accessed 12/09/2012.

$36 \mathrm{http}: / /$ www.coe.int/t/dg4/education/edc/default_en.asp
} 
(May 2010). ${ }^{37}$ Article 2 of the charter defines education for democratic citizenship as

education, training, awareness-raising, information, practices and activities which aim, by equipping learners with knowledge, skills and understanding and developing their attitudes and behaviour, to empower them to exercise and defend their democratic rights and responsibilities in society, to value diversity and to play an active part in democratic life, with a view to the promotion and protection of democracy and the rule of law.

As to the relationship between education for democratic citizenship and human rights education Article 3 states that

education for democratic citizenship focuses on democratic rights and responsibilities and active participation, in relation to the civic, political, social, economic, legal and cultural spheres of society, while human rights education is concerned with the broader spectrum of human rights and fundamental freedoms in every aspect of people's lives.

Article 5 refers to its lifelong learning aspect:

learning in education for democratic citizenship and human rights education is a lifelong process [...], an essential element of the promotion of social cohesion and intercultural dialogue and the valuing of diversity and equality, including gender equality.

At the end of November 2012, a conference was held in Strasbourg on "Human Rights and Democracy in Action - Looking Ahead", to discuss the implementation of the Council of Europe's "Charter on Education for Democratic Citizenship and Human Rights Education". The focus on intercultural competences through education has been further strengthened. ${ }^{38}$

The cultural dimension of citizenship was also very much strengthened by the European Year of Intercultural Dialogue (2008). The Council of Europe's White Paper on Intercultural Dialogue ${ }^{39}$ has been most relevant not only for its definitions in relation to inclusion, integration and diversity, but also for its views on active promotion of citizenship:

Citizenship enhances civic participation and so contributes to the added value newcomers bring, which in turn cements social cohesion.

37 Recommendation $\mathrm{CM} / \mathrm{Rec}$ (2010) of the Committee of Ministers to member states on the Council of Europe Charter on Education for Democratic Citizenship and Human Rights Education.

38 Council of Europe, Directorate of Democratic Citizenship and Participation, Developing Intercultural Competence through Education, 2013.

39 White Paper on Intercultural Dialogue "Living Together As Equals in Dignity", Council of Europe, May 2008. 
A concrete follow-up to the Council of Europe's White Paper occurred with the development of the "Autobiography of Intercultural Encounters" ${ }^{40}$ which provides a tool for teaching and learning intercultural competences.

The White Paper looks at cultural diversity, national minorities and intercultural dialogue with an emphasis on education for citizenship. This also includes aspects of learning that facilitate the acquisition of skills and the development of attitudes. Such learning may foster a lifelong awareness of the citizens' role in society, political life and the locality to which they belong. The White Paper also connects democratic values, the recognition of the dignity of every human being and the concomitant equality of all. Moreover it is linked with the work of the European Commission against Racism and Intolerance, the Anna Lindh Foundation and the North South Centre, etc. A useful contribution to education for democratic citizenship, human rights and intercultural dialogue was made by the San Marino Conferences of 2008 and 2009; they focused on an exchange on teaching religion and beliefs in education. In this context, education plays a key role in developing the ability to conduct intercultural dialogue, which is an integral part of developing democratic culture and building true citizenship. ${ }^{41}$

\section{Conclusion}

\section{Conceptual guidelines}

So far, the EU has concentrated much on the "output legitimacy" of citizenship-building, whereas it is necessary to include the citizens on the input side of such legitimacy, especially given the widening gap between institutions and citizens and the decreasing sense of belonging to the European project. ${ }^{42}$ Europe today is characterised by a seemingly contradictory process of increasing diversity and supranational governance, and is not equipped with the proper institutional architecture to cope with the economic, political, social and cultural challenges of today's world. There is also the challenge of combining the culturally different concepts of being a good citizen with the overarching concept of building an inclusive global but European oriented citizen in the ongoing globalisation vs Europeanisation debate.

40 Byram, M., Barrett, M., Ipgrave, J., Jackson, R. and Méndez García, M.C., Autobiography of Intercultural Encounters, Strasbourg, France: Council of Europe Publishing, 2009.

41 Council of Europe, Speaking across borders: the role of higher education in furthering intercultural dialogue, in Higher education series no.16, 2010.

42 Eurobarometer, Intercultural dialogue in Europe, December 2007; http://ec.europa.eu/public_opinion/flash/fl_217_sum_en.pdf 
European citizenship should evolve to a flexible but equilibrating notion of rights and responsibilities within a European and global space. It should be embedded in a multi-level and multi-dimensional polity, consisting of different levels and covering various social, economic, ethical and political dimensions.

The following conceptual guidelines for true citizenship education should be considered: The valorisation of the educational and cultural dimension of citizenship building in Europe is crucial to find answers for a morally robust engagement of the citizen in society at all levels of sustainable statehood; The promotion of an education to responsible citizenship and multiple identities needs to be understood and carried out in a wider societal context of the knowledge triangle. A more comprehensive, international and multi-perspective analysis of the interconnection between education and society will make societies more cohesive and sustainable, and; Education at various formal, informal and non-formal levels of learning fosters a culture of peace, understanding and dialogue which should lead to active and responsible citizenship in the EU, rooted in a value-driven and citizen-centric European future.

\section{Policy suggestions}

The knowledge society requires an in-depth development of lifelong learning benefitting from a variety of interconnecting learning resources of citizenship building. However, today's policy towards a learning society implies a more innovative capacity to (re)design (new) institutions of political, economic, social and educational governance which can respond properly to the challenges of the multi-faceted process of globalisation.

The learning society manifests fundamental structural trends towards the individualisation of risk and the threat of social exclusion while promoting social inclusion, personal fulfilment, and lifelong learning for employability and adaptability. Learning new skills should therefore be envisaged for citizenship as much as for employability. This includes learning for personal, civic and social as well as for employment-related purposes. It implies raising investment in people and knowledge and broadening opportunities for innovative, more flexible forms of learning, respecting multiple identities within the European meeting place. The policy consequence is that education institutions should accept lifelong learning as their collective responsibility, but that governments should invest in training teachers and trainers for all stages of learning, in informal, non-formal as well as in formal education and that Europe should strengthen its lifelong learning agenda for active citizenship. 
When referring to citizenship education, it seems therefore necessary to broaden the term "citizenship" beyond its mere legal connotation and adopt a more comprehensive approach. Citizenship education has to be conceived as embracing all members of a given society, regardless of their nationality, sex, or racial, social or educational background. Responsible citizenship is therefore to be seen as an universal concept of giving children and young people the knowledge, values and skills they require to participate in society and contribute to their own and society's wellbeing.

It also implies that the European/international dimension should be conceived as an integral part of citizenship education. While concerns relevant to citizenship education are primarily related to a particular national context and associated with the need to strengthen democracy or the participation of certain social groups, membership of the European Union also calls for its own form of civic awareness. The need for knowledge regarding Europe is covered in school curricula by a very wide variety of disparate elements. This is often limited to transmitting basic knowledge of the European Union (i.e. the functioning of its institutions, the various entitlements of its citizens, or important stages in the process of integration). However, teaching should also focus on matters more concerned with European identity (e.g. the foundations of a common European culture, the position of one's own country in the $\mathrm{EU}$ ), on subjects for discussion related to society (e.g. the main issues in European cooperation), or on learning values (e.g. understanding and promotion of present-day socio-cultural diversity), alongside traditional education, extra-curricular activities and projects, such as travel exchanges, school twinning, participation in EU competitions, improving intercultural skills as well as language proficiency, directly experimenting with the European dimension. Implementation of the European dimension in courses and extra-curricular activities however, very much depends on the skills of teachers, requiring professional development as much as initial teacher education.

In order to respond to these contextual and societal developments, the following broad guidelines of policy-oriented education activities are suggested:

- Valorise the educational and cultural dimension of European citizenship-building by promoting places of intercultural learning through European exchange programmes, and by introducing innovative learning methods and tools at the various educational levels;

- Develop a multilayered curriculum on integral human development. This may enhance the understanding of the new reality of European citizenship and the continuous socio-cultural and political transformations of multicultural societies; 
- Launch creative incentives to learn active and responsible citizenship. Formal, non-formal and informal learning, in an interdisciplinary perspective, are all needed to preserve and enrich our European heritage - political, cultural and economic;

- Launch an integrated strategy to foster education in human rights and responsibilities. The European Commission could build on work of the United Nations, the Council of Europe, and UNESCO, especially of two key international instruments: the UN Declaration on Human Rights Education and Training (2011) and the Council of Europe's European Charter on Education to Democratic Citizenship and Human Rights Education (2010). 

CHAPTER 14

\section{Territorial Cooperation and Multi-level Governance. The Stimulating Role of the Committee of the Regions}

\section{Introduction}

The purpose of this chapter is to analyse the link between the need for territorial cooperation and the (new) concept of multi-level governance. In the first part we explore the concept of multi-level governance in a conceptual, global and European perspective. We further develop the principles, capabilities and perspectives of European multi-actor governance and briefly refer in a final section to the importance of urban realities in the multi-level governance approach. The second part of the chapter deals with the role of the Committee of Regions in the multi-level governance approach. It identifies its major political lines of action, assesses the importance of the new legal instrument of European Grouping of Territorial Cooperation (EGTC) in linking territorial cooperation with multi-level governance and briefly comments on the CoR's recent initiatives to strengthen the multi-level governance approach in the EU context.

\section{Multi-level Governance in European Perspective}

\section{The conceptual setting}

The point of departure is a good understanding of the principles of governance. The basis for good governance is a well-functioning democratic political system that ensures representative and honest governments responsive to citizens' needs. This includes respect for human rights and basic civil liberties such as freedom of expression and of association. It encourages free and pluralistic media, worker and employer organisations and civil society organisations. The foundations of good governance are the rule of law and the effective administration of justice. It implies transparent and accountable government institutions and independent judiciaries. Good governance requires institutions for the efficient, equitable and responsible functioning of a market economy, a sound financial system, prevention of anti-competitive behaviour, socially responsible corporate governance and a system for property rights and contracts. 
The concept of multi-level governance is very much linked to the study of European integration in the 1990s. The Treaty of Maastricht relied on the subsidiarity principle and the concept of decentralisation. The study of the European Union has been characterised by two different theoretical development phases: the first phase was dominated by studies from the field of international relations: the EU is seen as an international organisation similar to others (e.g. NATO, OECD, UN); in the second phase these studies were revised and public policies were added: the EU is seen as a unique sui generis international organisation both in its nature and to the extent of its development. The multi-level governance approach belongs to the second phase.

In political science literature, varieties of multi-level governance are distinguished. Decentralisation is the term we normally use to explain the shift of (some) power from the central state toward multi-governance levels. In recent years, interest in the policy concept of decentralisation has increased, along with interest in the policy differences according to particular cases (particularity vs generalisation).

If we focus on the general policy characteristics of multi-level governance, the changing relationships between actors situated at different territorial levels, both from the public and the private sectors are put at the centre of analysis. This implies frequent and complex interactions between governmental actors and the increasingly important dimension of non-state actors. In particular, multi-level governance crosses the traditionally separate domains of domestic and international politics: it highlights the increasingly fading distinction between these domains in the context of European integration; supranational, national, regional, and local governments are interrelated in territorially overarching policy networks.

As to the scientific development of the concept, amidst all the diversity, there are two quite distinct and coherent approaches to decentralisation, based on different concepts of governance. In their ground-breaking article, political scientists Hooghe and Marks have distinguished two types of multi-level governance: ${ }^{1}$ The defining characteristics of Type I refer to multipurpose sub-central jurisdictions; separate memberships of these sub-central jurisdictions; a fixed number of levels of sub-central jurisdictions and one uniform design for the

Hooghe, L. and G. Marks, Unravelling the Central State, but How? Types of Multilevel Governance, in American Policy Review, 2003; and ibid., Contrasting Visions of Multi-Level Governance, in I. Bache and M.Flinders (eds.), Multi-Level Governance: Interdisciplinary Perspectives, Oxford University Press, chapter 2, 2003. 
whole system. ${ }^{2}$ By contrast, Type II systems are defined by: taskspecific jurisdictions; overlapping memberships; an unlimited number of jurisdictional levels and a flexible design. ${ }^{3}$

Some criticisms of this theoretical and policy concept have been expressed. First of all, it is not really a proper theory, but rather an approach. The main difference between multi-level governance and other integration theories is that it ignores the continuum or grey area between intergovernmentalism and supranationalism and leaves in its place a descriptive structure. Furthermore, multi-level governance does not address the sovereignty of states directly, but instead simply states that a multi-level structure is being created by subnational and supranational actors. Finally, the transfer of loyalty and sovereignty between national and supranational entities and the future of this relationship in the EU is not specifically addressed.

\section{Multi-level governance in the context of globalisation}

If we relate the concept of multi-level governance to the context of a growing multi-faceted globalisation, the current policy debate exhibits an ongoing tension between pro and contra views as well as paradoxical interpretations of its consequences: globalisation can be frightening, stimulating, overwhelming, destructive or creative, depending on one's point of view; there is a widespread sense of instability and insecurity in economic, social and political developments with repercussions on governance structures; and there is a growing concern about the impact of globalisation on culture and identity at various policy levels. In short, as previously mentioned in preceding chapters, globalisation as a phenomenon and a process is an opportunity if its positive and negative consequences are well managed at different policy levels involving a variety of actors. Common (institutional) solutions are proposed on different levels to manage diversities.

In line with the definition of governance given in the first part of this book, global governance is defined as the system of rules and institutions established by the international community and private actors to manage political, economic and social affairs. It warrants serious attention. Good governance, at both the national and global level, should further values such as freedom, security, diversity, fairness

The simplest such systems might involve, under a national government, a set of provincial authorities each with broad ranging, identical powers and responsibilities; and clear separate responsibilities for a given territory and population.

3 Traditional examples include countries such as the U.K.; relevant contemporary cases are found in many large urban areas, in which responsibility for different functions and services are divided among many different bodies, each organised in their own way, with different territorial boundaries, different numbers of sub-levels. 
and solidarity. It should also ensure respect for human rights, international rule of law, democracy and participation, promote entrepreneurship and adhere to the principles of accountability, efficacy and subsidiarity. We consider the United Nations and the multilateral system the best means of responding to the challenges of globalisation. Policy answers to these challenges are to be elaborated at the global, European, national, regional and local level.

Various economic, political, social and cultural requirements need to be distinguished to achieve a proper multi-level governance structure:

1) In the fields of economic governance, rule setting is required for managing and controlling market economies. There is an ongoing, wide debate on the role of (financial) markets and how to meet the needs and aspirations of people in their own communities. Therefore, (new) institution-building (i.e. rule setting) needs to favour progress and wellbeing in a social context.

2) In the field of political governance, the debate concerns some major policy themes such as: Fair rules do not automatically lead to fair results. Institutional efforts are needed to help those countries and regions in a weaker position. Currently, trade and investment are often favoured over human rights and the environment, partly due to a "democratic deficit" at various governing levels; The role of the state should be revisited based on the rule of law, democratic institutions and the work with social actors. Political governance should develop (institutional and policy) capacities to respond to the rapidly changing political and economic landscape. It has to accommodate internally to an increasing vocal civil society and, externally, to a growing number of policy constraints; and finally, the nation state is not doomed to disappear but it is now just one actor in the international political system, and has to work together with international governmental and non-governmental organisations in order to elaborate the necessary rules for the newly emerging governance structure at the global level.

3) In the peoples and citizens oriented social and cultural governance, a fairer framework for the movement of people and a respect for cultural diversity are essential. This would guarantee internal and external solidarity as well as ensure better proximity of the citizens/public sphere to the institutional fabric.

In short, a combined multi-level governance and multi-actor governance is taking place in an emerging flexible policy network according to the issues, competences and interests of governments, private actors and representatives of the civil society. 


\section{Multi-level governance and the European integration process}

As stated above, the development of the concept of multi-level governance is very much related to the European integration process. Regional integration is seen as a route towards a fairer and more inclusive globalisation. Countries are better able to manage the social and economic challenges of globalisation by working together on the international scene. No other international form of cooperation is characterised by such far-reaching integration as the European Union. This becomes evident by the number and scope of policy areas covered by the European Union and the way policies are developed. The European Union can be characterised by a mix of classic intergovernmental cooperation between sovereign states and farreaching supranational integration. The combination of common decision-making with the wide area of policy areas results in a deep entanglement of member states' national policy levels with the European policy level.

The multi-level governance approach describes the European Union as a political system with interconnected institutions that exists at multiple levels and that has unique policy features. In other words, the European Union is a political system with a European layer (i.e. European Commission, European Council and European Parliament, etc.), a national and a regional layer. These layers interact with each other in two ways: first, across different levels of government (i.e. vertical dimension) and second, with other relevant actors within the same level (i.e. horizontal dimension).

\section{European governance in global perspective}

The emerging multi-level/multi-actor approach is shaped by the Europeanisation vs globalisation debate. The number and relevance of actors in the European political arena has significantly increased. This is true both in terms of their numbers and their interactions. We recognise a dramatic increase in the areas where European rules are established which shape the policies of nation states, regions and cities.

Within this changing context, the European multi-level and multiactor approach faces a number of challenges: A perception of a "powerless state", which loses its capacity to regulate certain key areas. Consequently, member states have to adapt to the EU institutional architecture and decision-making structure; Policy-making is further complicated by the growing advocacy of non-governmental organisations at various levels with the emergence of a European civil society; and finally the same international intensification is also manifest in the business sector, both within a sector or country and within big corporations. These challenges substantially influence 
European economic, political and social developments in the globalising world. New institution-building for economic and political governance in a European setting is therefore crucial.

\section{1) Governance in European perspective: principles and capabilities of EU praxis}

The basic principles guiding European governance, legally anchored in the treaties, are democracy, social equity, respect for human rights and the rule of law. These need to be reflected in institutions, rules and political systems within countries, respected by all sectors of society and applied at various levels of governance. Processes of globalisation and Europeanisation inevitably have an impact on local values and cultures. The trust among people bound by common values and culture is the "glue" which binds local institutions to undertake joint actions. This social capital is essential for Europe's future developments and European institution-building.

The capabilities and prerequisites for European governance are a solid home base, efficient local governance and a focused regional integration:

(1) Because of a lack of effective and democratic governance to manage unity in diversity at various governance levels, the potentials of Europeanisation are not being fully realised. Governance of Europeanisation is bound up with governance at the national level. What is needed, are effective political and legal institutions, strong economic and technological capabilities, and policies that integrate economic and social goals. A fairer Europeanisation also requires action and empowerment of people at different levels, in local communities and economies, as well as in the rapidly developing new forms of regional cooperation and integration.

(2) The European policy agenda must also respect diverse local needs and respond to their demands. The local community is part of an integrating world. Greater decentralisation is needed, but should be accompanied by increased capacities and resources, and effective frameworks for democracy and participation in respect of multiple (cultural, regional) identities. Local administration does not mean isolation. On the contrary, globalisation and Europeanisation offer many opportunities for national and cross-border networking, cooperation and exchange among local authorities. Non-state actors can also play important roles provided they have sufficient resources.

(3) Regional integration promotes more equitable globalisation by empowering people to better manage global economic forces, improving the negotiating power of smaller countries, building capabilities to profit from global opportunities, and improving global economic connections. 
It should be comprised of interconnected and interacting regions. Such a process of "open regionalism" can address some of the imbalances of globalisation, while promoting development and equity within and between regions. The EU praxis is an interesting example of deeper forms of integration, including openness, social protection, inclusiveness and respect for the rule of law, human rights, gender equality and political democracy. The future agenda for European governance should therefore include institutions that can bring together different regions around further European integration in respect of cultural and regional diversity.

\section{2) Reform of European governance: perspectives}

In analogy with the definition of global governance, European Governance is characterised as a system of rules and institutions established by the European Community and private actors to manage political, economic and social affairs. As a consequence, good European governance should further values such as freedom, security, diversity, fairness and solidarity at various levels. It should also guarantee respect for human rights, international rule of law, democracy and participation, promote entrepreneurship and adhere to the principles of accountability, efficacy and subsidiarity. According to the 2001 "White Paper on European governance" ${ }^{, 4}$ the response to these new challenges so far has been haphazard. What has emerged to date is a fragmented and incoherent system consisting of a patchwork of overlapping networks and agencies in the economic, social and environmental fields. There is a wide range of diverse, partial or inadequate developments.

Reforms should enhance the representative, participatory, transparent and accountable character of European institutions and give a voice to people to articulate their concerns. These reforms should mobilise the energy, commitment and sense of solidarity and responsibility of key actors in the European Community.

\section{Multi-level/Multi-actor governance and urban realities: a promising city practice ${ }^{5}$}

\section{1) Context: urban realities}

Within the restructuring of the European multi-level/multi-actor governance approach, urban realities have become a shaping and determining factor. Throughout history, cities have always been driving

Commission of the European Communities, White Paper on European Governance, COM (2001) 428 final, Brussels, 35 p.

5 See Chapter 15 for a more extensive analysis of the importance of cities in citizenship building and intercultural dialogue. 
forces of culture, civilisation and development in Europe. ${ }^{6}$ They express the richness of Europe, its cultural and spiritual memory and its creative will to make history. Urban spaces are increasingly seen in a wider societal context, linking place, territory and scale with governance, inclusion and identity. The specificity of the urban context is further determined by the various governance levels that move from hierarchical to networking relations. Cities can be seen in today's Europe as major vehicles to create an "urban civitas", representing local communities of diversified values and practices at the citizen level. They are changing places, where tradition is continuously confronted with modernity. Today they may offer inclusive environments for practising governance and dialogue.

Urban policies that respond to this renewed role of cities in a multilevel/multi-actor governance structure are manifold: they vary from the need to develop "glocal" strategies, master spatial cohesion, propose qualitative density in space and environment, stimulate innovating and creative power, create urban diversity and flexibility within multifaceted identities, guarantee urban solidarity, social justice, cultural diversity and social capital development, engage in city diplomacy, etc. The creation of such a favourable environment presupposes an active investment in strong development coalitions between public, private and civil society stakeholders at territorial and issue levels.

\section{2) Content: urban opportunities}

Being laboratories of innovative democratic initiatives, cities may fully contribute to the development of sustainable knowledge societies and obtain more easily a new equilibrium between change and tradition in a stimulating urban environment with citizens' involvement. They are important sustainable and living sources for building and experiencing the multi-faceted identity of the citizens of multicultural Europe. Throughout history they have been shaping actors for promoting and facilitating creativity, imagination and integration. Today they are breeding and learning places for innovative democratic processes and meeting spaces for dialogue and encounters.

As for cultural diversity and dialogue, cities and regions have an important role to play in taking and managing actions to disseminate respect for cultural differences. A more structured dialogue therefore is an important tool. Indeed, local and regional authorities have major competences in promoting cultural activities and intercultural dialogue

6 Grazi, L., L'Europa e le città. La questione urbana nel processo di integrazione europea (1957-1999), Bologna: Il Mulino, 2006, 397 p. 
and they bear a major responsibility for shaping and supporting the rich variety of cultures.

Cities also have a key role in disseminating and applying best practice and exchange of experiences in this field, in particular through their coordination of multi-dimensional local and regional networks in several sectors, involving all relevant actors. Examples of such interconnecting networks exist in several member states where governments encourage centres of community cohesion to work together at the local level. These organisations, often having different ethnic, religious and language backgrounds, aim at integration, foster better bonds between the different communities and boost the confidence of the local population. They tend to reflect the make-up of their neighbourhood, revealing a common ground between the different communities rather than the differences that exist between them.

In conclusion, in a multi-level/multi-actor governance structure an imaginative city-based approach may contribute to design principles that allow for creativity and experimentation and favour citizens' participation at the grass roots level. In summary, cities may, on the basis of some conditions, provide a favourable, attractive and creative environment for citizens' participation in (formal and informal) democratic processes of active citizenship.

\section{The Committee of the Regions: Principles and Practices in European Multi-level/Multi-actor Governance}

\section{Policy lines of action}

Having set multi-level governance in a broad conceptual and European perspective, we now turn to the principles and practices of the Committee of the Regions (CoR) in European multi-level/multi-actor governance. The CoR is the EU's Assembly of Regional and Local Representatives. It now comprises 344 members - regional presidents, mayors or elected representatives of regions and cities. Since its establishment in 1994, it has worked to bring citizens closer to the European Union. In 2009, the Lisbon Treaty strengthened recognition of the Committee of the Regions' role.

As stated above, in 2001 the European Commission published its "White Paper on European Governance", highlighting among other things the role of consultation and systematic dialogue as good practices in governing. ${ }^{7}$ The CoR moved European governance forward by

7 White Paper on European Governance, COM (2000) 428 final. 
focussing on a more shared responsibility for regional and local authorities.

In its "White Paper on Multi-level Governance" 8 the CoR stressed the idea for a community method based on a system of governance that involves local authorities in the framing and implementation of the European project. In this context, multi-level governance is defined as follows:

The Committee of the Regions sees the principle of Multilevel Governance as based on coordinated action by the EU, the Member States and regional and local authorities according to the principles of subsidiarity and proportionality and in partnership, taking the form of operational and institutionalised cooperation in the drawing-up and implementation of the European Union's policies. ${ }^{9}$

Concrete proposals for strengthening the involvement of Europe's regions and cities in future EU decision-making were set out. In particular, the development of multi-level governance within the EU's governance model(s) should eventually lead to a European Charter on Multi-level Governance. In other words, further EU political process needs to be built in partnership with regions, cities and local authorities.

The CoR's Mission Statement ${ }^{10}$ was restated in 2009 on its fifteenth anniversary. It clearly defined its role, values and aspirations within the European institutional landscape. The priority policy concerns and the CoR's political role in European decision-making processes are well expressed in the speech of Mr. Luc Van den Brande on his election as president of the CoR in 2008. ${ }^{11}$

- Strengthening Europe as a value-based community: European collaboration is underpinned by a community of shared values such as the centrality of the human being, freedom, equality, respect for human rights, the acceptance of diversity as an asset, tolerance, justice and solidarity.

- Strengthening Europe as a political project: Europe is more than a large economic space and more than the sum of individual national concerns. That implies that Europe should be mindful of national, regional and local identities. It also means that Europe should be able to

8 White Paper of the Committee of the Regions on Multilevel Governance, CoR, $89 / 2009$ final.

9 CdR 273-2011 fin

$10 \mathrm{http} / /$ cor.europa.eu/en/about/Documents/Mission\%20statement/EN.pdf

11 Luc Van den Brande, Let's build Europe in partnership, 6/02/2008; http://europa.eu/rapid/press-release_COR-08-19_en.htm?locale=FR 
play a role in an increasingly globalised world. In short, Europe must grow from an economic project into a truly Citizens' Europe.

- Concern about the quality of people's life and wellbeing of its citizens: Key issues include affordable housing, jobs, education and lifelong learning, affordable and accessible healthcare, care for the most vulnerable members of our society such as children and senior citizens and solidarity between the generations.

- Recognition of the multi-level governance of Europe: a hierarchical Europe is rejected and a "Europe with the regions, towns and local authorities" is acknowledged. It means close collaboration and partnerships between public authorities, private interests and civil society organisations to respond to complex issues in the decisionmaking process and to manage various policy levels.

- Due consideration of local and regional realities: In the globalised, decentralised and flexible world, a growing awareness of the importance assertivity and dynamism of smaller entities and regions is developing. Therefore political and institutional structures are needed that take into account these changes towards decentralisation, flexibility, cultural and regional identity. In summary, local and regional realities are substantive elements of the multiple European realities.

\section{European Grouping of Territorial Cooperation (EGTC $)^{12}$}

The CoR has taken the lead in the debate and praxis of a European multi-level/multi-actor governance approach. Cohesion policy and multi-level governance are two of the major policy areas that are of key importance for local and regional authorities. ${ }^{13}$ An essential feature of the local and regional dimension of cohesion policy and multi-level governance is interregional cooperation between local and regional authorities supported through networks. Such networks can promote the dissemination of best practice across the EU and enable valuable experiences to be shared from which mainstream policy can be developed. Such networks also provide opportunities for joint action and partnerships, which can stimulate local dialogues and also facilitate the development of exciting projects so that they can get off the ground.

An important European legal policy instrument in the implementation of the cohesion policy is the European Grouping for

12 See Territorial Cooperation- EGTC on: http://www.cor.europa.eu; Papisca, A. (ed), Il Gruppo europeo di cooperazione territoriale:Nuove sfide allo spazio dell'Unione Europea, Venezia: Marsilio, 2009, 187 p. and Peace, Human Rights, Vol. 3, 2010.

13 The other substantive areas of importance for local and regional authorities are: the reform of the European budget; energy policy and climate change; the Lisbon objectives; cultural diversity and neighbourhood policy. 
Territorial Cooperation (EGTC). The European Committee has a specific consultative role in the area of cross-border cooperation (Article 265 of the EU Treaty). For that reason the European Committee has been one of the main political promoters of territorial cooperation and of EGTCs, linking it closely with multi-level governance.

An EGTC enables regional and local authorities from different member states to set up cooperation groupings with a legal personality. The important cooperation instrument was established in 2006 by the European Parliament and the European Council, with political support from the CoR. ${ }^{14}$ EGTCs enable regional and local authorities from different member states to cooperate more effectively. An EGTC is a tool for organising and managing cross-border, transnational or interregional cooperation measures, with or without EU financial support.

To carry out these tasks, an EGTC may create its own structure, have assets and hire staff, run a cross-border transport or health service, manage a project or programme partly financed by the ERDF, manage a project under the Framework Programme for Research and Technological Development, etc. But EGTCs have no powers in the areas of policing, justice or foreign affairs. Regional and local authorities, central governments, bodies governed by public law and associations can all set up a EGTC by signing a convention and adopting statutes, which must be reported to the relevant national authorities. EGTC members must be located in at least two member states.

In its own-initiative opinion in June 2008, the CoR indicated the great variety of scope, territorial scales and governance solutions that could emerge from the implementation of the EGTC regulation. ${ }^{15}$ Evidence was given as to the possible contribution to achieving territorial cohesion through an innovative multi-level governance format. Member states were urged to implement national provisions for the EGTC so that all regions and cities in Europe could participate in the scheme.

There are now 32 EGTCs operating and 17 more were in the pipeline during 2012. ${ }^{16}$ On February 25th, 2013, the findings of the EGTC Monitoring Report 2012 were presented by the coordinator of the EGTC Platform. ${ }^{17}$ The report contains several new aspects that will allow the

\footnotetext{
14 Regulation 1082/2006/EC, 5/07/2006.

15 CoR, EGTC: New impetus for territorial cooperation in Europe, 18th June 2008.

16 EGTC activities are summarised and accessible to the public in the EGTC Platform of the CoR: www.cor.europa.eu/egtc

17 EGTC Monitoring Report 2012: https://portal.cor.europa.eu/egtc/en
} 
evolution of the EGTC groupings to be measured. It gives an overview of the staff directly hired by the groupings and also of the EU funding that is actually spent on them. In addition to this, the report contains a chart with an aggregate picture of the activities implemented by each of the groupings. Detailed grids illustrate which EGTCs are currently involved in health policy, transport, employment, culture and others, including the flagship initiatives of the Strategy Europe 2020.

In summary, the EGTC is a radical step forward in implementation possibilities for cross-border cooperation. It offers regional and local authorities the option of creating a cross-border grouping with a legal personality. The new EGTC instrument presents a challenging opportunity to go for an extra-territorial approach and very much links territorial cooperation with multi-level/multi-actor governance. The praxis and recent initiatives of the CoR have been shaping the emerging new European institutional framework in linking territorial cooperation with multi-level governance. The EGTC offers "a bridge to bring ideas to life" with a territorial and citizen focus.

\section{The Ateliers of the CoR: strengthening the multi-level governance approach}

As stated in the CoR's political programme 2008-2010, the development of the European Union's governance model towards a truly multi-levelled system, is part of the core business of the European Committee. The CoR has relaunched the debate on EU governance and become the reference point for multi-level governance in the EU, which will hopefully result in the adoption of a European Charter on Multilevel Governance in 2013/2014.

Within this framework, ateliers (workshops) on multi-level governance have been organised by the Forward Studies Unit since late $2008 .^{18}$ The ateliers are structured in the form of multi-annual ateliers cycles (e.g. 2008-2009: "Multi-level Governance in Europe"; 20102011: "Co-governing Globalization: What Role for Local and Regional Authorities?"). They are in reality, laboratories where new concepts are tested, views shared, and innovative ideas developed and concrete examples of local and regional governance exchanged. The ateliers provide a new meeting place for academics and policy makers from varied backgrounds with a view to integrating innovative ideas in policy-oriented outcomes.

18 See Ateliers of the CoR on Multi-level Governance: http://cor.europa.eu/ en/activities/governance/Pages/cor-ateliers.aspx 


\section{Scoreboard for monitoring multi-level governance at the European Union level}

As a follow-up to its 2009 White Paper, the Scoreboard on Multilevel Governance is the tool created by the CoR to monitor on a yearly basis the development of multi-level governance at the EU level. It observes how far institutions have taken multi-level governance principles on board at the early stage of their policy-making cycle, within a clearly defined timeframe.

Thus far, two editions of the scoreboard have been produced, covering the period 2010-2012. Each of these scoreboards provides a comparative assessment of the multi-level governance at the EU level under four priority policy strategies of the EU. The first scoreboard edition (2011) reviewed the Europe 2020 Strategy, the 2020 Energy Strategy, the Stockholm Programme and the 2010 Spring Package. The second scoreboard edition (2012) studied the Common Agriculture Policy, the Structural Funds, the Single Market Act and the European Neighbourhood Policy.

Both the 2011 and 2012 scoreboard editions ${ }^{19}$ showed that EU institutions make strong statements on the virtues of multi-level governance, without practising a mainstreamed culture of multi-level governance in the preparatory phases of policies, meaning that there is often a lack of multi-level governance administrative routine. In particular, the scoreboards demonstrate that governance practices with respect to procedures (e.g. information and consultation, stakeholders' involvement and responsiveness) better respect the objectives of multilevel governance than the practices related to the content of policies (territorial approach, subsidiarity) and the use of innovative instruments (contracts, etc.). In short, the scoreboards reveal gaps in institutional practices and detects potentials for a better MLG architecture when designing policies and strategies at the EU level.

\section{Towards an EU multi-level governance charter: a collaborative process}

With its "White Paper on Multi-level Governance", the CoR pledged to consolidate the values and principles of this mode of governance within European and national institutional and political frameworks. Throughout a series of ateliers and with the assistance of an external contractor, in 2012 the CoR initiated an inclusive and participative reflection process, leading to the drafting of a first European Union Charter for Multi-level Governance prototype, with the view that the

19 http://cor.europa.eu/en/activities/governance/Pages/mlg-scoreboard.aspx 
existence of such a charter should lead to greater participation by local and regional authorities in the exercising of European democracy. ${ }^{20}$

\section{1) Co-creation workshop}

A co-creation workshop, organised in Brussels by CoR Contractor "Strategic Design Scenarios" (16/04/2012) gathered practitioners and experts on multi-level governance for a series of hands-on design and reflection activities. It aimed at exploring possible usages, forms and structures for the charter before initiating a more in-depth debate on its possible content. It is important in this perspective to contextualise the new legal and institutional opportunities brought about by the Lisbon Treaty as well as the current challenges (e.g. re-nationalisation, economic crisis, intergovernmentalism, increased heterogeneity of local and regional authorities, blocking minorities, etc.) for launching the Charter on Multi-level Governance.

The discussion focussed on the need for a clear and readable definition of multi-level governance, applied to a dynamic European context. The core principles (such as subsidiarity, participation, diversity, complementarity, solidarity, human rights, active citizenship, partnerships, accountability, openness) should constitute the core and real strength of the charter, and be made explicit and explained. The (administrative) practices of good multi-level governance in line with a renewal of the European Community method, should lead to coresponsibility and co-ownership of the process. This would bring citizens closer to a human-centric approach. Attention should also be given to permanent and transparent follow-up mechanisms to implement and enhance it.

2) Workshop on "Communicating and Disseminating the Future EU Charter for Multi-level Governance"

With the June 2012 atelier, the innovative participatory drafting exercise entered a final phase of joint reflection, notably on the communication aspects of the prospective charter. The aspects of a modern communication strategy fit for unlocking the e-features of an EU charter of the 21 st century were discussed in a half day brainstorming session in June 2012, which included a panel of leading communication experts and practitioners. A targeted, focussed and visual communication strategy with a feedback mechanism (public fora and online/Internet) towards civil society and EU citizens illustrating the benefits of multi-level governance was said to be of crucial importance for the policy relevance and success of the charter. The Report of the EU

20 CoR 273-2011 fin. 
Charter for Multi-level Governance was published in October $2012 .{ }^{21}$ Its official presentation is due in early 2014.

\section{Conclusion}

Multi-level governance shapes the Europeanisation vs globalisation debate and proposes innovative institutional responses and cooperation mechanisms for policy issues at various levels of decision-making. In various chapters we have already recognised an increase in the number and relevance of actors in the European political arena as well as in the areas where European rules are established. These developments determine the policies of nation states, regions and cities. Within this changing context, the European multi-level and multi-actor approach faces a number of challenges that substantially influence European economic, political and social developments in the globalising world. New institution-building for economic and political governance in a European setting is therefore crucial.

The basic principles of European governance in the global setting are anchored in the treaties. They should be reflected in institutions, rules and political systems and applied at various levels of governance. Consequently, good European governance is based on the values of freedom, security, diversity, fairness and solidarity at various levels. It should also guarantee respect for human rights, international rule of law, democracy and participation, promote entrepreneurship and adhere to the principles of accountability, efficacy and subsidiarity. Because of the fragmented, partial and often inadequate policy options for governance issues, a reform of European governance is very much needed. It should strengthen the representative, participatory, transparent and accountable character of European institutions and give a voice for citizens to articulate their concerns and participate at all levels of society building.

The Committee of the Regions has been playing a stimulating role in moving European multi-level/multi-actor governance forward by focussing on a more shared responsibility for regional and local authorities. The CoR has taken an active lead in the debate and praxis of European governance. The European Groupings of Territorial Cooperation illustrate cross-border cooperation between regional and local authorities within a legal and financial framework. Also, the recent initiatives of the CoR have been shaping the emerging new European institutional framework in linking territorial cooperation with multilevel governance, reinforcing the human-centric approach.

$21 \mathrm{http} / /$ cor.europa.eu/en/activities/governance/Documents/mlg-charter_rapport-sds.pdf 


\section{CHAPTER 15 \\ Building "Urban civitas" in Intercultural Dialogue Practices}

\section{Introduction}

In today's Europe we are experiencing a transformation in the perceptions of the role cities can play in developing sustainable communities of common interest and shared values. Cities are increasingly seen in a wider societal context, linking place, territory and scale with governance, inclusion and identity. Cities are hubs for diversity, integration and intercultural encounters and of vital importance for mobilising citizens. They are perceived as economic, political and social assets for changing European societies. Within this emerging new urban environment, culture and intercultural dialogue are mobilising sources for building a democratic "urban civitas" and giving a renewed spirit to the city.

The "genius loci", i.e. the spirituality in the space of the city in the 21 st century, is realised both by secular and sacral objects. As described by many cultural researchers, spiritual spaces and routes are built around the existential problems that are common to all people. They deal with the problems of life, love, suffering and death. Problems are common but emotions and ways of expressing them vary between cultures, creeds and communities. Urban spaces can be understood as the lived-in spaces that shape collective imaginaries. These are created by history, architecture, people's perceptions and their culture.

The working hypothesis of this chapter is the relevance of the creative urban edge of cities in citizenship building and intercultural dialogue. Cities can be seen in today's Europe as major vehicles for creating an urban civitas, representing local communities of diversified values and practices at citizen level. They are changing places where tradition is continuously confronted with modernity. Today they may offer inclusive environments for practising dialogue.

The chapter is divided in three sections. In the first section we present the broad conceptual context in which cities operate as meeting places, confronting past, present and future in various aspects of material and immaterial societal life. In the second section we analyse the challenges and opportunities for cities in building creative and sustainable urban realities in Europe. The final section looks at the 
growing importance of spiritual spaces and routes as expressions of intercultural dialogue practices in urban areas.

\section{Conceptual Context: the Urban Civitas}

Urban civitas addresses the combined and overlapping themes of inclusion, integration and diversity. ${ }^{1}$ Integration cannot be achieved without inclusion; a society that exhibits respect for diversity and dialogue needs both integration and inclusion. The concept of urban civitas links the "demos" with the "polis". Its full recognition requires the acceptance of some conceptual responses to intercultural dialogue and citizenship building.

\section{Moving from multiculturalism to interculturalism}

In accepting "urban civitas" as the underlying vision for linking intercultural dialogue with citizenship we follow Stavenhagen's anthropological definition of culture as capital, creativity and way of life. ${ }^{2}$ He distinguishes three main functions of culture. The conservation of culture: culture as an asset, tangible or intangible and a carrier of local identity; its protection against territorial and market trends shapes the urban context. The production of culture: culture as a commodity which needs to be reproduced not only to reconstitute the cultural capital but also as a source of economic development insofar as it is embedded in production processes. The valorisation of culture: culture as a set of norms and capacities which enrich local communities and may be used as bridge builders and carriers of good relations for social and economic exchange.

A dynamic and interactive process between these three functions of culture implies not only the peaceful co-existence of different cultures within society but also a mutually influencing and open dialogue between cultures. Such a conceptual change from multicultural coexistence to intercultural dialogue may avoid the trap of cultural relativism and provide the basis for an interreligious dialogue.

\footnotetext{
We refer to Peter Ramdsen's conceptual introduction to the UDIEX-ALEP thematic network, which brought about an exchange of experience regarding urban regeneration and inclusion in 24 European cities. See at http://urbact.eu/en/ udiex/synthesis_prospects, September 2006.

2 Stavenhagen, R., Cultural rights: a social science perspective, in Culture rights and wrongs, Paris: UNESCO, 1998.
} 


\section{Recognising multiple faced identities and cosmopolitan citizenship}

The debate concerning identity and citizenship is crucial for understanding the role of intercultural dialogue in developing advanced forms of democracy. As previously stated in Chapter 3, identity-building is not a constant and invariable process, but changes over time according to criteria such as birth, family, language, religion, territory, etc. This process has become even more complex and disturbed by growing individualisation, intolerant and distrustful behaviour as well as by the vagueness of the moral norms within society. In short, identity is becoming more and more a relation identity with no exclusive characteristics in modern societies.

The inclusion of a European dimension as an added value to a relation identity reinforces our conceptual point of departure. Multiplicity is therefore the basis of European identity, shaped by a community of shared values (such as solidarity, the rule of law, respect for diversity, attention to the person and the human dignity). This enriching effect is certainly true for a cultural identity that binds and unifies countries, regions and groups of persons by shared memories and expectations. The political meaning of the recognition of multi-faceted identities lies in mutual respect for the uniqueness of the person. It constitutes the basis for a more authentic dialogue and solidarity within and outside Europe, rooted in the universal human rights paradigm. ${ }^{3}$

\section{Humanising globalisation}

The process of humanising globalisation, defined as a multi-faceted phenomenon and process, provides another conceptual response to the globalisation vs Europeanisation debate. The mainly economically dominated process of globalisation has led to a commodification and depersonalisation of economic and social relations, a radical decrease in the power of states in managing socio-economic activities and an increasing control of democratic societies by transnational networks. Europe is however not an exclusive economic space, but a community of shared values, which is forced to re-visit its premises in a newly emerging geo-political and economic setting.

Dealing responsively with the various consequences of globalisation is based on a common pattern of values and mutual respect of differences. A more "compassionate globalisation" is required to

\footnotetext{
3 Papisca, A., Droits de la personne et démocratie-Les cultures à la source de l'universel, in European Commission DG EAC, Intercultural Dialogue, March 2002, pp. 132-140.

4 Falk, R., Realizing the Copenhagen Vision: The Political Imperative, op. cit.
} 
combat any cultural relativism. ${ }^{5}$ Structures are needed that create zones of common interests and shared values, as structures for civilised confrontation and disagreement. At the same time, different cultures need to re-examine their own realities in the context of globalisation in order to re-locate themselves in this new reality. This implies the emergence of a global consciousness and the acceptance of multifaceted identities and multiple modernities. ${ }^{6}$ In Chapter 13, the fundamental role of education herein was stressed, mainly through the introduction of learning processes that replace a culture of competition, distrust and fear for a culture of cooperation, peace and mutual respect.

\section{Revalorising the role of cultures in Europe}

Working from an anthropological definition of culture, European culture(s) is (are) identified as a dynamic interaction of historic, spiritual, religious, intellectual, material, artistic characteristics and attitudes. These characteristics illustrate the multiplicity and wealth of European cultures, cultural expressions and traditions. These diversified but shared cultural expressions finally make up Europe's social, cultural and human capital. This cultural multiplicity is also a source of inner strength and outer pride. No culture can be missed out in the European cultural landscape.

Although Europe is pre-eminently a space of cultural diversity (as was explained in Part 1), respect for cultural diversity should not lead to ethnic reflexes and exclusive attitudes. The binding role of an internal and external open culture approach is to be a guarantee for further European integration and a renewed cooperation with other cultures. As a consequence, we conceive culture in the first place as a source of inspiration for social integration, socio-economic development and societal inclusion. It certainly may give an impulse to greater commitment and participation of the citizen to the European project.

\section{Stimulating intercultural dialogue}

The term intercultural dialogue is strongly normative and is seen as a path towards the goal of attaining ways of living together. Ray Isar's definition $^{7}$ of intercultural dialogue as an inherently normative and

See Chapter 10.

6 Eisenstadt, S., The dialogue between cultures or between cultural interpretations of modernity - multiple modernities on the contemporary scene, in European Commission DG EAC, Intercultural Dialogue, March 2002, pp. 59-68.

7 Isar, Y.R., The intercultural challenge: an imperative of solidarity, in European Commission DG EAC, Intercultural Dialogue, March 2002, pp. 169-183. 
voluntaristic practice of "learning to live together", 8 well suits the purpose of this chapter. ${ }^{9}$ Intercultural dialogue can be instrumental in softening and avoiding the (negative) consequences of the globalisation process (i.e. the issue of minorities, migration, poverty, etc.). A dialogue between peoples and cultures can also be constructive if it is based on common and moral values. In the current tension between (economic) globalisation, the need for internal and external solidarity, and respect for different cultures and religions, such a dialogue can be a vehicle for conviviality in which cultures influence each other without destroying each other or clashing with each other.

As to the specific European dimension of intercultural dialogue, it is clear that Europe as a global actor has an important responsibility to enable and facilitate intercultural dialogue. ${ }^{10}$ Europe should be a communicative bridge builder and boundary breaker in such a dialogue. The specificity of the underlying characteristics of the European model is very related to mutual understanding and learning in open dialogue. Within this context, initiatives have been taken and policies developed to reinforce the dialogue between peoples, cultures and civilizations. ${ }^{11}$ As such, intercultural dialogue is an integrative force of (re) creating the urban civitas and providing urban spaces for interreligious dialogue.

In this perspective the role of education is crucial. The learning processes for intercultural dialogue, respect for religious diversity and civic education are based on integral human development. Places for educational and cultural encounters are crucial for practicing Europe's unity in diversity.

\section{Creative Urban Realities in Europe}

In the second section of the chapter we focus on the urban environment that is needed to favour actual intercultural dialogue. Urban realities are increasingly playing a role in stimulating creativity for economic, social, political and cultural development. Cities are breeding grounds for inclusion, integration and diversity. Our working hypothesis

8 This concept was used by the Delors International Commission on Education for the 21st Century, in Learning: The Treasure within, Paris: UNESCO, 1996.

9 See Chapter 11.

10 Bekemans, L., Culture vs globalisation in Europe: actual tension or possible dialogue?, in L. Anckaert, D. Cassimon and H. Opdebeeck (eds.), op. cit., pp. 191211; and ibid., Globalisation and Solidarity: Europe's duty in intercultural dialogue, in Intercultural Dialogue, European Commission DG EAC/Jean Monnet Action, March 2002, pp. 152-168.

11 Bekemans, L., The idea and practice of Europe in a globalising world: reality and responsibility, in Rivista Pace Diritti Umani, Vol. 1, April 2004, pp. 121-133. 
is that the "urban civitas", as explained in the first part of the chapter, is a major shaping factor in the promotion of intercultural dialogue. In other words, cities matter in intercultural dialogue.

\section{The urban context}

An understanding of the context is crucial in any process of urban development that includes both a transformation of the physical fabric and a consideration of culture as a transforming power. The specificity of the urban context is further determined by the various governance levels that move from hierarchical to networking relations.

The conditions of urban policies that respond to this renewed role of cities as reference frames in economy, polity, society and culture are manifold. They may vary from the need to develop glocal strategies, to master spatial cohesion, to propose qualitative density in space and environment, to stimulate innovating and creative power, to create urban diversity and flexibility within multi-faceted identities and to guarantee urban solidarity, social justice and cultural diversity. The creation of such a favourable environment presupposes an active investment in strong development coalitions between public, private and civil society stakeholders at territorial and issue levels.

\section{Urban challenges}

The challenges of urban realities in creating a favourable urban context vary. For some cities, the challenges are increasing population, rising house prices, a lack of available land, traffic congestion and overstretched public services; for other cities, depopulation, degradation, lack of jobs or low quality of life are the main issues. At least four key issues require attention in urban policies. They create the (pre)conditions for sustainable and creative urban development as well as for intercultural dialogue.

\section{1) Transport, accessibility and mobility}

Problems of social inclusion, education, housing and public space can be addressed through innovations in transport. Less cars often means more civic space and civic resources for people. Many cities are trying to reduce the negative effects of urban transport by providing high quality public transport and better management of traffic. Affordable access to public transport is a key component of such a strategy. Another possibility is increasing the opportunities for cycling and walking, which is not only a contribution to sustainability but also to public health. Moreover, a lot of European cities have made a substantial investment in tram or light rail systems. Successful management of urban transport often requires the city and its surrounding region to coordinate transport planning, construction and 
land-use. They all form part of an integrated transport strategy for the urban area and may provide the necessary conditions for increased citizens' involvement into local processes.

\section{2) Access to service facilities}

Effective and affordable services related to health, culture, education, training, retailing and public administration are vital to the quality of urban life. They make a city and its neighbourhoods more attractive and liveable. An unconventional and innovative solution to this challenge is to create city-wide amenities in deprived areas. This creates services, reduces isolation, stimulates encounters and improves the image of the area within the broader urban context. Another innovative solution to greater inclusion and integration of citizens into public life could be the creation of easy online access to public services such as e-government, e-health and e-learning.

Natural and physical environment

People want to live and work in cities with a distinct identity, where both the natural and built environment provides good environmental, living and housing quality. This requires coordination between various disciplines and competences involved in urban developments. Therefore, cities need to grow the infrastructure that can enable this emergent energy to upscale across the whole city by capitalising on their distinctive assets and stories.

Activities to launch urban renewal or improve urban quality require long term and integrated redevelopment plans that are citizens-based. In particular, housing-related programmes (such as the rehabilitation of common spaces, the construction of social housing, cohousing, security measures and crime prevention, efficient energy and water supplies, etc.) will need proper financing if increased citizens' participation in local democratic processes is to be successful.

Culture

Culture and the management of its diversity often challenge urban realities by creating opportunities as well as hindrances for dialogue. Cultural amenities are a key determinant of a city's attractiveness. In particular, a vibrant and diversified cultural offering may be an important place-specific factor in attracting people and creative industries. It may provide the conditions that encourage individual as well as business creativity. Moreover, local pride and identity and the image a city presents to the outside world are in a large part determined by the quality of its local cultural scene.

Culture is important for all cities, but particularly in changing the image of a deprived city. Its role often determines the success or failure of regeneration projects of urban areas. Festivals, exhibitions and 
cultural events are especially important in forming the brand image of a city. Culture can also be a valuable tool for intercultural dialogue as stated in Chapter 10 and 11. A cultural centre where communities meet, or a local cooperation project between various neighbourhoods, offers space for true encounters between peoples from different cultures. Cultural diversity can also be a source of innovation and entrepreneurship, and can become a positive force in the socio-economic development of cities.

\section{Urban opportunities}

If positive solutions are given for these urban challenges, cities can be the main actors for creating "urban civitas" in Europe, particularly for providing the environment for intercultural and interreligious dialogue, and hence strengthening citizenship building.

\section{1) Cities: sources for European identity, imagination and integration}

Throughout history, cities have always been driving forces of culture, civilisation and development in Europe. ${ }^{12}$ As was previously clearly stated in Chapter 14, cities express the richness of Europe, its cultural and spiritual memory. They have been meeting places on the roads to intercultural dialogue. ${ }^{13}$ The spirituality of a place can be the driving force for city planners and local decision makers in rediscovering European identity. ${ }^{14}$ Cities are the stories they tell about themselves. Pride, confidence and identity come from the collective imagination of people across the city. There is an opportunity to reconcile the past and to realistically link it to different possible futures through encouraging citizen participation.

This is why policy at regional, national and European level needs to have an urban dimension: to exchange experiences and best practices, to help overcome urban (social and cultural) ruptures and finally to bring forward new investment in social capital development. An imaginative city-based approach may help urban areas to design principles that allow for creativity and experimentation and favour citizen participation at grass roots level.

12 An excellent overview of the role of cities in history is given by Hall, P., Cities in Civilisation. Culture, Innovation and Urban Order, Phoenix: Weidenfeld \& Nicolson, 1998, $1169 \mathrm{p}$.

13 The programmes of cultural routes by UNESCO, the Council of Europe and the European Union relate to itineraries that connected people. They very much focus on practising dialogue of cultures and civilisations as a factor in the creation of a culture of peace.

14 Flanaghan, B., The Spirit of the City, Voices from Dublin's Liberties, Dublin, 1999. 


\section{2) Cities: engines for sustainable growth, social cohesion and urban quality}

Cities have also often been engines of economic and social development, creating growth, innovation and employment. Economic and social sustainability is in this perspective a key concept in urban policies. ${ }^{15}$ Economic, social and urban policies are mutually reinforcing: economic growth is sustainable when it goes hand in hand with efforts to reduce poverty, fight social exclusion and tackle urban problems. However, significant disparities in economic, social and urban opportunities as well as contradictory developments between northern and southern European cities exist. They often necessitate diversified urban policies and different types of urban action.

With increasing powers, cities today have the political opportunities to realise their objectives of sustainable growth and social cohesion within an increasing urban quality context. People want to live and work in cities with clean air, green and secure spaces, attractive architecture and high quality services, including cultural and recreational amenities. When cities have the structures and means to create urban quality they provide the conditions of an inclusive and democratic urban civitas for the multicultural composition of their inhabitants.

\section{3) Cities: facilitators for innovation and entrepreneurship in the knowledge society}

Cities often provide a stimulating environment for creativity, ${ }^{16}$ innovation and businesses. In the emerging European creative urban reality cities can stimulate the creation and development of small and medium-sized enterprises, micro-enterprises and social economy enterprises, set up business incubators, provide access to finance and other business services. In addition, experiences and practices illustrate that cities can simplify administrative demands, improve education and training opportunities, facilitate networking between education and enterprises and stimulate cooperation between companies, research institutes and universities. Being laboratories of innovative democratic initiatives, they fully contribute to the development of sustainable knowledge societies and obtain more easily a new equilibrium between change and tradition in a stimulating urban environment with citizen involvement.

See Girardet, S., Creating Sustainable Cities (Schumacher Briefings), London: Green Books, 1999.

16 Landry, Ch. and Fr. Bianchini, The Creative City, A Toolkit for Urban Innovators, London: Demos Publishers, May 2000. 


\section{4) Cities: promoters of social inclusion, equal opportunities and security for citizens}

The urban reality often reflects disparities between neighbourhoods, a problem that confronts Europe's large and medium-sized cities. The Urban Audit shows that almost all cities where unemployment is at a level of $10 \%$ or higher, have certain areas within which unemployment rates are at least double the city average. Within such deprived neighbourhoods, high unemployment is linked to poor housing, poor environment, poor health, poor education, few job opportunities and high crime rates.

Alongside these obvious disparities, certain groups within cities experience further disadvantage. Cities should therefore pay special attention to integrating immigrants, and prevent the social exclusion of young people. In short, they can favour social inclusion through measures of security and facilitate professional, social and cultural integration of fragile communities.

Social exclusion is at odds with the European social model that guarantees opportunities for every citizen. It has consequences for local businesses (less customers), for living environments (less security, vandalism) for inhabitants (lack of "positive thinking", creativity and enthusiasm at work) and for the growth potential of the city (which is less attractive). Tackling social exclusion is therefore crucial to sustainable urban policies. Connected to the promotion of social inclusion is also the need to guarantee citizen security. Urban safety, and, just as important, the perception of safety, has become a vital issue in urban policies. Cities are at the foreground for creating urban environments favourable to social inclusion and security, and consequently, to genuine and human-centric citizenship building and intercultural dialogue.

\section{Intercultural Dialogue Practices: Intercultural Routes and Spiritual Spaces}

Cultural Routes represent interactive, dynamic and continually evolving processes of human intercultural links that reflect the rich diversity of the contributions of different peoples to cultural heritage. Though cultural routes have resulted historically from both peaceful and hostile encounters, they present a number of shared dimensions that transcend their original functions, offering an exceptional setting for a culture of peace. Such a culture is based on ties of shared history as well as the tolerance, respect and appreciation for cultural diversity that characterise the communities involved. Cultural routes reveal the 
heritage content of a specific phenomenon of human mobility and exchange that has developed over centuries via communication routes..

Cultural routes are not only paths of communication and transport which include cultural properties and connect different people; they are special historic phenomena that cannot be created by applying one's imagination and will to the establishment of a set of associated cultural assets that happen to possess features in common (e.g. the Incan and the Roman Empire Routes). Sometimes they are the result of a long evolutionary process in which the collective interventions of different human factors coincide and are channelled towards a common purpose (such as the Route to Santiago, the African trade caravan Routes or the Silk Route). The cultural richness and variety of both the interrelationships and the characteristic assets directly associated with cultural routes refer to monuments, archaeological remains, historic towns, architecture, intangible heritage, cultural and natural landscapes, etc.

The Cultural Route programme launched by UNESCO is intended to promote mutual knowledge between civilisations and cultures while lending visibility to their interactions. Routes provide a better grasp of the mechanisms that in peoples' long memories may either encourage prejudice and misunderstanding or help to renew a dialogue between civilisations, cultures, religions and spiritual traditions.

Cultural itineraries facilitate an effective merging of cultures through the discovery of a common heritage and multiple identities. This is the case in particular with the Slave Route, East-West intercultural Dialogue in central Asia, Roads of Al-Andalus ${ }^{17}$ etc. An interesting related initiative is the programme of interreligious dialogue "Spiritual Convergence and Intercultural Dialogue". Its purpose is to bring out the dynamic nature of reciprocal cultural, artistic and textual interactions and influences between religions and spiritual traditions that resulted from the movement of persons, ideas and goods along the roads taken by pilgrims, migrants and tradesmen. It has led to meetings and exchanges along the roads of Faith where religions and spiritual traditions developed. Cultural routes are therefore an instrument for reading the European values that emerge from the complexity of the cultures and societies constituting Europe.

Spiritual places refer to the sacredness of space, buildings and objects. The condensed sacrum that is revealed or found in some places

17 The "Routes of al-Andalus: spiritual convergence and intercultural dialogue" project by UNESCO seeks to highlight the heritage of dialogue that gradually developed in medieval Spain and study and promote the creation of areas of dialogue between cultures and civilisations. 
establishes the structure of the surrounding world and shapes spatial relations. The sacred space may therefore be defined as a special case of symbolic space. The sacred monuments, sites and texts illustrate a common heritage with shared ethical and spiritual values. These sites have become meeting places for spiritual leaders to work together for peace and interreligious dialogue.

The renaissance of pilgrimaging, in particular the phenomenon of religious tourism, should be understood from this perspective. However, the phenomenon of the pilgrimage should not simply be identified with the phenomenon of wandering and travelling. Its main distinguishing feature lies in its religious and sacral implications. We are carried by the authenticity, identity and local genius of particular places and routes along the pilgrimage. Therefore pilgrimages should be protected from mercantilism and commercialisation.

The spiritual rebirth linked with the renaissance of trips to places of religious devotion is tied to the fact that man is capable of going beyond the material sphere of his existence. Still there is a danger that pilgrimage destinations are becoming a mere component of the tourist industry and losing their soul. Henceforth, architects and urban planners play an important role in finding an expression and a context for contemporary spirituality in pilgrimage locations, separating it from the dominating commercial activity of the tourist industry. Pilgrimages have always been borne out of spiritual needs. The places that are visited are sacred in different ways within different religions. Places of worship sometimes surround holy relics and sometimes mark the place of miraculous events. Many of these places belong to world cultural heritage and are worshipped not only by believers but also by all people sensitive to spiritual values in space, on the basis of the principle of mutual respect.

\section{Conclusion}

Cities are important sustainable and living sources for building and experiencing the multi-faceted identity of the citizens of multicultural Europe. Throughout history they have been shaping actors for promoting and facilitating creativity, imagination and integration. They always have been places on the roads of dialogue. Today they are laboratories and breeding grounds for innovative democratic processes in which intercultural dialogue can be an important vehicle. They provide learning places, built and non-built environments and meeting spaces for daily experiences of intercultural dialogue and encounters for conviviality.

In summary, cities may, on the basis of some conditions, provide a favourable, attractive and creative environment for citizen participation 
in (formal and informal) democratic processes of active citizenship. Roads of dialogue interconnect cities through the creation of occasions and areas of interchange and encounters. Interconnecting cities can, as history has proven, create the environment for intercultural practice between people and the meeting point for human-centric encounters. 

CHAPTER 16

\section{Learning Experiences of Participative and Deliberative Democracy}

\section{Introduction}

In this final chapter we argue that dialogue, while happening within the participative and deliberative democratic system, may significantly contribute to the improvement of democracy through a greater legitimacy, through a real empowerment of citizens and through a more active participation of citizens in public life. To break down the negative perception of a disconnection between citizens and decision-making institutions, the focus needs to be put on a transfer of the outcomes of public discourse to a multi-level governance structure, thus creating an opportunity for an increased political role for the Committee of the Regions.

In the first part, we describe the development of a European public sphere from the perspective of participative and deliberative democracy, its opportunities and characteristiccs. The second part deals with three interconnected but different learning experiences of participative democracy: the European Movement, the College of Europe and the non-profit organsation Ryckevelde. Finally the opportunities and challenges of participative democracy are assessed in view of an emerging deliberative democracy where civil dialogue becomes an important shaping factor in citizenship building.

\section{Development of a European Public Sphere in Participatory, Deliberative and Inclusive Democracy ${ }^{1}$}

The European Union faces numerous challenges in a period where the consequences of economic globalisation are being felt: a major consequence is the largely debated democratic deficit resulting from the great distance between citizens and decision-making institutions. On the citizen's side, one may observe the decreasing trend in civic activities

See Karasinska-Fendler, M., How Intercultural dialogue can improve European democracy- deliberative democracy approach, in L. Bekemans, M. KarasinskaFendler, M. Mascia, A. Papisca, C.A. Stephanou and P.G. Xuereb (eds.), op. cit., p. 85-97. 
potentially offered by democratic systems. Some experts call these problems symptoms of morbidity or fluidity, linked to the erosion of the sense of belonging to the local, regional, national and European community. European societies are moving towards communities of individuals instead of communities of persons at the expense of the common good. In the midst of a grave systemic financial and economic crisis, mainly due to the negative consequences of financial globalisation, trust-worthy institutions and confidence-building measures are more than urgent. Therefore, we believe that NGOs across Europe should form part of a regular, structured, and guaranteed dialogue with EU institutions. The inclusion of a new Article $8 \mathrm{~b}$ on participatory democracy in the Treaty of Lisbon is therefore a milestone in the development of participatory democracy and civil dialogue. ${ }^{2}$

Within the deliberative democracy the concept of dialogue is perceived as an inclusiveness-generating process with some specific conditions (i.e. social interaction, respect for different and changing views, shared commitment to problem resolution, building of a community of interests). If democratic conversation between citizens and governance is a central idea of democracy, there needs to be a permanent and mutual interaction of this two-way communication. Therefore, a particular role is to be played by various governances to provide channels for such a bottom-up and top-down symmetrical interaction. So it is imperative to connect this communication and interaction to governments, policymaking and governance at different levels.

It is a widely recognised opinion that there is no European demos, nor a genuine European-wide public sphere or a European polis. If the public sphere (today's common space in society is a highly complex network of various parts of public spheres) does not exist, how then do we explain the citizen's sense of belonging and commitment to democracy and rights? Criteria include the decision-making capacity, the deliberation process and representativeness. In the EU, a multitude

Article $8 \mathrm{~b}$ of the Treaty of Lisbon (OJ 17.12.2007, C 306/1) says: "1. The institutions shall by appropriate means, give citizens and representative associations the opportunity to make known and publicly exchange their views in all areas of Union action; 2. The institutions shall maintain an open, transparent and regular dialogue with representative associations and civil society; 3. The European Commission shall carry out broad consultations with parties concerned in order to ensure that the Union's actions are coherent and transparent; 4. Not less than one million citizens who are nationals of a significant number of Member States may take the initiative of inviting the European Commission, within the framework of its powers, to submit any appropriate proposal on matters where citizens consider that a legal act of the Union is required for the purpose of implementing the Treaties". 
of discussion fora exists at local, regional, national, international and transnational levels.

We assume that greater participation is a substantive value as an aspect of empowerment. European citizens must therefore be given chances to directly and personally experience what European citizenship means in practice; this can be realised through participation in dialogue with European institutions or through horizontal dialogue. In particular, civil and intercultural dialogue contributes to making European citizens a reality through encouraging their direct involvement in the integration process. It may be crucial in developing a sense of belonging to the Union and to making citizens able to identify with it. Therefore, the ability to dialogue should be developed and secondly, the venues and grounds for such dialogue need to be available. In this perspective history teaches us some good practices.

\section{Formal and Informal Learning Experiences of Participative Democracy}

More than 60 years ago, Europe was required to rebuild its future within a framework that went beyond national borders. History was running apace and Europe was urged to act in order to restore confidence among its citizens. New initiatives were launched and new organisations were created in the aftermath of the Second World War. ${ }^{3}$ They were meant to create confidence-building structures: the education of "European" citizens was therefore a challenge to be taken seriously.

At this particular juncture between continuity and change in European history, our case studies will illustrate interesting (historical) examples of bringing the European integration project close to the people, being a practice of participative democracy "avant la lettre". They illustrate, each with their own merits, a remarkable process of sensibilisation of the European integration project. Moreover, they teach us that, even in present times and dominated by new technology tools for improving participative democracy, interesting lessons can be drawn from initiatives, activities and good practices of learning participative democracy that were initiated quite some time ago.

Furthermore, they also show that some prerequisites are needed for developing deliberative democracy. The ideas and propositions expressed at the Hague conference in 1948 were structured in the "European Movement". Some of the suggestions have been concretised by the creation of the College of Europe in Bruges (B) in 1949, the oldest post-graduate institute offering a specific European formation,

See Chapters 2 and 3. 
and by the launching of "Ryckevelde" in 1956, a European and International information and formation centre promoting active citizenships. Reflecting on their history, their vision, mission and functions, we may learn some good practices of participative and deliberative democracy.

\section{The European Movement: a bottom-up approach shaped by inspiration and commitment}

\section{1) Context}

The International Committee of the Movements for European Unity (ICMEU) was created in 1947 in Paris to organise and promote a publicity campaign in support of European unity. It was the ICMEU that convened and hosted the Congress of Europe at The Hague in May 1948. With Churchill as its Honorary President, the congress was attended by some 800 participants (statesmen, MPs, businessmen, trade unionists, academics, etc.). Its major objective was laying the building blocks for peace, stability and cooperation in Europe. This was made explicit in three ambitions: 1) to demonstrate the existence of a body of public opinion in support of European unity; 2) to discuss the challenges posed by European unity and propose practical solutions to governments; and 3) to give new impetus to the international publicity campaign. Building on the success of the Hague Congress, the International Committee assumed responsibility for implementing the resolutions adopted by the participants in the political, economic, social and cultural fields. Accordingly, an Economic and Social Committee, a Legal Committee and a Cultural Committee were set up.

The European Movement was formally created on the $25^{\text {th }}$ October 1948, when the Joint International Committee for European Unity decided to change its name. It received public support by major political leaders. ${ }^{4}$ Duncan Sandys was elected President and Léon Blum, Winston Churchill, Alcide De Gasperi and Paul-Henri Spaak were elected as Honorary Presidents.

The European Movement aimed to look at the political, economic, technical and cultural problems posed by Europe and also to inform and mobilise public opinion in favour of European integration. It is interesting to note in this perspective the membership of the Council of European Municipalities and Regions and the International Federation

\footnotetext{
Former French Prime Minister, Léon Blum, Winston Churchill, the Italian Prime Minister, Alcide De Gasperi, the Belgian Prime Minister and Foreign Minister, PaulHenri Spaak, the French Foreign Minister, Robert Schuman, Count Richard Coudenhove-Kalergi and the German Chancellor, Konrad Adenauer were elected honorary presidents.
} 
of European Houses. The grass roots movement was backed by farsighted political leaders and concrete action was supported by vision.

The European Movement was ideologically very active in the beginning and organised many events on specific themes, preparing the formal process of European integration. In February 1949, the Brussels Political Congress defined individual, family and social rights that might be guaranteed in law by a European Charter of Human Rights. It also reviewed procedures for the appointment of delegates to the European Consultative Assembly and adopted the statute for a European Court. Two months later, the Westminster Economic Conference discussed monetary issues and laid the foundations for a future European Payments Union. Supporters of the pooling of basic industries, the congress participants also discussed the setting up of a European Economic and Social Committee.

The first major achievement of the European Movement was the creation of the Council of Europe in May 1949. The European Conference on Culture in Lausanne in December 1949 resulted in the establishment of the European Centre for Culture in Geneva and the College of Europe in Bruges. A few months later, the Social Welfare Conference in Rome drew up a plan for the harmonisation of European social security systems and proposed the creation of a European Commissariat for Labour and Population and a European fund for reconstruction and development. Other international conferences followed, successively considering the integration of Germany into a united Europe, the relations between the Europe being built and the Commonwealth, and the situation of the countries of Central and Eastern Europe. The European Movement also pursued an intensive publicity campaign, particularly through the European Youth Campaign.

One of its major functions during the 1950s through to the 1990s was the setting up of think-tanks and a network of mobilisation in the democratic countries of Europe and in countries subjected to totalitarian regimes. In summary, since 1948 the European movement has played an essential role in the process of European integration by exercising its influence on European and national institutions. It fought in favour of the direct election of the European Parliament by all European citizens, in favour of the Treaty on the European Union and also for a European Constitution. Its objective was to transform the relations between the European states and their citizens into a Federal European Union. To achieve this goal, the European Movement always put the citizen at the heart of community construction. Currently, The international European 
Movement ${ }^{5}$ is represented in 41 European countries and regroups 20 international Associations.

\section{2) Working}

The European Movement was led by an Executive Committee and an International Committee that, in turn, was supported by national councils in Austria, Belgium, Denmark, France, Greece, Iceland, Ireland, Italy, Luxembourg, the Netherlands, Norway, Portugal, Sweden, Switzerland, Turkey, West-Germany and the United Kingdom. To ensure that its views were heard, the International European Movement ran a publicity campaign that was aimed at political, economic, social and cultural leaders. It did not overlook the general public: it held public debates and funded a great many publications, including the monthly journal "Nouvelles de l'Europe". Therefore, despite experiencing ideological, human and material difficulties in the early 1950s The European Movement constituted a tremendous moral and inspiring force that enabled the European idea to move on to the next stage of initial practical achievements.

\section{The College of Europe: ${ }^{6}$ a unique higher learning institute on European affairs}

\section{1) Origin}

Not many institutes of higher learning in Europe have had as strong an influence on the development of European integration as the College of Europe. The College's origins date back to the 1948 Hague Congress, when Salvador de Madariaga, a Spanish statesman, thinker and writer in exile, proposed the establishment of a college where university graduates from many different countries could study and live together. It was founded by the European Movement in 1949, as a result of the European Conference on Culture in Lausanne.

The creation of the college is illustrative of the inspiring mood of the time, present at the level of the European intelligensia and political leadership as well as at the local level. Thanks to a number of favourable circumstances, Bruges became a conscious and deliberate choice for the college's site. ${ }^{7}$ Happy coincidences that involved a group of Bruges citizens led by the Reverend Father Karel Verleye ("les Amis de

http://www.europeanmovement.eu/

http://www.coleurop.be; Bekemans, L., D. Mahncke and R. Picht (eds.), The College of Europe - 50 years of service in Europe, College of Europe: Bruges, June 1999.

7 The president of the International Cultural Section of the European Movement, Don Salvador de Madariaga explicitly said that Bruges had promoted itself as the place for a post-university institute of European studies. 
Bruges"), the European Union of Federalists as well as local, provincial and national politicians, made the choice for the Bruges' site happen. In summary, the plans by the local committee and those by the International Cultural Section merged into one project, i.e. the actual launching of the College of Europe, with a short preparatory academic session in September 1949 with 22 students. It was seen as an initial step towards founding a future European University. Professor Hendrik Brugmans, one of the intellectual leaders of the European Movement at the time, became the first Rector of the College of Europe (1950-1972). After the fall of communism, and in the wake of the changes in Central and Eastern Europe, the College of Europe campus at Natolin (Warsaw, Poland), was founded in 1993 with the support of the European Commission and the Polish government. The College now operates as "one college - two campuses", strengthened by its "esprit du collège".

\section{2) Assessment}

1) The founders of the College of Europe were sure about their vision. For Salvador de Madariaga, Hendrik Brugmans and Father Karel Verleye, Europe was a historic and spiritual reality, which needed to be lived with respect to common values and enriching diversities. To realise this potential unity, Europeans need to be formed. So the college was created even before the existence of other European institutions.

2) This particular vision has proved to be very successful in the construction of a common multi-level Europe. The college's alumni work in many strategic places of the EU; through their specific competences and skills they have shaped its policy and complex functioning. Again, Europe today is placed at the crossroads of its history. Confronted with many and global challenges, Europe is confronted with economic, political and institutional challenges and opportunities for multi-level governance in a globalising context. Once again, vision has to inspire difficult and concrete realisations at political and institutional levels in order to bring the citizen closer to the European dream.

3) Apart from its successful development, another major element of this success story is the interaction between the college and its immediate environment, represented by the Local Committee. The committee, then also a section of the European Movement, was founded in 1949 as a non-profit association to spread the idea of a unified Europe and to stimulate interest in the workings and objectives of the College of Europe in Bruges. Conferences were organised and a European Winter programme was launched. From the mid 1960s, interest in cooperation declined, mainly due to a more specialised programme, less dedication among committee members and a more formal relationship. Only in the mid 1990s was the Local Committee revitalised. It is now organising a 
variety of activities from conferences and concerts to visits in view of strengthening the college's links with the economic, social and political environment. A final meeting ground between the college and the local environment is the area of housing and accommodation, in particular the many student residences in the town and the new campus in the restored 16th century Jesuit buildings. In summary, the city provides a learning basis for the European citizens of tomorrow and offers the space to develop plural identities for the future of Europe, a meeting place between theory and practice.

4) The "College Formula" ensures that, for 10 months, students live and follow together an intensive programme in a challenging and highly stimulating educational environment, which truly prepares them to live and work in an increasingly integrated Europe. The student body around 300 students in Bruges and up to 120 students in Natolin (Warsaw) - reflects a real diversity of culture and personal experience. It is a unique institute of postgraduate studies and training in European affairs. In its more than 60 year history it has trained more than 8,000 students in its two campuses and has a network of more than 100 visiting professors.

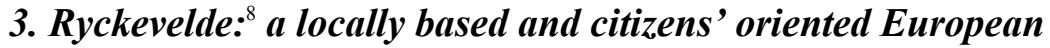 and international formation and information centre}

\section{1) Origin}

Ryckevelde is an independent, non-profit organisation promoting European citizenship, located in Damme (near Bruges, Belgium) and structurally supported by the Department of Education of the Flemish Government in Belgium and the Province of West-Flanders. The organisation was founded as a "Centre of Europe" by Karel Verleye in 1956. As a pioneer of European cooperation, he was also co-founder of the College of Europe in Bruges in 1949. The organisation operates from the belief that peace in Europe - both in the past and future depends on a democracy in which citizens truly participate. Its main objectives are to understand and experience Europe. This is why Ryckevelde empowers citizens to participate in European society by offering training and debates and running actions, events and projects on the European integration process.

Since 1956, Ryckevelde has developed a broad experience of the formation of young people and information about the European integration, with the aim of bringing Europe closer to its citizens. It favours European integration and an active European citizenship based

$8 \quad$ http://www.ryckevelde.be 
on some fundamental values, particularly a respect for each person within its social context. It is an organisation that adopts a bottom-up approach with a clear vision of transmitting forgotten factors of European integration to European citizens, young people and adults.

\section{2) Working}

With its vision, mission and grass roots perspective, Ryckevelde has nearly 60 years of experience in training and information activities that have stimulated participative democracy. They concern the following general activities:

- Training: Ryckevelde offers a variety of training sessions to schools of secondary and higher education. They are adapted to the students' needs, their age and educational level. Different methods are used: interactive presentations, simulation exercises and educational games. Adult groups are offered a variety of tailor made European training sessions. It also publishes didactical sets for teachers and adult groups: training sets for various target groups, didactical internet material and educational games.

- International school projects: helping schools to set up international projects and/or advising them with the content (didactical aspects) or organisational (practical/grant) aspects of their projects. Ryckevelde regularly organises international meeting sessions for teachers. They meet colleagues from all over Europe and get acquainted with the European educational space.

- EU Campaigns: In the week of May 9th every year, a European campaign is launched with quizzes, debates and concrete actions that draw people's attention to the European integration process and make them think about the future of the European project. A State of the European Union is organised in collaboration with the Flemish Parliament and the Flemish-European Liaison Office, where a critical Europe watcher sets out his/her vision on what the European Union should do in the coming year. At the same event, prizes are awarded for The Junior State of the European Union, The State of Creanovative and a Senior State of the European Union.

- Actions and debates: organisation of public debates on current European themes, as well as simulation sessions of the European Council with a view to raising awareness of the European democratic decision-making process.

- The yearly Karel Verleye Prize in memory of its founding father: a prize is awarded to students who have written a thesis on the forgotten factors of European integration, being education, culture, ethics, citizenship, etc. 
- Joint European projects: increasing involvement in European projects with a view to stimulate youngsters to actively reflect on the future of Europe, its vision and the European citizens' needs. Ryckevelde cooperates with the European SPES Forum in the project "Imagine Europe", financed as a youth democracy project within the Youth in Action Programme of the European Union and increasingly with the Jean Monnet Programme of the EU DG Education and Culture in its project "EU at School".

\section{Participative Democracy: an Assessment}

In the following section, some reflections on participative democracy are presented based on previous learning experience in formation and information on European issues. Participative democracy refers to an exchange of a diversity of views, the modes and organisation of civil dialogue and the citizens' initiative. ${ }^{9}$ The principle of participation aims at facilitating more inclusion of those issues and people that are usually under-represented but are of major concern for European citizens. In practice, this means the right of petition, binding referendum at peoples' initiative, at the initiative of a Head of State, government or prescribed by the European Constitution, removal procedures and forms of "online democracy", creating a European public sphere/space. We identify advantages and disadvantages, strengths and weaknesses of participative democracy practices and present an experience-based assessment.

\section{Strengths of participative democracy}

\section{1) Content focused and citizens oriented}

Contrary to representative democracy where citizens vote for individual politicians (because they are trust-worthy) or where citizens choose for a political party (because of the programmes' attractiveness), participative democracy focuses more on content themes. Representative democracy seems to be in crisis and the public perceives that politicians are too busy with their own agenda and less occupied with real problems. In a participative democracy, the citizen feels that his vote has a direct impact on reality. This increases his interest in the public cause, the common good and strengthens the citizen's involvement and participation in democratic life.

The European Movement, the College of Europe and Ryckevelde all show that the interest of citizens, students, young people and the broad public can be stimulated by proper information, focused formation and

Fazi, E. and J. Smith, Civil Dialogue - Making it work better, Civil Society Contact Group, 2006, 100 p. 
in-depth study about concrete and clear issues concerning the European Union, framed within a long term vision. When people are informed about the direct impact of European decisions on their life, they often recognise the relevance and importance of the issues at stake. Once interest is aroused, their preparedness to tackle and deepen more complex themes grows. The above learning examples illustrate a continuous link between people's daily life and the European context. Therefore methods, pedagogical tools, concrete targets as well as privileged testimonies are crucial in building up true participative democracy and promoting active and responsible European citizenship.

\section{2) Agenda setting}

Forms of participative democracy at the European level may put European issues high on the political agenda in a member state. In countries such as France, the Netherlands and Ireland where referenda were organised either on the "Treaty for establishing a European Constitution" or "the Reform Treaty", attention towards the European case has increased. European issues are (hotly) debated with positive and negative reactions, as the current debate among EU member states about policy answers to the crisis, demonstrates. It certainly opens up a space for opportunities for information, communication and the role of the media in transmitting fair and objective assessments about the EU policies. More than in the case for European Parliamentary elections, participative democracy focuses on specific European issues. In the present format of European Parliamentary elections, where national (regional) lists of candidates are presented, the elections are perceived as mere popularity polls of national (regional) parties, beyond the scope of the real issues.

\section{Weaknesses of participative democracy}

1) It remains a difficult task and challenge to explain complex technical issues to the citizen. Moreover, concretising Europe has its limits. The heterogeneity of the public often makes content discussion and debate difficult. More than before, the general public has become interested in issue-related participation and less in general debate. In summary, it will remain difficult to inspire or motivate the totality of the population with a general discourse. This has an impact on the methodology and pedagogy of participative democracy, the choice of themes and the organisation of formation and information. In representative elections, it is often not easy to make the majority of the population participate; this is often related to the democratic deficit, the indifference of citizens to the public cause and the waning trust in politics. 
2) As has been made clear in the referenda in France, the Netherlands and Ireland, people have been voting against or in favour for the most diverging and contradictory reasons. It is often easier to build a coalition against a proposition in public opinion than a coalition for it. Moreover, participative democracy tools, if not well designed and coherently explained to citizens, can be misused. Populists and populist parties can often very easy adapt their policies to the changing circumstances of proposed themes in the participative democracy. This often makes it difficult to draw general policy conclusions from the outcomes of referenda. The European cause needs European leaders!

\section{Conclusion}

From the above short analysis the following lessons can be drawn for the practice of participative democracy. ${ }^{10}$

1) Participative democracy covers commonly accepted features such as a) an involvement of non-state actors, mainly individual citizens and civil society organisations; b) an extension of the concept of citizenship beyond the conventional political sphere; c) a focus on policy-makers' permanent accountability between elections; d) a recognition of citizens' right to participate in public life through alternative channels, e) a possibility for citizens to take direct responsibility in public life; f) a possibility for citizens belonging to minority groups to make their voice heard in the public debate; and g) an emphasis of the role of civil society organisations as important forces of integration and empowerment at various levels. ${ }^{11}$

2) Prerequisites are needed for a well-functioning participative democracy. Such an applied vision and generous commitment should be shaped by different actors and partnerships at various policy levels, a sufficiently pro-active and autonomous civil society, territorial embeddedness, trust-building instruments and innovative methods, supportive financing structure, etc.

3) The building of European public spheres assumes a move from participative to deliberative democracy tools. Deliberative democracy is a form of democracy in which authentic deliberation is central to decision-making. It adopts elements of both consensus decision-making and majority rule. Originally driven by the need to tackle the shortcomings of representative democracy, civil dialogue appears in this context as a means of bringing citizens back to policy decision-making.

\footnotetext{
10 See also Berger, N., Participatory Democracy: organised civil society and the "new" dialogue, Paper given at the Federal Trust and UACES conference "Towards a European Constitution", London 1-2 July 2004.

11 Mascia, M., Participatory Democracy for Global Governance, op. cit.
} 
4) The importance of testimonies of best practices in formal and informal learning of participative democracy: a deliberative context is therefore needed if participative democracy is not to be reduced to a catalyst for public moods and used for political purposes.

5) The following points arise as key challenges for the development of (new) instruments for deliberative democracy: a) providing an enabling structure leading to concrete outcomes; b) the need for better horizontal coordination and equal access to information; c) strengthening trust and mutual understanding between NGOs and EU institutions; and d) the need for an inclusive approach.

6) Finally, European cooperation in the field of education means direct investment in Europe's future: a) in this perspective, the Comenius Regio Partnerships, ${ }^{12}$ (i.e. an action under the Lifelong Learning Programme) is important. It creates new opportunities for cooperation in school education between local and regional authorities, schools and other learning organisations across Europe; b) the establishment of a European (regional) programme similar to the Democracy Fund at the United Nations (UNDEF). Its primary purpose is to strengthen the voice of civil society and ensure the participation of all groups in democratic practices. It funds projects that enhance democratic dialogue and support for constitutional processes, civil society empowerment, etc.

$12 \mathrm{http} / /$ ec.europa.eu/education/comenius/regio_en.htm 



\section{Bibliography}

Acharya, A., Regional Worlds in a Post-Hegemonic Era, Bordeaux: Spirit Working Papers, 2009.

Amin, A., D. Massey and N. Thrift, Cities for the many, not the few, Bristol: Policy Press, 2000.

Anckaert, L., D. Cassimon and H. Opdebeeck (eds.), Building Towers. Perspectives on globalisation, Leuven: Peeters, 2002.

Appiah, K.A., Cosmopolitanism: Ethics in a world of strangers, New York: W.W. Norton, 2006.

Banks, J., et al., Teaching diverse learners, in L. Darling-Hammond and J. Bransford (eds.), Preparing teachers for a changing world: What teachers should learn and be able to do, San Francisco: Jossey-Bass, 2005, pp. 232274.

Barrett, M. (ed.), Interculturalism and Multiculturalism: Similarities and Differences, Strasbourg: Council of Europe, Publishing Department, 2013.

Baudot, J., Building a World Community, Globalisation and the Common Good, Seattle-London: Royal Danish Ministry of Foreign Affairs Copenhagen and University of Washington Press, 2001.

Bauman, Z., Liquid Modernity, Cambridge: Polity Press, 2000.

Beck, U, Conditio Humana. Il Rischio nell'eta globale, Roma-Bari: Editori Laterza, 2008, 401 p.

Bekemans, Léonce (ed.), A Value-Driven European Future, Brussels: P.I.E Peter Lang, 244 p., 2012.

Bekemans, L. and L. Morganti (eds.), The European Public Sphere. From critical thinking to responsible action, Brussels: P.I.E. Peter Lang, 300 p., 2012.

Bekemans, L. (ed.), Intercultural Dialogue and Multi-level Governance in Europe. A Human Rights Based Approach, Brussels: P.I.E. Peter Lang, 2012, $607 \mathrm{p}$.

Bekemans, L. and E. Mira (eds.), Civitas Europa, Cities, Urban Systems and Cultural Regions Between Diversity and Convergence, Brussels: P.I.E. Peter Lang, 292 p., February 2000.

Bekemans, L. (ed.), Culture Building Stone for Europe 2002, Brussels: European Interuniversity Press, 1994, 331 p.

Bennett, T., Differing Diversities. Cultural policy and cultural diversity, Strasbourg: Council of Europe Publishing, 2001. 
Bergan, S. and H. van't Land (eds.), Speaking across Borders: The Role of Higher Education in Furthering Intercultural Dialogue, Council of Europe, in Higher Education Series No.16, December 2010.

Biscop, S., The Value of Power, the Power of Values: A Call for an EU Grand Strategy, Egmont Paper 33, Brussels: Academia Press for Egmont, The Royal Institute of International Relations, 2009.

Bloomfield, J. and F. Bianchini, Planning for the Intercultural City, Stroud: Comedia, 2004.

Bodo, S. and R. Cifarelli (eds.), Quando la cultura fa la differenza, Rome: Meltemi, 2006.

Bóka, É., Europe in search of unity in diversity, ISES Füzetek 14, Köszeg: Szombathely, 2010, 64 p.

Brooks, S. and W. Wolhforth, Reshaping the World Order, in Foreign Affairs, 88(2): 49-63, 2009.

Brugmans, H., La Cité Européenne, Brussels: Presses Interuniversitaires Européennes, 1985, $176 \mathrm{p}$.

Commenne, V. (ed.), Economic Actors' Participation in Social and Environmental Responsibility, Paris: Editions Charles Léopold Mayer, 2006, $286 \mathrm{p}$.

Dantas, M.L., Building Teacher Competency To Work with Diverse Learners in the Context of International Education, in Teacher Education Quarterly, Winter 2007, p.75-94.

Deardorff, D.K., The Sage Book of intercultural competence, Thousand Oaks, CA: Sage, 2009.

De Groof J., Thoughts of autonomy in Policy and Law within the European Higher Education space, in Bekemans, L. et al. (eds.), Intercultural Dialogue and Citizenship. Translating Values into Actions. A Common Project for Europeans and their partners, Venice: Marsilio, March 2007, p.81-142.

De Lombaerde, P. and M. Schulz, The EU and World Regionalism. The Makability of Regions in the 21st Century, Surrey: Ashgate, 2009.

De Senarclens, P. and A. Kazancigil, Regulating Globalization. Critical Approaches to Global Governance, Tokyo: UNU Press, 2007.

Devuyst, Y., The European Union Transformed, Brussels: P.I.E. Peter Lang, 2006, 212 p.

Enderlein, H., S. Wälts and M. Zürn, Handbook on Multi-level Governance, Cheltenham, UK: Edward Elgar, 2010.

Falk, R., The Decline of Citizenship in an Era of Globalization, in Citizenship Studies, Vol. 4, no. 1, 2000.

Falk, R., On Human Governance, Cambridge: Polity Press, 1995.

Florida, R., The Rise of the Creative Class, New York: Basic Books, 2002, $404 \mathrm{p}$.

Gnesotto, N. and G. Grevi, The New Global Puzzle. What wor.ld for the EU in 2025?, Paris: Institute for Security Studies, 2006. 
Grevi, G., The Interpolar World: A New Scenario, in ISS Occasional Paper no. 79. Paris: EU-ISS, 2009.

Gundara, J.S., Interculturalism, Education and Inclusion, London: Sage Publications, 2000.

Hall, P., Cities of Tomorrow, An Intellectual History of Urban Planning and Design in the 20th century, Oxford: Blackwell Publishing, 2002, 576 p.

Héritier, A., Common Goods: Reinventing European Integration Governance, Lanham (MD): Rowman \& Littlefield, 2002.

Jensen, J., Whose Rules? Governing Globalization in a Mult-Stakeholder World, ISES Füzetek 9, Köszeg: Szombathely, 2008, 99 p.

Karolewski, I.P., Citizenship and Collective Identity in Europe, London and New York: Routledge, 2010, 253 p.

Keohane, R.O., International Institutions: Two Approaches, in International Studies Quarterly, 32: 379-39, 1988.

Keohane, R.O., Multilateralism: An Agenda for Research, in International Journal, 45 (XLV): 731-764, 1990.

Korthals Altes, E., Heart and Soul for Europe. An Essay on Spiritual Renewal, Assen (N1): Van Gorcum, 1999, 189 p.

Kühnhardt, R., European Union - the Second Founding, Baden-Baden: Nomos, 2008.

Lamy, P., Global Governance is a Challenge for Democracy (but an EU opportunity), in Europe's World, Spring 2010, (14): 48-52, 2010.

Latoszek, E., I. Kotowska, A. Nowak and A.Stẹpniak, European Integration Process in the New Regionasl and Global Settings, Warsaw: Warsaw School of Economics, Unversiy of Warsaw 2012, 422 p.

Lenoble, J. and N. Dewamdere, L'Europe au soir du siècle. Identité et Démocratie, Paris: Éditions Esprit, 1992, 315 p.

Lowenthal, P., Un droit, des morales, Bruxelles: P.I.E. Peter Lang, 2008, 156 p.

Martinello, M., La Démocratie Multiculturelle. Citoyenneté, Diversité, Justice Sociale, Paris: Presses de Sciences Po., 2011.

Mascia, M., Participatory Democracy for Global Governance. Civil Society Organisations in the European Union, Human Right Studies, Vol. 2, Brussels: P.I.E. Peter Lang, 2012, 170 p.

Mascia, M., Obiettivo sicurezza umana per la politica estera dell'Unione Europea, Padua: CLEUP, 2010, 322 p.

Morin, E. et al., Donner une âme à la mondialisation, in Revue Question no. 129, Gordes: Albin Michel, 2003, 236 p.

Office of Development Studies, Profiling the Provision Status of Global Public Goods, An ODS Staff Paper, New York: UNDP, December 2002, 68 p.

Olson, M., The Logic of Collective Action: Public Goods and the Theory of Groups, Cambridge, Mass.: Harvard University Press, 1971. 
O'Neill M. and N. Paun, Europe's Constitutional Crisis: International perspectives, Cluj-Napoca: European Studies Foundation Publishing House, 2008, 283 p.

Parekh, B., Rethinking Multiculturalism. Cultural Diversity and Political Theory, London: Macmillan, 2000.

Petrella, R., Le bien commun. L'éloge de la solidarité, Bruxelles: Labor, 1996, $93 \mathrm{p}$.

Pinder, J. (ed.), Foundations of Democracy in the European Union, London: MacMillan Press Ltd, 1999, 151 p.

Putnam, R., Making democracy work, New Jersey: Princeton University Press, 1993.

Rouyer, M., C.de Wrangel, E. Bousquet and S. Cubeddu (dir.), Regards sur le cosmopolitisme européen, Bruxelles: P.I.E. Peter Lang, 2011, 456 p.

Samuelson, P., The Pure Theory of Public Expenditure, in The Review of Economics and Statistics, Vol. 36, no. 4, November 1954.

Sandler, T., Global Challenges, Cambridge: Cambridge University Press, 1997.

Sen, A., Choice, Welfare and Measurement. Cambridge, Mass.: Harvard University Press, 1982.

Sen, A., Identity and Violence, New York: W.W. Norton, 2006.

Stevenson, N., Cultural Citizenship. Cosmopolitan Questions, Open University Press, 2003.

Thakur, R. and L. Van Langenhove, Enhancing Global Governance through Regional Integration, in Global Governance. A Review of Multilateralism and International Organisations, 12(3): 233-240, 2006.

Tourraine, Alain, Critique de la Modernité, Paris: Fayard, 1992, 453 p.

Valaskis, K., Long-term Trends in Global Governance: From 'Westphalia' to 'Seattle', in Governance in the 21st Century, Paris: OECD, 2001.

Weiler, J.H.H., The Constitution of Europe. Do the new clothes have an emperor, Cambridge: Cambridge University Press, 1999, 357 p.

Westendorff, D., From unsustainable to inclusive cities, Geneva: UNRID, 2004, $256 \mathrm{p}$. 


\section{'Multiple Europes'}

The series 'Multiple Europes' is multiple in two ways: it understands Europe in an interdisciplinary manner with a strong historical perspective, and it understands Europe as being inserted in transnational and global contexts. On both levels, the perspectives on Europe and the very role and understanding of Europe is multiple. The special emphasis of the series thus lies in understanding the pasts of Europe as well as its complex present.

The history of Europe and the history of European integration have influenced each other in the past and will continue to do so in the future. There is an inbuilt tension in the relation between European history and the history of European integration. Europe signifies a space and semantics much broader and more complex than the EU. The relations between ideas of Europe, European history, global history and European integration need to be faced more openly. In order to do this, an open dialogue between academic disciplines is just as necessary as critical self-reflection within each discipline. Furthermore, European history was preoccupied with looking at itself and needs to be connected to global relations.

\section{Series Editor: Hagen Schulz-Forberg,} Associate Professor for Global and European History

\section{Series Titles}

Globalisation vs Europeanisation. A Human-centric Interaction, Léonce BEKEMANS, No. 52, 2013

The Space of Crisis. Images and Ideas of Europe in the Age of Crisis: 19141945, Vittorio DinI \& Matthew D’AURIA (eds.), No.51, 2013

EU Enlargement. Current Challenges and Strategic Choices, Finn LAURSEN (ed.), No.50, 2013

Cosmopolitanisms in Enlightenment Europe and Beyond, Mónica GARCíASALMONES and Pamela SLOTTE (eds.), No.49, 2013

The European Public Sphere. From Critical Thinking to Responsible Action, Luciano Morganti \& Léonce BeKEMANS (eds.), No.48, 2012

Intercultural Dialogue and Multi-level Governance in Europe. A Human Rights Based Approach, Léonce BEKEMANS (ed.), No.47, 2012

Imagining Europe as a Global Player. The Ideological Construction of a New European Identity within the EU, Christoffer KøLVRAA, No.46, 2012

Capital City Cultures. Reconstructing Contemporary Europe in Vienna and Berlin, Monika De FranTz, No.45, 2011

Building a European Public Sphere. From the 1950s to the Present / Un espace public européen en construction. Des années 1950 à nos jours, Robert FRANK, 
Hartmut Kaelble, Marie-Françoise LÉVy \& Luisa PASSERINI (eds./dir.), No.44, 2010

'We belong to them'. Narratives of Belonging, Homeland and Nationhood in Territorial and Non-territorial Minority Settings, Tünde PUSKÁs, No.43, 2008

Imagining Europe. Europe and European Civilisation as Seen from its Margins and by the Rest of the World, in the Nineteenth and Twentieth Centuries, Michael WinTLE (ed.), No.42, 2008

Figures of Authority. Contributions towards a Cultural History of Governance from the Seventeenth to the Twentieth Century, Peter BECKER \& Rüdiger VON KrosigK (eds.), No.41, 2008

Europe and the Historical Legacies in the Balkans, Raymond DETREZ \& Barbara SEGAERT (eds.), No.40, 2008

Histoire économique et sociale de la construction européenne, René LEBOUTTE, $\mathrm{n}^{\circ} 39,2008$

Collective Traumas. Memories of War and Conflict in $20^{\text {th }}$-Century Europe, Conny Mithander, John Sundholm \& Maria Holmgren Troy (eds.), No.38, 2007

Reflections on Europe. Defining a Political Order in Time and Space, Hans-Åke PERSSON \& Bo STRÅTH (eds.), No.37, 2007

London - Berlin. Authenticity, Modernity, and the Metropolis in Urban Travel Writing from 1851 to 1939, Hagen SCHULZ-FORBERG, No.36, 2006

(Un)Doing Europe. Discourses and Practices of Negotiating the EU Constitution, Michał KRZYŻANOWSKI \& Florian OBERHUBER, No.35, 2007

Developing Cultural Identity in the Balkans. Convergence vs Divergence, Raymond DeTrEZ \& Pieter Plas (eds.), No.34, 2005

Statehood Before and Beyond Ethnicity. Minor States in Northern and Eastern Europe, 1600-2000, Linas ERIKSONAS \& Leos MÜLLER (eds.), No.33, 2005

Berlin en musée. Changements sociopolitiques et usages du patrimoine, Véronique CHARLÉTY, $\mathrm{n}^{\circ}$ 32, 2005

Democratisation in Turkey. The Role of Political Parties, Huri TÜRSAN, No.31, 2004

Unravelling Civilisation. European Travel and Travel Writing, Hagen ScHULZFORBERG, No.30, 2005

\section{Peter Lang-The website}

Discover the general website of the Peter Lang publishing group: 